\title{
O Lineamento Transbrasiliano na Bacia do Paraná: compartimentação crustal do embasamento e reativações fanerozóicas
}

\author{
Julia Barbosa Curto
}

TESE DE DOUTORADO № 120

PROGRAMA DE PÓS-GRADUAÇÃO EM GEOLOGIA

Brasília - 13 de Março/2015 
UNIVERSIDADE DE BRASÍLIA

INSTITUTO DE GEOCIÊNCIAS

\section{Lineamento Transbrasiliano na Bacia do Paraná: compartimentação crustal do embasamento e reativações fanerozóicas}

\section{Julia Barbosa Curto}

Tese de doutorado apresentada junto ao curso de Pós-Graduação em Geologia Área de concentração Geologia Regional, para obtenção do título de Doutora em Geologia.

Orientador: Prof. Dr. Reinhardt Adolfo Fuck Co-Orientadora: Profa. Dra . Roberta Mary Vidotti

Orientador Doutorado SWE: Dr. Richard Blakely - USGS - Menlo Park, CA 
UNIVERSIDADE DE BRASÍLIA

INSTITUTO DE GEOCIÊNCIAS

\title{
0 Lineamento Transbrasiliano na Bacia do Paraná: compartimentação crustal do embasamento e reativações fanerozóicas
}

\author{
Julia Barbosa Curto
}

\author{
TESE DE DOUTORADO № 120 \\ PROGRAMA DE PÓS-GRADUAÇÃO EM GEOLOGIA \\ Orientador: Prof. Dr. Reinhardt Adolfo Fuck \\ Co-Orientadora: Profa. Dra. . Roberta Mary Vidotti
}

Orientador Doutorado SWE: Dr. Richard Blakely - USGS - Menlo Park, CA

Comissão Examinadora:

Profa. Drạ. Roberta Mary Vidotti (Co-orientadora) - UnB

Prof. Dr. João Marinho Morais Neto - Petrobrás

Profa. Dra . Naomi Ussami - USP

Profa. Dra . Lucieth Cruz Viera - UnB

Profa. Dra . Mônica G. Von Huelsen - UnB 
Barbosa Curto, Julia

O Lineamento Transbrasiliano na Bacia do Paraná: compartimentação crustal do embasamento e reativações fanerozóicas / Julia Barbosa Curto; orientador

Reinhardt Adolfo Fuck; co-orientador Roberta Mary Vidotti. -- Brasília, 2015.

$190 \mathrm{p}$.

Tese (Doutorado - Doutorado em Geologia) -Universidade de Brasília, 2015.

1. Lineamento Transbrasiliano. 2. Bacia do Paraná. 3. Geofísica: dados magnéticos e gravimétricos. 4. Evolução Tectônica. 5. Reativação de estruturas no Fanerozóico. I. Adolfo Fuck, Reinhardt , orient. II. Mary Vidotti, Roberta, co-orient. III. Título. 
Ao meu amor, Edson 


\section{Agradecimentos}

Foram quatro anos de pesquisa, vividos intensamente. Ao iniciar o doutorado, assumi importante ato de compromisso e responsabilidade com a comunidade científica e a sociedade. Apesar de muitas vezes parecer arredio, o aluno de doutorado não trabalha de forma individualista. Muitas pessoas se envolveram direta ou indiretamente, contribuindo de alguma forma com a pesquisa e meu crescimento profissional. Gostaria de agradecer aqui a todas elas e às instituições que permitiram a realização da pesquisa.

A maior cobrança deve vir de você mesmo. Incentivos e orientações vieram de pessoas que ficarão para sempre em minha mente e meu coração. Agradeço aos meus orientadores, Professores Dr. Reinhardt Fuck e Dr ${ }^{a}$.Roberta Vidotti, por terem, em primeiro lugar, acreditado em meu potencial e me concedido a oportunidade de embarcar nessa trajetória ao lado de profissionais tão ilustres. Sou grata pelas reuniões e discussões sempre construtivas e pela dedicação em revisar textos da tese, resumos e artigos. Fico grata à Prof. ${ }^{a}$ Roberta pelo constante incentivo e por ter sido ótima companhia no trabalho de campo. E agradeço ao Prof. Fuck por me instigar com questionamentos e pela paciência em retirar meus "os" e "issos" dos textos.

Como parte do programa de doutorado-sanduiche-SWE do CNPq, eu tive a preciosa oportunidade de ser orientada pelo pesquisador do Serviço Geológico dos Estados Unidos - USGS, Dr. Richard Blakely. Agradeço ao Dr. Blakely por ter sido tão solícito em passar conhecimento geofísico e suporte durante minha estadia no pais, além da grande contribuição com sua detalhada revisão dos artigos. Nos corredores da USGS, discussões enriquecedoras com membros da equipe de métodos potenciais possibilitaram intensa experiência profissional, lembrando especialmente do Dr. Daniel Scheirer, Dr. Jonathan Glen e Gerry Connard. Sou grata também à Dr. Allegra Scheirer pelas conversas cientificas produtivas no café da manhã e pelo carinho durante os meses que passei hospedada em sua casa.

Os Professores Dr.Carlos J. S. de Alvarenga e Dr. Elton Dantas foram fontes inspiradoras que me ajudaram a vislumbrar desafios geológicos e procurar respostas coerentes. Agradeço a eles pelas discussões e pelas revisões de texto. Também sou grata aos professores e membros da banca de qualificação de doutorado, Dr. Roberto Moraes, Dr. Augusto Pires e Dr ${ }^{a}$. Mônica Von Huelsen, pelas contribuições fundamentais a evolução desse trabalho.

À FUB/Petrobrás por patrocinar o projeto de pesquisa Lineamento Transbrasiliano, no qual esta tese está inserida. Ao CNPq - Conselho Nacional de Desenvolvimento Científico e Tecnológico pelo suporte financeiro concedido. À ANP-Agência Nacional de Petróleo, Gás e Biocombustíveis, CPRM - Serviço Geológico do Brasil, CNEN- 
Comissão Nacional de Energia Nuclear e SGM/SIC-GO - Secretaria de Indústria e Comércio do Estado de Goiás por disponibilizar dados geofísicos para propósitos acadêmicos. À Geosoft Inc. por ter liberado a utilização do software Oasis Montaj para o processamento dos dados geofísicos. À Esri por disponibilizar o uso do software ArcGis para o processamento e integração de dados.

Aos laboratórios de Geofisica Aplicada-LGA e Sensoriamento Remoto - SRAE da UnB por prover a utilização de suas infraestruturas. Ao laboratório de Geocronologia e sua equipe por ter me auxiliado na preparação de amostras para análise. Ao Prof. Dr.Peter Hackspacher e ao mestre Kaique Rosante por terem me auxiliado na preparação de amostras para análise de traço de fissão em apatita, no Instituto de Geociências da Unesp - Rio Claro.

Ao Instituto de Geociências da UnB por me conceder o ambiente de trabalho necessário e saudável para a realização desta pesquisa. Devo a esta casa acadêmica por todos esses anos que me senti abraçada pelo conhecimento geocientífico que adentra suas salas e corredores. Aos meus colegas de laboratório pelos momentos de descontração e pelo incentivo nos momentos de ansiedade. Em especial, sou grata pelo carinho de minhas companheiras de estudo e queridas amigas Tatiana Diniz e Loiane Moraes. Não posso deixar de agradecer também ao motorista Zilberto, o grande Ziba, que foi "uma mão na roda" nas estradas difíceis da área de estudo.

"Faça um bom planejamento e se organize antes de começar seus trabalhos"; e "Se antecipe aos problemas”. Essas são duas grandes lições que meu querido pai sempre me passou e ainda faz questão de me lembrar, e que foram essenciais para que eu chegasse até aqui. Porém, quando minha experiência é ainda insuficiente e algo começa a dar errado, minha super-mãe prevê sinais de desespero em milésimos de segundo e já se prepara com palavras certeiras para erguer minha espinha e doces o bastante para acalmar meu anseio. Agradecer aqui é apenas ato simbólico. Preciso fazê-lo, intensamente, todos os dias, em conjunto ao agradecimento a Deus, por ter iluminado meu caminho e permitido que eu fizesse as escolhas que me definem hoje como profissional e ser humano.

Agradeço imensamente ao meu amado marido Edson pela compreensão ao tempo que me dedico à vida acadêmica e por me acompanhar em cada passo desse trabalho. Apesar de não ser geocientista, teve a paciência de assistir, às vezes mais de uma vez, a todos meus ensaios para apresentações em congresso, defesas de mestrado e doutorado. Sempre está interessado em entender um pouco mais da minha especialidade profissional, ainda mais depois de momentos em frente às diversas paisagens geológicas. O fato de também estar à busca de conhecimento e experiências, me faz o amar ainda mais e agradecer a Deus por tê-lo colocado em meu caminho. 


\section{Resumo}

A Plataforma Sul Americana inclui dois importantes componentes geológicos de escala continental e com raízes estruturais em comum: o Lineamento Transbrasiliano (LTB) e a Bacia do Paraná. Importante relação entre os dois ocorre na região entre o Arco Magmático de Goiás e a Faixa Paraguai, que impõem particularidades estruturais obscurecidas pela cobertura sedimentar da Bacia do Paraná. A área, alvo desse estudo, é recoberta por dados aerogeofísicos, magnéticos e gravimétricos, adquiridos com diferentes resoluções. Sua integração permitiu gerar mapas de anomalias magnéticas e anomalias Bouguer, este incluindo dados terrestres.Técnicas de processamento e modelagem geofísica foram utilizadas com objetivo de esclarecer a disposição de compartimentos crustais e estruturas do embasamento da bacia em diferentes níveis de profundidade. Três grandes descontinuidades magnéticas do LTB limitam compartimentos crustais na área, de leste para oeste: lineamentos Serra Negra, Baliza e General Carneiro, com direções gerais $\mathrm{N} 30^{\circ} \mathrm{E}, \mathrm{N} 60^{\circ} \mathrm{E}$ e $\mathrm{N} 70^{\circ} \mathrm{E}$, respectivamente, que separam mudanças significativas no background gravimétrico, ainda subdividido por lineamento adicional $\mathrm{N} 50^{\circ} \mathrm{W}$, São Vicente. Análise de lineamentos de $1^{\mathrm{a}}, 2^{\mathrm{a}}$ e $3^{\mathrm{a}}$ ordens aponta a predominância de orientações $\mathrm{NE}$, interpretadas como originalmente brasilianas e reativadas no Jurássico-Cretáceo, e direções NW, bem marcadas nas unidades sedimentares da bacia e com caráter distensivo, atribuído a reativação mesozóica. Análise do matched-filter aplicada a dados magnéticos e gravimétricos, com suporte da deconvolução de Euler e tilt-depth, aponta estimativas de profundidades importantes: (i) $2,5 \mathrm{~km}$, relacionado ao topo do embasamento da Bacia do Paraná; (ii) $6 \mathrm{~km}$, atribuído ao topo do embasamento da bacia neoproterozóica (Grupo Cuiabá); (iii) $20 \mathrm{~km}$, possivelmente associado à interface crosta superior/inferior; e (iv) 33-39 e $43 \mathrm{~km}$, relativos às espessuras crustais a oeste e sudeste do lineamento Serra Negra, respectivamente. A crosta a leste é formada pelo o Arco Magmático de Arenópolis e o limite noroeste do Bloco Paranapanema e a oeste é constituída por zona de transição crustal e o paleocontinente Amazônico. A modelagem geofísica conjunta 2D com dados gravimétricos e magnéticos esclarece a geometria assimétrica do embasamento da bacia, configurando pelo menos três meiográbens formados ao longo de estruturas reativadas do LTB. A região entre os lineamentos Serra Negra e General Carneiro caracteriza-se por menor espessura e maior fraqueza crustal, onde importantes estruturas se desenvolveram no Mesozóico: desde reativações com direção NW, vinculadas a soerguimento crustal e à implantação de pequenas bacias cretáceas alinhadas a NE. Dois depocentros importantes ocorrem: a norte do lineamento General Carneiro, com direção $\mathrm{N} 70^{\circ} \mathrm{E}$, e a leste da falha Serra Negra, com direção $\mathrm{N} 30^{\circ} \mathrm{E}-\mathrm{NS}$. 


\section{Abstract}

The South American Platform includes two major geological components of continental scale with common structural roots: the Transbrasiliano Lineament (LTB) and the Paraná Basin. An important relationship between the two is observed in the region between the Goiás Magmatic Arc and the Paraguay Belt, which impose structural features concealed by the sedimentary cover of the Paraná Basin. This region comprises our study area, and is covered by airborne magnetic and gravity surveys, acquired with different resolutions. These data were integrated to generate maps of magnetic and Bouguer anomalies, the latter included ground data. Data processing and geophysical modeling techniques were used in order to reveal the disposition of crustal compartments and the basin basement structures at different depths. Three large magnetic discontinuities limit crustal compartments in the area, from east to west: Serra Negra, Baliza and General Carneiro lineaments, with $\mathrm{N} 30^{\circ} \mathrm{E}, \mathrm{N} 60^{\circ} \mathrm{E}$ and $\mathrm{N} 70^{\circ} \mathrm{E}$ trending alignments, respectively, which separate significant changes in the gravity background, still subdivided by the additional Sao Vicente lineament, $\mathrm{N} 50^{\circ} \mathrm{W}$. Analyses of 1st, 2nd and 3rd order lineaments indicate predominance of NE trending directions, which were interpreted as Brasiliano structures, reactivated in the Jurassic-Cretaceous. NW directions, well-marked in the sedimentary units of the basin and with extensional character, were attributed to Mesozoic reactivation. Matched-filter analysis applied to magnetic and gravity data, supported by the Euler deconvolution and tiltdepth, yielded important depths estimates: (i) $2.5 \mathrm{~km}$ to the top of the Paraná Basin basement; (ii) $6 \mathrm{~km}$ to the top of the Neoproterozoic Basin basement (Cuiabá Group); (iii) $20 \mathrm{~km}$, possibly associated with the upper/lower crust interface; and (iv) 33-39 and $43 \mathrm{~km}$ related to crustal thicknesses west and southeast of the Serra Negra lineament, respectively. To the east, the crust is formed by the Arenópolis Magmatic Arc and the northwest boundary of Paranapanema Block, while to the west it consists of a crustal transition zone and the Amazon paleocontinent. The 2D geophysical modeling based on gravity and magnetic data sheds light on the asymmetric geometry of the basement of the basin, with at least three half-grabens formed by LTB reactivated structures. The region between the Serra Negra and General Carneiro lineaments is characterized by thinner crust and higher crustal weakness, where important structures have developed in the Mesozoic, including NW trending reactivations, linked to crustal uplift and deployment of small NE-aligned Cretaceous basins. Important depocenters occur: the first, to the north of General Carneiro lineament, and the second, to the east of the Serra Negra fault, with $\mathrm{N} 70^{\circ} \mathrm{E}$ and $\mathrm{N} 30^{\circ} \mathrm{E}-\mathrm{NS}$ trending directions, respectively. 


\section{Sumário}

Lista de Figuras

ix

Lista de Tabelas.... xvi

1. Introdução 1

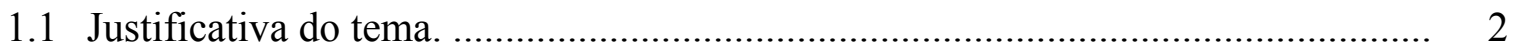

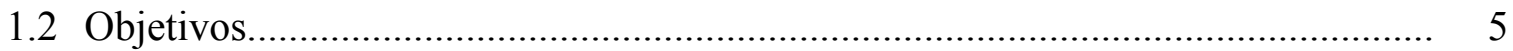

1.3 Localização da área de estudo............................................................................... 6

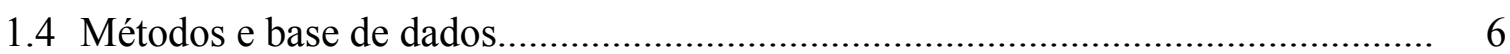

2. Contexto Geotectônico 9

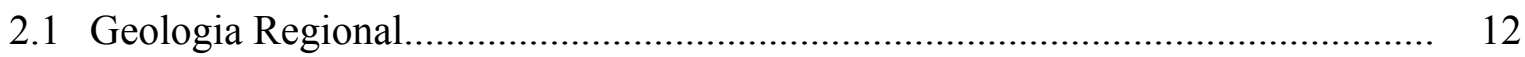

2.1.1 Faixa Brasília..................................................................................... 12

Arco magmático de Arenópolis 12

2.1.2 Faixa Paraguai............................................................................... 13

2.1.3 Bacia do Paraná..................................................................................... 14

Natureza do embasamento 14

Estratigrafia 15

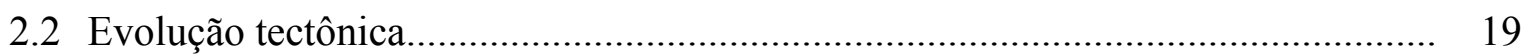

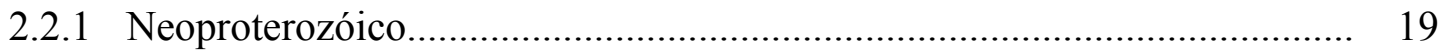

Orogenia Brasiliana 19

O Lineamento Transbrasiliano 21

2.2.2 Paleozóico-Mesozóico.......................................................................... 22

Evolução tectono-estratigráfica da Bacia do Paraná 22

2.3 Reconhecimento geológico de campo................................................................. 29

3. Geofísica 32

3.1 Construção da base de dados geofísicos............................................................. 32

3.1.1 Pré-processamento dos dados magnéticos........................................... 35

(i) Correções de posicionamento e padronização dos sistemas de projeção 35 
(iii) Análise e correção estatística do campo magnético ao longo das linhas de voo 36

(iv) Nivelamento da intersecção de linhas de voo 38

(v) Micronivelamento e decorrugação dos dados 38

(vi) Aplicação de filtros para a suavização de ruídos sistemáticos de alta frequência 39

3.1.2 Junção dos dados magnéticos.................................................................. 40

3.1.3 Processamento e junção dos dados gravimétricos....................................... 43

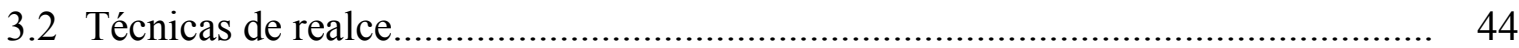

3.2.1 Posicionamento e geometria das anomalias magnéticas........................... 45

Redução ao polo 45

Amplitude do gradiente total 49

Derivada tilt 51

3.2.2 Caracterização das anomalias geofísicas em profundidade....................... 52

Matched-Filter 53

Deconvolução de Euler 59

3.3 Modelagem direta conjunta dos dados geofísicos............................................ 59

Propriedades fisicas de rochas 63

4. Optimizing depth estimates from magnetic anomalies using spatial analysis tools 67

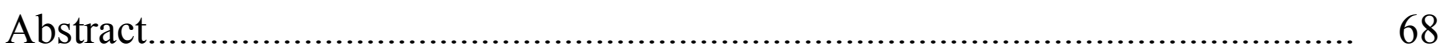

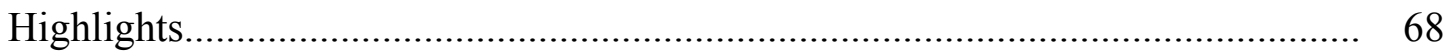

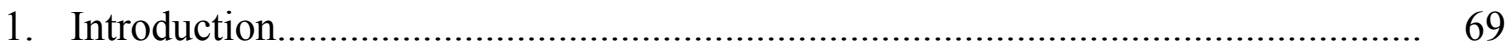

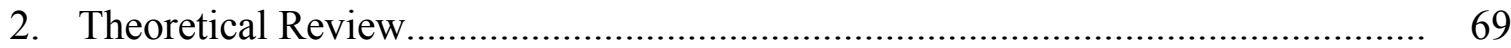

3. Spatial analysis of the tilt-depth............................................................................ 70

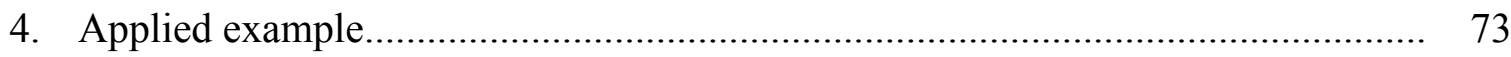

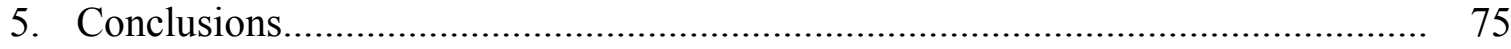

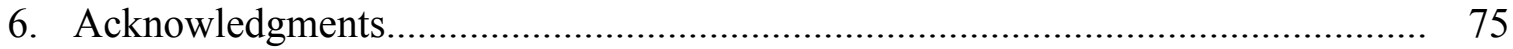

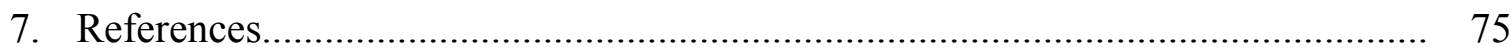

Appendix 79 
5. The tectonic evolution of the Transbrasiliano Lineament in northern Paraná Basin, Brazil, as inferred from aeromagnetic data

Abstract 87

1. Introduction. 87

2. Geological Setting 89

2.1 The Transbrasiliano Lineament.............................................................. 89

2.2 The Paraná Basin................................................................................ 90

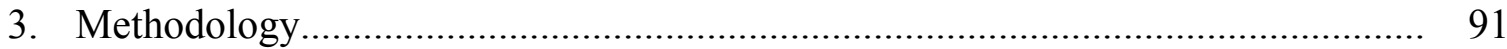

3.1 Pre-processing Stage of the Magnetic Data............................................. 91

3.2 Matched-Filter Analysis........................................................................ 92

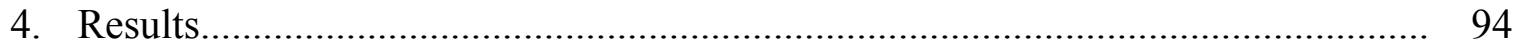

4.1 Magnetic Domains .................................................................................... 94

4.2 Depth Analyses of Magnetic Anomalies................................................... 95

4.3 Two-Dimensional Magnetic Modeling..................................................... 97

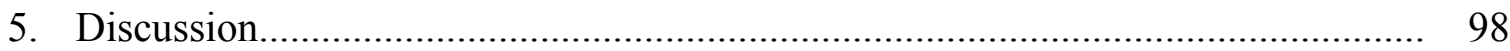

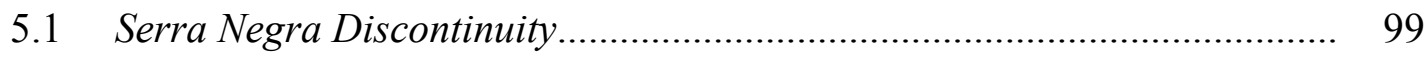

5.2 Baliza Discontinuity .......................................................................... 100

5.3 General Carneiro Discontinuity ............................................................. 100

5.4 São Vicente Lineament ............................................................................. 103

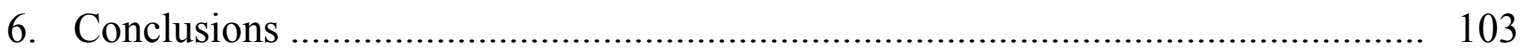

Appendix A: Airborne Geophysical Surveys.................................................. 103

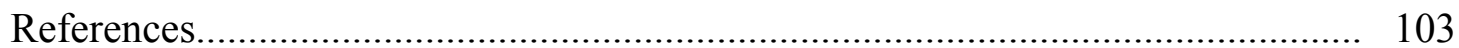

6. Crustal framework of the northwest Paraná Basin, Brazil: insights from joint modeling of magnetic and gravity data

Abstract.

Keywords

1. Introduction. 108

2. Geological setting. 108

$2.1 \quad$ Basement units................................................................................ 108

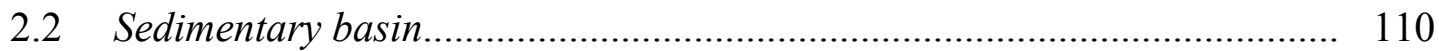

3. Geophysical Framework............................................................................... 110

4. Joint Modeling of Gravity and Magnetic Data..................................................... 112 


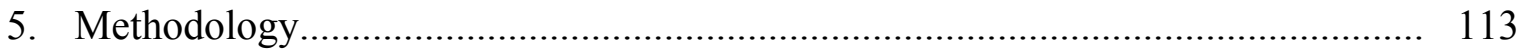

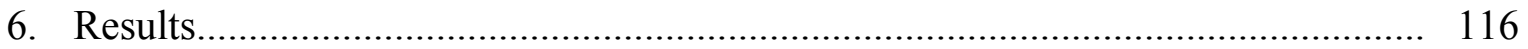

6.1 Depth estimates................................................................................... 116

6.2 Two-Dimensional Models..................................................................... 117

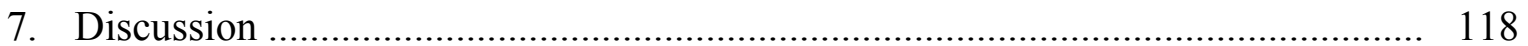

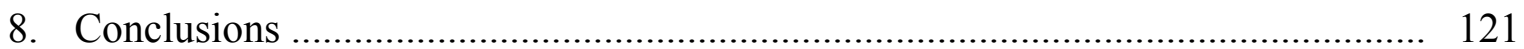

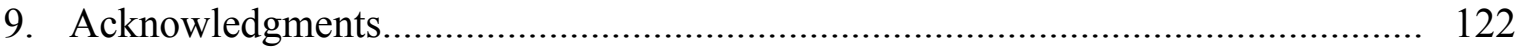

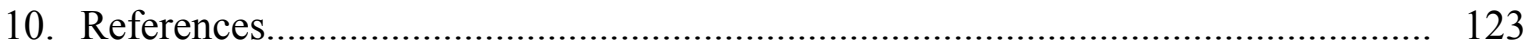

7. Análise tectônica 142

7.1 Interpretação Geofísica e integração com dados geológicos..................................... 143

7.2 Descontinuidades crustais e compartimentos tectônicos........................................... 144

7.3 Evolução Tectônica - do Neoproterozóico às Reativações Fanerozóicas................ 149

$\begin{array}{ll}\text { 8. Conclusões } & 158\end{array}$

Em relação a técnicas de processamento geofísico.................................................. 158

Em relação aos aspectos geotectônicos.................................................................. 160

9. Referências Bibliográficas 163

$\begin{array}{ll}\text { Anexos } & 179\end{array}$

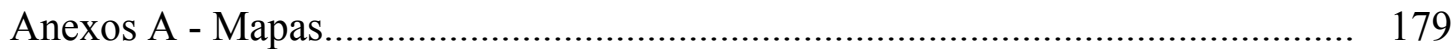

Anexos B - Resumos em anais................................................................ 184 


\section{Lista de Figuras}

Figura 1.1 No inset, localização da área de estudo na América do Sul, sobre a imagem de radar (SRTM). Em maior detalhe, a área de estudo.

Figura 2.1 Contexto geotectônico simplificado da Plataforma Sul-Americana (adaptado de Cordani et al., 2009). Localização geral do LTB na Plataforma Sul-Americana de acordo com interpretação de dados magnéticos (Vidotti et al., 2011) e sua compilação com trabalhos anteriores (Ex.: Ramos et al., 2010)

Figura 2.2 Mapa geológico da Província Tocantins e Bacia do Paraná (base de dados geológicos da CPRM, Schobbenhaus et al., 2004) sobre topografia (Imagem de radar - SRTM). O polígono com borda azul marca a localização da área de estudo. A: Arco Magmático de Arenópolis. No inset, localização do LTB na Plataforma Sul-Americana (Ver referências na Figura 2.1).

Figura 2.3 Unidades geológicas da Bacia do Paraná classificadas de acordo com as principais fases deposicionais (Milani, 1997; Schobbenhaus et al., 2004). O mapa também inclui isópacas da bacia (Milani, 1997), arcabouço estrutural regional (Zalán et al., 1991) e unidades do embasamento neoproterozóico (Cordani et al., 1984). Bacia dominada por elementos tectônicos com trends NW-SE, NE-SW e E-W. No inset, localização da Bacia do Paraná e LTB na Plataforma Sul-Americana (Ver referências na Figura 2.1)

Figura 2.4 Carta estratigráfica da Bacia do Paraná, de acordo com Milani (2004) e Milani et al. (2007) .. 18

Figura 2.5 Reconstrução hipotética do Gondwana em 600 Ma (Cordani et al., 2003, 2009, 2013, 2014). 20

Figura 2.6 Quadro tectono-estratigráfico da Bacia do Paraná, baseado em Heilbron et al.(2000).

Figura 2.7 Isópacas da Bacia do Paraná, do Ordoviciano ao Eotriássico (adaptado de Milani, 1997).

Observar o controle do Lineamento Transbrasiliano na distribuição das isópacas da Supersequência Ivaí, onde a Fm. Vila Maria aflora restritamente no limite norte da bacia......

Figura 2.8 Isópacas da Bacia do Paraná, do Mesotriássico ao Neocretáceo (adaptado de Milani, 1997). Observar um provável controle do Lineamento Transbrasiliano na distribuição das isópacas da Supersequência Gondwana III, composta pelos basaltos da Fm. Serra Geral e arenitos da Fm. Botucatu..

Figura 2.9 Aspectos de alguns floramentos e estruturas vistas em campo. (A) Formação Aquidauana, próximo à amostra LTBPR07 (Anexo A3); (B) Formação Furnas (ponto LTBPR04) na Cachoeira Cristal; (C) Rochas ultramáficas alcalinas de Montes Claros de Goiás (ponto LTBPR17); (D) Formação Furnas, próximo a Bom Jardim de Goiás; (E) Arenito falhado, próximo ao contato com o Grupo Cuiabá (ponto AJ06); (F) Arenito dobrado, próximo ao contato com o Grupo Cuiabá (ponto AJ08). Ver Anexo A3 para a localização dos pontos.

Figura 2.10 Roseta com as medidas de direção em juntas e falhas durante as duas campanhas de campo. As direções preferenciais são $\mathrm{N} 45^{\circ}-60^{\circ} \mathrm{E}, \mathrm{N} 25^{\circ}-30^{\circ} \mathrm{E}, \mathrm{N} 50^{\circ} \mathrm{W}, \mathrm{N} 80^{\circ} \mathrm{E}-\mathrm{N} 80^{\circ} \mathrm{W}$ e $\mathrm{N} 10^{\circ} \mathrm{W}$. 
Figura 3.1 Localização dos projetos de geofísica aérea e terrestre na área de estudo. No inset, localização do projeto Bacia do Paraná no Brasil.

Figura 3.2 Exemplos de dados espúrios nos dados magnéticos, identificados com o uso da quarta derivada do campo magnético anômalo dos projetos: A) Goiás 01 (3009), onde o dado espúrio é representado por único pico; e B) Barreiro (2022), onde ocorrem vários picos.

Figura 3.3 Recorte dos mapas de anomalias magnéticas não processadas do aerolevantamento 2022, destacando a sobreposição das linhas de voo em suas diferentes etapas.

Figura 3.4 a) Mapa de anomalias magnéticas de maior resolução, obtida a partir da junção dos projetos 1012, 2009, 2022, 2025 e 3009. As linhas pretas indicam os limites entre os projetos e a linha preta pontilhada indica o limite da Bacia do Paraná. b) Mapa de anomalias magnéticas de menor resolução, obtida a partir da junção dos projetos 1012, 2009, 2022, 2025, 3009 e Bacia do Paraná.

Figura 3.5 Mapa de anomalia Bouguer, obtida pela junção dos dados de gravimetria terrestre e do aerolevantamento da Bacia do Paraná.

Figura 3.6 Anomalia magnética associada ao corpo alcalino da Suíte Vulcânica de Santo Antônio da Barra (Junqueia-Brod et al., 2002). Dados magnéticos do levantamento da Bacia do Paraná, reduzidos ao polo segundo (A) RTP, com utilização de pseudo-inclinação; e (B) DRTP. (C) Amplitude do gradiente total, utilizada como validação parcial.

Figura 3.7 A) Perfil de uma fonte magnética sintética. B) Anomalia magnética resultante da fonte (A) gerada em $\mathrm{I}=90^{\circ}$. C) Anomalia magnética resultante da fonte (A) gerada em valores de I e D equivalentes aos utilizados para a área de estudo. D) Anomalia de (C) reduzida ao polo, com uso de I' $=-70^{\circ}$

Figura 3.8 Mapa de 10 prismas magnéticos (A) sem redução ao polo e (B) reduzidos ao polo, com a correção da inclinação magnética $\left(I^{\prime}\right)$ de $-70^{\circ}$. Alguns prismas possuem propriedades magnéticas, dimensões e valores de profundidade diferenciados (Tabela 3.4)......

Figura 3.9 A) Bloco com susceptibilidade magnética (s) de 0,0007 (SI). B) Anomalia magnética gerada pelo bloco em A e campo magnético com inclinação $(I)$ : $90^{\circ}$ e declinação $(D): 0^{\circ}$. C) Anomalia magnética gerada pelo bloco em A, com $I^{\prime}$ e $D$ 'iguais aos da área de estudo (I: $19,87^{\circ}$ e $D:-17,81^{\circ}$ ). D) Anomalia magnética de (C) reduzida ao polo, com a utilização de $I^{\prime}$ $=-70^{\circ}$. E) Amplitude do gradiente total (AGT) da anomalia magnética de C. Observa-se que a redução ao polo e a amplitude do sinal analítico centralizaram de forma eficiente a anomalia magnética com $I$ e $D$ iguais aos da área de estudo.

Figura 3.10 A) Duas fontes magnéticas geradas segundo $I=-19,87^{\circ}, D=-17,81^{\circ}$; B) anomalias magnéticas; C) anomalias magnéticas reduzidas ao polo; D) AGT; E) tilt.

Figura 3.11 Localização das subáreas analisadas com a técnica do matched-filter. A) Campo magnético anômalo reduzido ao polo. B) Mapa de anomalias Bouguer. 
Figura 3.12 Análise dos resultados de profundidade estimados com o uso da técnica matched-filter aplicada aos dados magnéticos. A) Histograma de densidade; em que as elipses apontam as populações principais. B a E) Média ponderada de cada população. As elipses apontam patamares na distribuição dos dados, indicando maior importância para esses intervalos de valores.

Figura 3.13 Análise dos resultados de profundidade estimados com o uso da técnica matched-filter aplicada aos dados gravimétricos. A) Histograma de densidade; em que as elipses apontam as populações principais. B a E) Média ponderada de cada população. As elipses apontam patamares na distribuição dos dados, indicando maior importância para esses intervalos de valores

Figura 3.14 Etapas envolvidas na modelagem direta 2D de fontes magnéticas e gravimétricas (Blakely, 1996). As variáveis p são características das fontes, como densidade, magnetização, profundidade ou espessura.

Figura 3.15 Aproximação para um corpo bidimensional por um polígono de N lados (Blakely, 1996) ....... 61

Figura 3.16 Medidas de susceptibilidade magnética realizadas in situ durante o trabalho de campo......

Figura 3.17 Gráfico de susceptibilidade magnética das amostras coletadas em campo.

Figura 4.A1 Airborne geophysical surveys compiled for this study (Curto et al., 2014). State companies that managed the surveys are shown as CPRM: Serviço Geológico do Brasil; CNEN: Comissão Nacional de Energia Nuclear; SIEG/MME: Secretaria de Indústria e Comércio de Goiás/Ministério de Minas e Energia; ANP: Agência Nacional do Petróleo, Gás Natural e Biocombustíveis. Blue polygon indicates limits of study area.

Figura 4.1 (a) Synthetic Model A, consisting of two magnetic prisms, M1 and M2, with same dimensions, infinite depth extent, and tops at depths of 3 and $5 \mathrm{~km}$, respectively. Anomalies calculated with the method of Bongiolo et al. (2013). (b) Profile calculated from Model A assuming geomagnetic inclination 90 degrees. (c) Total gradient amplitude of profile b. (d) Tilt derivative of profile $b$ in radians. (e) Contour maps of the tilt derivative for Model A. Solid contours are the zero value of the tilt angle, which is correspondent to the limit of the bodies. Dashed lines are equivalent to $26.54^{\circ}$ or $0.46 \mathrm{rad}$, where $h_{1}$ and $h_{2}$ is the horizontal distance between 0 and $+0.46 \mathrm{rad}$ and $-0.46 \mathrm{rad}$, respectively...

Figura 4.2 The main steps and parameters used to produce our depth map of magnetic anomalies....

Figura 4.3 (a) Synthetic Model B, consisting of tilt derivative map of 10 reduced-to-pole magnetic anomalies (P1 to P10). Anomalies calculated with the method of Bongiolo et al. (2013), assuming geomagnetic inclination $-20^{\circ}$. Solid blue lines are real magnetic sources limits. (b) Same as Model B. Dashed contour lines are the zero value of the tilt derivative, which is correspondent to the limit of the bodies. Solid lines are equivalent to $\pm 26.54^{\circ}$ or $\pm 0.46 \mathrm{rad} \ldots .$.

Figura 4.4 (a) Profile of real depth values of Model A, same as figure 1a. (b) Depth map based on the interpolation of average values $z_{l}$ e $z_{2}$, calculated from the tilt derivative of Model A 
Figura 4.5 Density graph showing the difference between real (real_depth) and estimated (est_depth) depth values calculated from Model B. Three depth estimates are based on the distance between contour lines $h_{1}$ to zero $\left(z_{1}\right)$, and $h_{2}$ to zero $\left(z_{2}\right)$; and the average $z_{1}$ e $z_{2}$. See figure 3 for location....

Figura 4.6 Depth map based on the interpolation of average values $z_{l}$ e $z_{2}$, calculated from the tilt derivative of Model B, described in table 1 and figure 3

Figura 4.7 (a) Study area, in northwest Paraná Basin. (b) Estimated depth values of magnetic anomalies observed from the Bacia do Paraná airborne survey, using tilt-depth technique (Salem et al., 2007), distance analysis tool and spline interpolation. Mapped Cretaceous units of Paraná Basin are represented in green (Schobbenhaus et al., 2004), including volcanic sills.

Figura 4.8 Depth estimates using Euler Deconvolution and structural index zero. Black contour lines are relative to \pm 0.46 (rad) values of the tilt derivative, which constrained the Euler solutions interpolation. Solid gray color represents "no Euler solutions" along the tilt limits. Cretaceous units of Paraná basin are displayed in green. These units include volcanic sills....

Figura 5.1 (a) Study area green polygon in South America. (b) The geological context of the Paraná Basin generalized from CPRM (Serviço Geológico do Brasil) 1:1,000,000 scale mapping (Schobbenhaus et al., 2004) and classified according to geological periods. Displayed intervals were chosen based mainly on Paraná Basin major depositional periods (Zalán et al., 1991; Milani, 1997).

Figura 5.2 Geological context of the study area with geological and structural data not included in Figure 1, due to scale (Schobbenhaus et al., 2004). Also shown are the fieldwork locations where data were collected. Lithology's acronyms are described in Figure 1

Figura 5.3 Maps of the (a) total-field magnetic anomaly and (b) the reduced-to-pole magnetic anomaly. Four magnetic domains are separated by three major NE-SW trending discontinuities: Serra Negra (A); Baliza (B); and General Carneiro (C). Also shown is the WNW-ESE trending São Vicente lineament (D). Black squares in Figure 3a represent areas selected for radial power spectrum analysis (Figures 4 and 5). Black lines in Figure 3b indicate profiles for twodimensional magnetic modeling (Figure 7)

Figura 5.4 Comparison of the radial power spectra of the Arenópolis, Bom Jardim, Rondonópolis, and Poxoréo domains

Figura 5.5 Schematic illustration showing the results and interpretation of matched-filter analyses for each magnetic domain, including the respective amplitude values (A). The amplitude filters calculated for each layer of the Rondonópolis spectral analyses were applied to the magnetic anomalies of the entire study area.

Figura 5.6 Anomalies emphasized for three depth zones as determined from matched-filter analysis (a) $20 \mathrm{~km}$; (b) $6 \mathrm{~km}$; (c) $1.5 \mathrm{~km}$. (a'-c') Identical to Figures 6a-6c but include interpretations. Black lines (Figure 6a') are the interpreted lineaments, including the major magnetic discontinuities: Serra Negra (A), Baliza (B), General Carneiro (C), and São Vicente (D). Red and blue dots (Figures 6b' and 6c') mark granites and alkaline bodies, respectively, based on magnetic anomalies interpreta- tions and geologic correlations. The green line (Figure 6c') 
marks the boundary of the Cretaceous volcanic rocks, mostly concealed by sedimentary rocks. Sigmoidal shapes are marked with red lines. The white dashed line in all panels outlines the border of the Paraná Basin. The red square shows the area of Figure 8

Figura 5.7 Two-dimensional models developed on the basis of the anomalous magnetic field reduced to pole. (a) X-2AG1MT pro- file, crossing the Poxoréo and Rondonópolis domains, limited by an important magnetic gradient associated with the General Carneiro Lineament. The Baliza lineament is located close to the east extreme of the profile and does not show apparent magnetic contrasts. (b) 2AG1MT-2JA1GO profile, crossing another important magnetic gradient, the Serra Negra Lineament, separating the Arenópolis and Bom Jardim domains. Blue lines show the 2AG1MT and 2JA1GO wells. See Figure 3 for map location.

Figura 5.8 (a) Magnetic anomalies filtered to emphasize source at $1.5 \mathrm{~km}$ depth. (b) Same as Figure $8 \mathrm{a}$ but with interpreted lineaments shown as black lines. Red and blue dots indicate deformed granites and alkaline bodies, respectively, interpreted from magnetic anomalies and geologic correlations. Numbers 1, 2, and 3 refer to Serra Verde, Macacos, and Araguaiana postorogenic granites, respectively. Letters A and B are Serra Negra and Baliza magnetic discontinuities, respectively. (c) The interpretation superimposed on geology. See Figure 1 for geologic labels. See Figure 6 for map location

Figura 5.9 Silurian-Ordovician sandstone from (a) Paraná Basin folded and (b) faulted by Baliza lineament and associated structures, adjacent to the Cuiabá Group. See Figure 2 for map location (AJ08 point). Rose diagrams with (c) 351 strike orientations of magnetic lineaments interpreted from matched-filter analysis (Figure 6), and (d) 128 regional field measurements of strike orientations acquired in the Bom Jardim de Goiás area and along a WNW profile crossing $1000 \mathrm{~km}$ in the study area (Figure 2). Most of our field measurements were undertaken in Paraná Basin units.

Figura 5.10 Map of geological and tectonic features of the study area that are mostly concealed by sediments of the Paraná Basin, including major crustal discontinuities, subsidiary structures, intrusive bodies, and the Serra Geral Formation boundary. Two Precambrian basement lithologies are illustrated. Light yellow dots are recorded seismicity, mostly along NW trending reactivated structures.

Figura 5.A1 Airborne geophysical surveys. State companies that managed the surveys are shown as CPRM (Serviço Geológico do Brasil); CNEN (Comissão Nacional de Energia Nuclear); SIEG/MME (Secretaria de Indústria e Comércio de Goiás/Ministério de Minas e Energia); ANP (Agência Nacional do Petróleo, Gás Natural e Biocombustíveis). Blue polygon indicates limits of study area.

Figura 6.1 Major tectonic units of the study area. The Transbrasiliano Lineament (TBL) is according to interpretation of magnetic data (Vidotti et al., 2011; Curto et al., 2014) and previous studies (e.g., Ramos et al., 2010). Crustal thickness data are derived from analysis of receiver function and seismic refraction compiled by Pavão et al. (2012).

Figura 6.2 A: Location of the Tocantins Province and Paraná Basin in the South American Platform. B: Geological units of inset A, classified according to the main formation time periods. Structures and Cretaceous alkaline intrusive bodies are exposed. Seismic refraction and receiver function data, compiled by Pavão et al. (2012), were also included. 
Figura 6.3 Generalized geology of the study area (Schobbenhaus et al., 2004). Lineaments A (Serra Negra), B (Baliza) and C (General Carneiro) are based on the interpretation of magnetic data. Also shown are the fieldwork locations.

Figura 6.4 Airborne gravity and magnetic surveys used in this study. Also, ground gravity data were acquired in previous research projects by Vidotti (1998) and various institutions, including the Instituto Brasileiro de Geografia e Estatística (IBGE), Instituto de Astronomia, Geofísica e Ciências Atmosféricas, Universidade de São Paulo (IAG/USP) and the Instituto de Geociências, Universidade de Brasília (IG/UnB). The database was provided by the Laboratory of Applied Geophysics (LGA) of IG/UnB

Figura 6.5 (a) Map of reduced-to-pole magnetic anomalies. (b) Map of Bouguer anomalies. Both maps show the locations cross-sections used in 2D modeling of the data. Lineaments A (Serra Negra), B (Baliza) and C (General Carneiro) are based on the interpretation of magnetic data. The crustal depth values are from analysis of receiver function data, as compiled by Pavão et al. (2012).

Figura 6.6 (a) Map of the tilt derivative of the reduced-to-pole magnetic anomalies. Black contour line indicates where the tilt derivative $=0$, which in principle overlies magnetic contacts. (b) Map of the vertical derivative of the Bouguer anomalies. See Figure 5 for explanation of other lines and labels. The drainage network shown in (b) corresponds with gravity lows, except the Araguaia River, which is intended only as a reference to facilitate comparison between spatial models

Figura 6.7 2D model of magnetic and gravity data from section $\mathrm{X}-\mathrm{X}$. The magnetic data were not previously reduced to pole. See Figures 3, 5 and 6 for location. Crustal thickness was obtained from receiver function analysis data, compiled by Pavão et al. (2012). Numbers and letters identify blocks and bodies. Their corresponding physical properties are described in table 1

Figura 6.8 Two-dimensional model of magnetic and gravity data from section $Y-Y^{\prime}$. The magnetic data reduced to pole. See Figures 3, 5 and 6 for map location. Numbers and letters identify blocks and bodies. Their corresponding physical properties are described in Table 1. Symbols and acronyms are described in figure 7.

Figura 6.9 Two-dimensional model of magnetic and gravity data from section Z-Z'. The magnetic data was reduced to pole. See Figures 3, 5 and 6 for map location. Numbers and letters identify blocks and bodies. Their corresponding physical properties are described in Table 1. Symbols and acronyms are described in figure 7.

Figura 6.10 Tectonic model inferred from magnetic and gravimetric models (Figures 7, 8 and 9) and geological data.

Figura 7.1 a) Geologia sobreposta à topografia (SRTM). b) Geologia sobreposta ao tilt do campo magnético anômalo da junção dos dados magnéticos de maior resolução. A linha vermelha marca a borda da Bacia do Paraná. AJ-06 e AJ-08 são amostras de rocha coletadas em campo. 
Figura 7.2 Análise de mecanismos cinemáticos no tilt do campo magnético anômalo. a) Fase sinistral N $30^{\circ}$ E do LTB; b) Fase dextral N60 $-70^{\circ} \mathrm{E}$; $\left.\mathbf{c}\right)$ Movimentação dextral NW. Estão expostos no mapa em amarelo, magenta e azul os componentes dos elipsóides $\mathrm{a}, \mathrm{b}$ e c, respectivamente. Os lineamentos são A: lineamento Serra Negra; B: Baliza; C: General Carneiro; e D: São Vicente.

Figura 7.3 Esquema de evolução tectônica para a área de estudo, desde a Orogenia Brasiliana ( 630 Ma) até a formação do Lineamento Transbrasiliano (LTB; 630-480 Ma) e da Bacia do Paraná (Paleozóico-Mesozóico). As seções NW-SE e Poxoréu- Iporá são idealizadas. Sem escala. 


\section{Lista de Tabelas}

Tabela 3.1 Principais características dos projetos aerogeofísicos utilizados neste estudo.

Tabela 3.2 Etapas de pré-processamento do campo magnético anômalo, enumeradas de acordo a descrição do texto a seguir

Tabela 3.3 Valores de inclinação e declinação geomagnéticas dos aerolevantamentos da área de estudo

Tabela 3.4 Propriedades dos 10 prismas expostos na Figura 3.8

Tabela 3.5 Índices estruturais para anomalias gravimétricas e magnéticas (Reid et al., 1990)

Tabela 3.6 Valores de densidade relativa e susceptibilidade magnética de amostras coletadas em trabalho de campo (os pontos visitados estão no Anexo A3)

Tabela 4.1 Description of the main features of magnetic prisms from Model B

Tabela 5.1 Ranges and Averages of Depth Obtained From Matched-Filter Analysis for Each Magnetic Domain Ranges/Average Depth for Each Zone $(\mathrm{km})$

Tabela 6.1 Physical properties used in the modeling of $\mathrm{X}-\mathrm{X}^{\prime}, \mathrm{Y}-\mathrm{Y}^{\prime}$ and $\mathrm{Z}-\mathrm{Z}^{\prime}$ sections. 


\section{1 . Introdução}

"Não tenho talentos especiais. Apenas sou apaixonadamente curioso"

Albert Einstein (1879 - 1955), fisico

Esta tese apresenta os resultados da análise tectônica do Lineamento Transbrasiliano no flanco noroeste da Bacia do Paraná, com ênfase nos mecanismos de formação e desenvolvimento da bacia. Foram utilizados dados geofísicos e geológicos regionais com objetivo de ampliar o conhecimento acerca do arcabouço tectônico e estrutural em amplo intervalo de profundidade, incluindo grandes domínios crustais, embasamento e seção fanerozóica. O texto é composto por oito capítulos. O presente capítulo dedica-se a valorizar o entendimento da evolução tectônica na área de estudo, sobretudo no que se refere à relação entre o Lineamento Transbrasiliano e a Bacia do Paraná. Justifica o propósito desta tese e enumera perguntas e hipóteses que motivaram e nortearam a pequisa. Por último, apresenta os métodos e conjunto de dados empregados.

O Capítulo 2 contextualiza os aspectos geológicos principais da Bacia do Paraná e de seu embasamento na área de estudo. É realizada a revisão bibliográfica sobre o desenvolvimento tectono-sedimentar da bacia e do contexto pré-cambriano de seu substrato, enfatizando os atributos estruturais do Lineamento Transbrasiliano. São descritos aspectos importantes da geologia da Faixa Paraguai e do Arco Magmático de Goiás, que compõem o arcabouço tectônico regional.

O Capítulo 3 apresenta a metodologia adotada em detalhes, com o objetivo de aprofundar o entendimento das técnicas de processamento e análise de dados geofísicos, empregadas nas diversas etapas de trabalho.

O Capítulo 4 é relativo ao manuscrito "Optimizing depth estimates from magnetic anomalies using spatial analysis tools", submetido à revista Computers \& Geosciences. O manuscrito inclui o aprimoramento da técnica tilt-depth, com base na análise espacial de dados magnéticos em ambiente de Sistema de Informação Geográfica (SIG). Apesar do enfoque metodológico, o artigo também apresenta breve discussão sobre as profundidades indicadas pelos lineamentos magnéticos na área de estudo.

O Capítulo 5 é relativo ao artigo "The tectonic evolution of the Transbrasiliano Lineament in northern Paraná Basin, Brazil, as inferred from aeromagnetic data", publicado na Journal of Geophysical Research - Solid Earth. O artigo descreve aspectos crustais e superficiais do 
Lineamento Transbrasiliano na região noroeste da Bacia do Paraná, com base na caracterização de lineamentos magnéticos e no uso da técnica matched-filter para estimar profundidades de fontes magnéticas.

O Capítulo 6 apresenta o segundo artigo "Crustal Framework of the northwest Paraná Basin, Brazil: insights from joint modeling of magnetic and gravity data", submetido e sob revisão na Tectonophysics. O artigo inclui a modelagem conjunta 2D de dados gravimétricos e magnéticos do Lineamento Transbrasiliano na área de estudo. A estruturação da Bacia do Paraná é vista em maior detalhe e relacionada a elementos tectônicos crustais. Esta parte da pesquisa foi realizada no Serviço Geológico dos Estados Unidos - USGS, Menlo Park, Califórnia, com a orientação do especialista em métodos potenciais, Dr. Richard Blakely.

O Capítulo 7 integra os resultados alcançados ao longo da pesquisa e discute, com maior profundidade, os aspectos tectônicos do Lineamento Transbrasiliano e de sua influência no desenvolvimento da Bacia do Paraná. O capítulo termina com a proposta de evolução tectônica para essa região da bacia, fundamentado na integração dos resultados e estudos geológicos.

As conclusões da pesquisa são listadas no Capítulo 8.

As figuras e tabelas são referenciadas no texto de acordo com sua disposição nos respectivos capítulos, ou seja, a "figura 4.1" se refere à figura 1 do Capítulo 4. Apesar da formatação própria dos artigos, a paginação da tese segue continuamente e está disposta sempre entre colchetes, para que seja diferenciada da paginação dos artigos. As referências bibliográficas dos artigos seguem em suas respectivas páginas finais.

\subsection{Justificativa do tema}

O Lineamento Transbrasiliano (Schobbenhaus et al., 1975) representa uma feição estrutural de escala continental, que foi ativa durante o Neoproterozóico e apresenta episódios de reativação desde então. No contexto da Plataforma Sul-Americana, separa uma grande massa continental a noroeste, o paleocontinente Amazônico, de outra grande massa continental a sudeste, formada pelo conjunto de fragmentos cratônicos de diferentes tamanhos e faixas móveis neoproterozóicas (Cordani et al., 1984; Feng et al., 2004; Fuck et al., 2008; Brito Neves e Fuck, 2013, 2014). Com direção predominantemente $\mathrm{N} 20^{\circ}-30^{\circ} \mathrm{E}$, o lineamento corta desde o extremo noroeste da Província Borborema ao centro da Província Tocantins e continua a sudeste, abaixo 
da porção noroeste da Bacia do Paraná, alcançando a região das Sierras Pampeanas, Argentina (Ramos, 2010).

O posicionamento das grandes sinéclises no Paleozóico do Gondwana Ocidental está relacionado com as estruturas estabelecidas durante o desenvolvimento das faixas móveis brasilianas/pan-africanas, do Neoproterozóico ao Eopaleozóico (Cordani e Sato, 1999; Cordani et al., 2000; Almeida et al., 2000). Como uma das feições de maior expressão deste contexto tectônico, o Lineamento Transbrasiliano é o objeto de estudo de grande projeto homônimo, que reúne pesquisadores e estudantes de pós-graduação de diversas universidades no intuito de contribuir para a compreensão acerca de sua origem e evolução, bem como sua influência nas unidades geológicas que afeta. Esse esforço conjunto está sendo concretizado por meio de estudos geológicos e geofísicos, regionais e de detalhe, ao longo de toda a extensão do lineamento em território brasileiro. Grande parte das pesquisas já apresenta resultados, tendo como exemplo a presente tese de doutorado.

Apesar dos estudos já realizados na tentativa de estabelecer relação entre o Lineamento Transbrasiliano e as grandes zonas de descontinuidade crustal (Cordani et al., 1984, 2003, 2009; Rapela et al., 2007; Ramos, 2010), existem poucos trabalhos que revelem informações no que se refere à sua origem e a sua participação na Orogenia Brasiliana - Pan Africana (Brito Neves et al., 1999) e na evolução das bacias fanerozóicas. Ainda parece distante a construção de modelo consistente que demonstre o papel exercido pelo lineamento na história geológica.

A Bacia do Paraná está entre as bacias fanerozóicas afetadas pelo Lineamento Transbrasiliano e guarda, em relação à sua história evolutiva, questões fundamentais que merecem melhores esclarecimentos. Além da presença significativa de sedimentos cenozóicos, aluvionares e coluvionares, grande parte da superfície da Bacia do Paraná é recoberta por basaltos do Cretáceo. Isso dificulta significativamente o mapeamento das estruturas resultantes da tectônica que permitiu a implantação da bacia e das estruturas relacionadas a processos de reativação ao longo do Paleozóico-Mesozóico.

O mapeamento estrutural da Bacia do Paraná foi efetuado, quase sempre, por meio da utilização de métodos indiretos, como sensoriamento remoto e geofísica (Soares et al., 1982; Machado, 1990; Soares, 1991; Zalán et al., 1991; Marques et al., 1993; Bologna et al., 2013). Especialmente na região noroeste da Bacia do Paraná há poucos poços perfurados e nenhum trabalho de interpretação sísmica, acessível à comunidade científica. O conjunto desses fatores não permite interpretação efetiva sobre o arcabouço estrutural e a disposição tectonoestratigráfica de suas unidades na região. A maior parte dos estudos geofísicos que incluíram a região setentrional da Bacia do Paraná em seu contexto (ex.: Fairhead e Maus, 2003; Feng et al., 
2004; Assumpção et al., 2009; Bologna et al., 2014), traz informações a respeito de descontinuidades litosféricas, sendo obtidas em escalas de investigação de caráter regional/continental. Há carência de pesquisas na região que utilizem a aplicação conjunta de métodos potenciais (magnetometria e gravimetria) na identificação e análise de estruturas em maior escala, derivadas ou não de descontinuidades litosféricas, para entender sua influência na história evolutiva da bacia.

O Lineamento Transbrasiliano é o principal elemento tectônico identificado na região noroeste da Bacia do Paraná (Cordani et al., 1984; Zalán et al., 1991; Fairhead e Mauss, 2003). Sua presença sugere provável controle tectônico na formação e na disposição tectonoestratigráfica das unidades geológicas. A possibilidade de contribuir com esclarecimento da relação entre o lineamento e a evolução da bacia inspirou este estudo. O reconhecimento de elementos geológicos próximos à superfície relacionados a grandes compartimentos tectônicos crustais por meio de processamento robusto e interpretação conjunta de dados magnéticos e gravimétricos compõe a principal abordagem metodológica desta tese.

O desenvolvimento da pesquisa teve como alicerce os seguintes questionamentos e hipóteses de trabalho:

(i) Qual o padrão magnético do Lineamento Transbrasiliano e seu significado estrutural na região noroeste da Bacia do Paraná?

A identificação dos elementos estruturais relacionados ao lineamento na região é mais complexa devido à cobertura sedimentar fanerozóica e vulcânica cretácea. Além disso, o lineamento apresenta comportamento estrutural um tanto distinto do padrão observado ao longo de toda sua extensão, mostrando certa dispersão em seu trend direcional $\mathrm{N} 20^{\circ}-30^{\circ} \mathrm{E}$ (Chamani, 2011). A pesquisa propõe caracterizar o lineamento na área, considerando que suas diferentes direções possam estar relacionados a mecanismos cinemáticos de tensões deformacionais e variações reológicas da crosta.

(ii) O Lineamento Transbrasiliano representa fase rúptil do final da Orogenia Brasiliana, mas há evidências de regime dúctil em profundidade.

A assinatura magnética do Lineamento Transbrasiliano, composta por grandes comprimentos de onda observados em dados de satélite (Fairhead e Maus, 2003), indica zona de transcorrência com raízes profundas. $\mathrm{O}$ alcance do lineamento na crosta e seu papel na evolução tectônica da área de estudo são objetos deste estudo. A caracterização do tectonismo gerado por estruturas pré-cambrianas é intríseca ao entendimento da fase inicial da Bacia do Paraná. 
(iii) A Bacia do Paraná foi influenciada pelas zonas de falhas do Lineamento Transbrasiliano.

Em geral, estruturas do embasamento podem controlar o desenvolvimento da bacia sedimentar pela configuração do substrato inicial e por reativação de estruturas durante suas fases posteriores. A distinção geofísica entre elas depende da resolução dos dados magnéticos e gravimétricos e da etapa de processamento. Mesmo sendo possível discriminar os lineamentos geofísicos interpretados em função de sua origem e, por meio de técnicas mais robustas, estimar diferentes profundidades, a superposição de diferentes fontes é uma dificuldade que deve ser considerada. A pesquisa visa identificar feições tectônicas e geológicas regionais précambrianas, bem como o relevo do embasamento da Bacia do Paraná na área de estudo. Apesar da limitação dos dados, as estuturas de reativação podem ser observadas a partir da integração de assinaturas geofísicas com a geologia mapeada em superfície, pressupondo continuidade entre as mesmas.

\subsection{Objetivos}

O foco principal desta tese é identificar, caracterizar e compreender as estruturas do Lineamento Transbrasiliano e seus principais reflexos na evolução tectônica do noroeste da Bacia do Paraná, desde sua fase inicial, no Eopaleozóico, até a consolidação completa de seu pacote deposicional, no Mesozóico. A magnetometria e a gravimetria são as ferramentas principais, utilizadas para enfatizar contrastes físicos relacionados às feições geológicas da área de estudo. Para que a meta maior seja alcançada, foram traçados os seguintes objetivos específicos:

(i) Compilação e processamento de dados geofísicos, magnéticos e gravimétricos, com a aplicação de transformações lineares e técnicas específicas para estimar profundidades das fontes.

(ii) Identificação de domínios e lineamentos magnéticos e gravimétricos.

(iii) Interpretação tectônica e estrutural dos lineamentos e domínios geofísicos.

(iv) Geração de modelos geofísicos 2D em seções definidas estrategicamente na área de estudo, utilizando como suporte dados de poços, trabalho de campo, geologia de superfície (Schobbennhaus et al., 2004) e estimativas de espessura crustal obtidas pela análise de função do receptor (Assumpção et al., 2002; 2013; Pavão et al., 2012).

(v) Proposta do modelo geológico e de evolução tectônica para a porção noroeste da Bacia do Paraná. 


\subsection{Localização da área de estudo}

Os limites da área de estudo foram definidos no sentido de incluir o contexto geológico do Lineamento Transbrasiliano no flanco norte da Bacia do Paraná, incluindo parte das unidades do embasamento pré-cambriano, exposto ao redor do limite da bacia (faixas de dobramento Brasília e Paraguai). A existência de dados geofísicos disponíveis também influenciou na delimitação da área.

A região de estudo engloba parte dos estados de Goiás (GO) e Mato Grosso (MT), como também pequena parcela do norte de Mato Grosso do Sul (MS), como observado na Figura 1.1. Inclui as cidades de Iporá-GO, Barra do Garças-MT, Poxoréo -MT e seu limite oeste está a quase $70 \mathrm{~km}$ da cidade de Cuiabá- MT, totalizando extensão leste-oeste de $521 \mathrm{~km}$ e norte-sul de $421 \mathrm{~km}$.

A principal estrada de acesso à região, a partir do Distrito Federal, é a BR-070, que estabelece trajeto no sentido geral leste-oeste.

A região é dominada por densa rede fluvial, na qual o Rio Araguaia delimita os estados de Goiás e Mato Grosso e é reconhecido por sua grande extensão. A sudoeste e nordeste da área estão localizadas as bacias hidrográficas do Pantanal e Araguaia, respectivamente.

\subsection{Métodos e base de dados}

O estudo envolveu a construção de base de dados em ambiente SIG (Sistema de Informações Geográficas), reunindo dados geológicos e imagens geofísicas, elaboradas após o processamento e aplicação de técnicas de realce de dados magnéticos e gravimétricos. Natureza dos dados e etapas envolvidas, desde sua compilação à geração dos produtos finais, estão descritas em detalhe no Capítulo 3.

Foram utilizados dados geofísicos provenientes de seis levantamentos aéreos, adquiridos desde a década de 1970, assim como por projetos recentes, realizados em 2004 e 2010. São eles: projetos Iporá (1012), Alto Garças (2009), Rondonópolis (2025) e Barreiro (2022), Arco Magmático de Arenópolis - Sequência Juscelândia (3009) e Bacia do Paraná. Todos incluem dados magnéticos, enquanto o último também contêm dados de gravimetria. Além desses, foram utilizados dados de gravimetria terrestre, que são parte da compilação de projetos anteriores desenvolvidos por Vidotti (1998) e várias instituições, como o Instituto Brasileiro de Geografia e Estatística (IBGE), Instituto de Astronomia, Geofísica e Ciências Atmosféricas, Universidade de São Paulo (IAG/USP) e Instituto de Geociências, Universidade de Brasília (IG/UnB). 
Foram adquiridos dados de análise de função do receptor (Assumpção et al., 2002; 2013; Pavão et al., 2012) e descrição de três poços estratigráficos perfurados na área de estudo, 2AG-1MT, 2JA-1-GO e 2TQ-1-MT, disponibilizados pela ANP (Agência Nacional do Petróleo, Gás Natural e Biocombustíveis).

Mapas geológicos foram gerados por meio da base de dados da CPRM (Serviço Geológico do Brasil) em escala 1: 1.000.000 (Schobbennhaus et al., 2004). Apresentam-se como conjunto de arquivos vetoriais (tipo shapefile, ARCGIS) para processamento em ambiente SIG (Sistema de Informações Geográficas). Adicionalmente, foram adquiridas medidas estruturais e de susceptbilidade magnética, e amostras de rocha foram coletadas em reconhecimento geológico regional, executado em duas saídas de campo durante o trabalho de doutorado (outubro de 2012 e janeiro de 2013). 

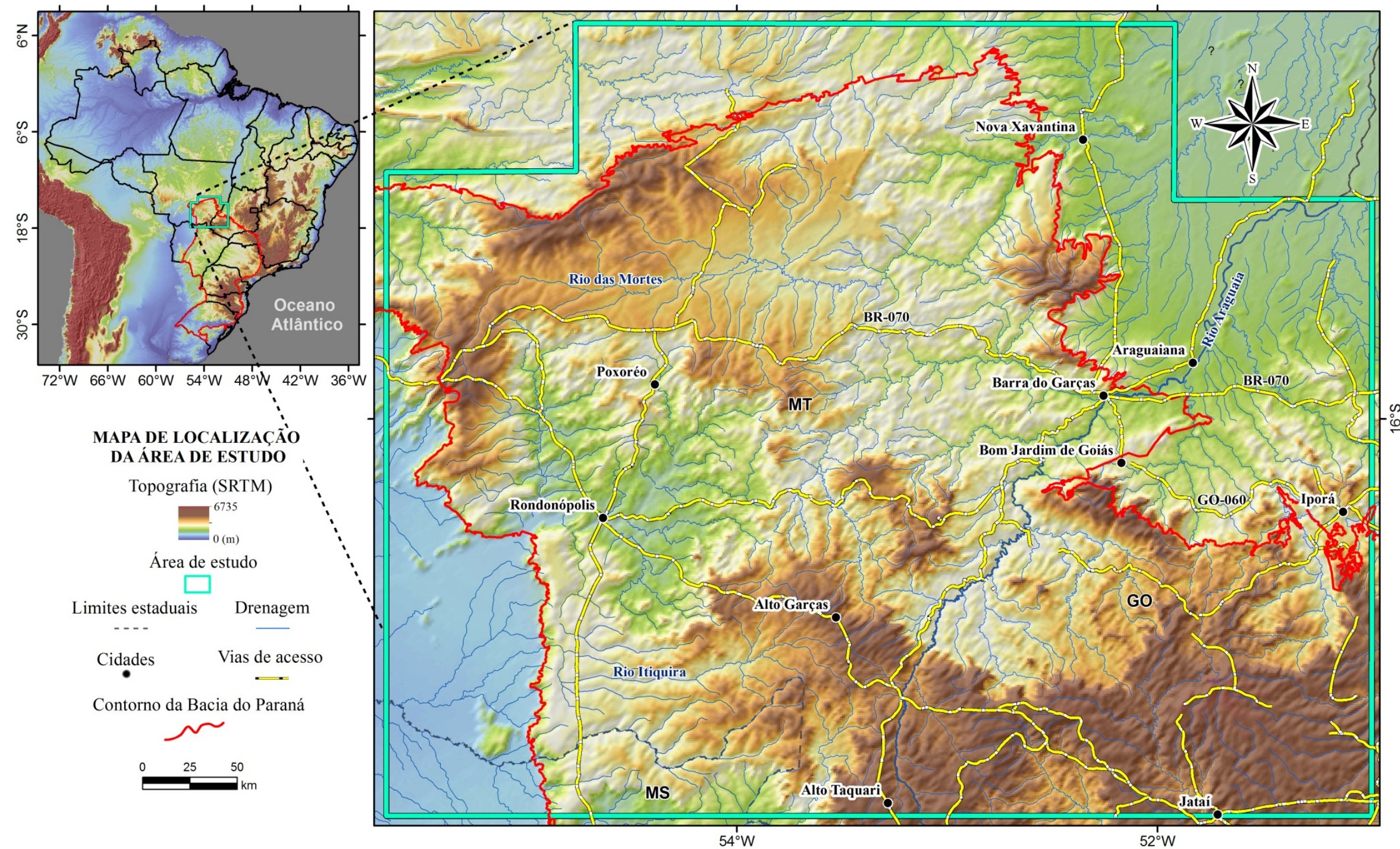

Figura 1.1 - No inset, localização da área de estudo na América do Sul, sobre imagem de radar (SRTM). Em maior detalhe, a área de estudo. 


\section{2 . Contexto Geotectônico}

"O maior inimigo do conhecimento não é a ignorância, mas a ilusão do conhecimento"

Stephen Hawking, fisico e matemático

A Plataforma Sul-Americana (Almeida, 1967) é composta pelas seguintes unidades geológicas: (1) escudos compostos pelos crátons e faixas móveis brasilianas; (2) bacias cratônicas Paraná, Amazonas e Parnaíba, que constituem a cobertura paleo-mesozóica; (3) riftes jurássicos-cretáceos e bacias de margem passiva associadas à fragmentação do Pangea e formação do Atlântico Sul; e (4) bacias de rifte pós-quebramento e plútons alcalinos relacionados à reativação neo-cretácea e terciária.

A região de estudo engloba um mosaico complexo de terrenos tectono-estratigráficos, assim denominados por representar entidades geológicas de certa extensão, delimitadas por um complexo de falhamentos, cada qual caracterizada por história geológica própria e diferente daquela dos terrenos vizinhos (Howell, 1985; Brito Neves, 2011). Estes terrenos incluem unidades pertencentes às faixas móveis neoproterozóicas Brasília (Almeida et al., 1981; Fuck et al., 1993,1994; Pimentel et al., 2000) e Paraguai (Almeida, 1967, 1985, Alvarenga et al., 2000; Boggiani e Alvarenga, 2004), amalgamadas na convergência brasiliana (Almeida e Hasui, 1984). Desde o início desta tese, em 2011, trabalhos alavancaram importantes discussões a respeito da colagem orogênica Brasiliana e formação do Gondwana (Pimentel et al., 2011; Tohver et al., 2012; Brito Neves e Fuck, 2013, 2014; Cordani et al., 2013a, b; Brito Neves et al., 2014, Fuck et $a l ., 2014)$. Além do conjunto pré-cambriano, a seção fanerozóica do flanco noroeste da Bacia do Paraná (Zalán et al., 1991; Milani, 1997) é especialmente abordada. Dessa maneira, a área de estudo abrange geograficamente a convergência de grandes unidades geotectônicas (Figuras 2.1 e 2.2).

As faixas móveis Brasília e Paraguai, junto com a Faixa Araguaia a norte, constituem a Província Tocantins (Almeida et al., 1977, 1981; Figura 2.1). Unidades supracrustais estão distribuídas sobre substrato dominantemente paleoproterozóico, diferenciado entre as duas faixas por apresentar histórias evolutivas significativamente distintas, separadas por grande descontinuidade crustal, o Lineamento Transbrasiliano - LTB (Schobbenhaus et al. 1975; Cordani et al., 1984). Esta zona estrutural, de dimensões continentais, está de alguma forma relacionada aos eventos tectônicos gerados durante a convergência das placas que formaram o supercontinente Gondwana (Brito Neves e Cordani, 1991; Cordani et al., 2009, 2013a, b) durante a colagem orogênica Brasiliana (800-500 Ma, Brito Neves e Fuck, 2013; Brito Neves et al., 2014). O pico orogênico ocorreu em ca. 630-600 Ma (Pimentel et al., 1991; Cordani et al., 
2013a ,b; Brito Neves et al., 2014). O LTB se implantou na fase final do Brasiliano (<560 Ma; Brito Neves e Fuck, 2013), sendo bastante ativo durante o Cambriano e com posteriores reativações no Fanerozóico (Brito Neves et al., 1984; Cordani et al., 2013a, b). A implantação da Bacia do Paraná se deu ao longo de feições alongadas NE-SW, iniciando-se no Ordoviciano e tendo sua história sedimentar interrompida no Cretáceo, quando ocorreu um dos maiores eventos de fluxo basáltico em continente já registrado na Terra, o magmatismo Serra Geral (Zalán et al., 1991).

No presente estudo, a abordagem geológica das unidades geotectônicas apresentadas acima é de caráter regional, sendo o LTB considerado como o componente tectônico de maior importância (Figura 2.2). A revisão e análise realizadas sobre a história tectono-estrutural da Bacia do Paraná consideram os eventos ocorridos desde a Orogenia Brasiliana até a reativação meso-cenozóica (Zalán, 2004).

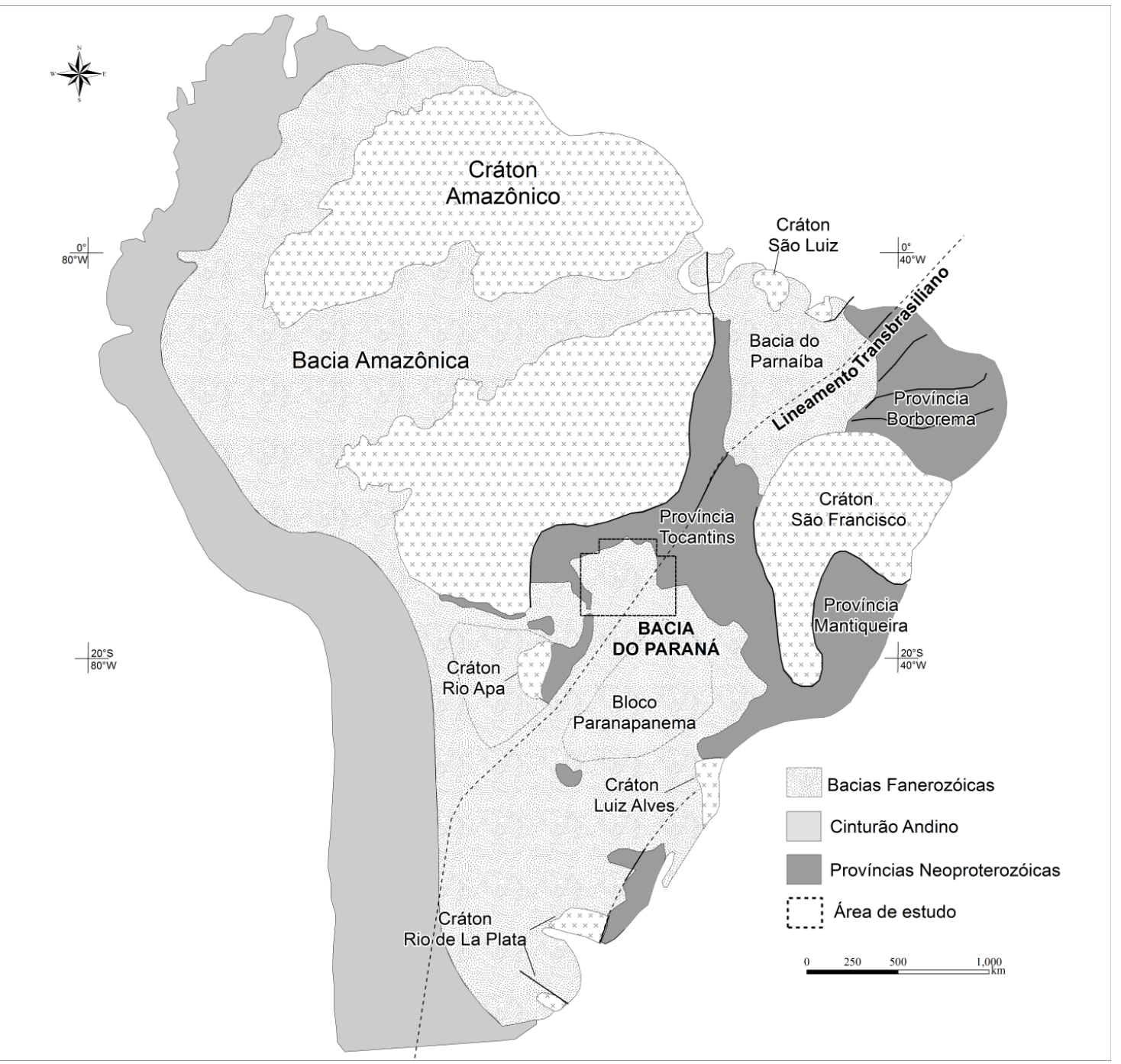

Figura 2.1 - Contexto geotectônico simplificado da Plataforma Sul-Americana (adaptado de Cordani et al. 2009). Localização geral do LTB na Plataforma Sul-Americana de acordo com interpretação de dados magnéticos (Vidotti et al., 2011) e sua compilação com trabalhos anteriores (Ex.: Ramos et al., 2010). 


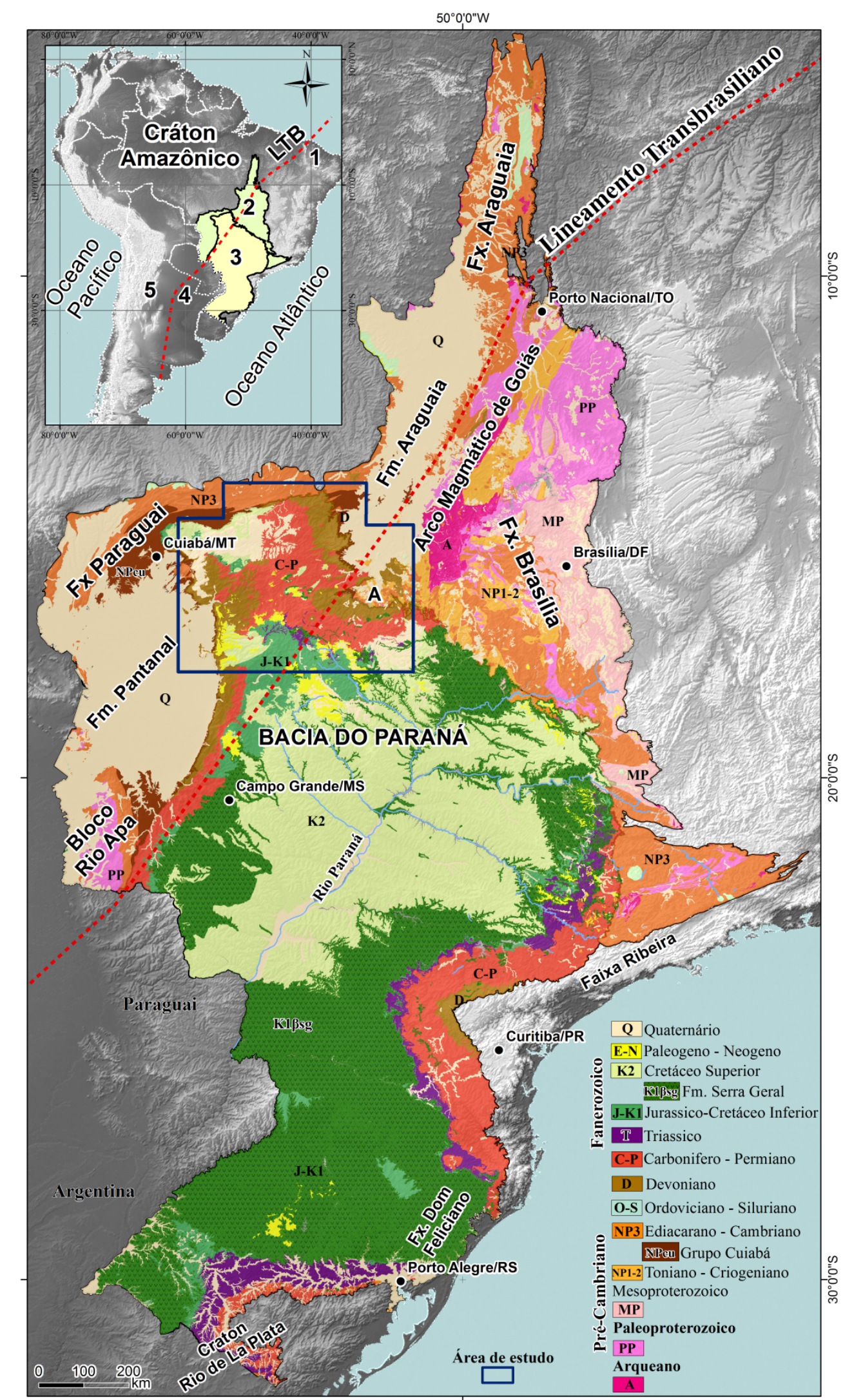

A: Arco Magmático de Arenópolis

1 - Província Borborema; 2 - Província Tocantins; 3 - Bacia do Paraná; 4 - Bacia Las Breñas ; 5 - Sierras Pampeanas

Figura 2.2 - Mapa geológico da Província Tocantins e Bacia do Paraná (base de dados geológicos da CPRM, Schobbenhaus et al., 2004) sobre topografia (Imagem de radar - SRTM). O polígono com borda azul marca a localização da área de estudo. A: Arco Magmático de Arenópolis. No inset, localização do LTB na Plataforma Sul-Americana (Ver referências na Figura 2.1). 


\subsection{Geologia Regional}

\subsubsection{Faixa Brasília}

A Faixa Brasília (Almeida et al., 1981; Fuck et al., 1993, 1994; Pimentel et al., 2000) apresenta orientação geral norte-sul e estende-se por cerca de $1.100 \mathrm{~km}$, desde o sudoeste de Minas Gerais até o sul do Estado de Tocantins (Figura 2.2). É resultado da deformação associada ao processo de convergência final da Orogenia Brasiliana, no Neoproterozóico. As unidades que compõem a faixa (Dardenne, 2000) estão resumidas em: (i) espessa pilha meso-neoproterozóica que inclui os grupos Paranoá, Canastra, Araxá, Ibiá, Vazante e Bambuí, sobrepostos ao embasamento paleoproterozóico e, em menor proporção, arqueano; (ii) o Maciço de Goiás, uma possível microplaca ou terreno alóctone, composto pelas rochas arqueanas de Crixás-Goiás, pelo embasamento siálico paleoproterozóico associado às faixas supracrustais e por complexos máfico-ultramáficos acamadados de Barro Alto, Niquelândia e Cana Brava e sequências vulcano-sedimentares associadas; e (iii) arco juvenil neoproterozóico, o Arco Magmático de Goiás.

A área de estudo engloba a extensão meridional do arco magmático, região de Arenópolis, sul de Goiás (Figura 2.2 e Anexo A1).

\section{Arco Magmático de Arenópolis}

As unidades geológicas das porções noroeste e sudoeste da Faixa Brasília pertencem dominantemente ao Arco Magmático de Goiás (Figura 2.2; Pimentel e Fuck, 1992). O arco é constituído por diferentes faixas de ortognaisses de composição diorítica a granítica que em geral separam unidades vulcano-sedimentares compostas por rochas máficas a félsicas, rochas metassedimentares e rochas metaultramáficas. Como observado no mapa geológico (Anexo A1), sua extensão meridional, a qual está parcialmente inclusa na área de estudo, é identificada como Arco Magmático de Arenópolis (Pimentel et al,. 2000). Este arco é bem conhecido na região de Piranhas (Pimentel, 1985; Pimentel e Fuck, 1986), Bom Jardim de Goiás (Seer, 1985) e JaupaciIporá (Amaro, 1989; Rodrigues et al., 1999). É constituído por ortognaisses supracrustais justapostos a um conjunto de falhas de transcorrência NNE-NNW, relacionadas ao LTB. Ortognaisses cálcio-alcalinos indicam fonte em magma primitivo (Pimentel e Fuck, 1986, 1987) com período de cristalização entre 890 e 860 Ma (Laux et al., 2005). Este magma seria proveniente de subducção de litosfera oceânica jovem durante processos de convergência, percursores à Orogenia Brasiliana (Almeida e Hasui, 1984). Sequências vulcano-sedimentares com alinhamento NNW a NNE são conhecidas, de oeste para leste: Bom Jardim de Goiás, Arenópolis (929 \pm 8 Ma), Iporá (636 \pm 6 Ma), Amorinópolis, Jaupaci (764 \pm 14 Ma) e Anicuns- 
Itaberaí (Pimentel et al., 2000, 2004). Entre 660 e 620 Ma, a evolução do arco é resultado da alternância de eventos distensivos com épocas de deformação intensa (Pimentel et al., 2003). Ao final do Neoproterozóico e início do Paleozóico, granitos potássicos pós-orogênicos se instalaram, tais como Serra Negra, Serra do Iran, Caiapó, Iporá, Sanclerlândia e Serra do Impertinente.

Dados de U-Pb e Sm-Nd mostram que o arco juvenil se estende para sudeste e nordeste, abaixo das bacias fanerozóicas do Paraná e Parnaíba, respectivamente (Pimentel et al., 2000; Fuck et al., 2001; Fuck et al., 2014).

\subsubsection{Faixa Paraguai}

A Faixa Paraguai (Almeida, 1985) bordeja a extensão sudeste do Cráton Amazônico, a norte, e o Bloco Rio Apa, a sul (Figura 2.2). É constituído por sedimentos ediacaranos a neocambrianos, seguido por magmatismo granítico tardio em 580 Ma e deformação entre 550$500 \mathrm{Ma}$ (Pimentel et al., 1996, Boggiani e Alvarenga, 2004, Godoy et al., 2007, 2010). Segundo Alvarenga et al. (2000), três unidades principais podem ser distinguidas: (i) uma mais inferior, que consiste de camadas glácio-marinhas e sedimentos turbidídicos com afinidades glaciais (Formação Puga e Grupos Jacadigo Boqui e Cuiabá); (ii) unidade carbonática que marca o final da influência glacial na bacia (equivalente ao Grupo Corumbá); (iii) unidade superior composta por sequências de rochas siliciclásticas (equivalente ao Grupo Alto Paraguai). A faixa é considerada por Alvarenga e Trompette (1993) como possível paleo-prisma sedimentar de antiga margem passiva. Em estudo de proveniência com isótopos de Nd, Dantas et al. (2009) dão suporte a hipótese de inversão tectônica para bacia tipo foreland. Na porção oriental da faixa, próximo ao contato com a Bacia do Paraná, ocorrem corpos graníticos de caráter ácido (Del'Arco et al., 1982), tal como o Granito São Vicente (Almeida e Mantovani, 1975), presente na porção oeste da área de estudo e datado pelo método de K-Ar e U-Pb em $504 \mathrm{Ma}$ (Amaral et al., 1966; Manzano et al., 2008; Godoy et al., 2010). Associado a este granito, encontram-se as “Vulcânicas de Mimoso”, constituídas por dacitos, riodacitos e riolitos (Del'Arco et al., 1982).

A Faixa Paraguai ocupa a porção norte da área de estudo e uma estreita faixa, na região de Bom Jardim de Goiás, dominantemente composta pelo Grupo Cuiabá (Anexo A1). Esta unidade é marcada por rochas metassedimentares, dobradas e metamorfizadas (Alvarenga e Trompette, 1988). Na região, são reconhecidas quatro fases de deformação, das quais as três primeiras são co-axiais, orientadas na direção $\mathrm{N} 20^{\circ}-30^{\circ} \mathrm{E}$, concordante com o trend geral do $\mathrm{LTB}$, e uma última, ortogonal (Seer, 1985; Seer e Nilson, 1985). 


\subsubsection{Bacia do Paraná}

A Bacia do Paraná é uma das cinco sinéclises fanerozóicas de maior extensão da Plataforma Sul-Americana, ocupando área de $1.500 .000 \mathrm{~km}^{2}$, sendo cerca de $80 \%$ em território brasileiro. Sotoposto ao longo do Rio Paraná, seu depocentro atual está próximo de $7 \mathrm{~km}$ de profundidade (Milani et al., 2007). É delimitada por altos estruturais e faixas móveis: (i) Arco de Assunção, a oeste, (ii) Faixas Paraguai e Brasília, a norte, (iii) Flexura de Goiânia e Arco do Alto Paranaíba, a nordeste, (iv) Faixa Ribeira, a leste, e (v) Faixa Dom Feliciano, a sul (Figura 2.3, Zalán et al., 1991). A sudoeste do Arco de Assunção, a bacia segue no Paraguai e Argentina, denominada de Bacia Chaco-Paraná. Apesar de seu formato, alongado e ovalado, ser típico de bacias cratônicas, a Bacia do Paraná só atingiu sua configuração atual no Cretáceo. Desde sua origem, no Ordoviciano, ao seu estágio final, no Cretáceo Superior, sucederam-se variações eustáticas globais, eventos tectônicos distensivos e compressivos, e ciclos de subsidência e soerguimento, que juntos condicionaram diferentes estágios evolutivos e a superposição de pelo menos três bacias (Zalán et al., 1991; Milani, 1997; Milani e Thomaz Filho, 2000). Durante o Cenozóico, sua sedimentação ficou restrita à formação de depósitos aluvionares e coluvionares.

\section{Natureza do embasamento}

O substrato da bacia se configurou ao fim da Orogenia Brasiliana, com a formação de mosaico de terrenos pré-cambrianos (Almeida e Hasui, 1984), formado predominantemente por terrenos granito-gnaíssicos, justapostos entre si ao longo de faixas móveis (Cordani et al., 1984). O conjunto de faixas móveis neoproterozóicas que bordeja a bacia integra a parte conhecida de seu embasamento: Faixas Paraguai (a oeste), Brasília (a norte), Ribeira (a leste) e Dom Feliciano (a sul). Já o embasamento não-aflorante, principalmente nas porções central e norte da bacia, é pouco conhecido.

Até o ano de 2008, dos 124 poços perfurados na bacia pela Petrobras e Paulipetro, somente quatro estão localizados em seu flanco norte e apenas dois deles alcançaram o embasamento. No poço AG-1-MT (Anexo A1), a oeste do LTB, a rocha basal, encontrada a 1.943m de profundidade, foi correlacionada ao Grupo Cuiabá e mostra idades aparentes brasilianas, em datação por K-Ar e Rb-Sr (Cordani et al., 1984). Já a leste do lineamento, em 3.437 m de profundidade do poço RA-1-MS, anfibólio de rocha granítica indica idade pré-Brasiliana, da ordem de 2.100 Ma, obtida pelo método K-Ar (Cordani et al., 1984). De acordo com Cordani et al. (2010a), esta rocha pode pertencer a três possíveis tectonozonas: (i) a uma área antiga e rejuvenescida, (ii) a extensão de um fragmento cratônico; ou (iii) a extensão do embasamento do Maciço de Goiás. A existência de um bloco litosférico tem sido proposta por diversos autores, 
tendo sido denominado de Bloco Paraná (Cordani et al., 1984; Campos Neto, 2000.) ou Bloco Paranapanema (Figura 2.1; Mantovani e Quintas, 1996; Mantovani e Brito Neves, 2005; Mantovani et al., 2005), o qual abrange a porção central e atual depocentro da sinéclise. A principal evidência é a ocorrência de extensa anomalia gravimétrica positiva, em formato triangular alongado no sentido NE-SW, bordejada por gradientes gravimétricos acentuados (Mantovani e Quintas, 1996).

O mapa regional do arcabouço estrutural da Bacia do Paraná (Zalán et al.,1991; figura 2.3), foi baseado, em sua maior parte, na interpretação qualitativa de dados aeromagnéticos. Junto com a orientação dos arcos, um importante conjunto de lineamentos identificado ao longo da bacia com direções principais NW-SE, NE-SW e E-W reflete o controle tectônico determinado por estruturações mais antigas.

\section{Estratigrafia}

Milani (1997) realizou extensa análise regional da evolução geológica da bacia, utilizando 83 poços do acervo técnico da Petrobrás. O autor classificou a bacia segundo hierarquização estratigráfica baseada em supersequências (Vail et al., 1977), que constituem-se em unidades de ordem II, com 20 a 60 Ma: Rio Ivaí (Ordoviciano-Siluriano), Paraná (Devoniano), Gondwana I (Carbonífero-Eotriássico), Gondwana II (Meso a Neotriássico), Gondwana III (NeojurássicoEocretáceo) e Bauru (Neocretáceo) (Figuras 2.3 e 2.4). Os três primeiros correspondem a ciclos transgressivos-regressivos enquanto os demais são frutos de sedimentação continental mesozóica com rochas ígneas associadas.

A Supersequência Rio Ivaí (Milani, 1997) marca o primeiro ciclo transgressivo-regressivo da Bacia do Paraná. De acordo com Assine et al. (1994), este pacote está limitado no topo por uma discordância regional, denominada Pré-Furnas, e é composta pelas formações Alto Garças, Iapó e Vila Maria (Faria, 1982; Assine e Soares, 1989; Assine et al., 1994; Milani, 1997), representados por sedimentos dominantemente marinhos. Há registros desde o estado de Santa Catarina até Mato Grosso e Goiás, com tendência de espessamento para oeste.

A Formação Vila Maria representa o período de máxima inundação desse ciclo sedimentar. No contexto da área de estudo, flanco norte da Bacia do Paraná (Anexo A1), este pacote possui $55 \mathrm{~m}$ de espessura, que inclui os arenitos da Formação Alto Garças, os diamictitos da Formação Iapó e os folhelhos fossilíferos e arenitos finos micáceos da Formação Vila Maria (Faria, 1982; Alvarenga et al., 1998). 


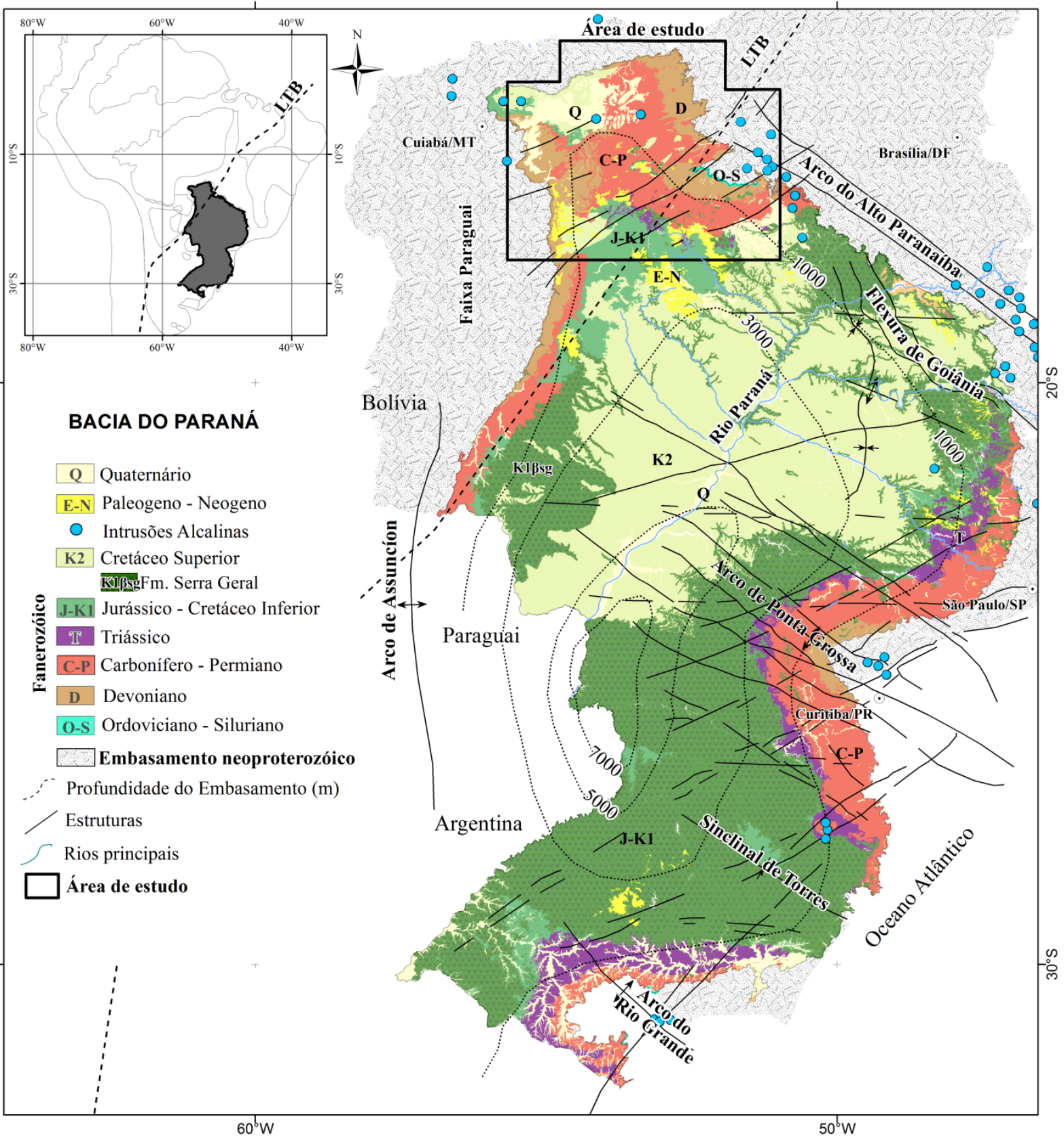

Figura 2.3 - Unidades geológicas da Bacia do Paraná classificadas de acordo com as principais fases deposicionais (Milani, 1997; Schobbenhaus et al., 2004). O mapa também inclui isópacas da bacia (Milani, 1997), arcabouço estrutural regional (Zalán et al., 1991) e unidades do embasamento neoproterozóico (Cordani et al., 1984). A Bacia é dominada por elementos tectônicos com trends NW-SE, NE-SW e E-W. No inset, localização da Bacia do Paraná e do LTB na Plataforma Sul-Americana (Ver referências na Figura 2.1).

A Supersequência Paraná (Milani, 1997) constituiu o segundo ciclo transgressivoregressivo da bacia. É composta pelo pacote pelítico da Formação Ponta Grossa, sobreposto ao pacote arenoso da Formação Furnas. Possui espessura máxima de 800 m, no estado do Paraná (Milani et al., 2007). O conteúdo icnofossilífero encontrado (Assine, 1996) sustenta a hipótese de acumulação em plataforma marinha rasa. Paleogeograficamente, este pacote foi 
provavelmente depositado em golfo aberto a oeste para o oceano Proto-Pacífico (Zalán et al., 1991). O topo da Supersequência Paraná é marcado por discordância devoniana, provavelmente associada à Orogenia Herciniana (Zalán et al., 1991; López-Gamundí e Rossello, 1993) ou à influência glacial (Caputo et al., 2008). No flanco norte da Bacia do Paraná (Anexo A1), este pacote é representado de 80 a 170 metros de espessura (Alvarenga et al., 1998).

Com a migração do Pangea para o norte, a Supersequência Gondwana I (Milani, 1997) apresenta o maior volume sedimentar da bacia e possui espessura máxima de $2.500 \mathrm{~m}$. Materializa ciclo transgressivo-regressivo completo, resultado da invasão e posterior saída do Oceano Panthalassa sobre o interior do Pangea (Milani et al., 2007). É composta, da base ao topo, pelo Grupo Itararé e Formação Aquidauana (equivalentes estratigráficos; França e Potter, 1988), Grupo Guatá, Grupo Passa Dois e formações Pirambóia/Sanga do Cabral. Estas unidades representam desde sedimentação associada a degelo até ambientes áridos no topo. A Formação Palermo (Grupo Guatá) representa condições de máximo afogamento marinho da bacia no Artinskiano (284,4 Ma - 275,6 Ma). Associado ao contínuo fechamento da bacia ao Oceano Panthalassa, um contexto ambiental hipersalino é registrado na Formação Irati (Grupo Passa Dois). A Formação Sanga do Cabral e seu equivalente setentrional, Formação Pirambóia, marcam o início do domínio da sedimentação continental.

A Supersequência Gondwana II (Milani, 1997) é representada unicamente pela Formação Santa Maria, que se restringe à porção meridional da bacia e reflete o fim das incursões marinhas e o predomínio da sedimentação continental.

Após o maior hiato deposicional da bacia (Figura 2.4), a Supersequência Gondwana III (Milani, 1997), amplamente distribuída na Bacia do Paraná, tem início com a formação de extensos campos de dunas (Formação Botucatu) e posterior evento magmático eocretáceo (Formação Serra Geral), relacionado aos momentos iniciais da ruptura do paleocontinente Pangea. Este evento traduziu-se como espessa cobertura de lavas, uma rede de diques e múltiplos níveis de soleiras ao longo de toda seção sedimentar (Milani et al., 2007). Cerca de $3 / 4$ da área da bacia são recobertos pelas rochas ígneas da Formação Serra Geral.

A Supersequência Bauru (Milani, 1997) é denominada por Fernandes e Coimbra (1996) como Bacia Bauru, já que sua sedimentação ocorreu graças ao novo ciclo de subsidência promovido pela carga das rochas magmáticas (Grupo Bauru / Caiuá). Sua sedimentação ocorreu sob condições semi-áridas a desérticas. Possui espessura máxima de cerca de $300 \mathrm{~m}$. Durante este período deposicional, dois eventos intrusivos de natureza alcalina e maior expressividade afetaram a borda da bacia: 87-80 Ma e 70-60 Ma (Almeida e Melo, 1981). 


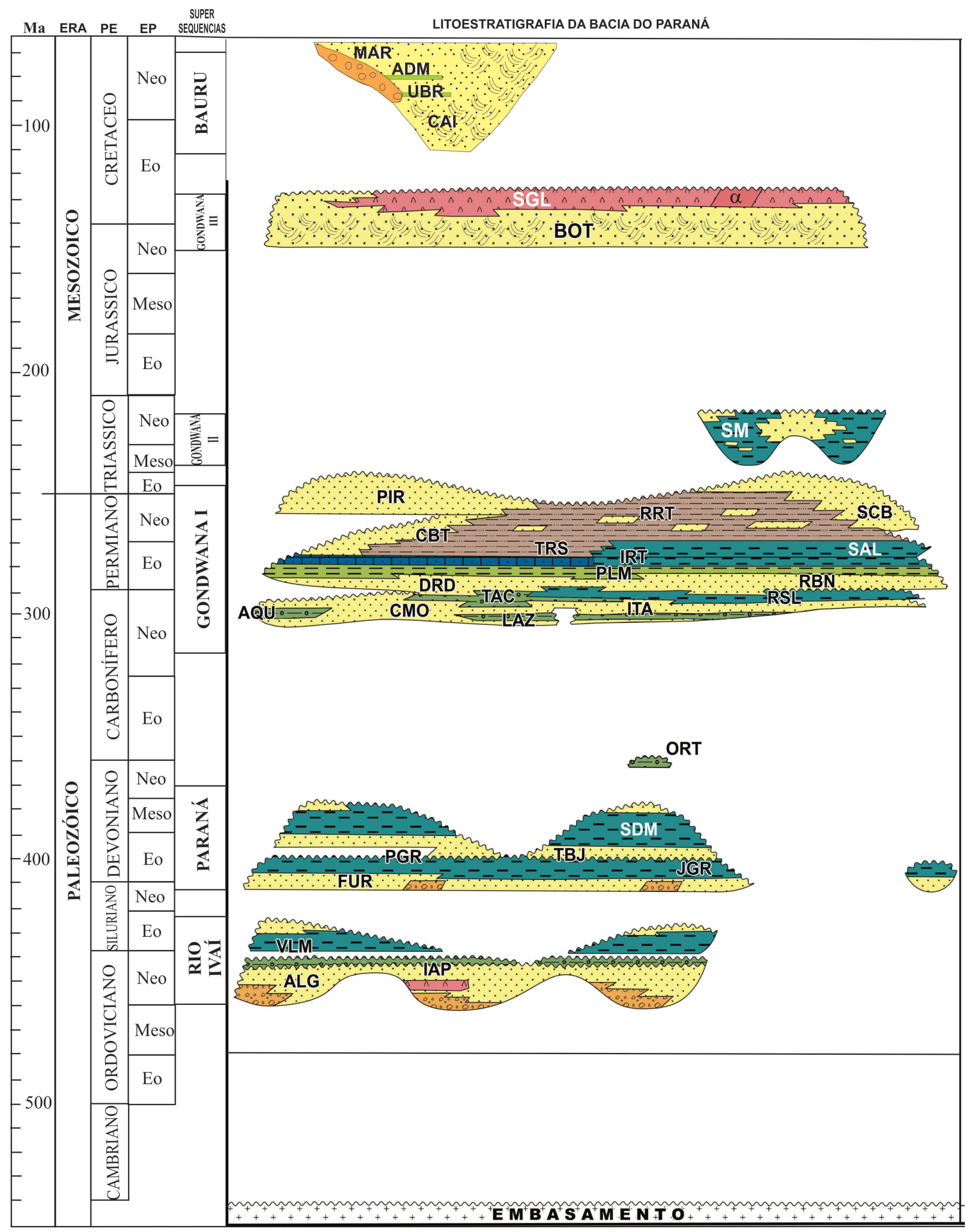

ALG- Fm. Alto Garças; IAP- Fm.Iapó; VLM- Fm.Vila Maria; FUR-Fm. Furnas; JGR- Mb. Jaguariaíva; PGR- Fm. Ponta Grossa; TB1- Mb. Tibagi; SDM- Mb. São Domingos; ORT- Mb. Diacmictito Ortigueira; LAZ- Fm. Lagoa Azul; CMO- Fm. Campo Mourão-; ITA- Fm. Itararé; AQU-Fm. Aquidauana; TAC- Fm. Taciba; RSL- Fm. Rio Sul; DRD- Fm. Dourados; PLM- Fm. Palermo. RBG- Fm. Rio Bonito; IRT- Fm. Irati; SAL- Fm.Serra Alta; TRS- Fm. Teresina; CBT- Fm. Corumbataí; RRT- Fm. Rio do Rasto; SCB- Fm. Sanga do Cabral; PIR- Fm. Pirambóia; SM- Fm. Santa Maria; BOT- Fm. Botucatu; SGL- Fm. Serra Geral; CAI- Fm.Caiuã; UBR- Fm. Uberaba; ADM- Fm. Adamantina; e MAR- Fm. Marília.

$$
\text { Arenito Conglomerado Siltito Folhelho Diamictito Carbonato Vulcânicas Arenito eólico }
$$

Figura 2.4 - Carta estratigráfica da Bacia do Paraná, de acordo com Milani (2004) e Milani et al. (2007). 


\subsection{Evolução Tectônica}

\subsubsection{Neoproterozóico}

\section{Orogenia Brasiliana}

A Orogenia Brasiliana (Almeida e Hasui, 1984), originalmente denominada como Ciclo Brasiliano (Almeida, 1969), representa o último estágio de evolução do embasamento da Plataforma Sul-Americana. Implica numa série de orogenias acrescionárias, com formação e coalescência de arcos magmáticos, e processos colisionais, levando ao fechamento de todos os sítios deposicionais deixados pela quebra do Supercontinente Rodínia, em torno de $750 \mathrm{Ma}$, e a consolidação de um novo supercontinente, o Gondwana, em 550 Ma (Brito Neves e Cordani, 1991; Brito Neves, 1999; Pìmentel et al., 2000; Cordani et al., 2003, Fuck et al., 2008; Brito Neves et al., 2014).

Um grande oceano Brasiliano separava a margem Laurentia - Pampia - Rio Apa Amazônia - Oeste Africano da maior parte dos demais cratóns descendentes do Rodínia, incluindo micro-continentes e arcos de ilha, como Rio de La Plata, Paraná, Luiz Alves, Maciço de Goiás, São Francisco e Borborema-Trans-Sahara (Figura 2.5; Cordani et al., 2003). Sua extensão na Província Tocantins é denominada Oceano Goiás e, para nordeste e sul, é reconhecido como Pharusiano e Pampeano, respectivamente (Brito Neves et al., 1984; Cordani et al., 2003; Fetter et al., 2003). Seu fechamento ocorreu durante um período de convergência entre 940-630 Ma, que caracterizou a formação do Arco Magmático de Goiás, entre 900-800 Ma (Pimentel et al., 2000), com um segundo pulso de magmatismo juvenil em $630 \mathrm{Ma}$ (Laux et al., 2005).

Alguns modelos existentes consideram uma primeira colisão entre os cratóns São Francisco e Paranapanema e posterior acreção entre o Arco Magmático de Goiás e o limite oeste do Maciço de Goiás, datada no segmento de Mara Rosa em 800-760 Ma (Pimentel et al., 2006; Ferreira-Filho et al.,2010). O encaixe deste conjunto com o Cráton São Francisco se dá em aproximadamente $630 \mathrm{Ma}$, marcado por magmatismo granítico na borda norte do Bloco Paranapanema (Pimentel e Fuck, 1987; Kuyumjian e Dias, 1991; Pimentel et al., 1997; Strieder e Suita, 1999; Araújo Filho, 2000; Campos-Neto e Caby, 1999; Soares et al., 2006). A colisão final é registrada em 630-550 Ma ao longo de todo o conjunto das faixas móveis Pampeana Paraguai - Araguaia - Pharusiana (Pimentel et al., 2000; Jahn et al., 2001). Intrusões póstectônicas graníticas cálcio-alcalinas ricas em $\mathrm{K}$ e magmatismo bimodal foram contemporâneas à deposição da Faixa Paraguai, registrando idade mínima de 560 Ma (Brito Neves et al., 2014). 


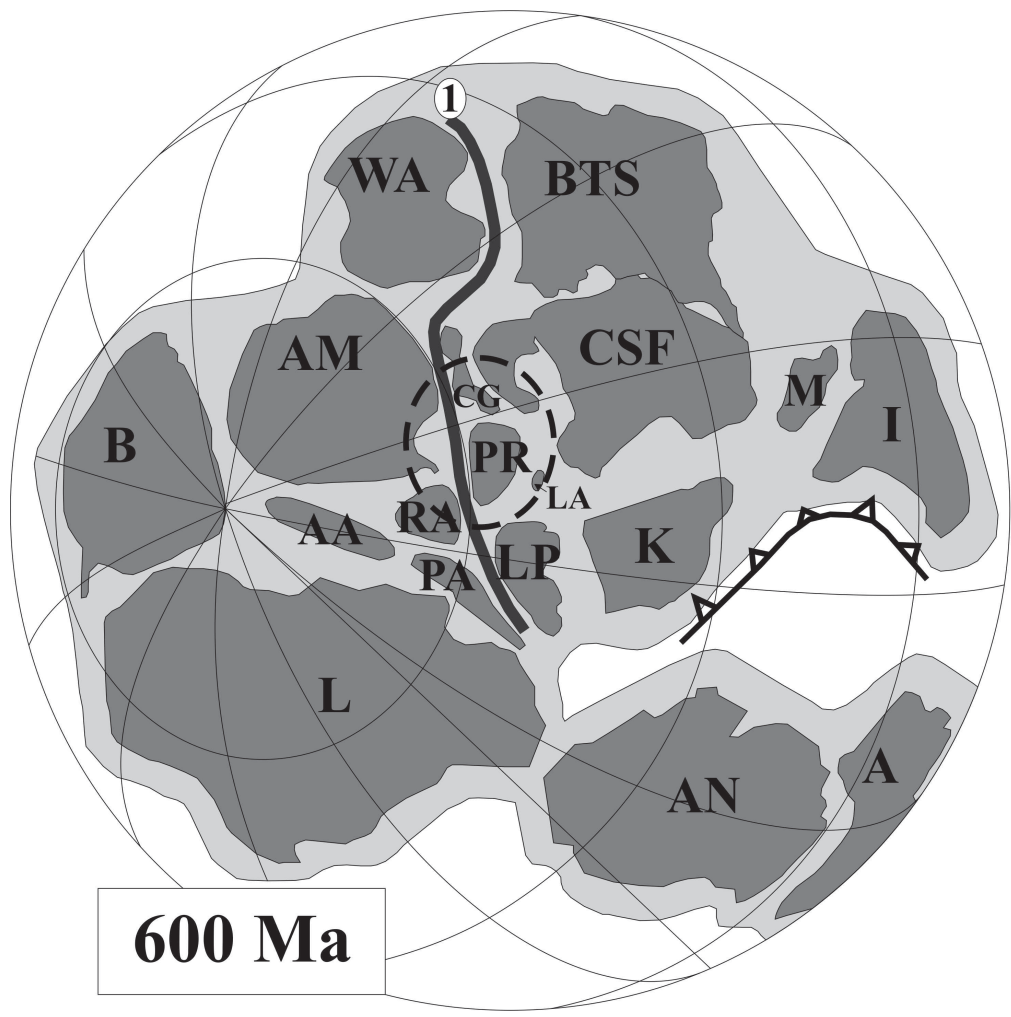

Contexto Gondwânico

(Brasiliano, $600 \mathrm{Ma}$ ) da área de estudo

1- Cinturão Pampeano-Goiás-Pharusiano

Fragmentos e massas cratônicas:

AA-Arequipa/Antofalla

A- Australia

AM- Amazonia

AN- Antarctica

B- Baltica

BTS- Borborema-Trans-Sahara

CG- Goiás Central

CSF - São Francisco

I- India

L- Laurentia

LA- Luiz Alves

LP- Rio de La Plata

M- Madagascar

WA- West African

PA-Pampia

RA- Rio Apa

PR- Paraná

S- Siberia

Figura 2.5 - Reconstrução hipotética do Gondwana em 600 Ma (Cordani et al., 2003, 2009, 2013, 2014).

Polaridade metamórfica é crescente para o interior das faixas móveis e suas vergências tectônicas regionais ocorrem na direção de suas respectivas entidades cratônicas (Fuck et al., 1993; Hasui, 2009). No entanto, a Faixa Paraguai também apresenta vergência oposta ao cráton Amazônico nas zonas internas da faixa (Alvarenga e Trompette, 1993). Finalmente, a cratonização do embasamento do supercontinente Gondwana foi alcançada durante o Cambriano-Ordoviciano (Brito Neves, 1999; Heilbron et al., 2000).

De forma complementar à proposta evolutiva acima descrita, segundo Mantovani et al. (2005) as características gravimétricas da Faixa Paraguai a oeste-noroeste da Bacia do Paraná são compatíveis com assinaturas de arco de ilha, formado provavelmente pelo consumo de litosfera oceânica entre o Bloco Paranapanema e o Bloco Rio Apa, considerado como a extensão meridional do Cráton Amazônico (Cordani et al., 2009; Ramos et al., 2010). O estudo de perfis magnetotelúricos na Faixa Paraguai sustenta a hipótese do fechamento de oceano entre a placa Amazônica e o bloco Paranapanema, indicado por uma zona crustal altamente condutora de aproximadamente $100 \mathrm{~km}$ de extensão lateral (Bologna et al., 2013).

Utilizando dados de gravimetria e de condições isostáticas, Molina et al. (1988) propuseram que um importante espessamento crustal na bacia pode ter sido resultado de material mantélico derivado de processos de underplating. Esse evento de subducção seria 
contemporâneo à formação do Arco Magmático de Goiás, que em seu segmento norte, apresenta afinamento crustal por delaminação, como descrito por Soares et al. (2006) em experimento de refração sísmica profunda. Dessa forma, processos de delaminação podem ter ocasionado espessamento crustal na Bacia do Paraná e afinamento crustal no arco. Esta hipótese também é sustentada pelos valores de espessura crustal obtidos por função do receptor (Assumpção et al., 2002) e modelagem gravimétrica (Vidotti et al., 1998), segundo os quais grande parte da crosta sob a Bacia do Paraná mostra espessuras de 40 a 46 km. Em seu flanco norte, na região do Arco Magmático de Goiás, a espessura da crosta é de aproximadamente $32 \mathrm{~km}$ (Assumpção et al., 2004, 2012). Mariani et al. (2013) sugerem fenômeno de underplating resultante do magmatismo cretáceo. Em estudo de estruturas crustais com ondas de superfície, An e Assumpção (2006) favorecem a hipótese de subsidência ao contrário de underplating, sem densificação significativa da crosta sob a bacia.

\section{O Lineamento Transbrasiliano}

O sistema de falhas transcorrentes do Lineamento Transbrasiliano - LTB (Schobbenhaus et al., 1975) corresponde ao último evento tectônico relacionado à Orogenia Brasiliano-Pan Africana (Marini et al., 1984a,b; Cordani et al., 2010b).

A extensão do LTB no continente Africano é reconhecida como zona de cisalhamento Hoggar 450'- Kandi (Caby et al., 1981; Caby, 1989, Cordani et al., 2003; Arthaud et al., 2008), que se prolonga desde a região central da Argélia até a costa do Togo (região do golfo da Guiné), local onde, no supercontinente Pangea, apresentava continuidade com a zona de cisalhamento Sobral-Pedro II (norte do Ceará). Já sua extensão meridional tem sido recentemente inferida por diversos autores (Ramos e Vujovich, 1993; Milani e Ramos, 1998; Feng et al., 2004; Rapela et al., 2007; Ramos et al., 2010 ). Por meio da modelagem de velocidade de ondas S, Feng et al. (2004) reconhecem uma extensão sudoeste do LTB, com certa curvatura na direção oeste, abrangendo a Faixa Paraguai e a porção sul da Bacia do Pantanal. Segundo Cordani et al. (2009), o LTB continua a leste do Bloco Rio Apa. Vidotti et al. (2011; Anexo B1) sugerem o traçado geral do LTB ao longo do Plataforma Sul-Americana (Figura 2.1). Estruturações NE-SW, que controlam o pacote mais antigo da Bacia do Paraná, prosseguem através do Paraguai até a Faixa Pampeana Oriental (Ramos e Vujovich, 1993; Rapela et al., 2007) e ao longo da Bacia Las Brenãs (Milani e Ramos, 1998). Ramos et al. (2010) associam essas estruturas ao sistema de falhas do LTB e as correlacionam à descontinuidade crustal na margem leste da Serra de Córdoba, Argentina. 
Brito Neves e Cordani (1991), Brito Neves (1999), Cordani et al. (2009, 2013) e Brito Neves e Fuck $(2013,2014)$ reconhecem que o LTB separa dois grandes domínios: o Cráton Amazônico a oeste - domínio Pré-Brasiliano; e o conjunto de terrenos afetados pela Orogenia Brasiliana a leste - domínio Brasiliano (Figura 2.1). Cordani et al. (2009) relacionam o fechamento do domínio oceânico Pampeano-Goiás-Pharusiano (Figura 2.5) com a zona de ocorrência do LTB, caracterizando junção desses dois domínios e a formação do supercontinente Gondwana.

No limite norte da Bacia do Paraná, o LTB separa a Faixa Paraguai de outro domínio de embasamento (Cordani et al., 1984), constituído provavelmente pela extensão meridional do Arco Magmático de Goiás - Arenópolis - ou pelo Bloco Paranapanema. Nessa região são encontrados pequenos corpos graníticos alongados, intensamente deformados, que mostram foliação milonítica NNW-NNE sub-vertical, interrompendo estruturas deformacionais anteriores. O caráter dúctil-rúptil deste sistema é observado próximo a Bom Jardim de Goiás na falha Serra Negra, que separa o Grupo Cuiabá de sequência metavulcano-sedimentar associada ao Arco Magmático de Arenópolis e desloca o granito Macacos (Anexo A1) em aproximadamente $8 \mathrm{~km}$ (Seer, 1985; Pimentel e Fuck, 1992). De acordo com Cordani et al. (2010b), estas rochas estão intimamente relacionadas ao LTB e indicam a existência pretérita de um grande oceano, consumido por subducção por ocasião das colisões continentais que ocorreram durante amálgama do Gondwana.

A cinemática predominante no LTB possui caráter de transcorrência destral, como observado na região de Bom Jardim de Goiás (Pimentel e Fuck, 1992); Porangatu - GO (Chiarini, 2007; Dantas et al., 2007), na zona de cisalhamento Sobral-Pedro II (Arthaud, 2007) e em suas extensões argentina (Rapela et al., 2007) e africana (Ferré et al., 2002). No entanto, Seer (1985) registra transcorrência sinistral na falha Serra Negra.

Atualmente, o LTB é uma importante zona sismogênica, que se interpreta como efeito de alívio de tensões ao longo de zonas de fraqueza no quadro geral de deslocamento da Placa Sul Americana (Mioto e Hasui, 1988). A menor espessura crustal é indicada como possível geradora dos sismos (Rocha et al., 2011; Assumpção e Sacek, 2013).

\subsubsection{Paleozóico-Mesozóico}

\section{Evolução Tectono-Estratigráfica da Bacia do Paraná}

A implantação da Bacia do Paraná ocorreu na forma de depressões alongadas na direção NE-SW, induzidas pela reativação de descontinuidades brasilianas (Zalán et al., 1991; Milani, 
1997). O campo de esforços necessário para desencadear processos de reativação durante o Paleozóico e Mesozóico teve origem, em sua maior parte, na margem meridional do Pangea, que se comportou durante este período como uma zona de subducção do Oceano Panthalassa, configurando a formação de bacias de antepaís e acresção de terrenos alóctones (Milani e Ramos, 1998). Essa sucessão de orogenias marcou dois ciclos principais (Ramos et al. 1986; Ramos, 1988): Famatiniano (Ordoviciano a Devoniano), que inclui as orogenias Oclóyica e Precordilheirana, e Gondwânico (Carbonífero a Triássico), composto pelas orogenias Chanica e Sanrafaélica (Figura 2.6).

Três eventos distensivos principais são relacionados às fases de subsidência da Bacia do Paraná (Milani, 1997) e ocorreram há cerca de 440 Ma, 296 Ma e 144 Ma (Quintas et al., 1999). De acordo com Milani (1997), mapas de isópacas mostram a evolução da bacia em seus diferentes formatos e trends deposicionais (Figuras 2.7 e 2.8 ).

Segundo Zalán et al. (1991) e Milani (1997), o primeiro evento distensivo (Ordoviciano Siluriano) reflete os sinais iniciais da reativação das zonas de fraqueza, predominantemente transcorrentes, como resultado do campo compressivo e sobrecarga tectônica originados na borda do continente pela Orogenia Oclóyica (500 a 425 Ma; Ramos et al., 1986). Sua geometria define depocentros transtensivos, desenvolvidos em substrato dominado pelas faixas móveis neoproterozóicas e alongados na direção NE-SW, onde a Supersequência Rio Ivaí (NeoOrdoviciano) compreende espessura máxima de 400 m (Zalán et al., 1991; Milani e Ramos, 1998). Como observado nos mapas de isópacas (Figuras 2.7), o LTB exerce controle significativo na deposição desta sequência, que ocorre restrita ao flanco norte e noroeste da bacia. Já as regiões cratônicas permaneceram como áreas positivas e foram cobertas somente a partir do Ordoviciano, com a deposição da Formação Alto Garças há 450 Ma (Heilbron et al., 2000).

A existência de rifteamento como mecanismo percursor ao início da subsidência é proposta por estudos com base em dados geofísicos. Marques et al. (1993) propõem a existência de rifte central, abaixo do atual depocentro da bacia. Vidotti et al. (1998) relacionam uma anomalia gravimétrica negativa bem marcada no eixo norte da bacia, alongada na direção NNESSW e posicionada entre duas anomalias positivas, a assinaturas típicas de ambientes tipo rifte. Com base em modelagem gravimétrica, estes autores estimam a base do graben em $8 \mathrm{~km}$ de profundidade, coincidente com uma camada de alta velocidade observada em dados de função do receptor (Assumpção et al., 2009). Esta é uma questão ainda em debate, pois a única evidência de rocha magmática Paleozóica na bacia é a existência de um corpo basáltico encontrado no 
poço 2TL-1-MS (Três Lagoas), a $4.572 \mathrm{~m}$ de profundidade (Mizusaki, 1989), datado pela técnica Ar/Ar em $443 \pm 10 \mathrm{Ma}$ (York, 2003).

Do Siluriano ao Jurássico, arcos regionais se formaram isostaticamente em resposta à subsidência. Reativações condicionaram sua localização, tal como flexuras marginais, alinhamentos estruturais e zonas de maior subsidência (Almeida, 1980; Zalán et al., 1991). O Arco de Assunção, no limite oeste da Bacia do Paraná, foi provavelmente desenvolvido no Eodevoniano (Zalán et al., 1991).

O segundo evento distensivo (Permo-Carbonífera) ocorreu por processo de flexura litosférica, com aceleração da subsidência a partir do Emsiano, em resultado do aprofundamento rápido do substrato (Milani e Ramos, 1998), induzido pela Orogenia Precordilheirana (Ramos et al., 1986). Assim, os sedimentos da Supersequência Paraná apresentam espessura de até $800 \mathrm{~m}$ na Bacia do Paraná, enquanto as sequências cronocorrelatas na Argentina, Bolívia e África do Sul alcançaram milhares de metros de espessura, sugerindo comunicação entre o golfo da Bacia do Paraná e os extensos ambientes marinhos das bacias de foreland do Gondwana Ocidental (Gohrbandt, 1993; apud Heilbron et al., 2000). Nesta fase, os sedimentos foram depositados em condição estável na bacia, apresentando geometria tabular.

No Eocarbonífero desenvolveram-se calotas de gelo em áreas próximas e sobre parte da bacia, juntamente com o rebaixamento do nível do mar. A partir do Westfaliano, inicia-se a terceira e mais longa fase de subsidência da bacia, influenciada pela Orogenia Chanica (Ramos et al., 1986), quando a Supersequência Gondwana I acumulou até $2.500 \mathrm{~m}$ de sedimentos. No final do Permiano, a morfologia da Bacia do Paraná foi profundamente modificada, coincidente com o clímax da Orogenia Sanrafaélica (Ramos et al., 1986). A sedimentação continua até o Eotriássico (Supersequência Gondwana II), restrita às porções gaúcha e uruguaia da bacia (Milani et al., 2007) e, enquanto isso, a porção norte passa por processos erosionais.

Entre o Neotriássico e o Neojurássico não ocorre deposição na bacia, marcando importante hiato em seu registro estratigráfico.

O estágio de reativação Wealdeniana (Almeida 1967, 1969), também denominada MesoCenozóica (Zalán, 2004) ou Sul-Atlantiana (Cretáceo-Paleógeno; Hasui, 2009), caracteriza a tectônica gerada na abertura do Atlântico Sul. Neste período, as estruturas de reativação mostraram forte relação com as estruturas do embasamento brasiliano. De acordo com Alvarenga et al. (1998), em observação realizada no flanco norte da Bacia do Paraná, a tectônica cretácea afetou as sequências paleozóicas, cortadas por uma série de falhas que, em alguns casos, mostram deslocamentos verticais maiores que $500 \mathrm{~m}$. O soerguimento tectônico ocorrido no 
Eocretáceo (Tello Saenz et al., 2003; Hackspacher et al., 2004) foi acompanhado pela formação de altos estruturais, como a Flexura de Goiânia (Hasui et al., 1975) e os arcos do Alto Paranaíba (Ladeira et al., 1971; Hasui e Haralyi, 1991), Bom Jardim de Goiás (Fulfaro et al., 1994) e Ponta Grossa (Almeida et al., 2000).

Também em resultado à reativação meso-cenozóica, ocorreram manisfestações magmáticas de natureza básica e alcalina na bacia (Almeida, 1969), juntamente com a deposição dos arenitos eólicos da Formação Botucatu (Gondwana III). O magmatismo Serra Geral, com o acúmulo de até $2.000 \mathrm{~m}$ de lavas basálticas e félsicas, marcou o fim dos eventos de sedimentação distensiva da Bacia do Paraná. A fase principal de atividade vulcânica ocorreu há 133-132 Ma (Marques e Ernesto, 2004), originada em manto litosférico subcontinental heterogêneo, migrou de sul para norte, finalizando com a colocação do enxame de diques de Ponta Grossa (131-129 Ma), Serra do Mar (132-119 Ma) e Florianópolis (129-119 Ma). A maior parte dos diques está disposta preferencialmente ao longo de estruturas NW-SE.

A sobrecarga exercida pelos derrames Serra Geral gerou o último processo de subsidência que levaria ao início de nova bacia, denominada Bacia Bauru (Fernandes e Coimbra, 1996). Durante esse período, dois eventos magmáticos de maior intensidade e natureza alcalina foram registrados em 87-80 Ma e 70-60 Ma (Almeida e Melo, 1981). As manifestações magmáticas ocorreram como corpos intrusivos na borda da bacia, especialmente sua porção setentrional, e em ocorrências isoladas no interior da bacia. 


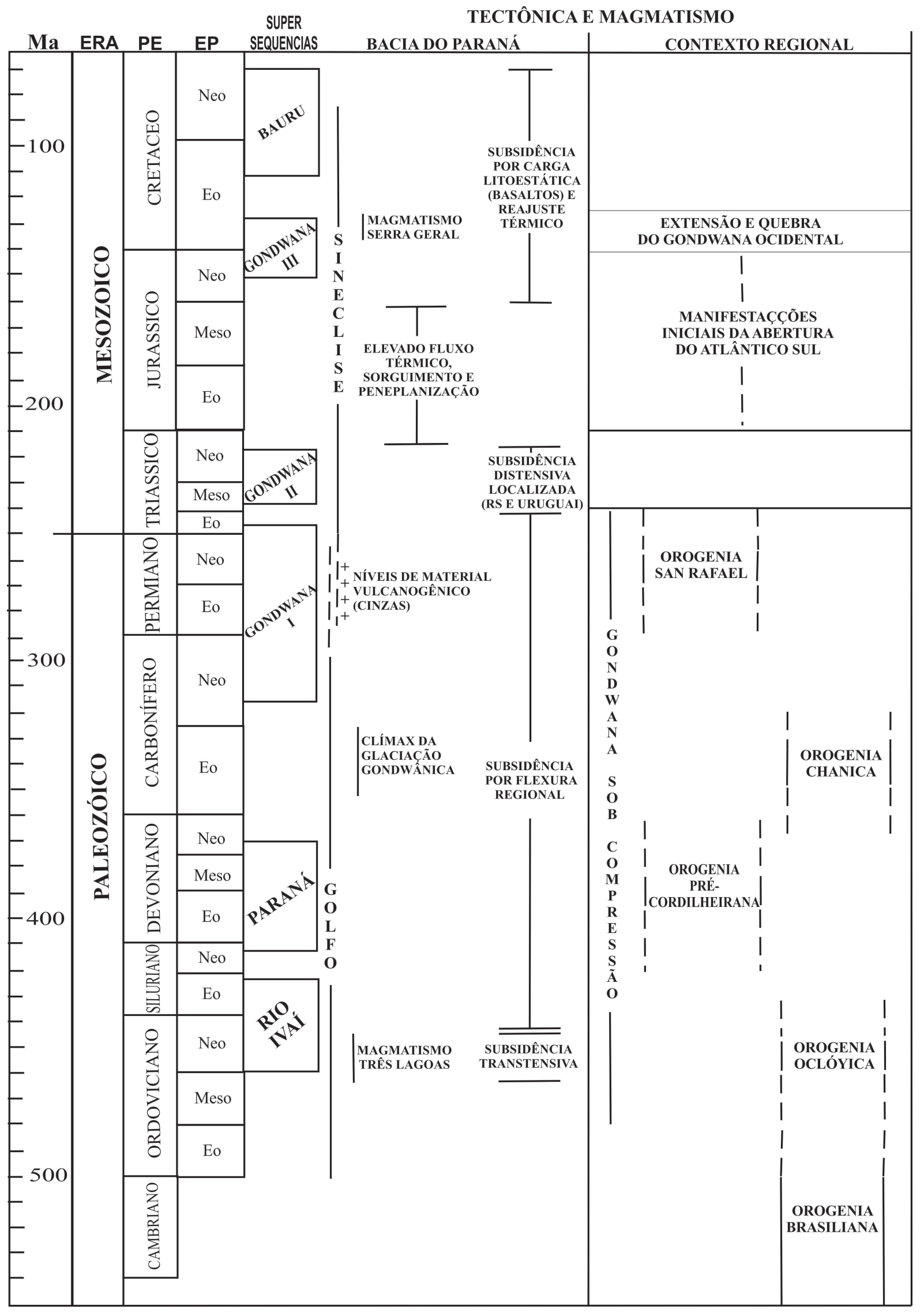

Figura 2.6 - Quadro tectono-estratigráfico da Bacia do Paraná, baseado em Heilbron et al.(2000). 


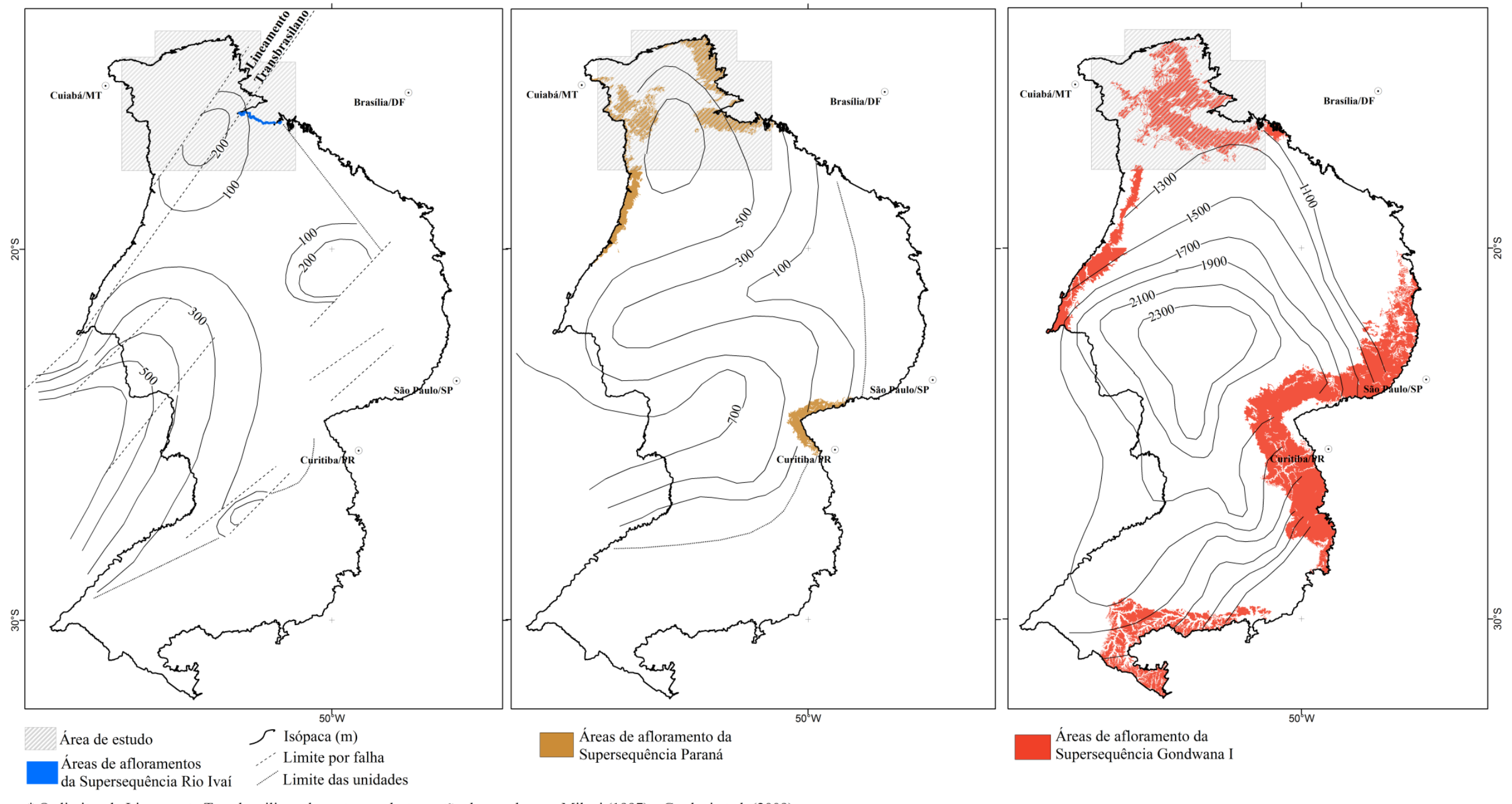

* Os limites do Lineamento Transbrasiliano,de oeste para leste, estão de acordo com Milani (1997) e Cordani et al. (2009)

Figura 2.7 - Isópacas da Bacia do Paraná, do Ordoviciano ao Eotriássico (adaptado de Milani, 1997). Observar o controle do Lineamento Transbrasiliano na distribuição das isópacas da Supersequência Ivaí, onde a Fm. Vila Maria aflora restritamente no limite norte da bacia. 


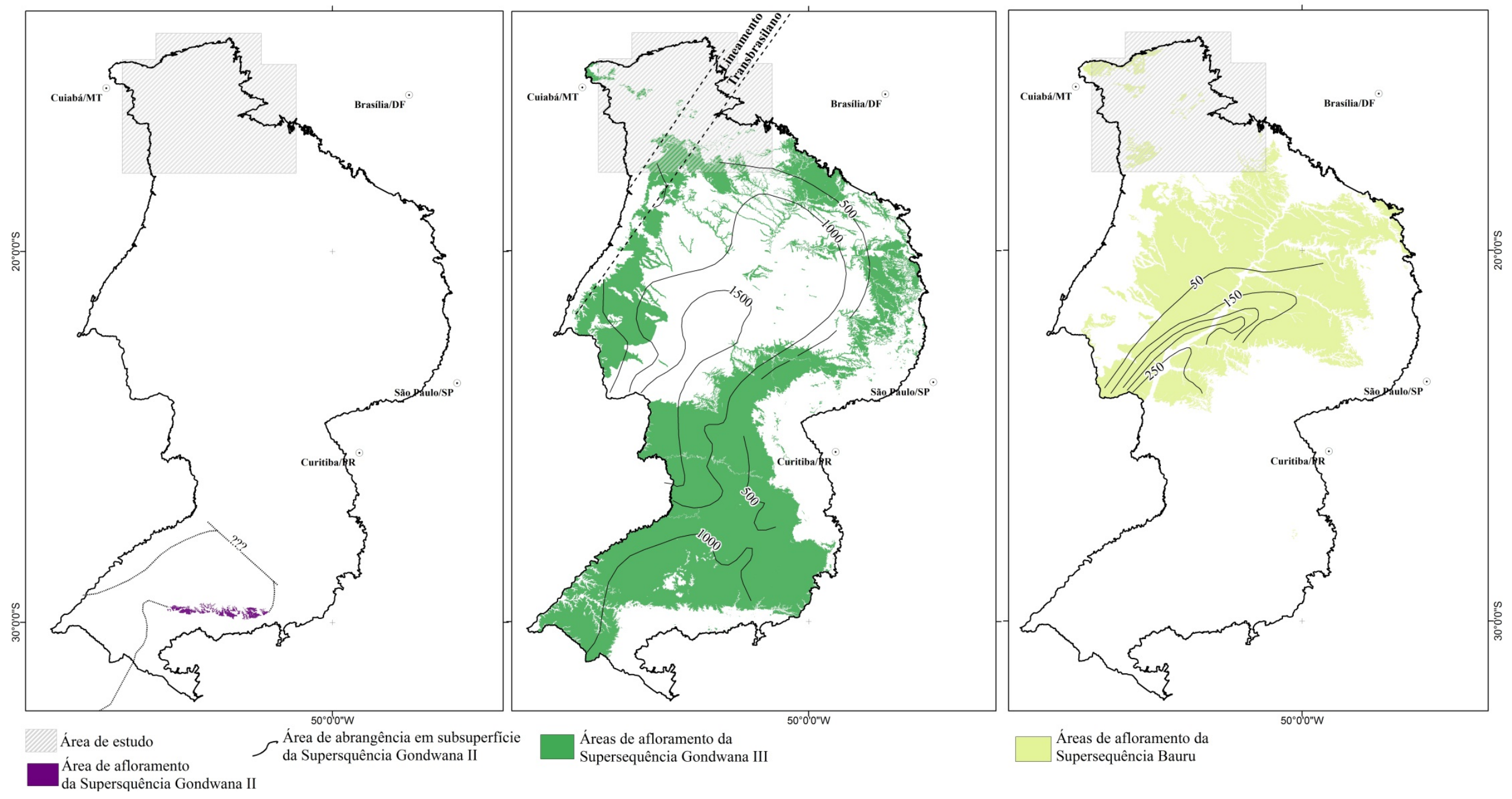

Figura 2.8 - Isópacas da Bacia do Paraná, do Mesotriássico ao Neocretáceo (adaptado de Milani, 1997). Observar provável controle do Lineamento Transbrasiliano na distribuição das isópacas da Supersequência Gondwana III, composta pelos basaltos da Fm. Serra Geral e arenitos da Fm. Botucatu. 


\subsection{Reconhecimento geológico de campo}

A base de dados geológicos regionais utilizada neste estudo é composta por: (1) mapas geológicos gerados a partir da base de dados SIG, na escala 1:1.000.000 (Schobennhaus et al., 2004), disponibilizados pela CPRM; (2) descrições geológicas de três poços estratigráficos perfurados pela Paulipetro/Petrobras: 2AG-1-MT, 2JA-1-GO e 2TQ-1-MT; e (3) dados geológicos e estruturais coletados em campanhas de campo realizadas durante $o$ desenvolvimento da tese.

O trabalho de campo foi realizado em duas etapas, em outubro de 2012 e em janeiro de 2013. A primeira foi conduzida em concomitância com a saída de campo do curso de Sistemas Deposicionais, ministrado pelo Prof. José Souza de Alvarenga. A campanha de campo teve duração de seis dias e compreendeu a região entre Iporá/GO, Baliza/GO e Barra do Garças/MT. Foram coletadas 12 amostras, identificadas com a sigla inicial AJ (Anexo A3).

A segunda etapa de campo foi realizada desde Montes Claros de Goiás - GO a São Vicente - MT, totalizando aproximadamente $2.500 \mathrm{~km}$, utilizando-se a rodovia BR-070 como principal via de acesso aos afloramentos. Durante os quatro dias de campo, foram coletadas 15 amostras, identificadas com a sigla inicial LTBPR (Anexo A3). Algumas destas amostras foram retiradas preferencialmente ao longo de planos de fratura. As unidades da Bacia do Paraná visitadas afloram em cachoeiras e em paredões de grandes chapadas (Figura 2.9, A,B e D), mas em muitos casos estavam fortemente intemperizadas. Os granitos Iporá (AJ01), Serra Verde (AJ06) e São Vicente (LTBPR13) ocorrem em forma de matacões e lajedos. Ao contrário destes, não foram registrados bons alforamentos de rochas alcalinas, as quais foram encontradas apenas em chão de estrada de terra ou como pequenos blocos rolados nos sopés de morros (Figura 2.9, C)

Foram obtidas cerca de 128 medidas estruturais relacionadas a direção de juntas e falhas, tal como atitude de falhas e camadas. As direções preferenciais são N45-60E, N25-30E, N50W, N80E-N80W e N10W (Figura 2.10). Próximo a Bom Jardim de Goiás (Figura 2.9, D), arenito com características típicas da Formação Furnas (Bacia do Paraná) apresenta conjunto de juntas $\mathrm{NS}, \mathrm{N} 20^{\circ} \mathrm{E}$ e $\mathrm{N} 20^{\circ} \mathrm{W}$. No ponto AJ08 (Figura 2.9, E e F) ocorre arenito grosso, pouco friável, dobrado e falhado, correlato à sequência Siluro-Devoniana da Bacia do Paraná e próximo ao contato com o Grupo Cuiabá. Foram caracterizados plano de falha $\mathrm{N} 55^{\circ} \mathrm{E} / 70^{\circ} \mathrm{NW}$, com presença de epidoto, muscovita e quartzo, e juntas $\mathrm{N} 30^{\circ} \mathrm{E} / 75^{\circ} \mathrm{NW}$ (Figura 2.9, E). Esta últimas direções estão relacionadas ao LTB, cuja reativação afetou as sequências sedimentares iniciais da bacia.

Em trabalho concomintante a esta tese de doutorado, Andrade et al. (2012) mapearam a região de Bom Jardim de Goiás e Baliza/Torixoréu, na divisa de Goiás e Mato Grosso. Os 
autores descrevem falhas com orientações entre $\mathrm{N} 60^{\circ} \mathrm{E}-\mathrm{EW}$, que mostram rejeitos verticais superiores a $500 \mathrm{~m}$, e falhas $\mathrm{N} 65^{\circ}-75^{\circ} \mathrm{W}$, que não sofreram significativos movimentos após o Permo-carbonífero.

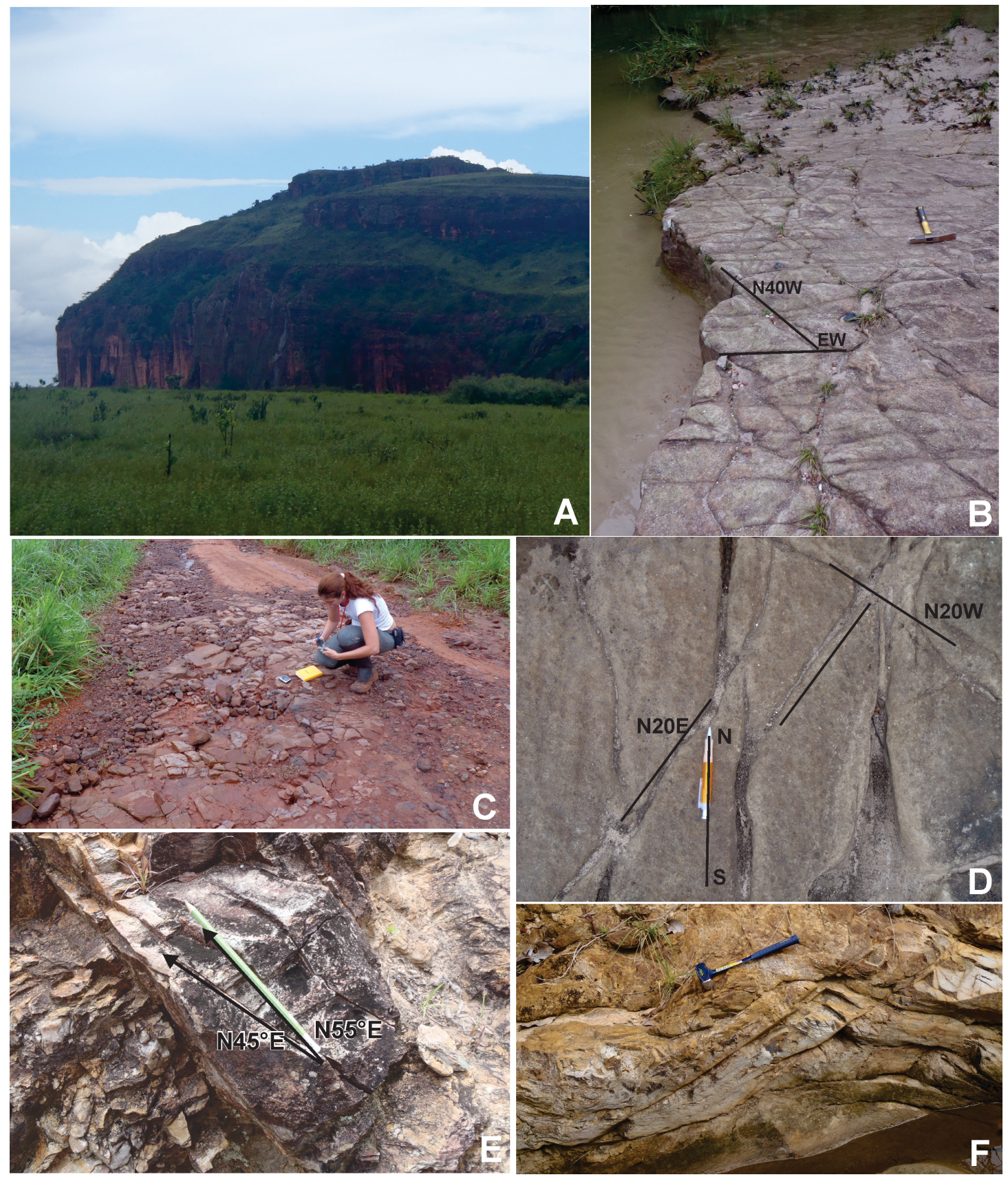

Figura 2.9 - Aspectos de alguns afloramentos e estruturas vistas em campo. (A) Formação Aquidauana, próximo à amostra LTBPR07 (Anexo A3); (B) Formação Furnas (ponto LTBPR04) na Cachoeira Cristal; (C) Rochas ultramáficas alcalinas de Montes Claros de Goiás (ponto LTBPR17); (D) Formação Furnas, próximo a Bom Jardim de Goiás; (E) Arenito falhado, próximo ao contato com o Grupo Cuiabá (ponto AJ06); (F) Arenito dobrado, próximo ao contato com o Grupo Cuiabá (ponto AJ08). Ver Anexo A3 para a localização dos pontos. 


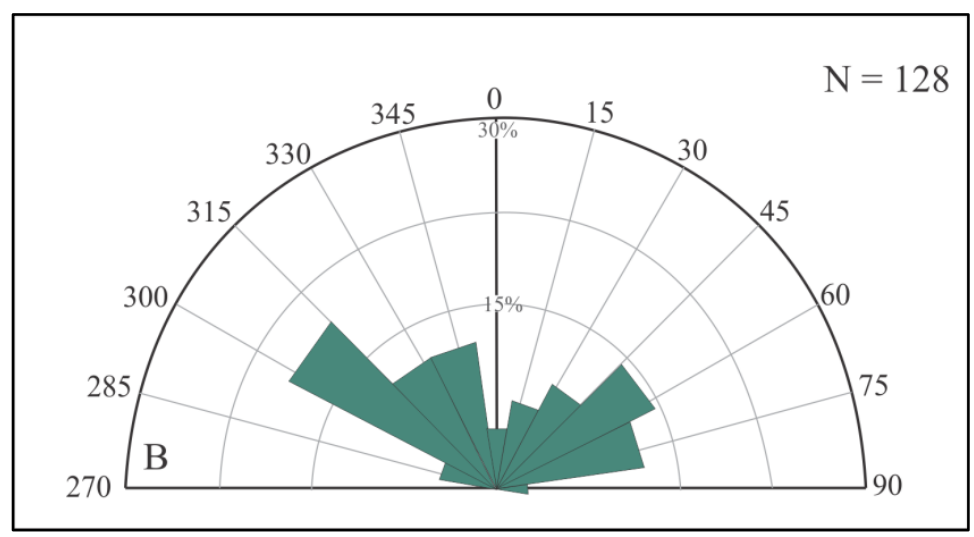

Figura 2.10 - Roseta com as medidas de direção em juntas e falhas durante as duas campanhas de campo. As direções preferenciais são $\mathrm{N} 45^{\circ}-60^{\circ} \mathrm{E}, \mathrm{N} 25^{\circ}-30^{\circ} \mathrm{E}, \mathrm{N} 50^{\circ} \mathrm{W}, \mathrm{N} 80^{\circ} \mathrm{E}-\mathrm{N} 80^{\circ} \mathrm{W}$ e $\mathrm{N} 10^{\circ} \mathrm{W}$ 


\section{Geofísica}

"A lógica pode te levar de $A$ a $B$, mas a imaginação te leva a qualquer lugar"

Albert Einstein (1879-1955), fisico

Neste estudo foram analisados e interpretados dados geofísicos com o objetivo de compreender as relações entre as principais estruturas do Lineamento Transbrasiliano (LTB) e o arcabouço tectônico da Bacia do Paraná. A análise geofísica da bacia e de seu limite com embasamento pode ser limitada, a priori, aos primeiros 2 a $5 \mathrm{~km}$ de profundidade na região de estudo. Porém, ao considerar as dimensões e o possível alcance do LTB em níveis de maior profundidade crustal, a escolha da escala de trabalho foi definida como regional, a fim de ser garantir contribuições de assinaturas geofísicas provenientes de toda a crosta.

A compilação dos dados geofísicos foi conduzida de acordo com dois objetivos principais: (1) criar um banco de dados de maior resolução a partir da junção dos projetos 1012, 2009, 2022, 2025 e 3009 e (2) preparar um banco de dados de menor resolução a partir da integração da malha de dados resultante da primeira junção, do projeto aerogeofísico da Bacia do Paraná e dados de geofísica terrestre (Figura 3.1). Os processos foram realizados com suporte de valores de susceptibilidade magnética e densidade relativa medidos durante as campanhas de campo, bem como de dados obtidos na literatura (Telford et al., 1990; Ventura et al., 2011), incluindo o paleomagnetismo das rochas ígneas da Formação Serra Geral e das rochas alcalinas cretáceas (Ernesto e Pacca, 1988; Dutra, 2011). Nas seções a seguir, serão expostas as vantagens e desvantagens de cada uma dessas duas análises.

\subsection{Construção da base de dados geofísicos}

Foram utilizados seis projetos aerogeofísicos, sendo cinco de alta resolução e um de baixa resolução, além de dados de gravimetria terrestre (Figura 3.1, Tabela 3.1).

Os dados dos projetos Iporá (1012), Alto Garças (2009), Rondonópolis (2025) e Barreiro (2022) foram adquiridos entre os anos de 1971 e 1976, com espaçamento de linhas de voo de 1 $\mathrm{km}$ e direção norte-sul para os dois primeiros e leste-oeste para os dois últimos. As linhas de controle são perpendiculares às linhas de voo com espaçamento de $20 \mathrm{~km}$, com exceção do projeto Iporá, cujo espaçamento é de $22,5 \mathrm{~km}$. A resolução espacial e a acurácia na aquisição desses dados são proporcionais à limitação dos recursos instrumentais e tecnológicos da época em que foram realizados os levantamentos. A altura de voo, que apresenta variações relativamente significativas, é nominalmente caracterizada em $150 \mathrm{~m}$, enquanto o intervalo de 
amostragem dos dados magnéticos é de 1 segundo e, excepcionalmente para o projeto Barreiro, de 2 segundos. O projeto 1012 é de propriedade do Serviço Geológico do Brasil (CPRM) e os projetos 2009, 2022 e 2025 da Comissão Nacional de Energia Nuclear (CNEN).

O projeto Arco Magmático de Arenópolis - Sequência Juscelândia (3009), realizado em 2004, faz parte da primeira etapa dos aerolevantamentos geofísicos do Estado de Goiás, disponibilizados pela SIEG/MME (Secretaria de Indústria e Comércio do Estado de Goiás/Ministério de Minas e Energia), em parceria com a CPRM, na forma de banco de dados. Esses dados apresentam alta resolução espacial, tendo sido adquiridos com altura de voo de 100 $\mathrm{m}$, ao longo de linhas de voo direcionadas norte-sul e espaçadas em $500 \mathrm{~m}$. Possuem alta precisão instrumental, com intervalo de amostragem de $0,1 \mathrm{~s}$. As linhas de controle leste-oeste estão distanciadas em $5 \mathrm{~km}$.

Em 2010, a Agência Nacional de Petróleo (ANP) conduziu extenso aerolevantamento na Bacia do Paraná, que cobriu toda a região compreendida entre o Arco de Ponta Grossa e o extremo norte da bacia. O Projeto Bacia do Paraná possui resolução espacial de escala regional, com linhas de voo norte-sul espaçadas em $6 \mathrm{~km}$ e adquiridas em altitude média de voo de 1800 m. As linhas de controle leste-oeste estão separadas por $18 \mathrm{~km}$. O levantamento inclui dados de magnetometria e gravimetria, adquiridos a cada $0,01 \mathrm{~s}$.

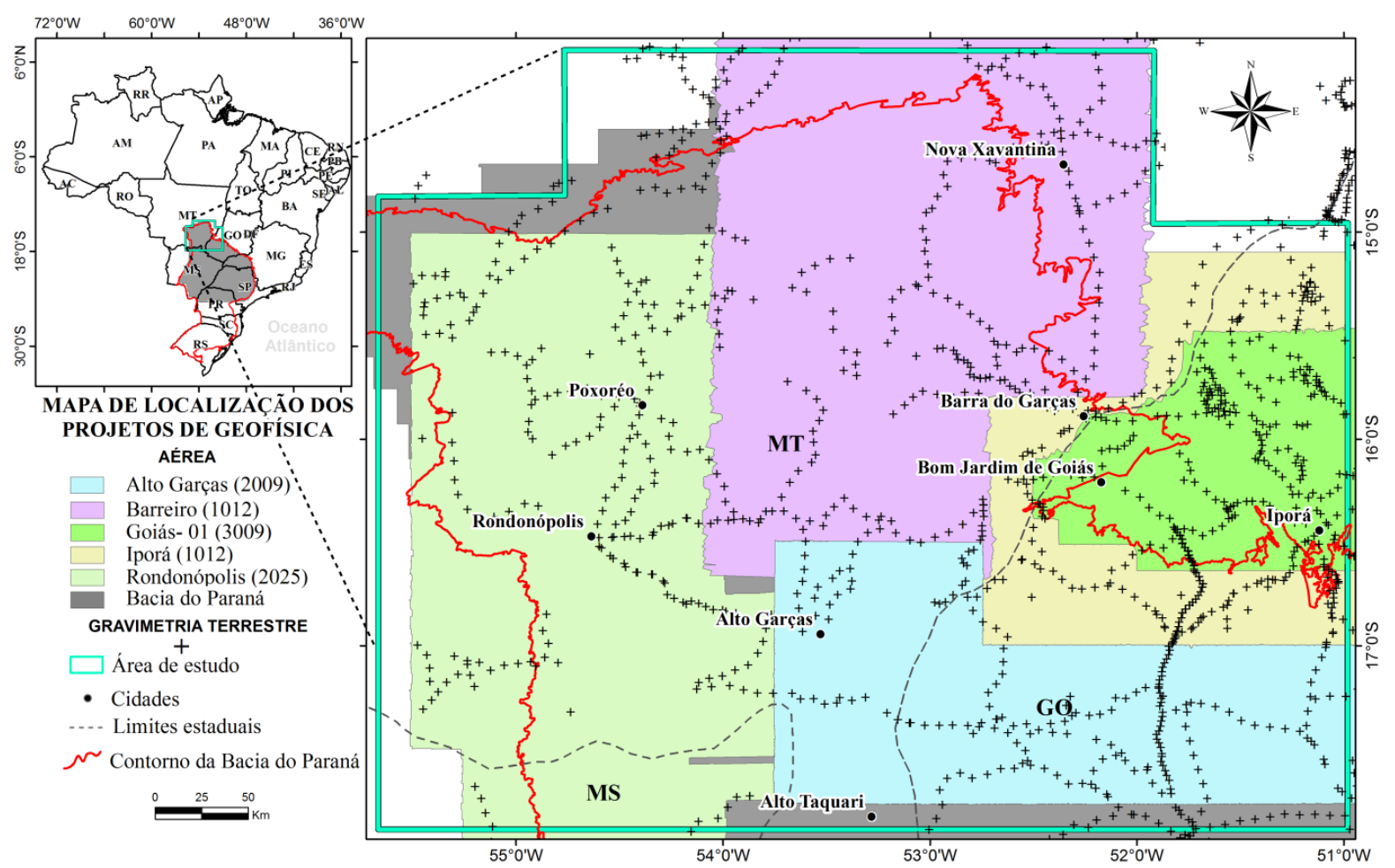

Figura 3.1 - Localização dos projetos de geofísica aérea e terrestre na área de estudo. No inset, localização do projeto Bacia do Paraná no Brasil.

Dentre os projetos aerogeofísicos da área de estudo, apenas o da Bacia do Paraná possui dados de gravimetria, tendo a cobertura do levantamento sido limitada pela borda atual da bacia. 
Os dados de gravimetria terrestre são parte da compilação de projetos anteriores desenvolvidos por Vidotti (1998) e várias instituições, incluindo o Instituto Brasileiro de Geografia e Estatística (IBGE), Instituto de Astronomia, Geofísica e Ciências Atmosféricas da Universidade de São Paulo (IAG/USP) e Instituto de Geociências da Universidade de Brasília (IG/UnB). A base de dados gravimétrica foi unida à malha de dados da Bacia do Paraná com o propósito de observar as assinaturas de parte do embasamento exposto em superfície, especificamente o Arco Magmático de Arenópolis.

Todos os dados geofísicos foram disponibilizados na forma de banco de dados e com a condição de uso restrito a propósitos acadêmicos.

Tabela 3.1 - Principais características dos projetos aerogeofísicos utilizados neste estudo

\begin{tabular}{|c|c|c|c|c|c|c|}
\hline Projetos & Iporá & $\begin{array}{c}\text { Alto } \\
\text { Garças }\end{array}$ & Barreiro & Rondonópolis & Goiás 01 * & $\begin{array}{l}\text { Bacia do } \\
\text { Paraná }\end{array}$ \\
\hline Código & 1012 & 2009 & 2022 & 2025 & 3009 & -- \\
\hline Fonte & CPRM & CNEN & CNEN & CNEN & SIEG/MME & ANP \\
\hline $\begin{array}{c}\text { Ano do } \\
\text { Levantamento }\end{array}$ & 1973 & 1971 & 1976 & $1976 / 1977$ & 2004 & 2010 \\
\hline $\begin{array}{c}\text { Localização } \\
\text { (Estados) }\end{array}$ & $\mathrm{GO} / \mathrm{MT}$ & $\mathrm{GO} / \mathrm{MT} / \mathrm{MS}$ & MT & $\mathrm{MS} / \mathrm{MT}$ & $\mathrm{GO}$ & $\begin{array}{c}\mathrm{MT} / \mathrm{MS} / \mathrm{GO} \\
\mathrm{MG} / \mathrm{SP} / \mathrm{PR}\end{array}$ \\
\hline Área coberta $\left(\mathrm{km}^{2}\right)$ & 46.000 & 30.000 & 66.000 & 85.000 & 58.834 & 727.333 \\
\hline $\begin{array}{c}\text { Dados } \\
\text { Geofísicos** }\end{array}$ & Magnéticos & Magnéticos & Magnéticos & Magnéticos & Magnéticos & $\begin{array}{l}\text { Magnéticos e } \\
\text { Gravimétricos }\end{array}$ \\
\hline $\begin{array}{l}\text { Espaçamento } \\
\text { linhas de voo }\end{array}$ & $1 \mathrm{~km}$ & $1 \mathrm{~km}$ & $1 \mathrm{~km}$ & $1 \mathrm{~km}$ & $0,5 \mathrm{~km}$ & $6 \mathrm{~km}$ \\
\hline $\begin{array}{c}\text { Direção } \\
\text { linhas de voo }\end{array}$ & $\mathrm{N}-\mathrm{S}$ & $\mathrm{N}-\mathrm{S}$ & E-W & E-W & $\mathrm{N}-\mathrm{S}$ & $\mathrm{N}-\mathrm{S}$ \\
\hline $\begin{array}{c}\text { Espaçamento } \\
\text { linhas de controle }\end{array}$ & $22,5 \mathrm{~km}$ & $20 \mathrm{~km}$ & $20 \mathrm{~km}$ & $20 \mathrm{~km}$ & $5 \mathrm{~km}$ & $18 \mathrm{~km}$ \\
\hline $\begin{array}{c}\text { Direção } \\
\text { linhas de controle }\end{array}$ & E-W & E-W & E-W & N-S & E-W & E-W \\
\hline Altura do voo & $150 \mathrm{~m}$ & $120 \mathrm{~m}$ & $150 \mathrm{~m}$ & $150 \mathrm{~m}$ & $100 \mathrm{~m}$ & $1800 \mathrm{~m}$ \\
\hline $\begin{array}{l}\text { Intervalo das } \\
\text { medições }\end{array}$ & $1 \mathrm{~s}$ & $1 \mathrm{~s}$ & $2 \mathrm{~s}$ & $1 \mathrm{~s}$ & $0,1 \mathrm{~s}$ & $0,01 \mathrm{~s}$ \\
\hline Magnetômetro & $\begin{array}{c}\text { Fluxgate - } \\
\text { Gulf Mark } \\
\text { III }\end{array}$ & Fluxgate & $\begin{array}{c}\text { Geometrics } \\
\text { - G-803 }\end{array}$ & $\begin{array}{c}\text { Geometrics } \\
\text { - G-803 }\end{array}$ & $\begin{array}{c}\text { Geometrics- } \\
\text { G-22 e } \\
\text { Scintrex-CS-2 }\end{array}$ & Scintrex CS-3 \\
\hline $\begin{array}{c}\text { Resolução do } \\
\text { Magnetômetro }\end{array}$ & $1 \mathrm{nT}$ & $?$ & $1 \mathrm{nT}$ & $1 \mathrm{nT}$ & $0,001 \mathrm{nT}$ & $0,001 \mathrm{nT}$ \\
\hline Gravímetro & --- & --- & --- & --- & --- & $\begin{array}{c}3 \text { sensores } \\
\text { Gravitom-M e } \\
\text { GT-1A }\end{array}$ \\
\hline
\end{tabular}

* Goiás 01: Projeto Arco Magmático de Arenópolis - Seqüência Juscelândia.

**Estão expostos somente os tipos de dados utilizados na tese. 


\subsubsection{Pré-Processamento dos dados magnéticos}

Alguns dos projetos utilizados (1012, 2009, 2022 e 2025) são provenientes de levantamentos da década de 70 e apresentam problemas resultantes da limitação instrumental e tecnológica da época, como a indisponibilidade de Sistemas de Posicionamento Global (GPS, Global Positioning Sytems) para navegação da aeronave. Além disso, seus respectivos bancos de dados atuais foram construídos a partir da digitalização de curvas isogâmicas do campo magnético total, armazenadas em registros analógicos (CPRM, 2011). Esses dados foram tratados no presente estudo de forma diferenciada, na qual a execução cuidadosa da etapa de préprocessamento foi fundamental para garantir a qualidade dos produtos gerados.

O pré-processamento foi iniciado a partir do campo magnético total ou anômalo, caso o primeiro não estivesse incluso no banco de dados. Nesse caso, o campo magnético anômalo foi calculado com a subtração do campo magnético terrestre, relativo à data do aerolevantamento, do campo magnético total. Foram realizadas as seguintes etapas de pré-processamento, aplicadas de acordo com características e peculiaridades de cada projeto geofísico (Tabela 3.2):

Tabela 3.2 - Etapas de pré-processamento do campo magnético anômalo, enumeradas de acordo a descrição do texto a seguir.

\begin{tabular}{|c|c|c|c|c|c|c|}
\hline & $\begin{array}{c}\text { Iporá } \\
1012\end{array}$ & $\begin{array}{c}\text { Alto Garças } \\
2009\end{array}$ & $\begin{array}{c}\text { Barreiro } \\
2022\end{array}$ & $\begin{array}{c}\text { Rondonópolis } \\
2025\end{array}$ & $\begin{array}{c}\text { Goiás 01 } \\
3009\end{array}$ & $\begin{array}{c}\text { Bacia do } \\
\text { Paraná }\end{array}$ \\
\hline $\boldsymbol{i}$ & & & & & & \\
\hline $\boldsymbol{i i}$ & & & & & \\
\hline $\boldsymbol{i i i}$ & & & & & \\
\hline $\boldsymbol{i v}$ & & & & & \\
\hline $\boldsymbol{v}$ & & & & & \\
\hline $\boldsymbol{v i}$ & & & & & \\
\hline
\end{tabular}

\section{(i) Correções de posicionamento e padronização dos sistemas de projeção}

Os projetos aerogeofísicos apresentam diferenças relacionadas aos sistemas de projeção. Os sistemas foram padronizados neste estudo para coordenadas geográficas e Policônica/Brasil, Datum WGS-84. A sobreposição, parcial ou total, e adjacência entre projetos aerogeofísicos permitiram a análise de possíveis erros de posicionamento. Os projetos aerogeofísicos Iporá (1012) e Alto Garças (2009) mostraram deslocamento nas coordenadas, de aproximadamente $11.200 \mathrm{~m}$ e $11.700 \mathrm{~m}$ para sul, respectivamente, tendo sido realizada a devida correção no banco de dados. 


\section{(ii) Interpolação dos dados}

A interpolação dos dados magnéticos depende primeiramente da distribuição e do espaçamento da amostragem (Naidu e Mathew, 1998). O limite utilizado como parâmetro de corte para separar ruídos de pequeno comprimento de onda dos dados reais é identificado pelo comprimento de onda de Nyquist, dado por

$$
\lambda_{N}=2 \Delta_{x}
$$

onde $\lambda_{N}$ representa o comprimento de onda mínimo, entre amostras espaçadas por $\Delta_{x}$ (Reid, 1980). Em dados dispostos entre linhas de voo, a dimensão das células de interpolação deverá ser maior do que o comprimento de onda de Nyquist. Na maior parte dos casos, utiliza-se a dimensão de 1/4 a 1/5 do espaçamento entre as linhas de voo (Luyendyk, 1997; Reeves, 2005).

Dois tipos de interpolação comumente utilizados para métodos potenciais foram analisados: o bicubic spline ou spline bidirecional (Bhattacharyya, 1969) e a curvatura mínima (Briggs, 1974). O primeiro gera polinômios cúbicos, que representam uma função para cada intervalo entre os pontos de observação. A interpolação utiliza a continuidade da função e suas duas derivadas sucessivas para todos os pontos. A rotina automatizada deste método se dá em duas etapas executadas em 1D: interpolação dos dados ao longo da linha de aquisição e a subsequente interpolação entre as linhas. O ponto forte do método está no fato de que a função e sua inclinação e curvatura são contínuas na área de observação. Por outro lado, o ajuste do polinômio em setores, para dados distribuídos aleatoriamente, se torna difícil. O método da curvatura mínima minimiza esse problema, limitando a interpolação próxima aos seus valores originais. Este método promove uma superfície suave, mas mudanças abruptas do gradiente ou inclinação (a primeira derivada) pode ocorrer na proximidade dos dados. Neste estudo optou-se por utilizar a curvatura mínima devido à junção de diferentes projetos geofísicos que, em alguns casos, não se sobrepõem completamente, formando gaps ou espaços vazios, sem dados.

\section{(iii) Análise e correção estatística do campo magnético ao longo das linhas de voo.}

Ruídos nos dados podem ser causados, por exemplo, por imprecisões e erros instrumentais durante o levantamento, erros de digitalização de dados antigos e falhas na etapa de préprocessamento (Luyendyk, 1997). Foi conduzida análise estatística do campo magnético anômalo com o objetivo de detectar possíveis discrepâncias nos seguintes casos: (1) entre valores do campo magnético ao longo de cada linha de voo e (2) entre as médias de valores do campo magnético de linhas de voo adjacentes.

No primeiro tipo de análise, determinar quais dados são causadores de ruído não é tarefa trivial. Nos aerolevantamentos mais recentes (3009 e Bacia do Paraná), cálculo e observação da quarta derivada do campo magnético anômalo em perfil (ex.: Blum, 1999) permitiram que os 
dados espúrios fossem destacados como picos (Figura 3.2A), facilitando sua retirada do banco, sendo em seguida substituídos por uma interpolação por curvatura mínima. Já para os aerolevamentos da década de 70, a quarta derivada apontou inúmeros picos (Figura 3.2B), o que reflete a menor qualidade desses dados. Dessa maneira, para estes levantamentos, optou-se pela utilização posterior de outros procedimentos, descritos abaixo, como a decorrugação e filtros passa-baixa.

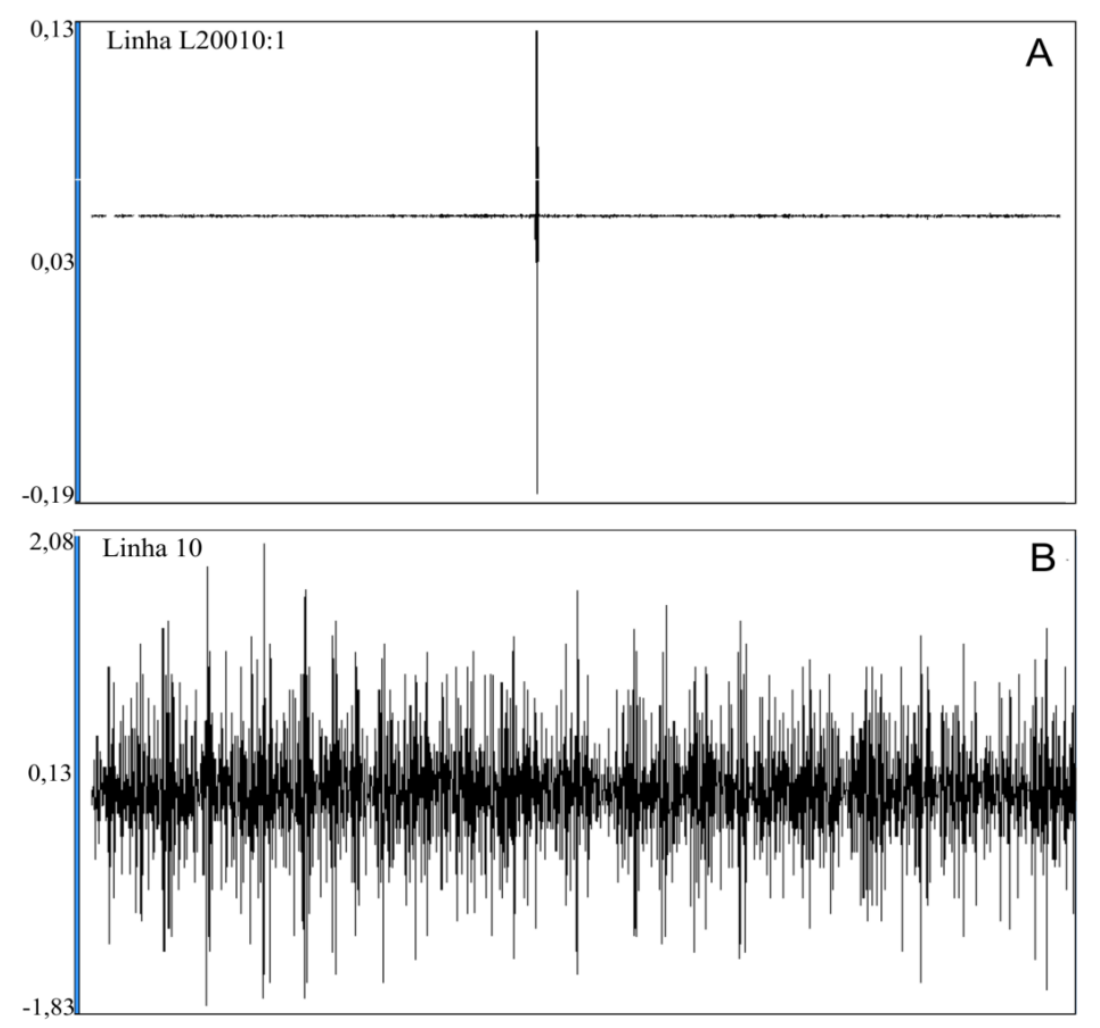

Figura 3.2 - Exemplos de dados espúrios nos dados magnéticos, identificados com o uso da quarta derivada do campo magnético anômalo dos projetos: A) Goiás 01 (3009), onde o dado espúrio é representado por único pico; e B) Barreiro (2022), onde ocorrem vários picos.

No segundo tipo de análise, as linhas que apresentaram médias significativamente distintas em relação às linhas vizinhas foram ajustadas estatisticamente de acordo com o background do campo magnético total ou anômalo da região, somando-se ou subtraindo-se uma constante $c$. Este procedimento foi aplicado ao projeto aerogeofísico Barreiro (2022), o qual mostra, originalmente, diferença abrupta da média estatística dos dados magnéticos entre linhas de voo e entre diferentes fases do levantamento. De maneira similar, o projeto Rondonópolis (2025) também mostra mudança entre dados adquiridos a sul e aqueles ao norte. A sobreposição das linhas de voo entre diferentes etapas do aerolevantamento 2022 indica claramente esse contraste (Figura 3.3). 


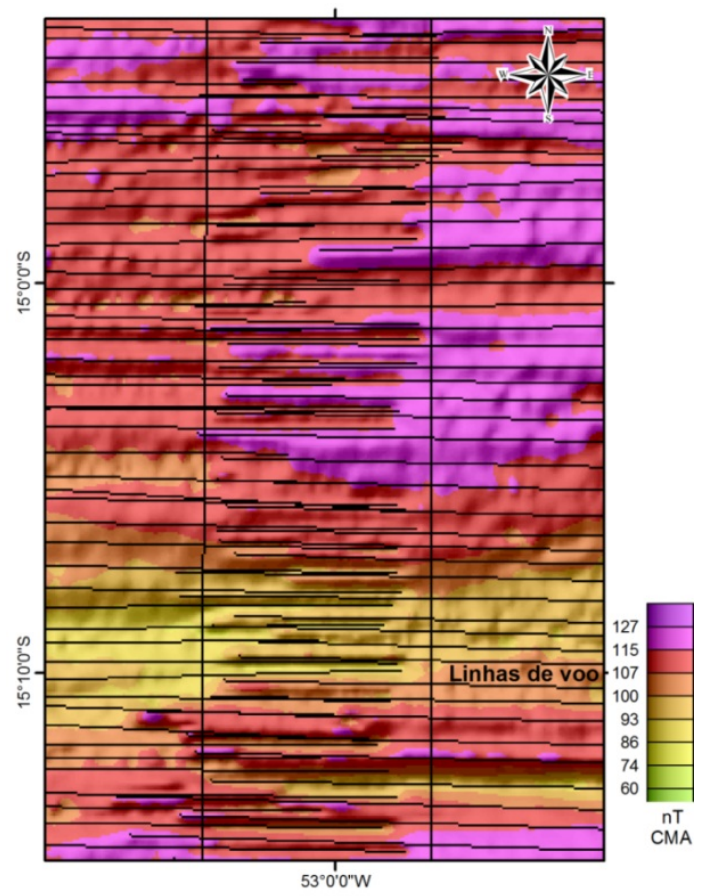

Figura 3.3 - Recorte dos mapas de anomalias magnéticas não processadas do aerolevantamento 2022, destacando a sobreposição das linhas de voo em suas diferentes etapas.

\section{(iv) Nivelamento na intersecção de linhas de voo.}

O nivelamento utilizado consiste no ajuste entre os valores do campo magnético encontrados no ponto de intersecção das linhas de voo com as linhas de controle (Foster et al., 1970; Green, 1983). Foster et al. (1970) descrevem método de cálculo do ajuste polinomial ao longo das linhas pelo método dos mínimos quadrados, que será subtraído do dado original, reduzindo os erros de intercecção. Os levantamentos aerogeofísicos mais recentes foram disponibilizados com nivelamento e micronivelamento dos dados, conduzidos durante a etapa de pré-processamento dos projetos. O nivelamento dos dados dos projetos aerogeofísicos da década de 70 é um processo necessário, porém os bancos de dados não incluem as linhas de controle, exceto o projeto 2022. A consistência das linhas de controle foi checada previamente e, apenas em alguns locais, mostrou utilidade para o nivelamento.

\section{(v) Micronivelamento e decorrugação dos dados}

Após o nivelamento dos dados, o micronivelamento é aplicado quando há persitência de ruídos com grande comprimento de onda ao longo das linhas de voo. O procedimento para retirar ou minimizar esses ruídos consiste na decorrugação (Urquhart, 1988) ou micronivelamento (Minty, 1991). A decorrugação é geralmente realizada a partir da subtração de um grid residual contendo os ruídos deixados pelo nivelamento. 
Minty (1991) descreve processo de filtragem que remove assinaturas ao longo das linhas de voo, que possuem comprimento de onda maior que o espaçamento das linhas de controle e, transversalmente à linha de aquisição, quando o comprimento de onda for maior que duas vezes o espaçamento das linhas de aquisição. Blum (1999) automatizou o processo por meio de algoritmo executável no software Oasis Montaj, que assume linhas de aquisição norte-sul. No caso dos projetos 2025 e 2022, os quais possuem linhas de aquisição leste-oeste, os seguintes passos foram adotados, segundo procedimento descrito pelo autor:

1) Salvar o grid do campo anômalo em forma de base de dados.

2) Rotacionar a base de dados para norte-sul.

3) Interpolar em grid, usando mínima curvatura.

4) Salvar o grid para a base de dados.

5) Criar canal para o filtro passa alta, que será proporcional à razão do espaçamento das linhas de aquisição e ao espaçamento do grid.

5) Interpolar em grid o canal de dados do filtro passa alta.

6) Transpor o grid; forçar na direção Y.

7) Salvar o grid para a base de dados.

8) Criar canal para o filtro passa baixa, que será proporcional à razão entre o espaçamento das linhas de controle e ao espaçamento do grid.

9) Rotacionar o banco de dados para a direção original.

10) Interpolar em grid.

11) Subtrair o grid final do grid original.

$\mathrm{Na}$ decorrugação, o grid residual também pode ser calculado de maneira mais simples, por exemplo utilizando a soma da seguinte sequência de procedimentos (Geosoft, 2014):

1) Aplicação do filtro Butterworth passa-alta, equivalente a duas a quatro vezes o espaçamento das linhas de aquisição, ao longo da direção das mesmas. A ordem do filtro pode variar, devendo ser efetuados testes para a verificação dos parâmetros mais adequados.

2) Aplicação do filtro cosseno direcional devido ao problema de nivelamento ser principalmente direcional. As assinaturas que deverão passar para o grid de ruído são aquelas na direção das linhas de aquisição com nível de energia determinado pelo usuário. Como no filtro Butterworth, testes devem ser efetuados para a determinar os parâmetros mais adequados.

(vi) Aplicação de filtros para a suavização de ruídos sistemáticos de alta frequência

Mesmo após o nivelamento e micronivelamento dos dados, ruídos de alta frequência podem ainda dificultar a interpretação de anomalias. Filtros passa-baixa (Naidu e Mathew, 1998), como 
o filtro de convolução coseno 3x3 (janela Hanning; Oppenheim et al., 1998) são comumente utilizados (ex.: Blum, 1999; Chiarini, 2007; Silva, 2007). Ele é usualmente aplicado desde que assinaturas de interesse não sejam removidas. Em casos mais extremos, como o Projeto Barreiro, foi necessário aplicar um filtro adicional, o Butterworth (Oppenheim et al., 1998). O parâmetro de corte do filtro foi determinado de forma a corresponder aproximadamente à dimensão horizontal das anomalias a serem filtradas.

\subsubsection{Junção dos dados magnéticos}

A junção dos dados magnéticos foi conduzida em duas etapas. Primeiro, os grids dos levantamentos 1012, 2009, 2022, 2025 e 3009 foram unidos com o propósito de gerar um mapa de anomalias magnéticas de maior resolução. Na segunda etapa, o levantamento da Bacia do Paraná foi incorporado à junção. Este processo foi efetuado por meio da ferramenta GridKnitt, disponível no software Oasis Montaj (Geosoft, 2014).

Previamente à junção, os grids foram ajustados para um mesmo nível de observação e tamanho da célula, definidos com base na maior altura de voo e maior espaçamento entre as linhas de voo. O nivelamento do plano de observação foi realizado com o uso da continuação ascendente. Esta técnica suaviza os pequenos comprimentos de onda em relação aos maiores, o que simula um aumento da altura de voo do levantamento, sendo utilizada em muitos casos para a eliminação de fontes mais rasas e ruídos (Milligan e Gunn, 1997). A equação utilizada no domínio da frequência para produzir a continuação ascendente (Reeves, 2005) é:

$$
F(\omega)=e^{-h \omega}
$$

onde $h$ é o valor a ser adicionado a partir do plano de observação original. O mapa de maior resolução resultou em tamanho de célula e altura de observação de $250 \mathrm{~m}$ e $1000 \mathrm{~m}$, respectivamente. Na segunda etapa, o grid de maior resolução foi ajustado com referência ao levantamento da Bacia do Paraná, com nível de observação de $1800 \mathrm{~m}$ e célula de $1500 \mathrm{~m}$. É importante ressaltar que a altitude desse levantamento é barométrica, ou seja, nominalmente constante em relação ao nível do mar. Portanto, a operação de nivelamento deve considerar a diferença entre o nível do mar e a topografia, o que pode ser feito a partir de um modelo digital de terreno.

Devido à natureza do processamento, os grids de cada levantamento possuem níveis de base (background) do campo magnético distintos. Essa diferença entre os grids deve ser compensada por meio de ajuste estatístico na área de sobreposição nos grids vizinhos. A sequência de junção em pares gera uma diferença entre o primeiro e último grids. Além disso, ruídos inerentes aos 
levantamentos antigos também interferem na qualidade da junção dos grids (Figura 3.4a). Esse problema foi minimizado com a junção do grid do levantamento da Bacia do Paraná, que foi definido como a base principal para o ajuste estatístico efetuado pelo algoritmo, prevalecendo seus principais parâmetros, como o nível de base (background) do campo magnético e dimensão da célula (1500 m).

A ordem de grandeza determinada para os lineamentos interpretados em mapas de anomalias magnéticas é relativa. Os mapas gerados a partir das junções do campo magnético anômalo possuem intervalo de valores de intensidade mais amplo do que cada grid individualmente, e a escala de cores utilizada para representar esse intervalo maior gera menor contraste visual de anomalias locais, ou seja, há uma aparente perda de detalhes. Porém, é possível observar a magnitude de uma mesma fonte magnética em relação a maior número de fontes. A ocorrência de bacia sedimentar e seu embasamento aflorante na área de estudo ressalta a importância da comparação de fontes magnéticas em uma mesma escala de intensidade magnética. Isso também leva a implicações na análise qualitativa da profundidade das fontes, conforme descrito nos próximos tópicos. Assim, os produtos derivados da junção regional auxiliaram na interpretação dos grandes lineamentos e domínios magnéticos da área de estudo. Nos artigos apresentados nos próximos capítulos, será visto que os mapas de anomalias magnéticas regionais (Figura 3.4b) foram mais úteis para o objetivo deste estudo do que os produtos de maior resolução (Figura $3.4 a)$. 

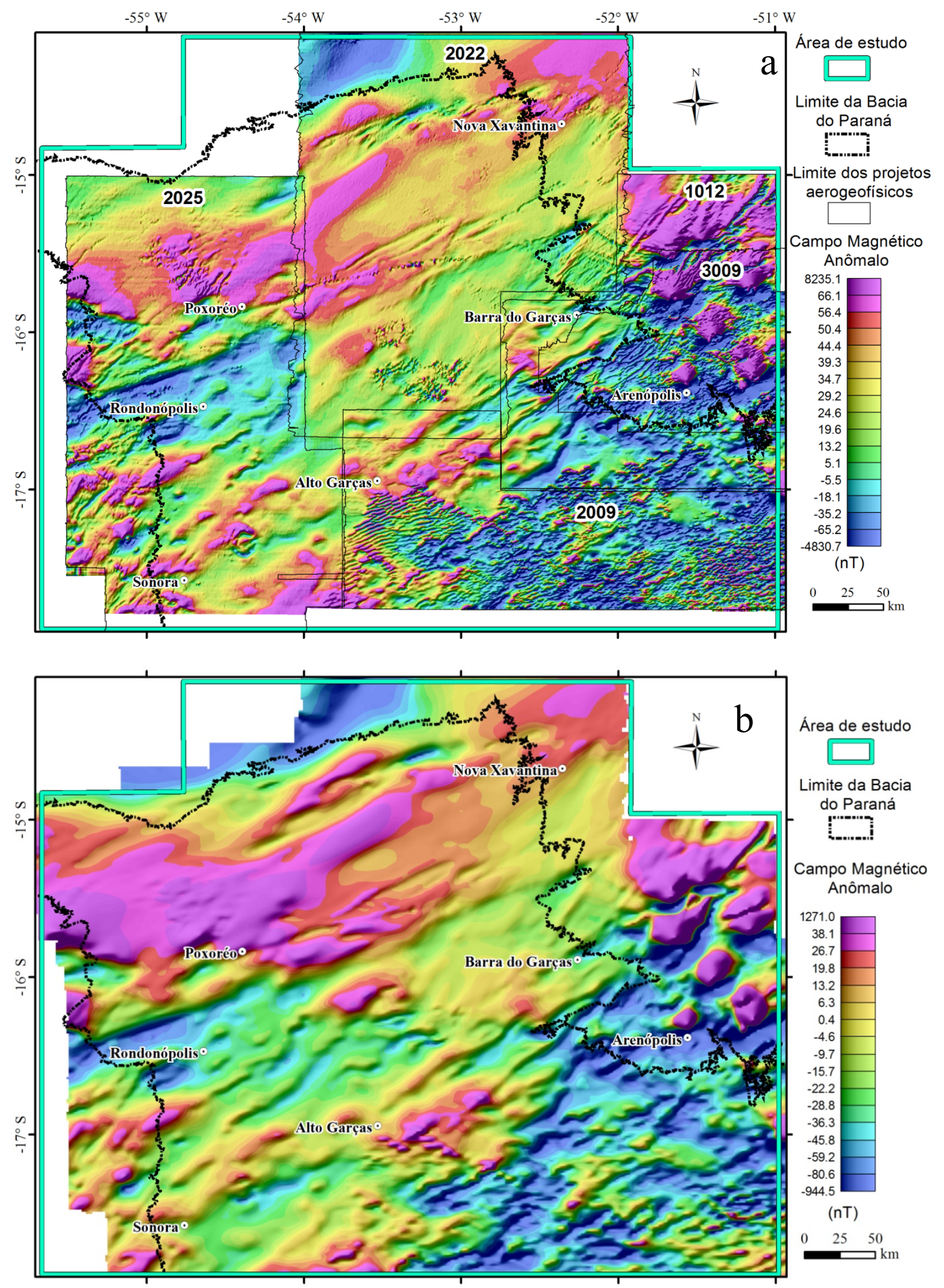

Figura 3.4 - a) Mapa de anomalias magnéticas de maior resolução, obtida a partir da junção dos projetos 1012, 2009, 2022, 2025 e 3009. As linhas pretas indicam os limites entre os projetos e a linha preta pontilhada indica o limite da Bacia do Paraná. b) Mapa de anomalias magnéticas de menor resolução, obtida a partir da junção dos projetos 1012, 2009, 2022, 2025, 3009 e Bacia do Paraná. 


\subsubsection{Processamento e junção dos dados gravimétricos}

Neste estudo foi definido o mapa de anomalias Bouguer como mapa base para o processamento e interpretação dos dados gravimétricos. A anomalia Bouguer é obtida após a remoção de efeitos que não estão diretamente ligados a variações de densidade na crosta terrestre do campo gravimétrico observado. Esse processo é denominado de redução do dado gravimétrico (Blakely, 1996; Reynolds, 2011).

Os dados de anomalia Bouguer do levantamento aerogeofísico da Bacia do Paraná estão inclusos no banco de dados, devidamente nivelados.

A gravimetria terrestre foi disponilizada somente como dados de anomalia Bouguer. Estes dados estão distribuídos aleatoriamente na área de estudo (Figura 3.1) e foram utilizados principalmente para analisar as assinaturas das rochas do embasamento na região nordeste da área.

Dados de anomalia Bouguer de ambos projetos foram interpolados, com o método da curvatura mínima e tamanho de célula de $1500 \mathrm{~m}$. Os dados terrestres foram nivelados de acordo com a altitude de voo do aerolevantamento da Bacia do Paraná (1800 m), utilizando o filtro de continuação ascendente (Reeves, 2005). Em seguida, os grids foram unidos por meio da ferramenta GridKnitt, disponível no software Oasis Montaj (Geosoft, 2014), sendo o levantamento da Bacia do Paraná definido como base para o processo de junção (Figura 3.5). 


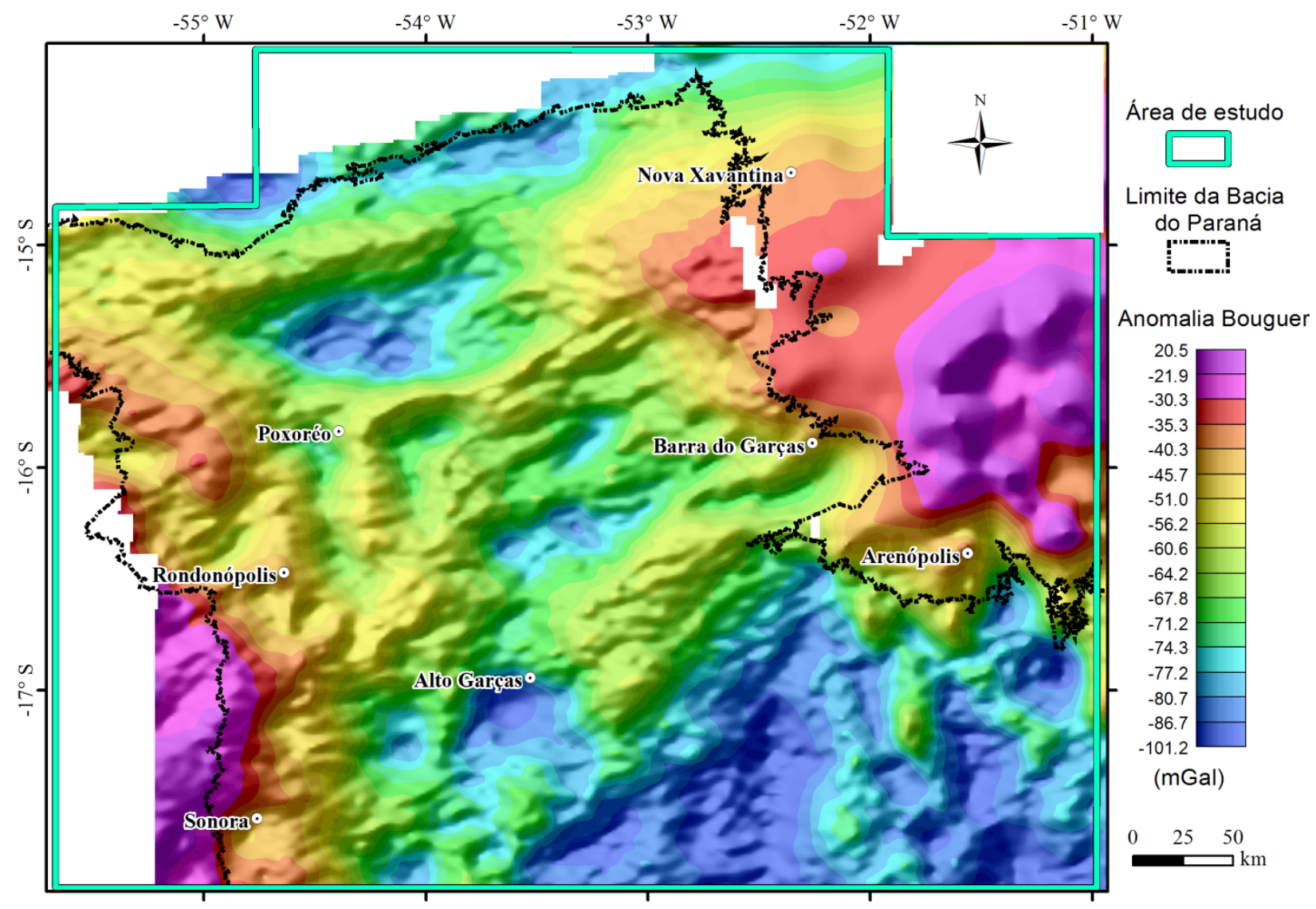

Figura 3.5 - Mapa de anomalia Bouguer, obtida pela junção dos dados de gravimetria terrestre e do aerolevantamento da Bacia do Paraná.

\subsection{Técnicas de realce}

Para o realce de anomalias magnéticas, utilizou-se como base primária o campo magnético anômalo, ou seja, o campo magnético total corrigido do campo geomagnético de referência (IGRF), nivelado e micronivelado. A anomalia Bouguer foi utilizada como base para a interpretação dos dados gravimétricos, gerada a partir das correções de todas as variações do campo gravitacional da Terra que não resultem de diferenças de densidade nas rochas em subsuperfície, denominada de redução gravimétrica.

A maior parte das técnicas de realce foi analisada e avaliada por meio de testes efetuados no programa desenvolvido em ambiente Matlab, GRAV_MAG_PRISM (Bongiolo et al., 2013), no qual dados magnéticos e gravimétricos sintéticos foram gerados em malha de dados de $250 \times 250$ m. O objetivo dos testes é entender a geometria e intensidade das anomalias em diferentes situações do campo potencial terrestre e avaliar empiricamente o desempenho das técnicas nessas diferentes condições. As fontes causativas correspondem a prismas com variáveis 
relativas a dimensões, valores de densidade e magnetização, com fatores de inclinação e declinação, tanto do campo magnético atual, como remanescente.

\subsubsection{Posicionamento e geometria das anomalias magnéticas}

O campo geomagnético é geometricamente mais complexo que o campo gravitacional da Terra e exibe variações irregulares em orientação e magnitude em função de latitude, longitude e tempo (Kearey et al., 2009). Dessa forma, com o intuito de centralizar as anomalias magnéticas em relação às fontes causativas, foram utilizadas as seguintes técnicas: redução ao polo do campo magnético anômalo (Baranov e Naudy, 1964) e cálculo da amplitude do gradiente total (Nabighian, 1984; Roest et al., 1992; MacLeod et al., 1993; Nabighian et al., 2005).

\section{Redução ao polo}

A redução ao polo (Baranov e Naudy, 1964; Grant e Dodds, 1972) é uma técnica de processamento que reposiciona a anomalia magnética segundo o valor de inclinação do campo magnético terrestre no polo $\left( \pm 90^{\circ}\right)$, centralizando o pico da anomalia em relação a sua fonte causativa, dado por

$$
L(\theta)=\frac{1}{\left[\sin (\mathrm{I}) \_\mathrm{i} \cos (\mathrm{I}) \cos (\mathrm{D}-\theta)^{2}\right]}
$$

onde $\theta$ é a direção do número de onda, $I$ é a inclinação magnética e $D$ é a declinação magnética.

Como observado por Grant e Dodds (1972), apud MacLeod et al. (1993), o algoritmo de redução ao polo (RTP) é instável em baixas latitudes magnéticas, onde os valores de inclinação são menores que $\pm 20^{\circ}$. Dessa forma, esses autores implementaram no sistema de processamento MAGMAP do software Oasis Montaj, o uso de uma pseudo-inclinação I' definida pelo usuário (Equação 3.4), que deve ser maior que a inclinação absoluta utilizada para controlar a amplitude do filtro em regiões com baixos valores de inclinação. É usualmente proposto que $I$ ' seja igual ao ângulo complementar de $I$. Como a inclinação da área de estudo está próxima aos $-20^{\circ}$, o valor de correção é correspondente a $-70^{\circ}$.

$$
L(\theta)=\frac{[\sin (I)-i \cdot \cos (I)(D-\theta)]^{2}}{\left[\sin ^{2}\left(I^{\prime}\right)+\cos ^{2}\left(I^{\prime}\right) \cdot \cos ^{2}(D-\theta)\right] \cdot\left[\sin ^{2}(I)+\cos ^{2}(I) \cdot \cos ^{2}(D-\theta)\right]} s e,\left(\left|I^{\prime}\right|<|I|\right), I^{\prime}=I \quad \text { Eq. } 3.4
$$

onde $\theta$ é a direção do número de onda, $I$ é a inclinação; $I$ ' é a pseudo-inclinação e $D$ é a declinação magnética. 
As versões mais recentes do software Oasis Montaj, 8.01 - 8.2 (Geosoft, 2014), incluem a ferramenta de redução ao poço diferencial (Arkani-Hamed, 1988, 2007; Swain, 2000; Cooper e Cowan, 2005), denominada DRTP. Esta técnica leva em conta variações na direção do campo magnético e de magnetização da crosta na região, ideal para grandes levantamentos. ArkaniHamed (2007) adiciona uma modificação à técnica (MDRTP), considerando as dificuldades existentes do algoritmo DRTP para baixas inclinações magnéticas. De acordo com este autor, essa variação da técnica preserva a redução ao polo em quase toda a área, exceto em inclinações magnéticas muito baixas, onde as anomalias são ligeiramente modificadas. A aplicação de filtros passa-baixa direcional é sugerida para a remoção de ruídos na direção NS.

Não foi possível desenvolver uma metodologia eficiente que permitisse o uso de DRTP (Cooper e Cowan, 2005) na junção de diferentes projetos aerogeofísicos, os quais possuem diferenças significativas de I (Tabela 3.3). Com o intuito de realizar uma simples comparação entre os métodos na área de estudo, RTP e DRTP foram aplicados aos dados do projeto da Bacia do Paraná. A figura 3.6 mostra em detalhe uma anomalia magnética relacionada ao corpo alcalino da Suíte Vulcânica de Santo Antônio da Barra (Junqueira-Brod et al., 2002). A amplitude do gradiente total (Nabighian, 1984) é utilizada como validação parcial. Observa-se que o RTP e o DRTP centralizam a anomalia em relação à fonte, mas distorções ocorrem em ambos os casos. Vale ressaltar que a presença de magnetização remanescente também é fator complicador para a redução ao polo, já que pode apresentar diferentes valores de $I$ em relação ao do campo atual. Portanto, este estudo optou por utilizar a versão clássica de RTP, com utilização da pseudo-inclinação (MacLeod et al.,1993).

Tabela 3.3 - Valores de inclinação e declinação geomagnéticas dos aerolevantamentos da área de estudo.

\begin{tabular}{|c|c|c|c|}
\hline Levantamentos & $\begin{array}{c}\text { Data do } \\
\text { Levantamento }\end{array}$ & $\mathbf{D *}$ & I* \\
\hline Iporá (1012) & 1973 & $-13,6$ & $-10,3$ \\
\hline Alto Garças (2009) & 1971 & $-12,5$ & $-11,4$ \\
\hline Barreiro (2022) & 1976 & $-7,7$ & $-12,5$ \\
\hline Rondonópolis (2025) & 1976 & $-10,0$ & $-10,9$ \\
\hline Goiás 01 (3009) & 2004 & $-18,3$ & $-19,0$ \\
\hline Bacia do Paraná & 2010 & $-18,3$ & $-21,9$ \\
\hline
\end{tabular}

* medidos no centro da porção do levantamento inserido na área de estudo

Os valores de I, D e intensidade do campo magnético terrestre atual da área de estudo foram calculados com uso de sua coordenada central e a data do levantamento, representado pela malha de dados do aerolevantamento dominante, o Projeto da Bacia do Paraná $\left(\mathrm{I}=-19,9^{\circ} ; \mathrm{D}=-17,8^{\circ}\right)$. 


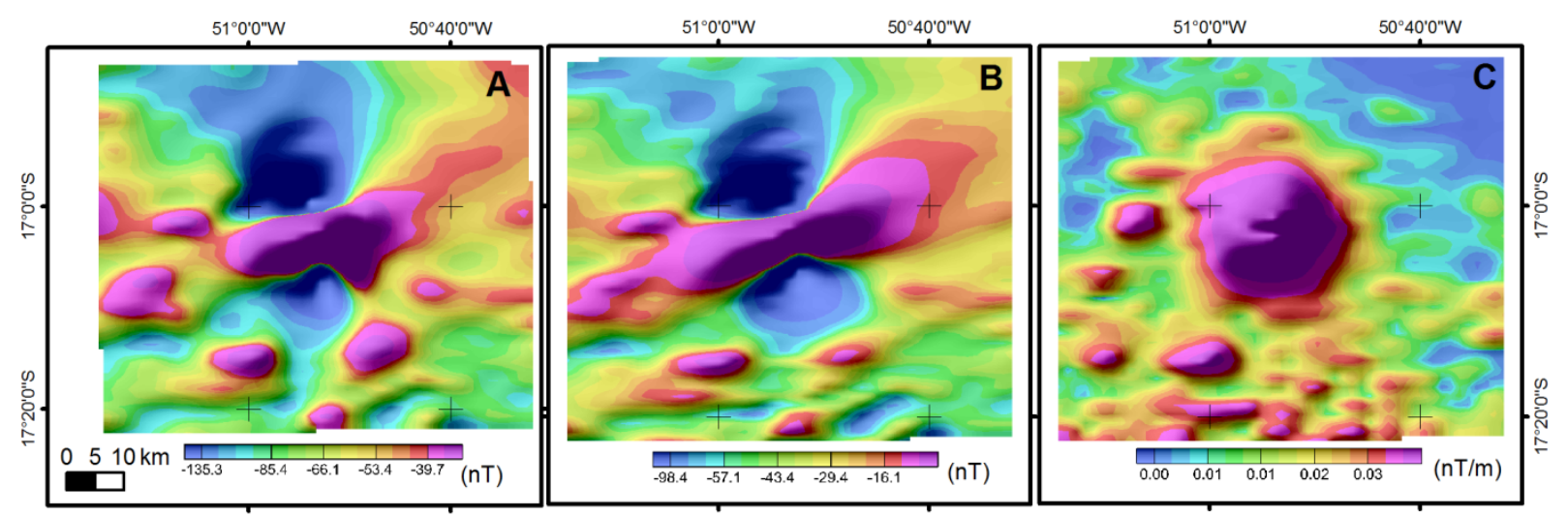

Figura 3.6 - Anomalia magnética associada ao corpo alcalino da Suíte Vulcânica de Santo Antônio da Barra (Junqueia-Brod et al., 2002). Dados magnéticos do levantamento da Bacia do Paraná, reduzidos ao polo segundo (A) RTP, com utilização de pseudo-inclinação; e (B) DRTP. (C) Amplitude do gradiente total, utilizada como validação parcial.

Com o uso do programa GRAV_MAG_PRISM (Bongiolo et al., 2013), dados magnéticos sintéticos foram gerados com valores atuais de $I$ e $D$ correspondentes ao utilizado para a área de estudo: $-19,9^{\circ}$ e $-17,8^{\circ}$, respectivamente. Em perfil, observa-se a eficiência da técnica de redução ao polo (RTP) com a correção de amplitude (I') de $-70^{\circ}$ (Figura 3.7).

Testes também foram efetuados em um conjunto de 10 prismas (Figura 3.8; Tabela 3.4). De acordo com o exposto no artigo do Capítulo 4, observa-se que o RTP com o uso de I' centraliza as anomalias. O ruído na direção de $D$ é minimizado, mas por outro lado, são introduzidos lóbulos negativos com distorções na direção de $I^{\prime}\left(\sim 70^{\circ}\right)$, além de ocorrer uma redução na amplitude das anomalias, equivalente às distorções descritas por Swain (2000) e Arkani-Hamed (2007). Um dos prismas (P10, Figura 3.8) foi criado com dimensões similares a um dique, cruzando o centro da área com direção próxima a $D$ e localizado a $1000 \mathrm{~m}$ de profundidade. Apesar do operador de $I^{\prime}$ suprimir os pequenos comprimentos de onda na direção de $D$, a assinatura do prisma permanece visível. 


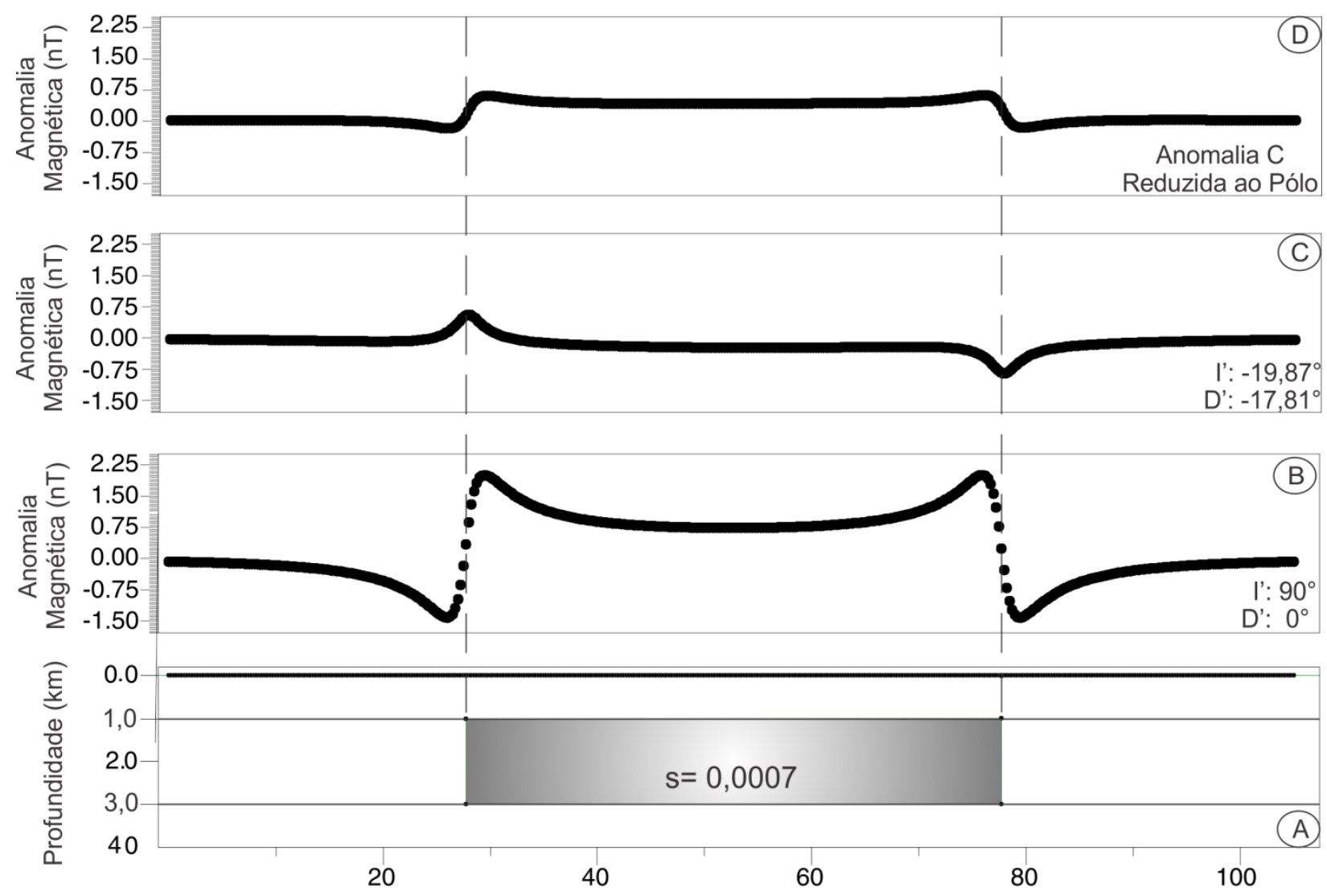

Figura 3.7 - A) Perfil de uma fonte magnética sintética. B) Anomalia magnética resultante da fonte (A) gerada em I $=90^{\circ}$. C) Anomalia magnética resultante da fonte (A) gerada em valores de I e D equivalentes aos utilizados para a área de estudo. D) Anomalia de (C) reduzida ao polo, com uso de $I^{\prime}=-70^{\circ}$.
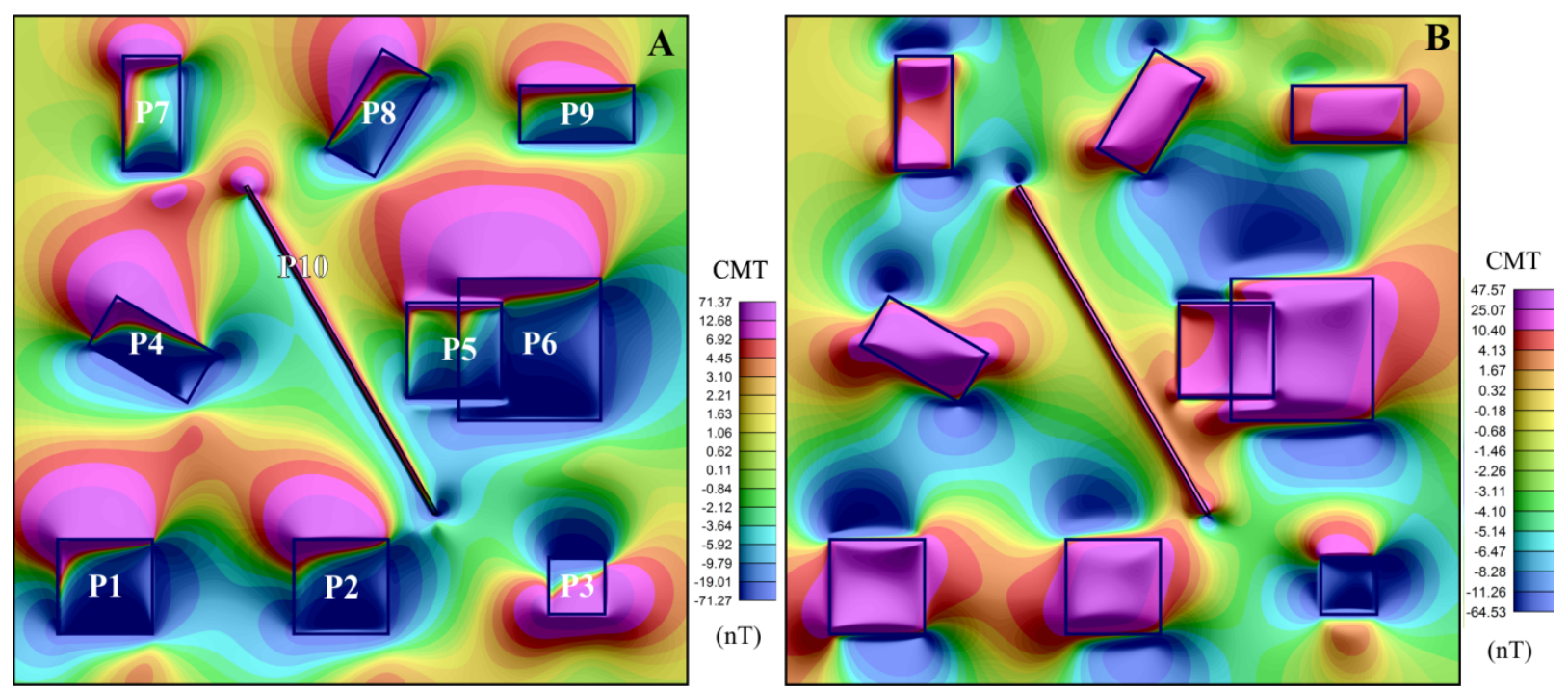

Figura 3.8 - Mapa de 10 prismas magnéticos (A) sem redução ao polo e (B) reduzidos ao polo, com a correção da inclinação magnética $\left(I^{\prime}\right)$ de $-70^{\circ}$. Alguns prismas possuem propriedades magnéticas, dimensões e valores de profundidade diferenciados (Tabela 3.4). 
Tabela 3.4 - Propriedades dos 10 prismas expostos na Figura 3.8.

\begin{tabular}{|l|c|c|c|c|c|}
\hline Fontes & $\begin{array}{l}\text { Profundidade } \\
\text { do topo (km) }\end{array}$ & $\begin{array}{c}\text { Magnetização } \\
\text { (nT) }\end{array}$ & \multicolumn{2}{|c|}{ Magnetização Rem.* } \\
\hline Intensidade & I & D \\
\hline P1 & 1 & 0.13 & 0 & & \\
\hline P2 & 4 & 0.13 & 0 & & \\
\hline P3 & 1 & 0.13 & 0.015 & 181.7 & 36.6 \\
\hline P4 & 2 & 0.13 & 0 & & \\
\hline P5 & 1 & 0.13 & 0 & & \\
\hline P6 & 4 & 0.13 & 0 & & \\
\hline P7 & 2 & 0.13 & 0 & & \\
\hline P8 & 2 & 0.07 & 0 & & \\
\hline P9 & 2 & 0.04 & 0 & & \\
\hline P10 & 1 & 0.37 & 0 & & \\
\hline
\end{tabular}

*Rem.: remanescente; I: inclinação; D: declinação

\section{Amplitude do gradiente total}

Nabighian (1972) introduziu o conceito do sinal analítico (gradiente total), que utiliza as derivadas horizontais e vertical da anomalia magnética produzida por uma fonte 2D. A amplitude do sinal analítico é enfatizada como o envelope da anomalia em 2D, que independe da direção de magnetização da fonte. Nabighian (1984) levantou a possibilidade de aplicar esta técnica em ambiente 3D e Roest et al. (1992) desenvolveram aplicações práticas do sinal analítico na estimativa de características da fonte magnética em $3 \mathrm{D}$, como geometria e profundidade. Dessa forma, o uso do sinal analítico para os dados em malha (grid; 3D) foi possibilitado, utilizando-se da função de sua amplitude

$$
|A(x, y)|=\sqrt{\left(\frac{\partial M}{\partial x}\right)^{2}+\left(\frac{\partial M}{\partial y}\right)^{2}+\left(\frac{\partial M}{\partial z}\right)^{2}}
$$

onde $\frac{\partial M}{\partial x}, \frac{\partial M}{\partial y} \mathrm{e} \frac{\partial M}{\partial z}$ são as derivadas de primeira ordem do campo magnético $M$ nas direções $\mathrm{x}, \mathrm{y}$ e $z$, respectivamente. O produto dessa combinação foi denominado de sinal analítico 3D ou amplitude do sinal analítico (Roest et al.,1992). Em razão de complexidades matemáticas intrínsecas ao sinal analítico e que não foram ainda devidamente esclarecidas na literatura para fontes em 3D, alguns trabalhos propõem utilizar o termo "Gradiente Total" (Nabighian et al., 2005) ou "Amplitude do Gradiente Total” (Alan Reid, 2014, comunicação pessoal). Discussão acerca desse ponto é exposta por Haney et al. (2003) e Li (2006).

A amplitude do gradiente total em 3D realça os limites da anomalia magnética. A principal importância da técnica está no fato de sua função ser eficiente no posicionamento 
aproximado das anomalias magnéticas em relação as suas fontes em baixas inclinações geomagnéticas, sendo utilizada como alternativa ao uso da redução ao polo.

Nos testes com dados magnéticos sintéticos, gerados com valores de $I$ e $D$ correspondentes à área de estudo: $19,87^{\circ}$ e $-17,81^{\circ}$, respectivamente (Figura 3.9), observa-se a comparação entre amplitude do gradiente total (AGT) e as técnicas de redução ao polo para a centralização de anomalias magnéticas em relação à sua fonte.

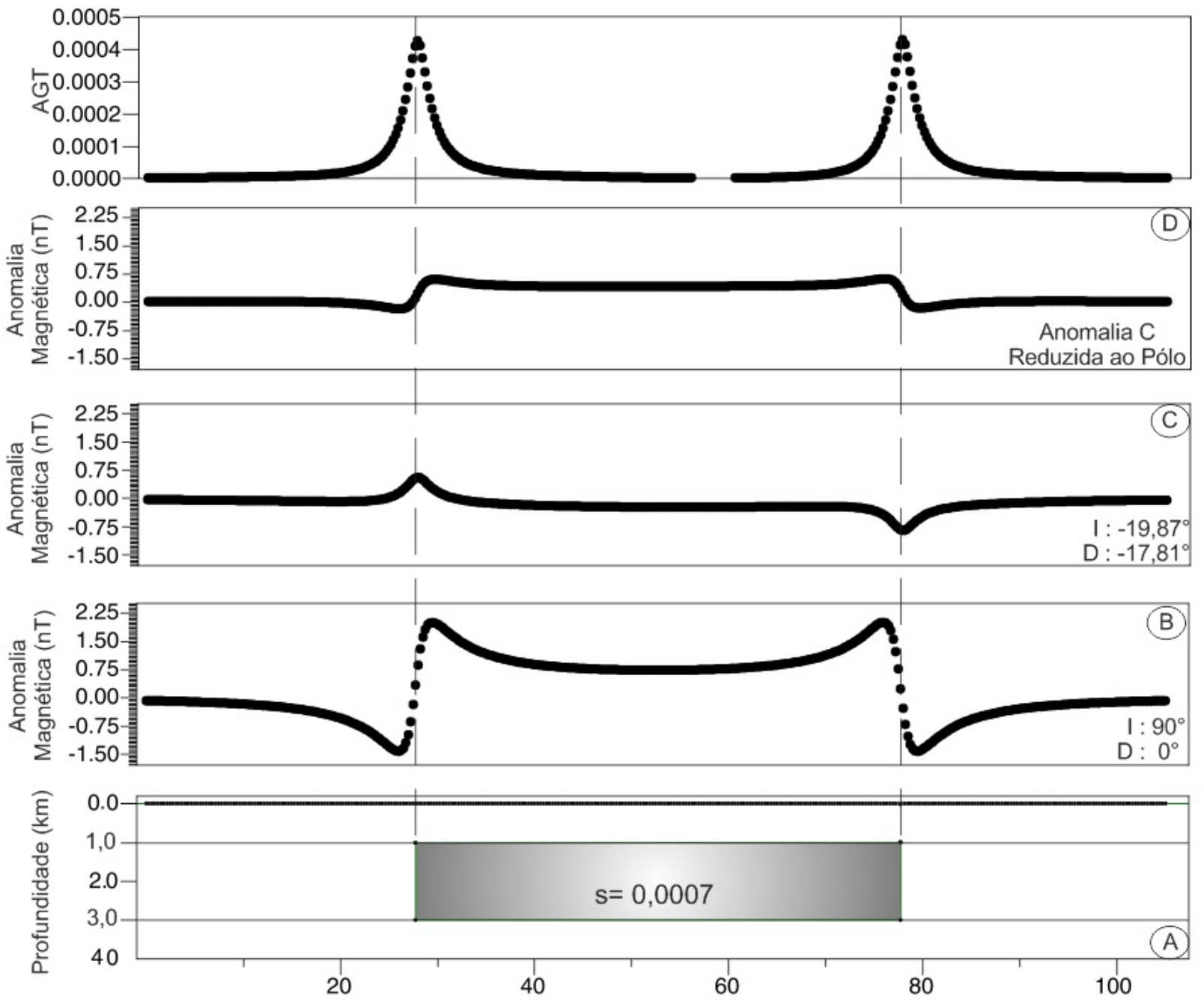

Figura 3.9 - A) Bloco com susceptibilidade magnética (s) de 0,0007 (SI). B) Anomalia magnética gerada pelo bloco em A e campo magnético com inclinação (I): $90^{\circ}$ e declinação $(D): 0^{\circ}$. C) Anomalia magnética gerada pelo bloco em A com $I$ e $D$ do campo magnético iguais aos da área de estudo $\left(I:-19,87^{\circ}\right.$ e $\left.D:-17,81^{\circ}\right)$. D) Anomalia magnética de $(\mathrm{C})$ reduzida ao polo, com a utilização de $I^{\prime}=-70^{\circ}$. E) Amplitude do gradiente total (AGT) da anomalia magnética de C. Observa-se que a redução ao polo e a amplitude do gradiente total centralizaram de forma eficiente a anomalia magnética com $I$ e $D$ iguais aos da área de estudo. 


\section{Derivada tilt}

A derivada ou ângulo tilt (Miller e Singh, 1994; Verduzco, 2004), também conhecido como inclinação do sinal analítico (Blum, 1999), é uma importante técnica de realce de anomalias magnéticas. É calculado pela razão da primeira derivada vertical sobre o gradiente horizontal

$$
\theta=\tan ^{-1}\left[\frac{\left(\frac{\partial M}{\partial z}\right)}{\sqrt{\left(\frac{\partial M}{\partial x}\right)^{2}+\left(\frac{\partial M}{\partial y}\right)^{2}}}\right]
$$

onde $\frac{\partial M}{\partial x}, \frac{\partial M}{\partial y} \mathrm{e} \frac{\partial M}{\partial z}$ são as derivadas de primeira ordem do campo magnético $M$ nas direções $\mathrm{x}, \mathrm{y} \mathrm{e}$ $z$, respectivamente. Uma vez reduzido ao polo, o valor zero do tilt indica a localização do contato das fontes magnéticas. Devido à natureza da função arco-tangente, os valores do tilt são restritos a $-90^{\circ}$ e $90^{\circ}$ ou a $-\pi / 2$ e $\pi / 2$. Em razão disso, essa técnica realça com a mesma intensidade fontes magnéticas com diferentes amplitudes e profundidades, diferentemente do AGT (Equação 3.6). O AGT perde resolução em profundidade quando comparado a fontes mais rasas e com características físicas similares (Figura 3.10).

Por um lado, a presença de remanescência e a baixa latitude magnética da área de estudo apontam o AGT como técnica preferencial em relação à redução ao polo para a centralização de anomalias magnéticas. Por outro lado, o objetivo deste estudo é a observação de assinaturas geofísicas regionais rasas a profundas e, dessa forma, o campo magnético anômalo reduzido ao polo foi utilizado para estimar profundidades a partir da derivada tilt, como é descrito no artigo do capítulo 4. O AGT foi focado na validação parcial da redução ao polo e na caracterização de feições magnéticas rasas.

O tilt também pode ser utilizado para o realce de anomalias gravimétricas. 


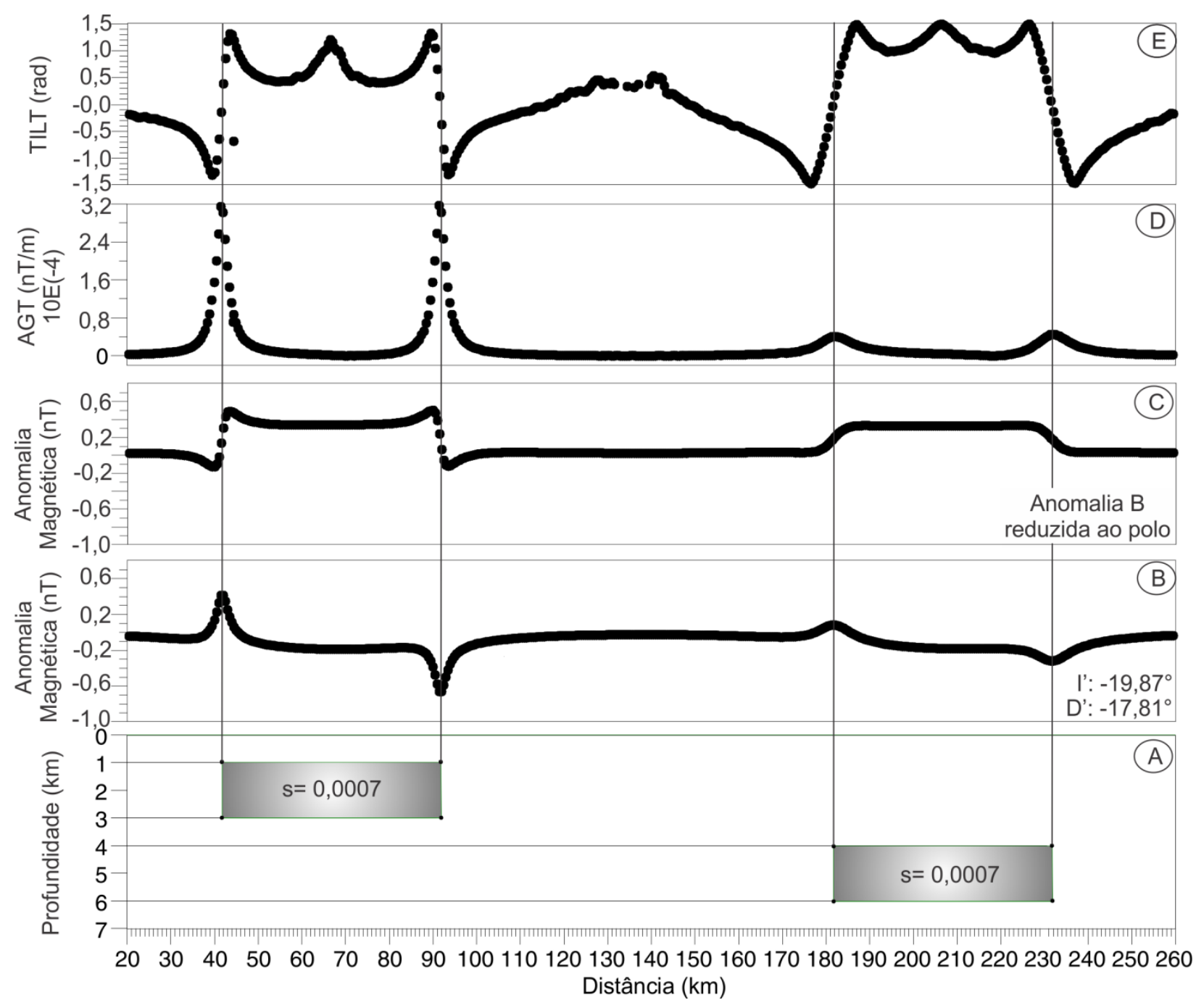

Figura 3.10 - A) Duas fontes magnéticas geradas segundo $I=-19,87^{\circ}, D=-17,81^{\circ}$; B) anomalias magnéticas; C) anomalias magnéticas reduzidas ao polo; D) AGT; E) tilt

\subsubsection{Caracterização das anomalias geofísicas em profundidade}

As anomalias magnéticas e gravimétricas foram classificadas de acordo com sua geometria e intensidade. A classificação foi realizada a partir da observação dos mapas do campo magnético anômalo e da anomalia Bouguer. O processo foi complementado com a observação integrada de diferentes mapas. Cada mapa é resultado da aplicação de técnicas de processamento, as quais realçam, prioritariamente, parâmetros específicos das fontes causativas, tais como: (1) geometria; (2) magnitude; e (3) profundidade. Os resultados são abordados nos artigos e no capítulo de discussões.

$\mathrm{O}$ aspecto de anomalias magnéticas e Bouguer se resume em anomalias regionais amplas, com variação suave, sobre as quais podem ser superpostas anomalias locais com menor comprimento de onda. Em geral, os pequenos e grandes comprimentos de onda refletem feições 
geológicas rasas e profundas, respectivamente. Um método simples de isolar a componente residual de dados gridados consiste na retirada de uma superfície de tendência regional, calculada a partir de ajuste polinomial de $1^{\mathrm{a}}$ ou $2^{\mathrm{a}}$ ordem.

As componentes regional e residual dos campos potenciais podem ser identificadas em função do número de onda $k$ no espectro radial de potência, onde suas respectivas profundidades $Z$ podem ser determinadas pela inclinação $-2 k Z$ de linhas retas ajustadas no espectro de potência (Spector e Grant, 1970; Blakely, 1996). Metade da inclinação da linha equivale a uma estimativa de profundidade. Para um conjunto de fontes magnéticas, é essencial que os comprimentos de onda menores que o corte de Nyquist sejam desprezados (Kearey et al., 2009).

A separação semi-qualitativa de mais de duas partes do espectro de potência, com o objetivo de reconhecer conjuntos de fontes magnéticas e gravimétricas em diferentes profundidades, pode ser efetuada por uma técnica conhecida como Matched Filter (Syberg, 1972; Phillips, 2001), que será descrita a seguir em maior detalhe.

Outra técnica de estimativa de profundidade, o tilt-depth (Salem et al., 2010), é descrita no capítulo 4, que inclui um artigo cuja abordagem é essencialmente metodológica.

\section{Matched-Filter}

Phillips (2001) aprimorou a separação de $n$ componentes residuais do espectro radial de potência por meio das inclinações de múltiplas linhas retas ajustadas ao espectro, permitindo a estimativa de profundidades para cada camada. Uma vez que as profundidades foram estimadas, filtros são utilizados para realçar anomalias provenientes das diversas camadas.

Esta técnica foi utilizada para realçar diferentes níveis de profundidade na Bacia do Paraná, reconhecendo cerca de quatro conjuntos principais de fontes magnéticas e gravimétricas: rochas vulcânicas cretáceas intra-sedimentares, limite bacia/embasamento, níveis crustais intermediário e profundo. O último nível foi considerado somente na análise com dados de gravimetria, pois nesta área, de forma generalizada, assumimos que em profundidades maiores que $30 \mathrm{~km}$ as rochas não possuem mais propriedades magnéticas (Blum e Pires, 1996). A região NE da área de estudo, que inclui o embasamento exposto, foi excluída da análise do matched-filter em virtude da presença das assinaturas com grandes amplitude e comprimento de onda relacionadas às rochas intrusivas da Província Alcalina de Goiás (PAGO; Junqueira-Brod et al., 2002), que suprime as assinaturas mais profundas, que também possuem grande comprimento de onda. Além disso, uma das principais razões em utilizar esta técnica é determinar feições e estruturas 
intra-sedimentares e o limite bacia-embasamento, e não o de estudar profundidades de corpos alcalinos.

Em função da diversidade geológica e tectônica na área de estudo, optou-se por aplicar o matched-filter em sub-áreas de mesmo tamanho, parcialmente sobrepostas (Figura 3.11). A análise do matched-filter (Syberg, 1972; Phillips, 2001) envolveu três passos: (1) Cálculo do espectro radial de potência a partir de subconjuntos do grid de anomalia gravimétrica Bouguer e do campo magnético anômalo, antes da aplicação do processo de redução ao polo; (2) a forma do espectro é modelada de acordo com o melhor ajuste das retas, equivalente a camadas de fontes em suas diferentes profundidades, onde as camadas magnéticas mais rasas são limitadas em profundidade (fonte tipo dipolar) e a camada mais profunda é modelada como meio espaço (halfspace), enquanto as camadas gravimétricas são todas consideradas em meio espaço (half-space); e (3) filtros de amplitude ou Wierner são calculados para cada camada e aplicados às anomalias com objetivo de realçar aquelas provenientes de cada nível em profundidade. Cada camada corresponde à média máxima de uma população estatística de fontes verdadeiras. Em caso de aerolevantamentos, os resultados de profundidade devem ter a altura de voo subtraída. O levantamento da Bacia do Paraná foi realizado com altitude barométrica de $1800 \mathrm{~m}$, porém a elevação da área de estudo é de aproximadamente 1000, 1300 e 1200 m nas porções sudeste, central e noroeste, respectivamente. Ou seja, para aumentar a acurácia dos resultados, principalmente em relação às camadas mais rasas, os valores de elevação do modelo digital de terreno foram subtraídos da altitude de voo para obter a altura de voo em relação ao terreno. A média da altura de voo foi calculada para cada subárea e subtraída dos seus respectivos resultados do matched-filter.

Em geral, fontes magnéticas rasas e profundas dominam as partes de alto e pequeno número de onda do espectro de potência, respectivamente, o que facilita o processo de ajuste das retas. Por outro lado, é teoricamente impossível distinguir fontes magnéticas rasas e profundas quando ambas possuem grandes comprimentos de onda (Phillips, 2001). Esta limitação foi considerada durante a análise do matched-filter.

Os valores de profundidade estimados com uso da técnica do matched-filter para as anomalias gravimétricas e magnéticas foram analisados estatisticamente por meio de gráficos de densidade (Figuras 3.12 e 3.13). Populações de profundidade mais significativa foram determinadas por conjuntos de valores mais comuns, enquanto a minoria, que não se ajusta a qualquer população, foi desconsiderada para o cálculo das médias ponderadas de cada população. As médias ponderadas equivalentes às profundidades magnéticas são: 1,2; 4,4; 12 e $19 \mathrm{~km}$. Patamares 
identificados nos gráficos indicam níveis de profundidade importantes, como: 2,5; 5,5; 16 e 20 $\mathrm{km}$. Da mesma forma, a análise das anomalias gravimétricas resultou nas profundidades de 2,4; 15; 33 e 43 km; com níveis importantes em: 2,7 e 42 km.

Para gerar um mapa de anomalias gravimétricas e magnéticas que representasse esses níveis de profundidade de maior interesse para toda a área de estudo, foram selecionados os espectros de potências modelados com os dados magnéticos e gravimétricos da subárea mais representativa. Esse procedimento é descrito no artigo do Capítulo 5. Em razão da disponibilidade e diversidade de dados magnéticos ser mais ampla do que a dos dados de gravimetria, o primeiro artigo desta tese mostra os resultados alcançados apenas com a interpretação dos dados magnéticos. Os resultados com os dados gravimétricos serão discutidos nos capítulos 6 e 7. 

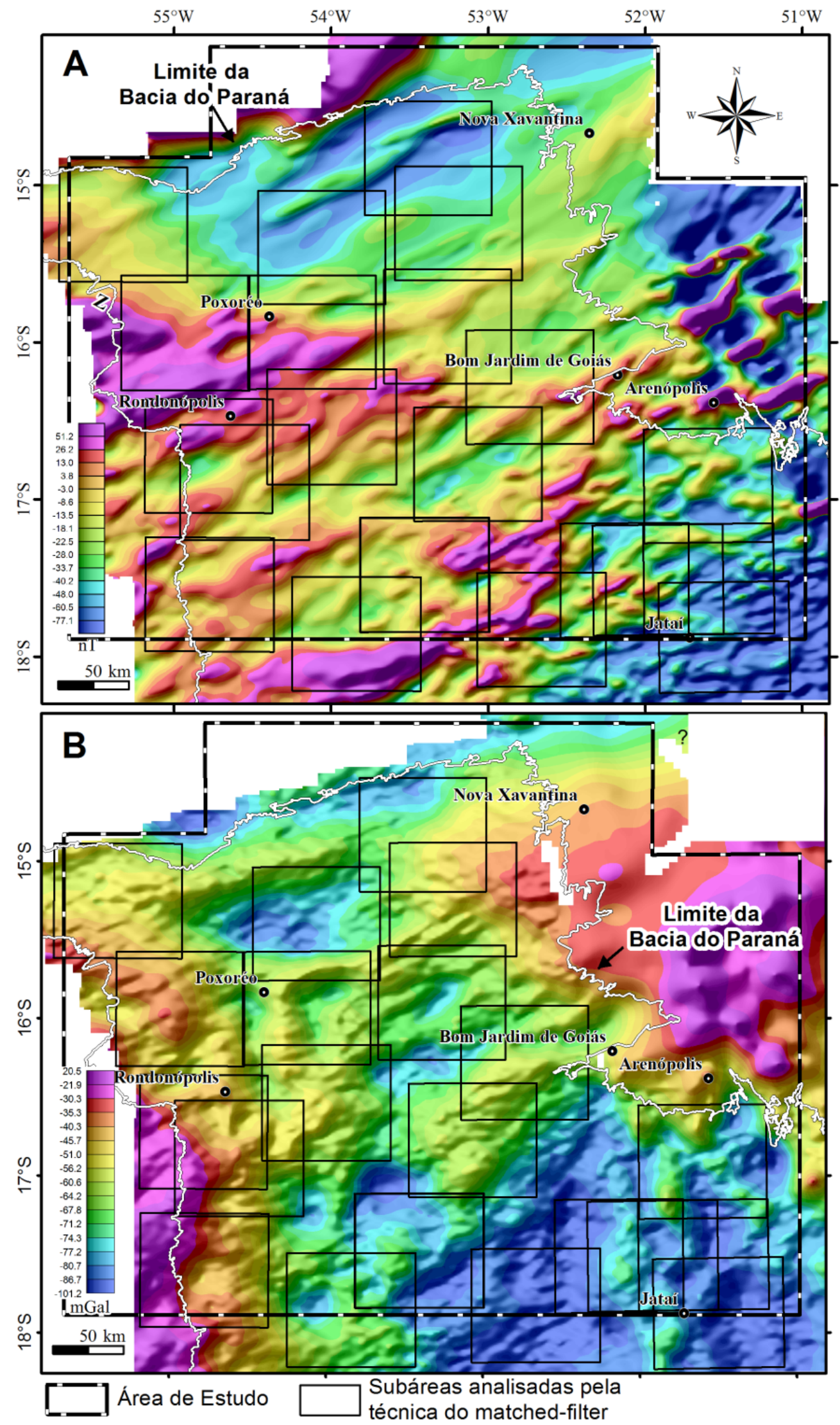

Figura 3.11 - Localização das subáreas analisadas com a técnica do matched-filter. A) Campo magnético anômalo reduzido ao polo. B) Mapa de anomalias Bouguer. 

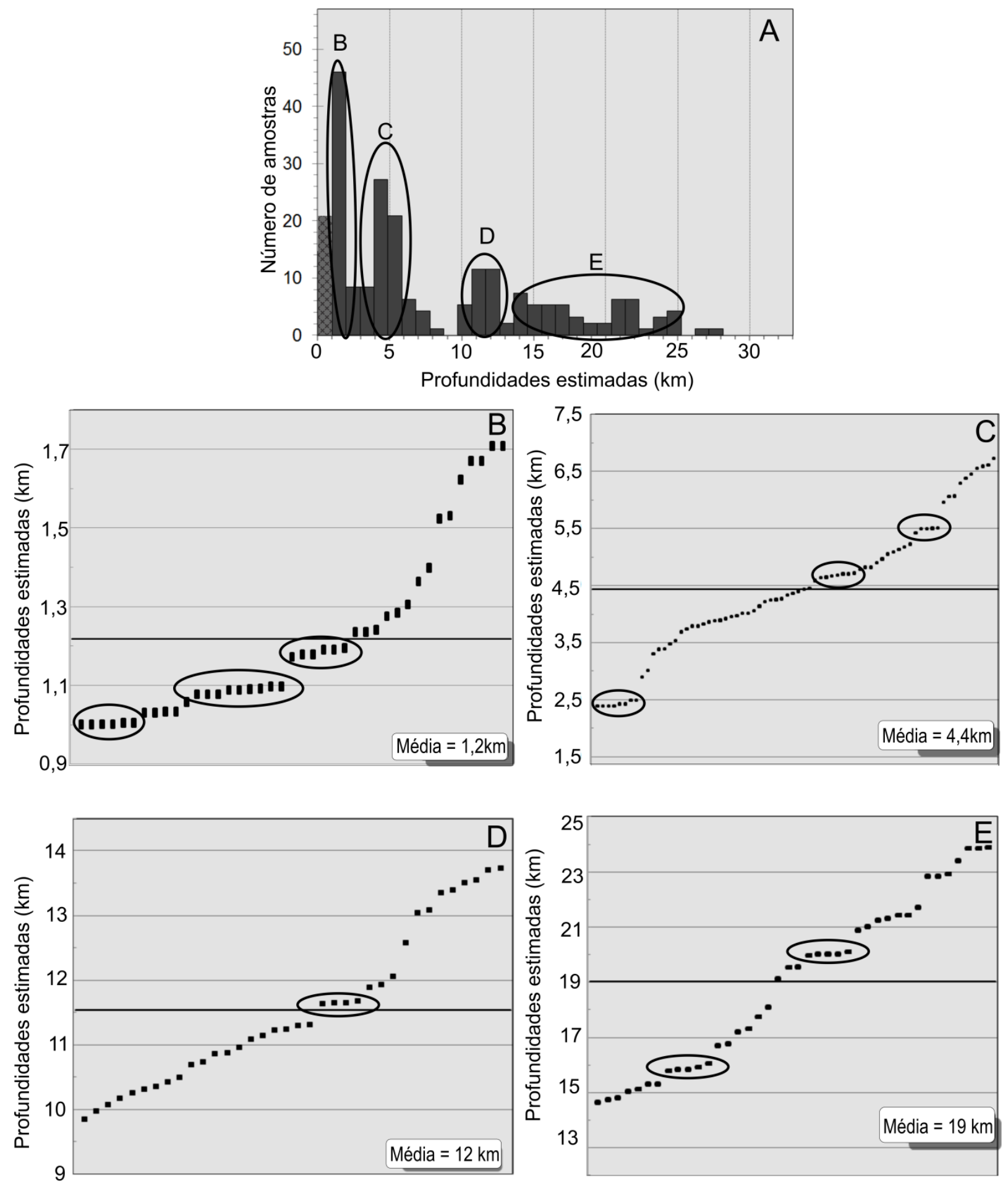

Figura 3.12 - Análise dos resultados de profundidade estimados com o uso da técnica matched-filter aplicada aos dados magnéticos. A) Histograma de densidade; em que as elipses apontam as populações principais. B a E) Média ponderada de cada população. As elipses apontam patamares na distribuição dos dados, indicando maior importância para esses intervalos de valores. 

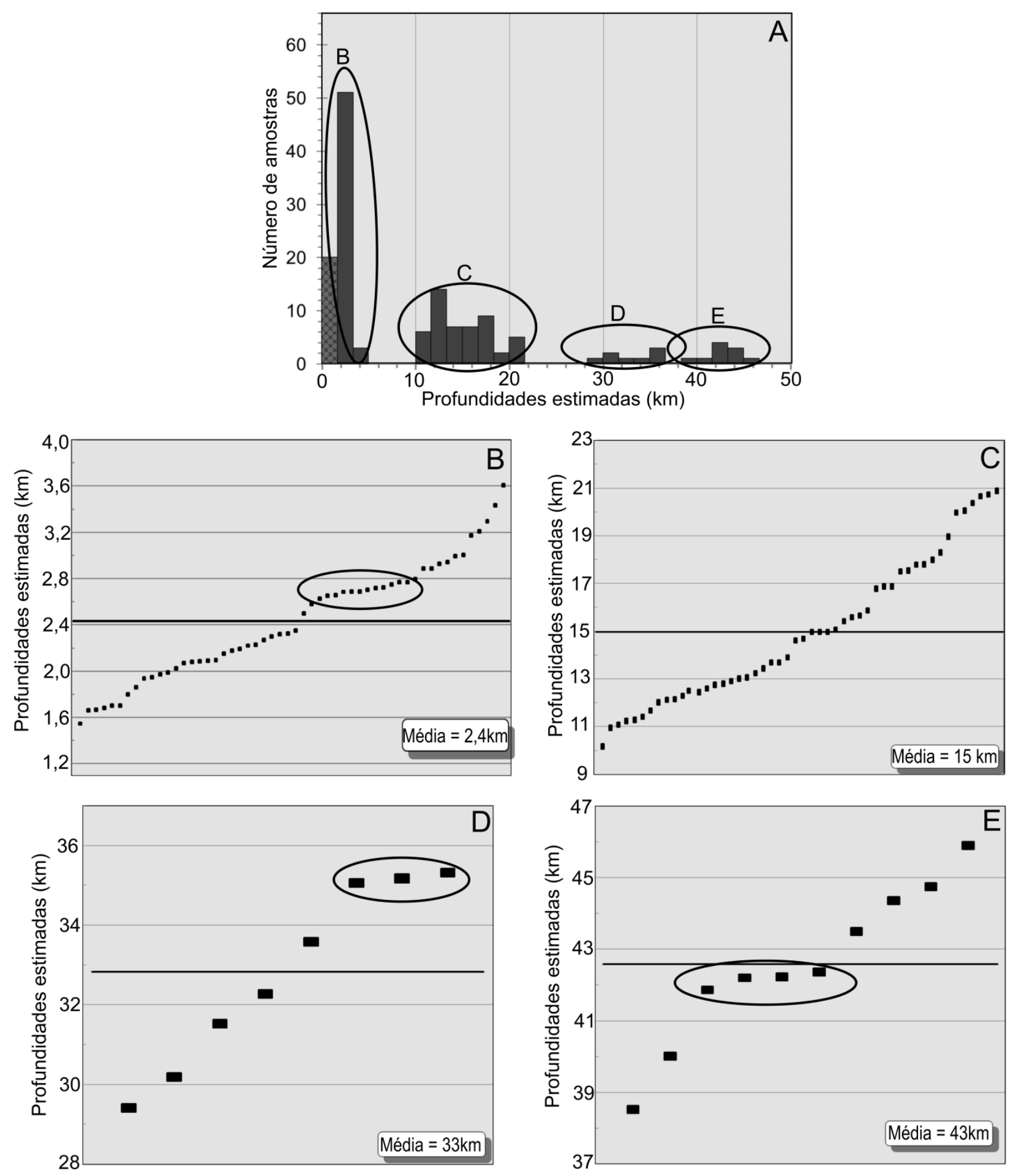

Figura 3.13 - Análise dos resultados de profundidade estimados com o uso da técnica matched-filter aplicada aos dados gravimétricos. A) Histograma de densidade; em que as elipses apontam as populações principais. B a E) Média ponderada de cada população. As elipses apontam patamares na distribuição dos dados, indicando maior importância para esses intervalos de valores. 


\section{Deconvolução de Euler}

A Deconvolução de Euler pode ser aplicada tanto a dados magnéticos (Thompson, 1982; Reid et al., 1990), como gravimétricos (Marson e Klingele,1993). A técnica padrão utiliza os valores desses dados e de seus respectivos três gradientes ortogonais, para determinar profundidades e localização das fontes (Reid et al., 1990). A equação básica da Deconvolução de Euler é

$$
\left(x-x_{0}\right) \frac{d T}{d x}+\left(y-y_{0}\right) \frac{d T}{d y}+\left(z-z_{0}\right) \frac{d T}{d z}=N(B-T)
$$

Onde $\left(x_{0}, y_{0}, z_{0}\right)$ é a localização de uma fonte magnética cuja anomalia magnética de campo total no ponto $(x, y, z)$ é $T$ e $B$ é o campo regional. $N$ é a média da taxa de variação de um campo com a distância. Essa variável, denominada de índice estrutural (IE), assume diferentes valores para diferentes tipos de fontes magnéticas (Tabela 3.5).

Tabela 3.5 - Índices estruturais para anomalias gravimétricas e magnéticas (Reid et al., 1990)

\begin{tabular}{|c|c|c|}
\hline \multicolumn{1}{|c|}{ Fonte } & $\begin{array}{c}\text { IE }^{*} \\
\text { gravimétrico }\end{array}$ & $\begin{array}{c}\text { IE } \\
\text { magnético }\end{array}$ \\
\hline Esfera & 2 & 3 \\
\hline Cilindro horizontal & 1 & 2 \\
\hline Falha (pequeno degrau) & 0 & 1 \\
\hline Contato & -1 & 0 \\
\hline *indice estrutural & &
\end{tabular}

Variações complementares a esta técnica surgiram com o propósito de controlar a dispersão de soluções, concentrando-as ao longo das fontes e de seus limites, como o Extended Euler para fontes em 2D (Mushayandebvu et al., 2001) e na análise de fontes isoladas (FitzGerald et al., 2004).

Em razão deste estudo trabalhar com dados regionais, foi utilizada a Deconvolução de Euler padrão em dados 3D. Os resultados foram utilizados como suporte na modelagem conjunta 2D dos dados magnéticos e gravimétricos, conforme exposto no tópico a seguir. Uma discussão da eficácia desta técnica na área de estudo é desenvolvida no artigo do Capítulo 4.

\subsection{Modelagem direta conjunta dos dados geofísicos}

Após a análise das anomalias magnéticas e gravimétricas da área de estudo, foi realizada a interpretação dessas anomalias por meio da modelagem direta 2D. A modelagem direta implica em construir modelos como fontes causativas, com base na intuição geofísica e geológica da área 
de estudo (Blakely, 1996). A anomalia calculada é comparada àquela observada e os parâmetros do modelo são ajustados, tais como densidade, magnetização, profundidade ou espessura, a fim de otimizar a correspondência entre as duas anomalias. As etapas envolvidas nesse processo são realizadas repetitivamente (Figura 3.14), até que o ajuste final seja satisfatório. Nos software de modelagem atuais, o cálculo da anomalia do modelo é realizado automaticamente enquanto o modelo é ajustado, permitindo maior interatividade no ajuste entre as anomalias. O software utilizado para a modelagem conjunta dos dados magnéticos e gravimétricos é o GM-SYS (Oasis Montaj, Geosoft).

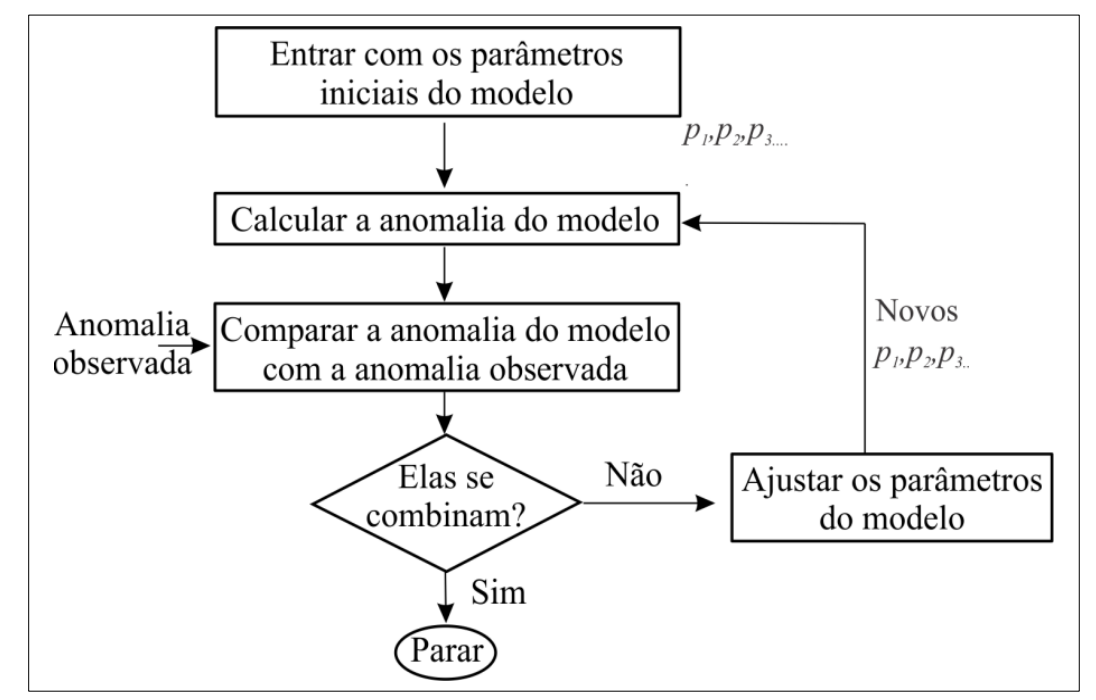

Figura 3.14 - Etapas envolvidas na modelagem direta 2D de fontes magnéticas e gravimétricas (Blakely, 1996). As variáveis $p$ são características das fontes, como densidade, magnetização, profundidade ou espessura.

Os modelos gerados são caracterizados por formas irregulares, em que o cálculo das anomalias é realizado dividindo-se o modelo em uma série de compartimentos de formas regulares e calculando-se o efeito combinado desses compartimentos para cada ponto de observação (Kearey et al., 2009). Em razão de muitas feições geológicas terem formato alongado em uma determinada direção, como por exemplo, diques, dobras, falhas e contatos, a modelagem é comumente efetuada como corpos bidimensionais, em que somente os eixos x e z são considerados como variáveis (Blakely, 1996). Na construção da anomalia gravimétrica de um modelo bidimensional, o corpo modelado é comparado a uma pilha de placas infinitamente finas (Talwani et al., 1959) com uma borda inclinada, que se estende ao infinito para dentro e fora da figura (Figura 3.15). O formato de cada lâmina se aproxima a um polígono de $n$ lados. Considerando o ponto de observação na origem e a densidade do corpo constante, a anomalia gravimétrica dessa placa $g$ é dada por 


$$
\begin{gathered}
g=2 \gamma \rho \Sigma \sum_{n=1}^{N} \frac{\beta_{n}}{1+\alpha_{n}^{2}}\left[\log \frac{r_{n+1}}{r_{n}}-\alpha_{n}\left(\theta_{n+1}-\theta_{n}\right]\right. \\
\alpha_{n}=\frac{x_{n+1}-x_{n}}{z_{n+1}-z_{n}} \\
\beta_{n}=x_{n}-\alpha_{n} z_{n}
\end{gathered}
$$

onde $\rho(x, z)$ é a densidade da placa; $z_{n}$ e $z_{n+1}$ e $x_{n}$ e $x_{n+1}$ são as coordenadas $z$ e $x$ dos dois pontos extremos de um lado $n$; e a distância $r$ e os ângulos $\theta$ são definidos como na figura abaixo.

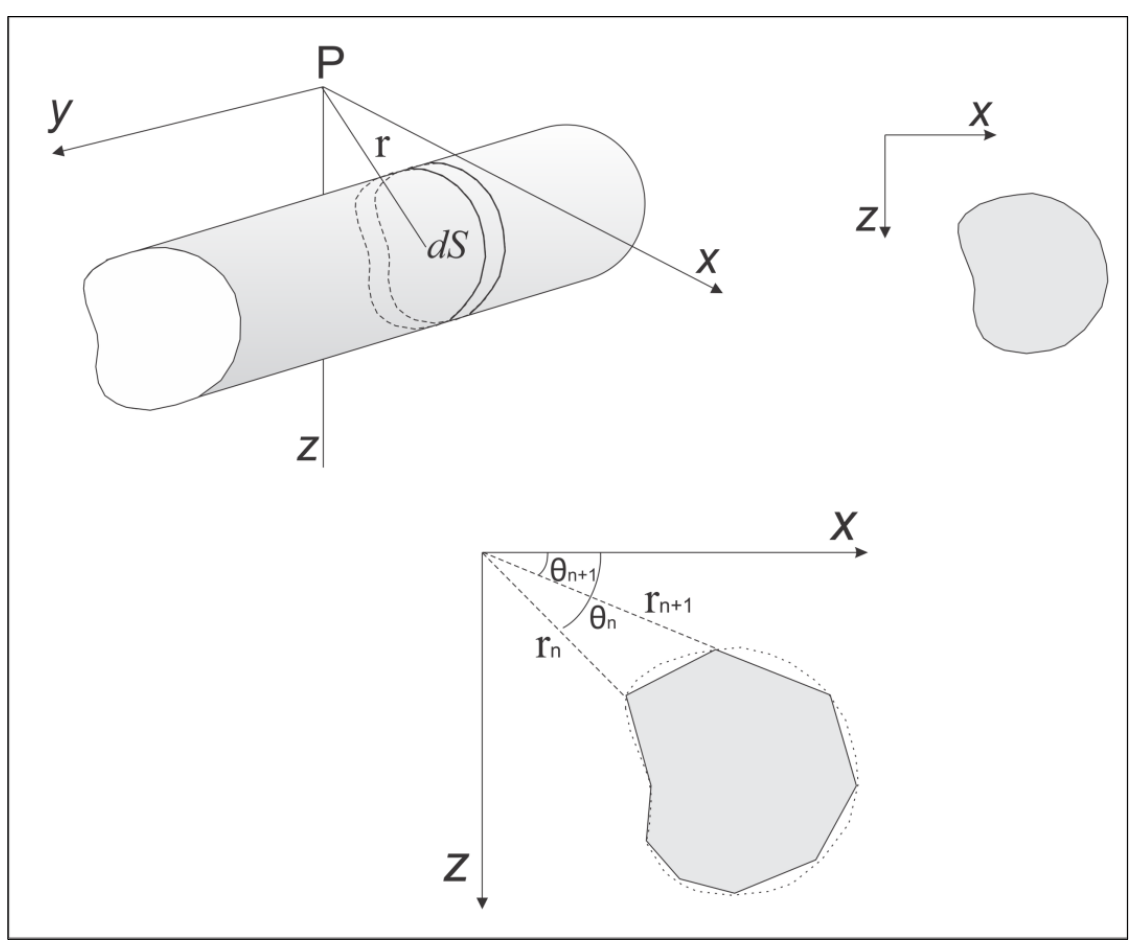

Figura 3.15 - Aproximação para um corpo bidimensional por um polígono de $N$ lados (Blakely, 1996).

Considerando um corpo uniformemente magnetizado, a atração magnética do corpo bidimensional apresentado acima será equivalente a faixas planas de carga magnética, estendidas infinitamente nas direções $\pm y$ (Blakely, 1996). As atração magnética exercida pelas componentes horizontal $\left(B_{x}\right)$, vertical $\left(B_{z}\right)$ das faixas é dada por

$$
\begin{aligned}
& B_{x}=-2 C_{m}(\mathbf{M} * \widehat{\mathbf{n}})\left[\hat{\mathbf{s}}_{x} \log \frac{r_{2}}{r_{1}}-\hat{\mathbf{s}}_{z}\left(\theta_{1}-\theta_{2}\right)\right], \\
& B_{z}=-2 C_{m}(\mathbf{M} * \widehat{\mathbf{n}})\left[\hat{\mathbf{s}}_{z} \log \frac{r_{2}}{r_{1}}-\hat{\mathbf{s}}_{x}\left(\theta_{1}-\theta_{2}\right)\right]
\end{aligned}
$$


onde $\mathbf{M}$ é a magnetização; $\widehat{\mathbf{n}} \mathbf{e} \widehat{\mathbf{s}}$ são os vetores normal e paralelo à faixa, respectivamente, onde $\widehat{\mathbf{n}}$ sempre obedecerá a regra da mão direita e $\widehat{\mathbf{n}}_{x}=\widehat{\mathbf{s}}_{z}$ e $\widehat{\mathbf{n}}_{z}=-\widehat{\mathbf{s}}_{x}$. O valor da constante $C_{m}$ depende do sistema de unidades.

A anomalia do campo magnético total $(\Delta \mathrm{T})$ desta faixa é dada por

$$
\Delta \mathrm{T}=\sum_{l=1}^{N}\left(\hat{F}_{x} B_{l x}+\hat{F}_{z} B_{l z}\right)
$$

Onde $B_{l x}$ e $B_{l z}$ são os componentes $x$ e $z$ de $\mathbf{B}$ em razão do lado $l$; e $\hat{F}_{x}$ e $\hat{F}_{z}$ são os componentes $x$ e $z$ do campo ambiente, sem pertubações.

A interpretação magnética em 2D possui maiores restrições do que a gravimétrica, pois é muito mais sensível a erros associados à variação ao longo da direção das estruturas, onde a razão comprimento-largura de uma anomalia magnética deve ser de pelo menos 10:1 para uma aproximação bidimensional ser válida, em contraste com a razão 2:1 exigida para anomalias gravimétricas (Kearey et al., 2010). Quando o corpo modelado possui comprimento limitado, a dimensionalidade do cálculo é referida como 2,5 D (Rasmussen e Pedersen, 1979; Cady, 1980).

As anomalias magnéticas são interpretadas de acordo com mudanças na magnetização da crosta. Devido à natureza dipolar das anomalias magnéticas, sua modelagem é uma tarefa complexa. As seções para a modelagem foram definidas sub-perpendiculares às anomalias magnéticas, com e sem redução ao polo. O campo magnético anômalo, sem redução ao polo, foi utilizado como base para a modelagem de uma seção menor, localizada na porção SE da área de estudo. Esta área dispõe de dados de paleomagnetismo (Ernesto e Pacca, 1988). A modelagem foi realizada com o objetivo de entender melhor o comportamento magnético das soleiras intrusivas da Formação Serra Geral e a contribuição de seu magnetismo remanente no campo magnético. O campo magnético anômalo reduzido ao polo foi utilizado para seções mais longas, que incluem regiões onde não há dados de magnetização remanente.

A interpretação das anomalias Bouguer é baseada nas variações laterais de densidade e de seu aumento com a profundidade, referente a mudanças do campo gravimétrico relacionado somente à geologia, sem efeitos topográficos, mas ainda assim, não são relativas a anomalias residuais. A altura das estações $(1800 \mathrm{~m})$ e a topografia são preservadas na modelagem, e a densidade do espaço acima da topografia é equivalente à constante de densidade da correção de terreno para a anomalia Bouguer $\left(2,67 \mathrm{~g} / \mathrm{cm}^{3}\right)$. A topografia foi inserida na modelagem por meio do modelo digital de terreno (MDT) do banco de dados do aerolevantamento da Bacia do Paraná. Devido à 
área de estudo não estar restrita à porção norte da bacia e não apresentar variações significativas na topografia, compensações isostáticas não foram consideradas. Além disso, o objetivo deste estudo é de investigar fontes tanto da crosta superior como de níveis mais profundos, incluindo o limite manto-crosta.

O conhecimento do contexto geológico e tectônico deve ser incorporado em cada passo do processo da modelagem direta (Blakely, 1996). Durante esse processo, ambiguidades são inevitáveis ao modelo e devem ser levadas em consideração como alternativas que apresentem o mesmo ajuste aos dados observados. As ambiguidades foram em parte minimizadas pelo fato de terem sido utilizados simultaneamente dados magnéticos e gravimétricos. Quanto mais dados geofísicos e complementares são levados em conta, menor o grau de ambiguidade. $\mathrm{O}$ artigo do capítulo 6 mostra os resultados alcançados e desenvolve uma discussão acerca do desafio de modelar anomalias em diferentes contextos geotectônicos e com poucos dados complementares.

\section{Propriedades fisicas de rocha}

Com o intuito de dar suporte à interpretação geofísica, foram realizadas medidas de susceptibilidade magnética $(\mu)$ em afloramentos, com o uso do susceptibilímetro e condutivímetro MPP-EM2S (Figura 3.16). Em muitos pontos não foi possível fazer as medições devido a dificuldades técnicas e instrumentais. Entretanto, após o trabalho de campo, as medições também foram realizadas nas amostras coletadas, no laboratório de Geocronologia do Instituto de Geociências da Universidade de Brasília (IG/UnB). O valor final da susceptibilidade magnética $(\mu)$ é relativo a média das medições realizadas para cada amostra (Tabela 3.6).

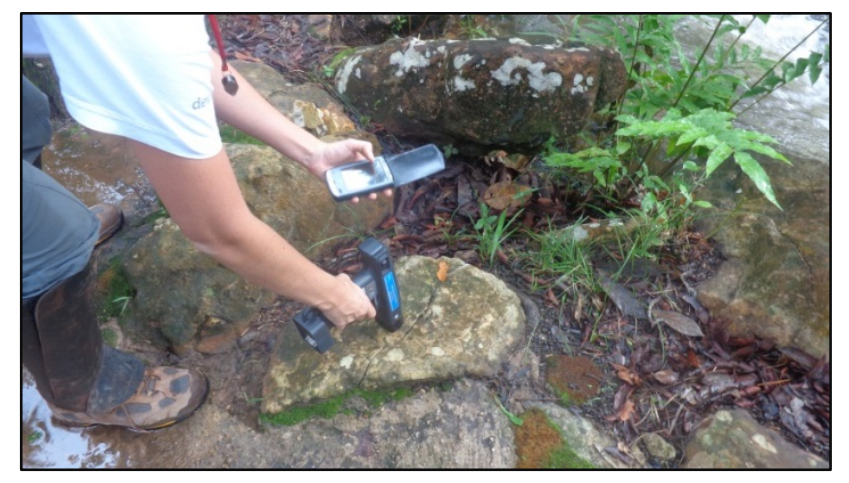

Figura 3.16 - Medidas de susceptibilidade magnética realizadas in situ durante o trabalho de campo.

No laboratório de Geoquímica do IG/UnB foram realizados ensaios de densidade em algumas das amostras coletadas em campo, com o objetivo de representar a densidade relativa geral das principais unidades geológicas da área de estudo, como granitos, rochas sedimentares e alcalinas (Tabela 3.6). Para medir a densidade relativa (Drel) das amostras de rocha, foram utilizados 
balança de precisão (1g) e becker graduado de $1 \mathrm{~L}$, parcialmente preenchido com água, cujo valor de densidade é $1 \mathrm{~g} / \mathrm{cm}^{3}$. O procedimento adotado utiliza o peso da amostra e o volume de líquido deslocado por ela, o qual será igual ao seu próprio volume. Previamente ao início do ensaio, as amostras selecionadas foram serradas em forma de cubos de modo que fosse possível inserí-las no becker. Foram adotadas as seguintes etapas:

1. Pesagem da amostra de rocha $\left(P_{r}\right)$;

2. Determinação do volume da água do becker $\left(V_{l}\right)$;

3. Determinação do volume de água com a amostra inserida no becker $\left(V_{2}\right)$;

4. Cálculo da Drel de acordo com a equação

$$
\text { Drel }=\frac{P_{r}}{V_{2}-V_{1}}
$$

O método usado para calcular a Drel deve ser utilizado para amostras sólidas e maciças, com pouca porosidade. Algumas medidas com amostras de arenito foram realizadas apenas nas mais consolidadas. De qualquer maneira, a imprecisão do método é considerada na análise dos resultados.

Tabela 3.6- Valores de densidade relativa e susceptibilidade magnética de amostras coletadas em trabalho de campo (os pontos visitados estão no Anexo A3)

\begin{tabular}{|c|c|c|c|}
\hline Amostra & Drel* & Suscp* & Rocha \\
\hline AJ06 & 2,50 & 12,87 & Granito Serra Verde \\
\hline LTBPR01A & 3,02 & 17,88 & Rocha ultramáfica do complexo alcalino de Santa Fé de Goiás \\
\hline LTBPR01B & & 4,56 & Arenito cozido no complexo alcalino de Santa Fé de Goiás \\
\hline LTBPR02 & 2,63 & 0,39 & Granito-gnaisse do Arco Magmático de Goiás \\
\hline LTBPR03 & & 0,01 & Arenito fino a médio avermelhado da Fm. Aquidauana \\
\hline LTBPR04 & & 0,00 & Arenito grosso branco da Formação Furnas \\
\hline LTBPR05 & & 0,00 & Arenito fino a médio avermelhado da Formação Aquidauana \\
\hline LTBPR07 & & 0,01 & Arenito médio argiloso avermelhado da Formação Aquidauana \\
\hline LTBPR09 & & 0,00 & Arenito fino a médio rosado da Formação Aquidauana \\
\hline LTBPR10 & 2,49 & 0,01 & Arenito médio, branco e consolidado, pouco friável (Fm. Bauru?) \\
\hline LTBPR11 & 2,60 & 0,07 & Arenito médio com espessa capa de alteração \\
\hline LTBPR13 & 2,41 & 1,90 & Granito São Vicente (fácies porfirítica) \\
\hline LTBPR16A & 2,07 & 0,00 & Arenito grosso branco da Fm. Furnas \\
\hline LTBPR16B & & 0,00 & Siltito avermelhado \\
\hline LTBPR17A & & 0,87 & Arenito cozido no complexo alcalino de Montes Claros de Goiás \\
\hline LTBPR17B & 2,30 & 11,83 & Rocha ultramáfica do complexo alcalino de Montes Claros de Goiás \\
\hline LTBPR18A & & 0,19 & Arenito cozido no complexo alcalino de Montes Claros de Goiás \\
\hline LTBPR18B & 2,42 & 4,60 & Rocha ultramáfica do complexo alcalino de Montes Claros de Goiás \\
\hline LTBPR19 & 2,73 & & Nefelina sienito do complexo alcalino de Iporá \\
\hline
\end{tabular}

*Drel: densidade relativa; Suscp: susceptibilidade magnética (SI) 
As rochas de complexos alcalinos de Goiás, encontradas em campo (Pontos LTBPR - 01, 02 e 18; Anexo A3), são compostas por sua variação ultramáfica. Dunitos, peridotitos e piroxenitos foram descritos em Santa Fé de Goiás (Barbour et al., 1979) e Montes Claros de Goiás (Pena, 1975, apud Junqueira-Brod et al., 2002). Amostras de nefelina sienito foram coletadas no Morro do Macaco (Ponto LTBPR19), na região de Iporá. Como observado na tabela 3.6, as rochas alcalinas apresentam, em geral, os valores mais elevados de densidade relativa (Drel) e susceptibilidade magnética $(\mu)$, dentre as demais rochas amostradas (Anexo A1). Presença de minerais máficos e baixa porosidade influenciam nesse aspecto. Em contato com essas rochas, arenitos da Bacia do Paraná apresentavam cores acizentadas, demonstrando cozimento pela intrusão das alcalinas (LTBPR01B) e maiores valores de $\mu$ (Figura 3.17).

A susceptibilidade magnética $(\mu)$ das amostras coletadas nos granitos Iporá (AJ02), Serra Verde (AJ06) e São Vicente (LTBPR13) não refletem de forma ideal a resposta magnética total do corpos intrusivos. A variação nas concentrações de minerais máficos e feldspáticos pode gerar contrastes significativos entre os valores de $\mu$. Portanto, o recomendável nestes casos é a realização de medidas nas diversas fácies das intrusões. A amostra de granito-gnaisse do Arco Magmático de Goiás, localizado próximo ao contato com as rochas alcalinas de Santa Fé de Goiás, apresenta menos de $20 \%$ de minerais máficos, resultando em valores muito baixos de $\mu$. Ao contrário, o Granito Serra Verde possui $\mu$ elevado, possivelmente relacionado a processos deformacionais.

Os arenitos da Bacia do Paraná apresentam susceptibilidade magnética muito baixa (Figura 3.17). Os afloramentos das formações Aquidauana e Bauru, diferentemente da Formação Furnas, mostraram-se consolidados e menos friáveis, apresentando valores de densidade compatíveis com os granitos (Tabela 3.6). Os granitos observados em campo são em geral compostos por porfiroblastos de feldspatos e certo grau de fraturamento, fatores que influenciam na diminuição da densidade da rocha. 


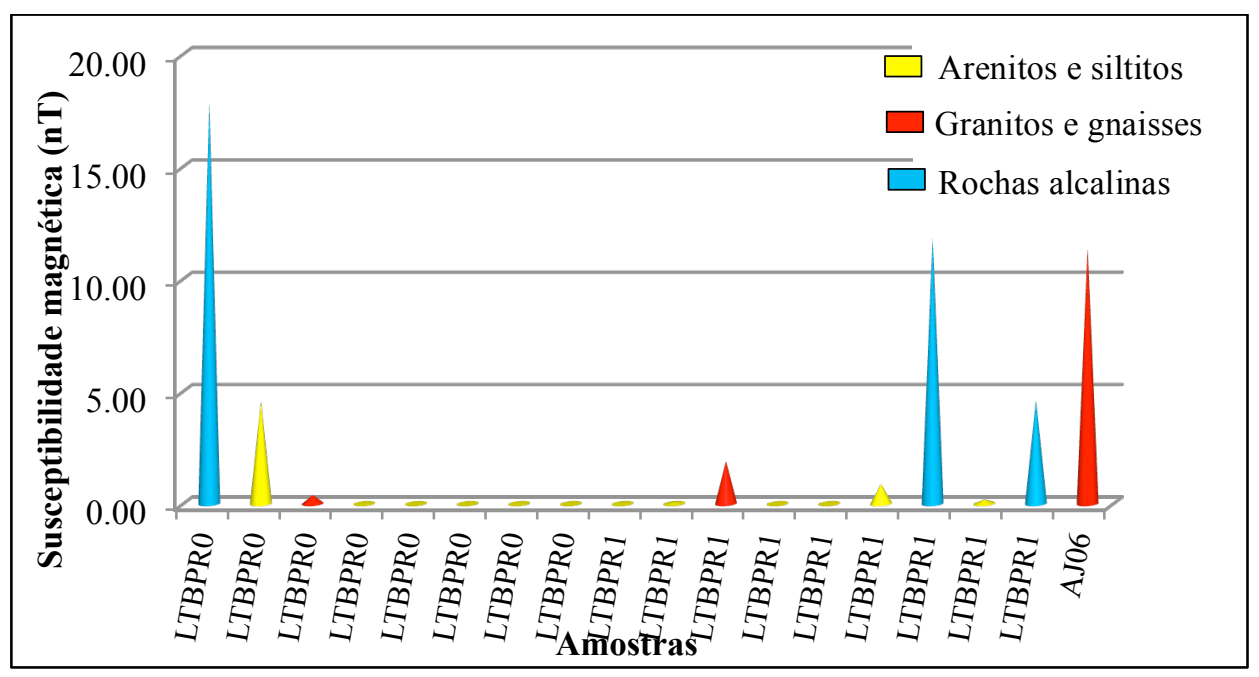

Figura 3.17 - Gráfico de susceptibilidade magnética das amostras coletadas em campo.

Devido à imprecisão dos valores de susceptibilidade magnética e densidade relativa obtidos em campo, também foram utilizadas como referência para a modelagem valores obtidos na literatura (Reynolds, 2011; Kearey et al., 2009; Hrouda et al., 2009). Hrouda et al. (2009) mostram uma revisão de estudos de caso, que reúne as principais rochas e suas propriedades magnéticas. 
Optimizing depth estimates from magnetic anomalies using spatial analysis tools

Authors:

Julia B. Curto ${ }^{1}$, Tatiana Diniz ${ }^{1}$, Roberta M. Vidotti ${ }^{1}$, Richard J. Blakely ${ }^{2}$, Reinhardt A. Fuck ${ }^{1}$

'Instituto de Geociências, Universidade de Brasília, Brasília, Brasil

${ }^{2}$ U.S. Geological Survey, Menlo Park, CA, United States

Corresponding author: Julia B. Curto (julia.curto@gmail.com)

Corresponding author's address: Instituto de Geociências, Universidade de Brasília Campus

Darcy Ribeiro ICC - Ala Central CEP 70.910-900 - Brasília / DF - Brasil

Key words: Tilt; depth; magnetic anomaly; spatial analysis; GIS 


\begin{abstract}
We offer a methodology to analyze the spatial and statistical properties of the tilt derivative of magnetic anomalies, thus facilitating the mapping of the location and depth of concealed magnetic sources. This methodology uses commonly available graphical information system (GIS) software to estimate and interpolate horizontal distances between key attributes of the tilt derivative, which then are used to estimate depth and location of causative bodies. Application of the method to synthetic data illustrates its reliability to determine depths to magnetic contacts. We also achieved consistent depth results using real data from the northwest portion of the Paraná Basin, Brazil, where magnetic anomaly interpretations are complicated by low geomagnetic inclinations and rocks with remanent magnetization. The tilt-derivative method provides more continuous and higher resolution contact information than the 3D Euler deconvolution technique.
\end{abstract}

Highlights

GIS analysis complements the tilt-depth technique

Continuous depth solutions

Interpolation of magnetic depth values 


\section{Introduction}

Various methods are available to automatically and rapidly analyze magnetic anomalies in order to estimate the locations and depths of geologic sources over large, regional areas. Modern methods generally use gridded magnetic data and focus on the depth to geologic contacts, such as concealed faults, intrusive margins, and sedimentary basins. For example, the Euler deconvolution technique is based on Euler's differential equation and provides estimates of depths to two-dimensional (Thompson, 1982) and three-dimensional (Reid et al., 1990) sources. The Euler method requires assumption of a "structural index", a parameter characteristic of the source geometry, and provides a scatter of depth solutions that must be evaluated by additional assumptions (Thompson, 1982; Fairhead et al., 1994; Barbosa et al., 1999).

Here we discuss the tilt-depth method (Salem et al., 2007), which is based on the ratio of the vertical and horizontal gradients of magnetic anomalies caused by vertical contacts (Miller and Singh, 1994; Verduzco, 2004; Salem et al., 2010). This method yields depth solutions along and adjacent to the contact, thus largely overcoming the problem of scattered solutions characteristic of the Euler approach. We further demonstrate a methodology of spatial and statistical analysis of the tilt derivative within a geographic information system (GIS) platform, which leads to more accurate estimates of the depth to the magnetic contact. Finally, we provide examples of our methodology by applying it to synthetic anomaly data and to field data from the northwest region of the Paraná Basin, Brazil, where major magnetic sources are concealed beneath sedimentary deposits. The Paraná Basin provides a particularly stringent test of the method because low geomagnetic inclinations and subsurface rocks with unknown remanent magnetizations complicate interpretation of magnetic data from this region (e.g., Curto et al., 2014).

\section{Theoretical Review}

Many methods for edge detection and depth-to-source estimation rely on horizontal and vertical derivatives of magnetic anomalies (Nabighian, 1984; Blakely and Simpson, 1986; Thurston and Smith, 1997; Fedi and Fiori, 2000; Phillips, 2000; Ferreira et al., 2013). The total-gradient method, for example, calculates the analytic signal by combining horizontal and vertical derivatives of magnetic anomalies, calculated either from profile or gridded data. Maxima of the total gradient are centralized over causative sources and have shapes indicative of the source depth (Nabighian, 1972; Roest et al., 1992; Macleod, 1993). However, the amplitude of the total gradient attenuates with increasing depth to source, thus hampering interpretations when both shallow and deep sources (Figure 1c) are present. 
The local phase of the magnetic field, or tilt derivative (Miller and Singh, 1994; Verduzco et al., 2004), overcomes this attenuation problem by using the ratio of the vertical and horizontal gradients. The tilt angle is given by

$$
\theta=\tan ^{-1}\left(\frac{\frac{\delta M}{\delta z}}{\frac{\delta M}{\delta h}}\right)
$$

where $\delta M / \delta h=\sqrt{(\delta M / \delta x)^{2}+(\delta M / \delta y)^{2}}$, and $\delta M / \delta x, \delta M / \delta y, \delta M / \delta z$ are first-order derivatives of the magnetic field $M$ in the $x, y$, and $z$ directions, respectively. The tilt angle $\theta$ has values between $\pi / 2$ and $-\pi / 2\left(-90^{\circ}\right.$ and $\left.90^{\circ}\right)$. Salem et al. $(2007,2010)$ showed that, for magnetic anomalies caused by vertical contacts and reduced to the pole,

$$
\theta=\tan ^{-1}\left(\frac{h}{z}\right)
$$

where $\mathrm{z}$ is the depth to the contact and $h$ is the horizontal distance perpendicular to the contact. It is clear from equation 2 that $\theta=0$ directly over the contact. It also can be shown that the horizontal gradient of the tilt derivative in the vicinity of $\theta=0$ is a measure of the depth to the contact. One way to estimate the horizontal gradient of the tilt derivative (and thus the depth to source) is by measuring the horizontal distance between specific contours on opposite sides of the zero-contour (Figure 1e). Using this as a rule of thumb, it is possible to conduct a simple qualitative interpretation of source depths. For example, $z=h$ when $\theta= \pm \pi / 4$, so the horizontal distance between the $+\pi / 4$ and $-\pi / 4$ contours is a measure of $2 z$.

Other tilt-derivative contours can be used as well. We empirically observed that anomaly interference for close or overlapping magnetic sources is greater for larger tilt angles, whereas much smaller tilt angles hamper the tilt visualization in $3 \mathrm{D}$, consequently affecting our interpretations. Best results were found when we used two measurements:

- $h_{1}$, the horizontal distance between $\theta$ contours 0 and +0.46 radians $\left(+26.6^{\circ}\right)$, and

- $h_{2}$, the horizontal distance between $\theta$ contours -0.46 and 0 .

Each measurement provides an estimate of source depth; i.e., $z_{1}=2 h_{1}$ and $z_{2}=2 h_{2}$ (i.e., $\theta=$ 0.46 radians when $h=0.5 z$; Figure $1 \mathrm{e})$.

\section{Spatial analysis of the tilt-depth}

In our methodology, tilt-depths are estimated with a four-step procedure: We (1) calculate the tilt derivative of the reduced-to-pole magnetic field; (2) display contour lines of the tilt in radians; (3) measure the variables $h_{1}$ and $h_{2}$; and (4) calculate $z_{1}=2 h_{1}$ and $z_{2}=2 h_{2}$. The first two steps 
are achieved within Oasis Montaj ${ }^{\circledR}$ (Geosoft $\left.{ }^{\circledR}\right)$, and we automate the last two steps using the ArcGIS ${ }^{\circledR}$ platform (Esri $\left.{ }^{\circledR}\right)$ and adding two additional steps: (5) a statistical analysis of depth estimates, and (6) interpolation between specific contours. All six steps are described below (Figure 2) and can be adapted easily to other cases, including situations with different magnetic field parameters.

Step 1: Prior to the tilt derivative calculation, magnetic anomalies should be reduced to the pole. The reduction to the pole algorithm (Baranov and Naudy, 1964) is unstable at low geomagnetic inclinations (Blakely, 1996) and distorts magnetic anomalies along the magnetic declination direction. Directional filtering and amplitude correction are ways to minimize the noise problem (Grant and Dodds, 1972; Macleod et al., 1993), and we used the latter method in working with low-latitude data. The amplitude correction is based on the pseudo-inclination value, which is the difference between the magnetic inclination at the survey location and at the pole $\left(90^{\circ}\right)$.

To illustrate our methodology, we calculated the magnetic anomalies over two hypothetical magnetic sources. Model A used geomagnetic inclination values of $90^{\circ}$ and included two prisms (M1 and M2) with equal dimensions, equal magnetization, different depths, and sides oriented north-south or east-west (Figure 1). Model B used geomagnetic inclination values of $-20^{\circ}$ and included 10 prisms (P1 to P10) with different depths, sizes, orientations, and magnetization values (Figure 3, Table 1). All prisms were infinitely extended in the vertical direction, except P5 and P7 in Model B, which were 2 and $10 \mathrm{~km}$ thick, respectively. The magnetic field for Model B was reduced to the pole assuming a pseudo-inclination of $-70^{\circ}$. Reduction to the pole did centralize magnetic anomalies over their causative sources, but anomaly elongations and subsidiary peaks still remain. The tilt-derivative calculation uses field gradients in all three directions (Eq.1), so directional distortion can become evident (Figure 3b).

Table 1 - Description of the main features of magnetic prisms from Model B.

\begin{tabular}{c|c|c|c|c|c}
\hline \multirow{2}{*}{ Sources } & $\begin{array}{c}\text { Depth of } \\
\text { the top } \mathbf{( k m )}\end{array}$ & $\begin{array}{c}\text { Magnetization } \\
(\mathbf{n T})\end{array}$ & \multicolumn{3}{|c|}{ Remnant Magnetization } \\
\cline { 4 - 6 } & 1 & Intensity (nT) & $\mathbf{I}$ & $\mathbf{D}$ \\
\hline P1 & 1 & 0.13 & 0 & & \\
P2 & 4 & 0.13 & 0 & & \\
P3 & 1 & 0.13 & 0.015 & 181.7 & 36.6 \\
P4 & 2 & 0.13 & 0 & & \\
P5 & 1 & 0.13 & 0 & \\
P6 & 4 & 0.13 & 0 & \\
P7 & 2 & 0.13 & 0 & \\
P8 & 2 & 0.07 & 0 & \\
P9 & 2 & 0.04 & 0 & \\
P10 & 1 & 0.37 & 0 \\
\hline
\end{tabular}


Step 2: This step is achieved by simply plotting the $-0.46,0$, and +0.46 radian contour lines in Oasis/Montaj and exporting them as vector files in ArcGIS format.

Step 3: Depth values are calculated along the contour lines by using the near function analysis available in ArcGIS software. This tool calculates the shortest distance between two lines or from a point to a line. In the interest of finding regularly-spaced depth values along the source margins, the \pm 0.46 rad contour lines were converted to points spaced $50 \mathrm{~m}$ apart. The near function then was used to determine $h_{1}$ and $h_{2}$ at each +0.46 and $-046 \mathrm{rad}$ point, respectively.

Step 4: Both $h_{1}$ and $h_{2}$ values were doubled, resulting in two depth estimates, $z_{1}$ and $z_{2}$. For airborne geophysical data, the flight height should be subtracted from the resulting values.

Step 5: Equation 2 shows that $\theta(h)$ is symmetric about $h=z$, and thus parameters $z_{1}$ and $z_{2}$ should be equal. In practice, the difference between $z_{1}$ and $z_{2}$ can be used as a measure of reliability. Our near-distance function analysis of prisms M1 and M2 (Model A; Figures 1 and 4) indicated that accurate results are achieved by simply averaging $z_{1}$ and $z_{2}$ for this simple case. However, the tilt derivative derived from prisms P1 to P10 (Model B; Figure 3) shows interference between closely spaced magnetic sources, especially with longer wavelength anomalies (deeper sources). Contour lines related to negative tilt angles are strongly affected by anomaly skewness caused by the reduction-to-pole filtering at low magnetic inclinations ( $\mathrm{I}=$ $20^{\circ}$ ). The elongated skewness is greatest near the limits of the area (Figure 3), causing large depth-estimation errors in these regions (Figure 5). These errors are less commonly associated with positive tilt angles, except for partially overlapping sources, where larger errors are associated with both positive and negative contour lines and consequently, causing larger error for $h_{1}$ and $h_{2}$ values, respectively (Figures 3 and 5). Even though there is some uncertainty with $z_{2}$, the average of $z_{1}$ and $z_{2}$ exhibits more constant trends along the margins of each magnetic source (Figure 5). Depth results associated with strongly distorted tilt contour lines were simply excluded, since they are clearly recognized in the map (Figure 6).

Step 6) Line width and color provide a useful way to display source depths. To represent depth, $z_{1}$ and $z_{2}$ were interpolated onto smooth surfaces. The -0.46 and +0.46 radian contour lines were converted to closed polygons, using the buffer tool, with the purpose of providing a spatial boundary for the surface interpolation and forcing depth determinations close to their respective sources (Figures 4 and 6). Otherwise depth values would be interpolated between distant, nonrelated magnetic sources. We used the algorithm, spline with barriers, available in the ArcGis 10.0 platform to do the interpolation (Terzopoulos, 1988; Zoraster, 2003). The values calculated by the spline function are close to the original values, using low degree polynomials applied to 
data subsets. The algorithm performs the maximum possible number of iterations or until it reaches a maximum difference between the principal and the estimated value, user-defined. The result is displayed as smooth surfaces. Other interpolators may be used, providing they include criteria related to maximum distance and range limit.

Depth estimates for the synthetic prisms were satisfactory for both tested magnetic inclinations, $90^{\circ}$ (Model A, Figure 4) and - 20 (Model B, Figure 6). The knowledge of the typical errors associated with distortions of the magnetic anomaly was used to guide our interpretations for the real case presented in the next section.

\section{Applied example}

The northwest region of the Paraná Basin, Brazil, was chosen as a field example to demonstrate the methodology presented in this paper. Our goal at present is to estimate depths of tectonic and geologic elements investigated in previous studies (Zalán et al., 1991; Milani et al., 2004; Curto et al., 2014). These elements include vertical contacts of intrusive bodies and intra-sedimentary volcanic rocks, and structural lineaments within the basement. The inclination and declination of the geomagnetic field are $-20^{\circ}$ and $-18^{\circ}$, respectively, in this area, and this low inclination is reflected in skewness and distortion of the magnetic anomalies (See Appendix for data description). Reduction to the pole was applied to observed anomalies using a pseudoinclination of $-70^{\circ}$, as done in Model B previously (Figure 6).

The shapes of the 0 and \pm 0.46 contours are similar in most areas, suggesting stable results. Contours show less consistency in other locales, however, emphasizing the importance of calculating both $\mathrm{z}_{1}$ and $\mathrm{z}_{2}$, and then averaging. In contrast to our results for Model $\mathrm{B}$, the tilt derivative of these real data shows less distortion in locales without relevant magnetic sources, as well as near the limits of the area, probably reducing the presence of large errors.

The depth map (Figure 7) shows increasing depth northwestward toward the flank of the basin, possibly indicating larger volumes of volcanic rocks in the Cretaceous sedimentary units in the SE portion of the study area. Magnetic lineaments striking $\mathrm{N} 30^{\circ} \mathrm{E}$ and $\mathrm{N} 60^{\circ}-70^{\circ} \mathrm{E}$ are evident across the entire area and show depth variations along their length. Semi-circular contacts may represent magnetic intrusive bodies. Our depth solutions indicate a magnetic basement around 2$3 \mathrm{~km}$ deep in this locale (Figure 7), below the metasedimentary basement recorded in the 2AG1MT well $(1.9 \mathrm{~km})$, suggesting that the basement is not a significant magnetic contrast with overlying sedimentary rocks. 
In the southeast region of the study area, the 2JA1GO well bottomed at a depth of $2.1 \mathrm{~km}$ without reaching basement. Here we found a large range of depth values, all shallower than 3 $\mathrm{km}$ and probably related to intra-sedimentary volcanic sills emplaced in the Cretaceous (Figure 7). On the other hand, the depth values vary from 5 to $15 \mathrm{~km}$ in the north part of the area, indicating a thickening of the sedimentary section and/or of its metasedimentary basement, as discussed by Curto et al (2014).

Our results are generally consistent with other geophysical interpretations of this area, which used other depth estimation techniques (Curto et al., 2014). The depth map from the present study (Figure 7) includes information about the level of reliability. Unreliable depths, indicated by red dashed circles, are related to elongated distortions caused by reduction to the pole, as noticed in the tilt derivative calculated from Model B (Figure 6).

For the same area, we compared depth estimates calculated by our methodology (Figure 7) and by the standard 3D Euler deconvolution (Figure 8). Since the tilt-depth technique assumes a vertical contact, we calculated Euler solutions assuming a structural index of zero (Reid et al, 1990). As expected, most of the Euler solutions calculated from the reduced-to-pole magnetic field are positioned along the zero contour line of the tilt derivative. The choice of window size was a trade-off between reducing interference of close anomalies arising from different sources, which needs smaller windows sizes, and including broad anomalies arising from deep sources, provided by larger window sizes. We used $5 \times 5$ windows and a grid interval of $1.5 \mathrm{~km}$. The expected depth estimates are about 1.5 to $14 \mathrm{~km}$. Following the procedure used for depth values interpolation described in the previous section, Figure 8 shows Euler depth estimates. In comparison with the results achieved using the tilt depth technique (Figure 7), the Euler deconvolution shows three main differences: 1) shallower depth estimates in general (about 93\% are $<3 \mathrm{~km}$ ); 2) depth solution gaps, where the numbers of solutions are insufficient to allow interpolation with the same resolution as presented with tilt-depth; 3) overlapping solutions with different values, leading to some ambiguity during interpretation. Given these differences in depth ranges, the two methods are directly proportional to each other, and, in principle, the methods can be used to complement each other. For example, in depth analysis of sedimentary basins, the tilt derivative is superior at delineating the basin-basement contact and deeper sources, whereas Euler deconvolution with structural index 0 enhances shallower features within the sedimentary section. 


\section{Conclusions}

This paper demonstrates a practical methodology to estimate the depths of magnetic sources by way of spatial and statistical analysis of the tilt derivative. Solutions are robust, even in areas with low magnetic inclination and remanent magnetization. Tests with synthetic data show the reliability of the method and indicate situations where inaccurate results may occur, such as overlapped magnetic sources and distortions caused by reduction to the pole at low geomagnetic inclinations. The knowledge of systematic errors is necessary for a careful interpretation of the results. Interpolation of depth values calculated using different tilt angles increases the chance of determining more reliable results. The main depth zones estimated in the northwest portion of the Paraná Basin correspond to data from wells and previous studies. In contrast with depth solutions calculated using Euler deconvolution, the tilt analysis provides depth estimates distributed continuously along the contact of magnetic sources, involving a larger range of depth values. Differently from the Euler deconvolution, which works with window sizes, the tilt angle works with the entire magnetic spectrum, leveling shallow and deeper magnetic anomalies to the same amplitude. The procedure described in this paper is suitable for any geophysical data processing and geographic information system programs.

\section{Acknowledgments}

We are grateful for the sponsorship of FUB/Petrobrás under cooperation term 0050.0053151.09.9; and to CNPq - Conselho Nacional de Desenvolvimento Científico e Tecnológico for the grants to JBC and RAF. We also thank ANP - Agência Nacional do Petróleo, Gás Natural e Biocombustíveis, CPRM - Serviço Geológico do Brasil, CNEN Comissão Nacional de Energia Nuclear, and SGM / SIC-GO (Secretaria de Indústria e Comércio do Estado de Goiás) for providing access to geophysical data for academic purposes; GEOSOFT for providing the software Oasis Montaj 8.1; ESRI for providing the tool package ArcGis 10 under the contract $\mathrm{n}^{\circ} 2011$ MLK 8733; IMAGEM for making possible the agreement between IG-UnB and ESRI; the Laboratory of Remote Sensing and the Laboratory of Applied Geophysics of the IG-UnB (Instituto de Geociências da Universidade de Brasília) for the use of their facilities. We are particularly grateful to Gerry Connard for his constructive review of this paper.

\section{References}

Baranov, V., Naudy, H., 1964. Numerical calculation of the formula of reduction to the magnetic pole. Geophysics 29, 67-79, doi: 10.1190/1.1439334. 
Barbosa, V. C. F., Silva, J. B. C., Medeiros, W. E., 1999, Stability analysis and improvement of structural index estimation in Euler deconvolution. Geophysics 64 (1), 48-60, doi: 10.1190/1.1444529.

Blakely, R. J., 1996. Potential Theory in Gravity and Magnetic Applications, 2nd ed. Cambridge University Press, Cambridge, UK, 441pp.

Blakely, R. J., Simpson, R. W., 1986. Approximating edges of source bodies from magnetic or gravity anomalies. Geophysics 51, 1494-1498.

Bongiolo, A. de B. e S., Souza, J. De., Ferreira, F. J. F., Castro, L. G. de., 2013. Grav_Mag_Prism: A Matlab/Octave program to generate gravity and magnetic anomalies due to rectangular prismatic bodies. Revista Brasileira de Geofísica 31 (3), 347-363.

Curto, J. B., Vidotti, R. M., Fuck, R. A., Blakely, R. J., Alvarenga, C. J. S., Dantas, E. L., 2014. The tectonic evolution of the Transbrasiliano Lineament in northern Paraná Basin, Brazil, as inferred from aeromagnetic data. Journal of Geophysical Research: Solid Earth 119 (3), 15441562, doi:10.1002/2013JB010593.

Fairhead, J. D., Bennet, K. J., Gordon, D. R. H., and Huang, D., 1994. Euler: Beyond the "Black Box". In: 64th Annual International Meeting, Society Exploration Geophysicists, Expanded Abstracts, 422-424.

Fedi, N, Florio, G., 2001. Detection of potential field sources boundaries by enhanced horizontal derivative method. Geophysical Prospecting 49, 40-58, doi: 10.1046/j.1365-2478.2001.00235.x

Ferreira, F. J. F., Souza, J. De., Bongiolo, A. de. B. e S, Castro, L. G. de., 2013.Enhancement of the total horizontal gradient of magnetic anomalies using tilt angle. Geophysics 78 (3), J33-J41.

Grant, F.S., Dodds, J., 1972. MAGMAP FFT Processing System Development Notes, Paterson Grant and Watson Ltd, Toronto, Canada.

MacLeod, I. N., Jones, K., Dai, T.F., 1993. 3-D Analytic signal in the interpretation of total magnetic field data at low magnetic latitudes. Exploration Geophysics 24, 679-688.

Milani, E.J., Ramos, V. A.,1998. Orogenias paleozóicas no domínio sul-ocidental do Gondwana e os ciclos de subsidência da Bacia do Paraná, Revista Brasileira de Geociências 28 (4), 527-544.

Miller, H. G., Singh, V., 1994. Potential field tilt- a new concept for location of potential field sources. Journal of Applied Geophysics 32, 213-217, doi: 10.1016/09269851(94)90022-1 
Nabighian, M. N., 1972. The analytic signal of two-dimensional magnetic bodies with polygonal cross-section; Its properties and use for automated anomaly interpretation. Geophysics 37 (3), 507-517, doi: 10.1190/1.1440276.

Nabighian, M. N., 1984. Toward a three-dimensional automatic interpretation of potential field data via generalized Hilbert transforms; fundamental relations. Geophysics 49 (6), 780-786, doi: $10.1190 / 1.1441706$.

Phillips, J. D., 2000. Locating magnetic contacts: A comparison of the hor- izontal gradient, analytic signal, and local wavenumber methods. In: 70th Annual International Meeting, SEG, Expanded Abstracts, 402-405.

Reid, A.B., Allsop, J.M., Granser, H., Millett, A.J., Somerton, I.W., 1990. Magnetic interpretation in three dimensions using Euler deconvolution. Geophysics 55 (1), 80-91, doi: $10.1190 / 1.1442774$.

Roest, W. R., Verhoef, J., Pilkington, M., 1992. Magnetic interpretation using the 3D analytic signal. Geophysics 57 (1), 116-125, doi: 10.1190/1.1443174.

Salem, A., Williams, S., Fairhead, J. D., Ravat, D., Smith, R., 2007. Tilt- Depth method: A simple depth estimation method using first-order magnetic derivatives. Leading Edge 26, 15021505, doi:10.1190/ 1.2821934

Salem, A., Williams, S., Samson, E., Fairhead, D., Ravat, D., Blakely, R.J., 2010. Sedimentary basins reconnaissance using the magnetic tilt-depth method. Exploration Geophysics 41, 198209, doi: 10.1071/EG10007

Schobbenhaus, C., Gonçalves, J. H., Santos, J. O. S., Abram, M. B., Neto, R. L., Matos, G. M. M., Vidotti, R. M., Ramos, M. A. B., Jesus, J. D. A., 2004. Carta Geológica do Brasil ao Milionésimo, Sistema de Informações Geográficas - SIG, 46 CD-ROOM, scale 1:1,000,000, CPRM, Brasília, DF, Brazil.

Terzopoulos, D., 1988. The computation of visible-surface representations. IEEE Transactions on Pattern Analysis and Machine Intelligence 10 (4), 417-438.

Thompson, D.T., 1982. EULDPH: a new technique for making computer-assisted depth estimates from magnetic data. Geophysics 47 (1), 31-37, doi: 10.1190/1.1441278

Thurston, J. B., Smith, R. S., 1997. Automatic conversion of magnetic data to depth, dip, and susceptibility contrast using the SPITM method. Geophysics 62, 807-813, doi: 10.1190/1.1444190 
Verduzco, B., Fairhead, J. D., Green, C. M., MacKenzie, C., 2004. New insights into magnetic derivatives for structural mapping. The Leading Edge, 23, 116-119.

Zalán, P. V., S. Wolff, M. A. M. Astolfi, I. S. Vieira, J. C. J. Conceição, V. T. Appi, E. V. Santos Neto, J. R. Cerqueira, A. Marques (1991), The Paraná Basin, Brazil, in Interior cratonic basins, edited by M. W. Leighton et al., Memoir 51, pp. 681-708, AAPG, Tulsa, Oklahoma.

Zoraster, S.,2003. A surface modeling algorithm designed for speed and ease of use with all petroleum industry data. Computers \& Geosciences 29 (9), 175-182. 


\section{Appendix}

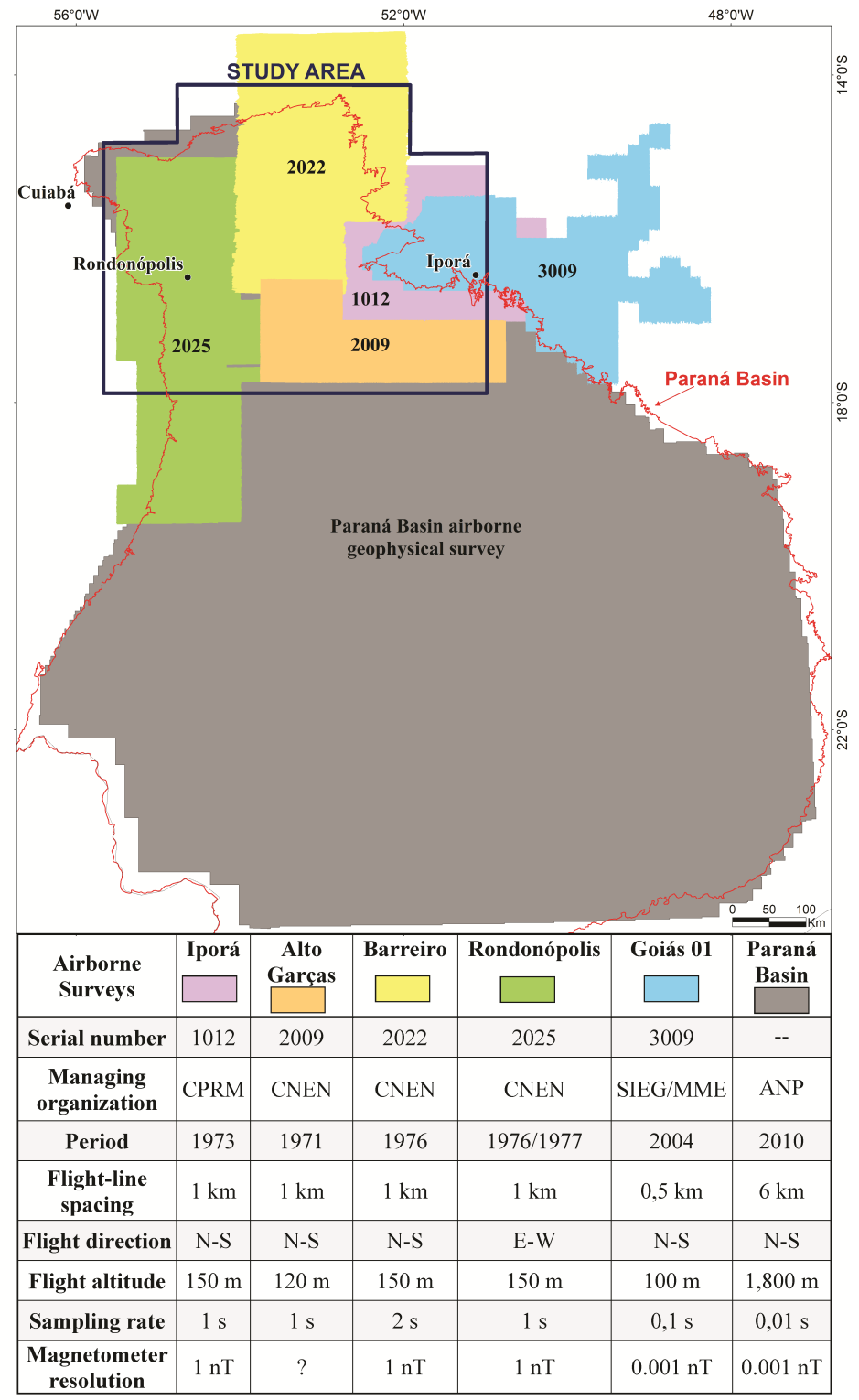

Figure A1 - Airborne geophysical surveys compiled for this study (Curto et al., 2014). State companies that managed the surveys are shown as CPRM: Serviço Geológico do Brasil; CNEN: Comissão Nacional de Energia Nuclear; SIEG/MME: Secretaria de Indústria e Comércio de Goiás/Ministério de Minas e Energia; ANP: Agência Nacional do Petróleo, Gás Natural e Biocombustíveis. Blue polygon indicates limits of study area. 
FIGURE 1

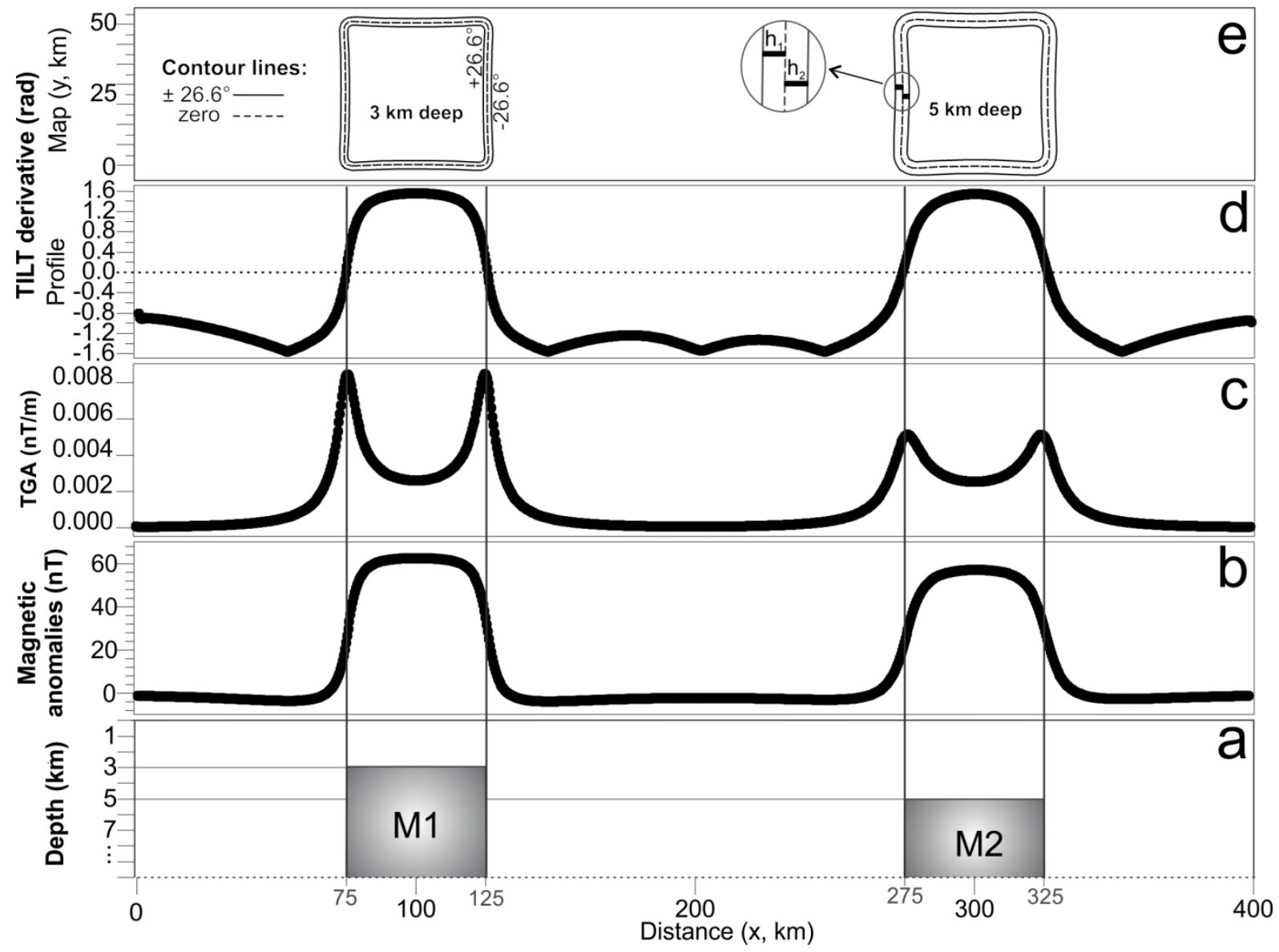

Figure 1 - (a) Synthetic Model A, consisting of two magnetic prisms, M1 and M2, with same dimensions, infinite depth extent, and tops at depths of 3 and $5 \mathrm{~km}$, respectively. Anomalies calculated with the method of Bongiolo et al. (2013). (b) Profile calculated from Model A assuming geomagnetic inclination 90 degrees. (c) Total gradient amplitude of profile b. (d) Tilt derivative of profile $b$ in radians. (e) Contour maps of the tilt derivative for Model A. Solid contours are the zero value of the tilt angle, which is correspondent to the limit of the bodies. Dashed lines are equivalent to $26.54^{\circ}$ or $0.46 \mathrm{rad}$, where $h_{1}$ and $h_{2}$ is the horizontal distance between 0 and $+0.46 \mathrm{rad}$ and $-0.46 \mathrm{rad}$, respectively. 
FIGURE 2

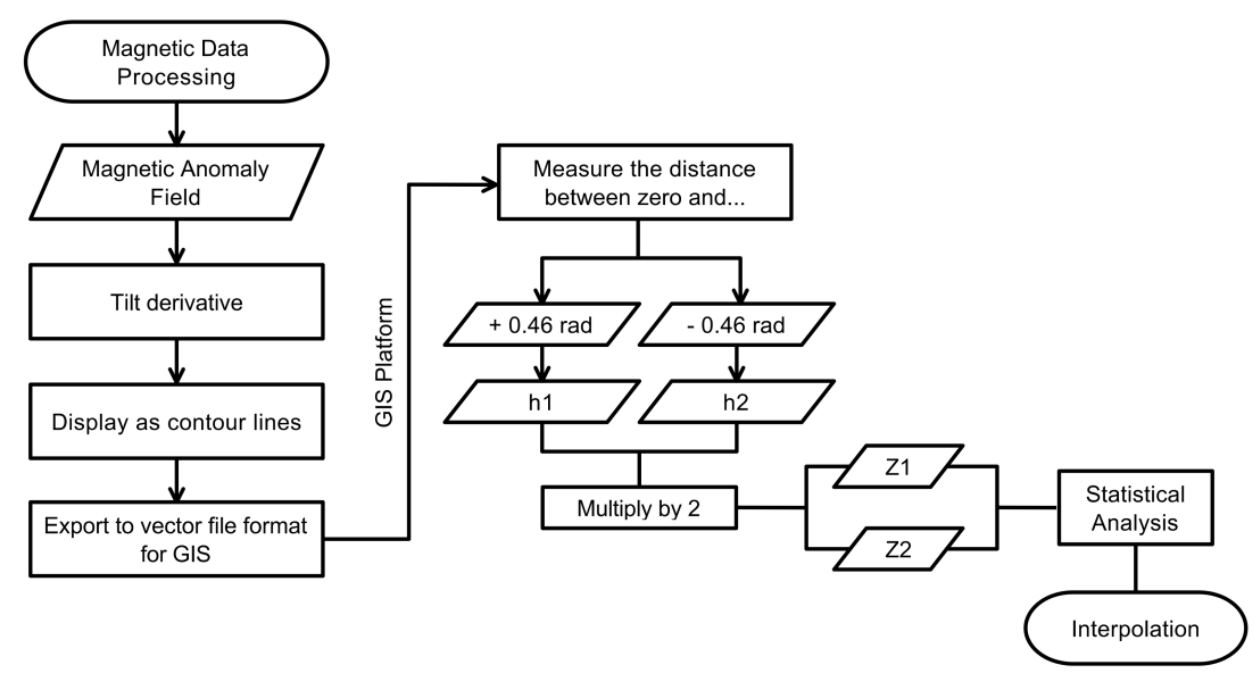

Figure 2 - The main steps and parameters used to produce our depth map of magnetic anomalies. 
FIGURE 3
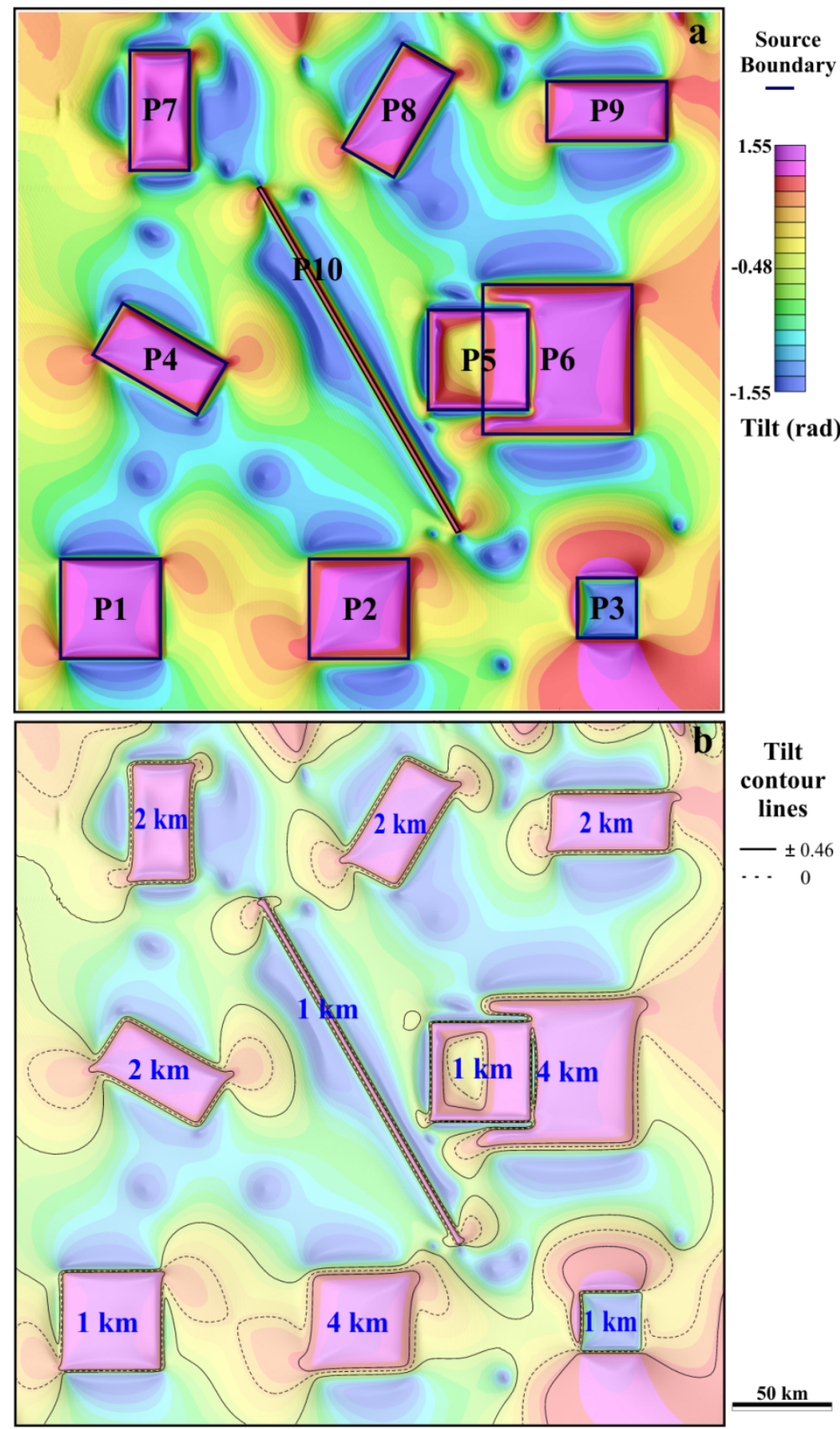

Figure 3 - (a) Synthetic Model B, consisting of tilt derivative map of 10 reduced-to-pole magnetic anomalies (P1 to P10). Anomalies calculated with the method of Bongiolo et al. (2013), assuming geomagnetic inclination $-20^{\circ}$. Solid blue lines are real magnetic sources limits. (b) Same as Model B. Dashed contour lines are the zero value of the tilt derivative, which is correspondent to the limit of the bodies. Solid lines are equivalent to $\pm 26.54^{\circ}$ or $\pm 0.46 \mathrm{rad}$. 
FIGURE 4

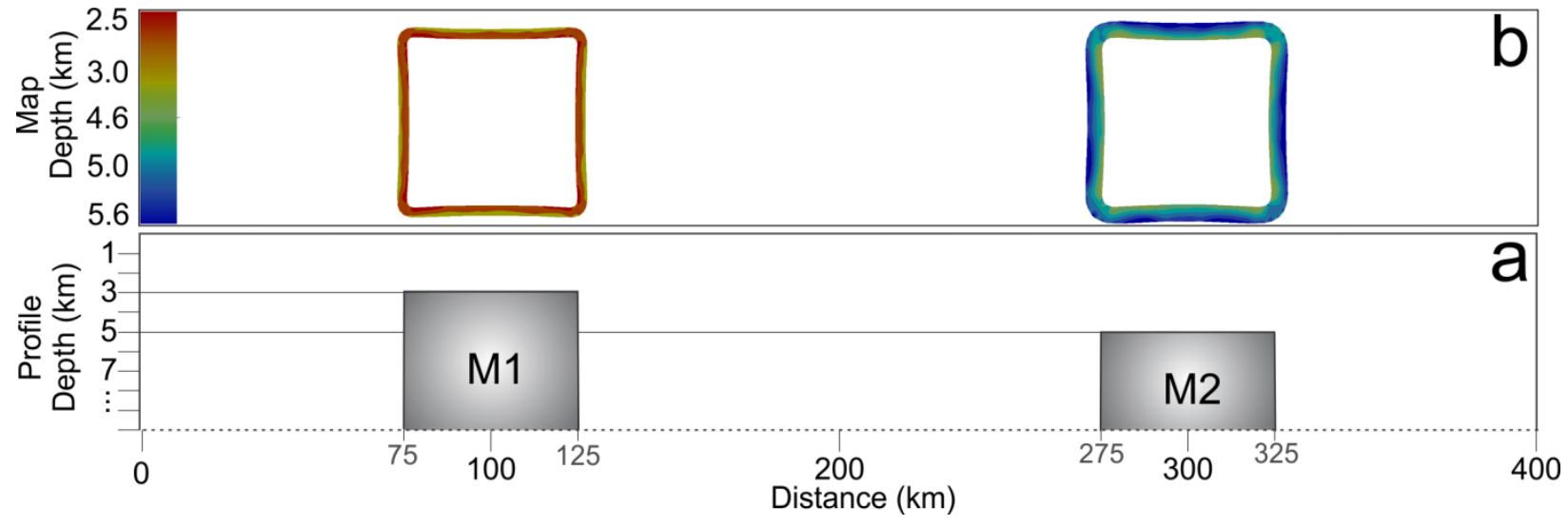

Figure 4 - (a) Profile of real depth values of Model A, same as figure 1a. (b) Depth map based on the interpolation of average values $z_{1}$ and $z_{2}$, calculated from the tilt derivative of Model A.

FIGURE 5

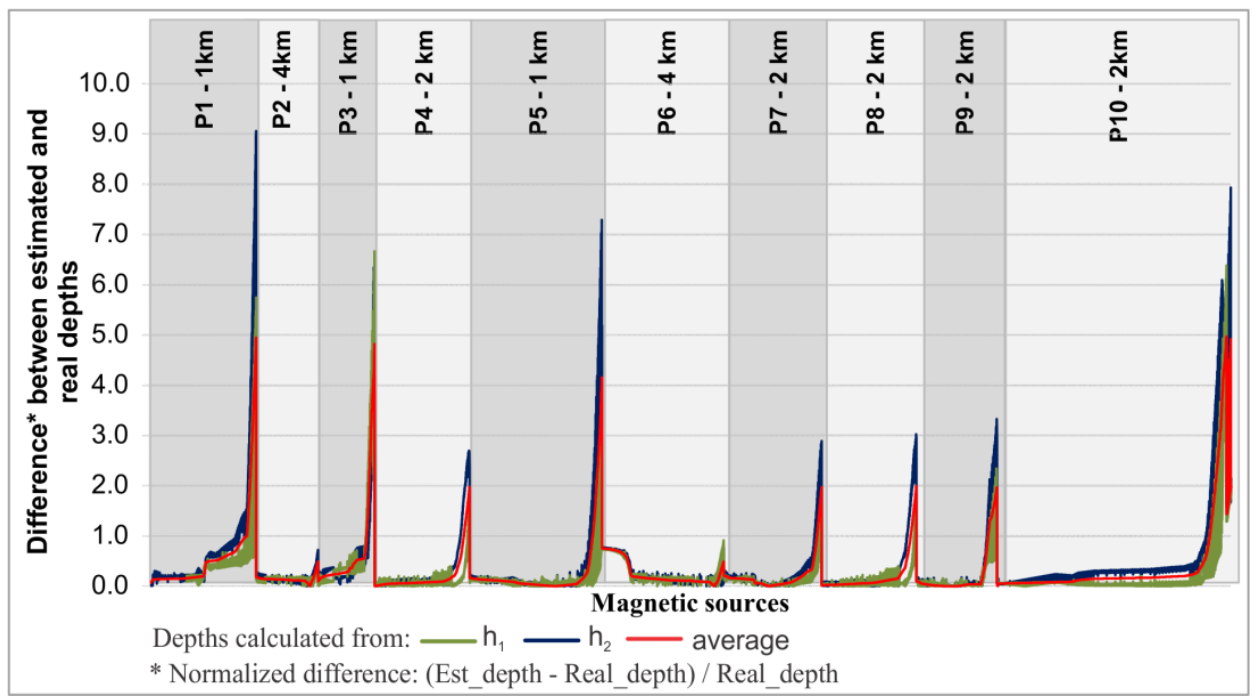

Figure 5 - Density graph showing the normalized difference between real (real_depth) and estimated (est_depth) depth values calculated from Model B (vertical axis) in relation to their respective magnetic anomalies, P1 to P10 (horizontal axis). Depth values located on the half of the distance between different magnetic sources were excluded from statistics. Three depth estimates are based on the distance between contour lines $h_{1}$ to zero $\left(z_{1}\right)$, and $h_{2}$ to zero $\left(z_{2}\right)$; and the average $z_{1}$ e $z_{2}$. See figure 3 for location. 
FIGURE 6

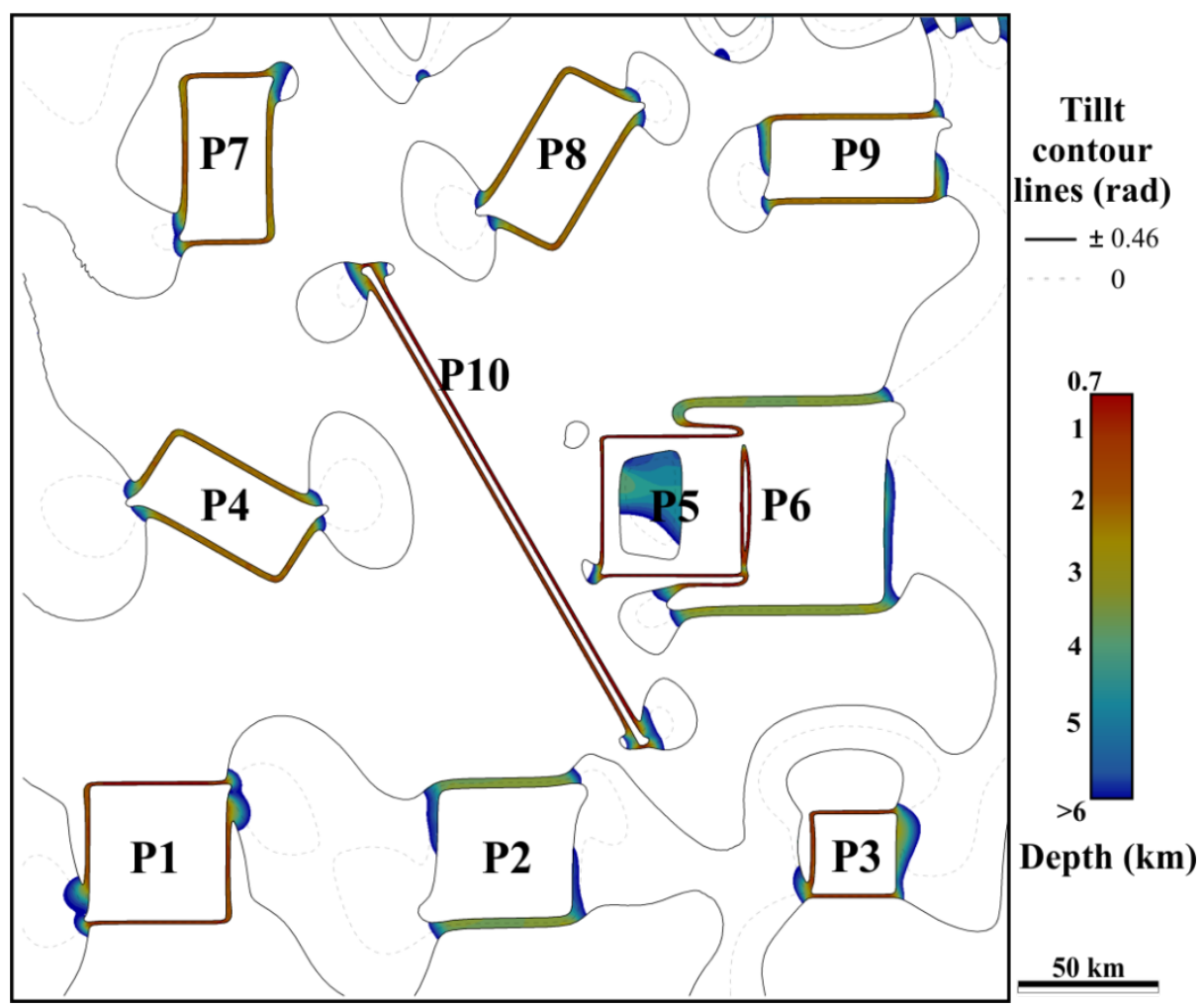

Figure 6 - Depth map based on the interpolation of average values $z_{1}$ e $z_{2}$, calculated from the tilt derivative of Model B, described in table 1 and figure 3. 
FIGURE 7

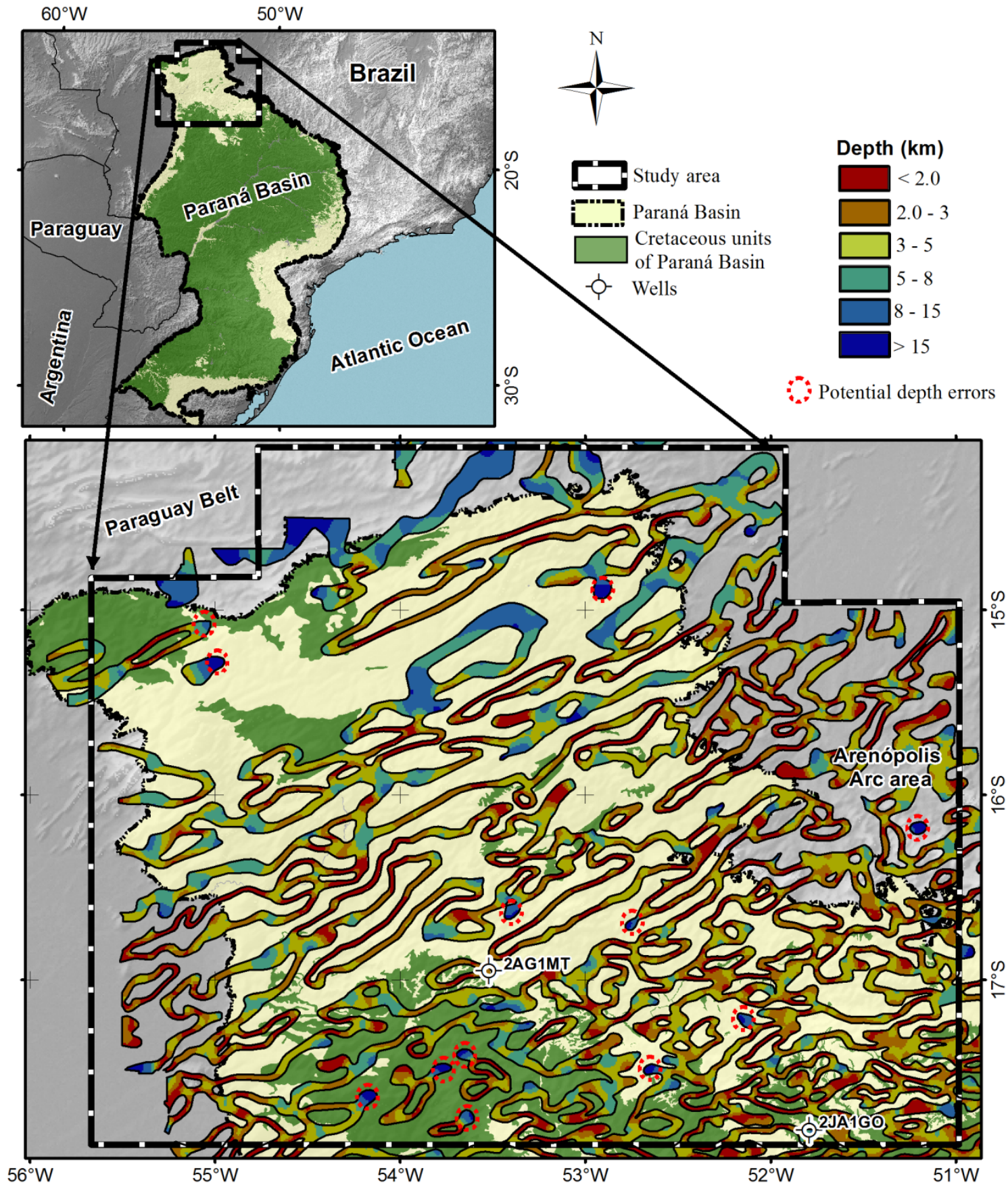

Figure 7 - (a) Study area, in northwest Paraná Basin. (b) Estimated depth values of magnetic anomalies observed from the Bacia do Paraná airborne survey, using tilt-depth technique (Salem et al., 2007), distance analysis tool and spline interpolation. Mapped Cretaceous units of Paraná Basin are represented in green (Schobbenhaus et al., 2004), including volcanic sills. 


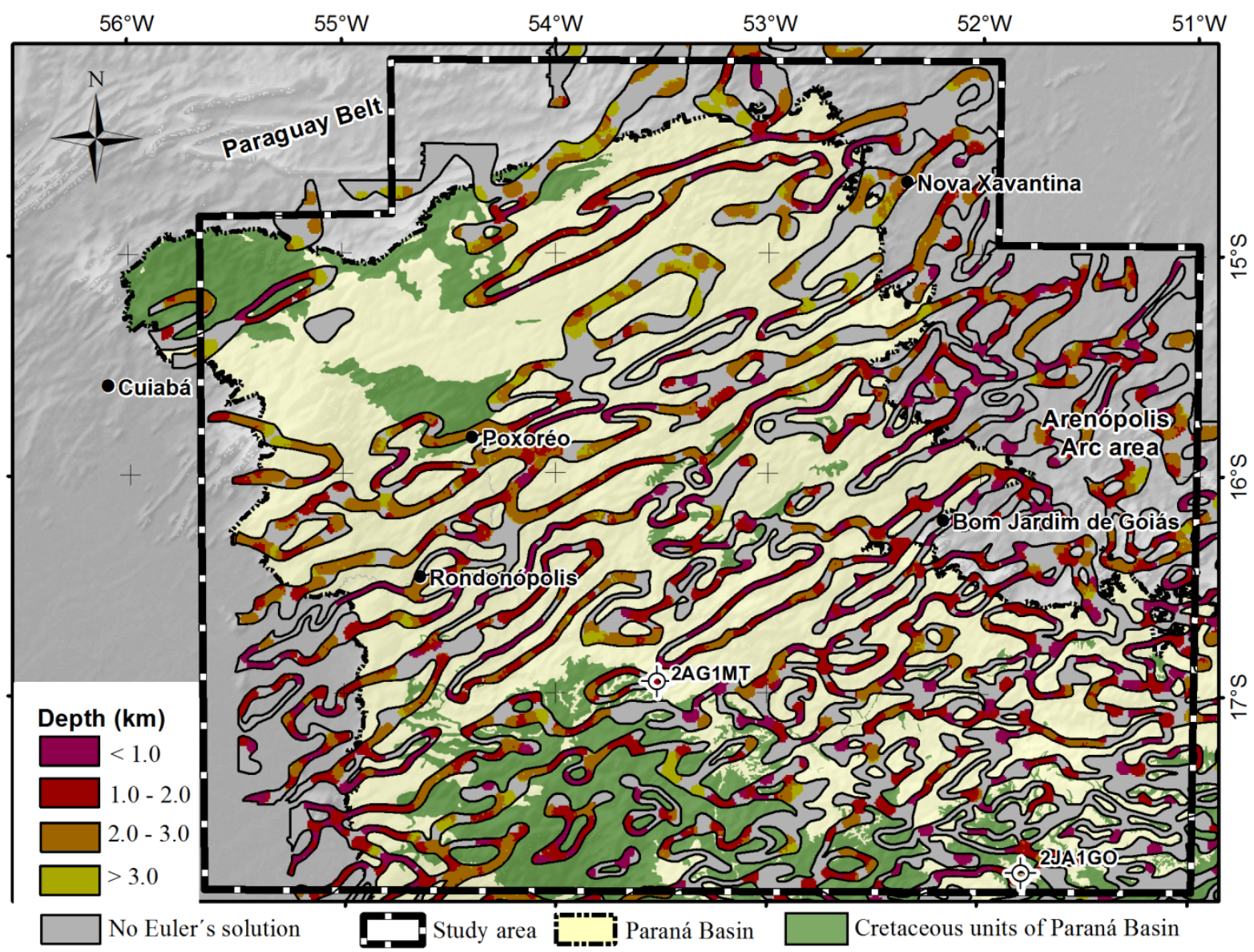

Figure 8 - Depth estimates using Euler Deconvolution and structural index zero. Black contour lines are relative to $\pm 0.46(\mathrm{rad})$ values of the tilt derivative, which constrained the Euler solutions interpolation. Solid gray color represents "no Euler solutions" along the tilt limits. Cretaceous units of Paraná basin are displayed in green. These units include volcanic sills. 


\section{Journal of Geophysical Research: Solid Earth}

\section{RESEARCH ARTICLE \\ 10.1002/2013JB010593 \\ Key Points: \\ - Transbrasiliano fault zone separates \\ The tectonic evolution of the Transbrasiliano \\ Lineament in northern Paraná Basin, Brazil, as inferred from aeromagnetic data} four tectonic domains in the Parana Basin

- Magnetic sources are characterized within the basin, basement and lower crust

- Structural reactivations controlled by the Transbrasiliano lineament

Correspondence to:

J. B. Curto,

julia.curto@gmail.com

\section{Citation:}

Curto, J. B., R. M. Vidotti, R. A. Fuck, R. J. Blakely, C. J. S. Alvarenga, and E. L. Dantas (2014), The tectonic evolution of the Transbrasiliano Lineament in northern Paraná Basin, Brazil, as inferred from aeromagnetic data, J. Geophys. Res. Solid Earth, 119, doi:10.1002/2013JB010593.

Received 12 AUG 2013

Accepted 1 FEB 2014

Accepted article online 7 FEB 2014

\author{
Julia B. Curto ${ }^{1}$, Roberta M. Vidotti ${ }^{1}$, Reinhardt A. Fuck ${ }^{1}$, Richard J. Blakely ${ }^{2}$, \\ Carlos J. S. Alvarenga ${ }^{1}$, and Elton L. Dantas ${ }^{1}$ \\ ${ }^{1}$ Instituto de Geociências, Universidade de Brasília, Brasília, Brazil, ${ }^{2}$ U.S. Geological Survey, Menlo Park, California, USA
}

Abstract Data from six airborne magnetic surveys were compiled and analyzed to develop a structural interpretation for the Transbrasiliano Lineament in northern Paraná Basin, Brazil. Magnetic lineaments, interpreted to reflect geologic contacts and structures at different depths, were illuminated using the matched-filter technique applied to aeromagnetic anomalies. Field-based structural measurements generally support our magnetic analysis. We estimated three primary magnetic zones: (i) a zone of deep magnetic sources at $20 \mathrm{~km}$ depth, (ii) an intermediate basement zone at $6 \mathrm{~km}$ depth, and (iii) a shallow zone of near-surface geological features at $1.5 \mathrm{~km}$ depth. The deepest zone exhibits three major NE trending crustal discontinuities related to the Transbrasiliano Lineament, dividing the region into four geotectonic blocks. Anomalies associated with the intermediate zone indicate directional divergence of subsidiary structures away from the main Transbrasiliano Fault, which strikes $\mathrm{N} 30^{\circ} \mathrm{E}$. The shallow magnetic zone includes near-surface post-Brasiliano orogenic granites. Our analysis identified NE trending sigmoidal lineaments around these intrusions, indicating intense zones of deformation associated with probable shear structures. At the shallow depth zone, magnetic anomalies caused by Cretaceous alkaline intrusive bodies and basalts of the Serra Geral Formation are enhanced by the matched-filter method. These igneous bodies are related to extensional NW striking lineaments and seismicity aligned along these lineaments suggests that they currently are reactivated. Prior to flexural subsidence of the Paraná Basin, reactivation processes along transcurrent elements of the Transbrasiliano Lineament promoted extensional processes and formed initial Paraná Basin depocenters. Cretaceous and more recent sedimentation also correlate with reactivations of NE striking structures.

\section{Introduction}

The South American platform hosts one of the largest transcurrent fault systems in the world, the Transbrasiliano Lineament (Figure 1, TBL in the inset). The TBL, first discussed by Schobbenhaus et al. [1975], is a NE trending, strike-slip fault system extending from Sierras Pampeanas, Argentina, to the Atlantic Ocean, and crossing the northern flank of Paraná Basin in Brazil. This major fault system is manifested by a distinctive, continent-scale magnetic discontinuity [Fairhead and Maus, 2003; Ramos et al., 2010].

Many zones of crustal weakness developed in the South American platform during Precambrian time and provided important controls on the origin and evolution of intracratonic basins [Brito Neves et al., 1984; Cordani and Sato, 1999; de Almeida et al., 2000]. The TBL evolved during this time and has gone through at least three episodes of reactivation [Marini et al., 1984; Brito Neves et al., 1999]. TBL surface exposures are evident in central Brazil, where Precambrian basement crops out [Dantas et al., 2007], but are lacking exposures within Paleozoic basins except where the TBL has been reactivated.

The Paraná Basin (Figure 1) is one of the five largest Paleozoic basins in South America. Its tectonic and structural framework is known largely from geophysical interpretations employing potential field and seismological methods [Molina and Ussami, 1989; Vidotti et al., 1998; Assumpção et al., 2002; Mantovani et al., 2004]. The initial depocenters of the Paraná Basin were developed within NE trending structures [Zalán et al., 1991; França et al., 1995; Heilbron et al., 2000], some associated with the TBL. Geological mapping of the Paraná Basin shows NE trending alignments, suggesting that sedimentation was controlled by the TBL [França et al., 1995; Milani, 1997]. NE and NW striking basement structures were widely reactivated in the Paraná Basin, causing block-bounded uplifts and subsidence [Zalán et al., 1991]. 


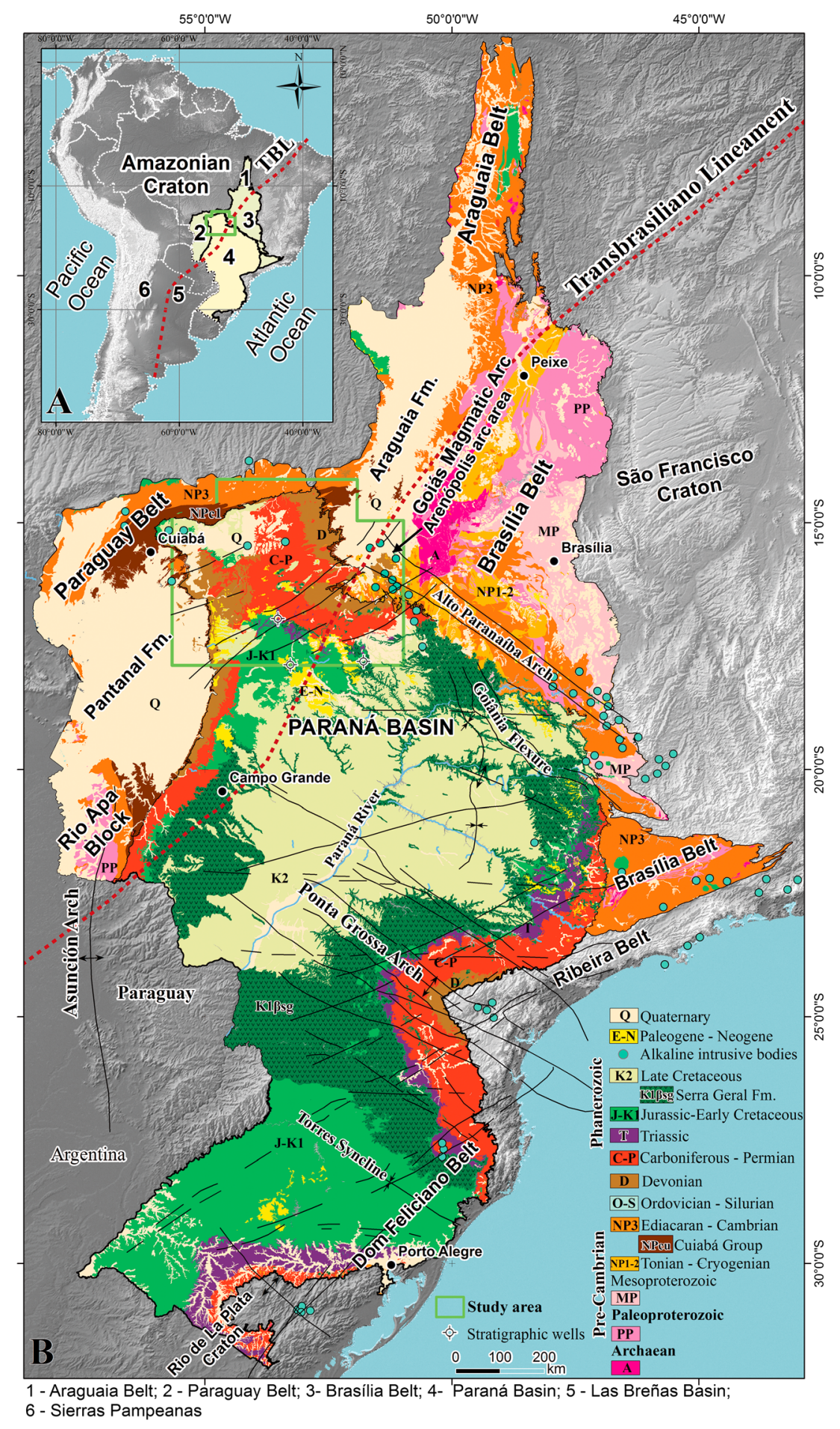

Figure 1. (a) Study area green polygon in South America. (b) The geological context of the Paraná Basin generalized from CPRM (Serviço Geológico do Brasil) 1:1,000,000 scale mapping [Schobbenhaus et al., 2004] and classified according to geological periods. Displayed intervals were chosen based mainly on Paraná Basin major depositional periods [Zalán et al., 1991; Milani, 1997].

Despite its tectonic importance, only a few high-resolution magnetic anomaly studies have been applied to detailed mapping of the TBL [Chiarini, 2007; Ferreira, 2009]. In this paper, we describe analysis of airborne magnetic data and field observations to illuminate the tectonic framework of the TBL and the tectonic evolution of Paraná Basin, from initiation of subsidence to later reactivation. We aim to contribute to a better 


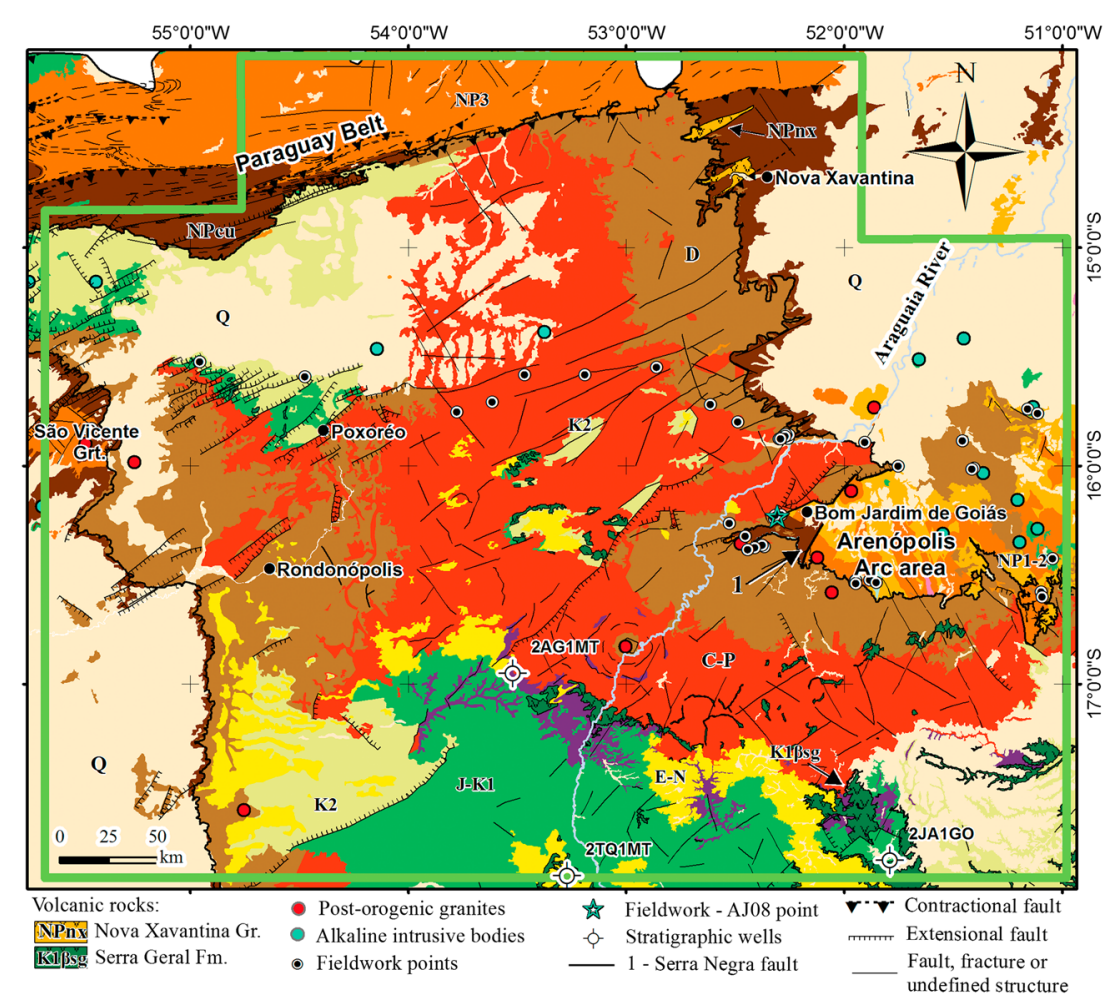

Figure 2. Geological context of the study area with geological and structural data not included in Figure 1, due to scale [Schobbenhaus et al., 2004]. Also shown are the fieldwork locations where data were collected. Lithology's acronyms are described in Figure 1.

understanding of different structural and tectonic regimes within the crust of northern Paraná Basin. In addition, we correlate phases of reactivation with major tectonic events occurring in the South America platform.

\section{Geological Setting}

Our study area is located in the northern Paraná Basin and includes parts of the Brasilia and Paraguay Neoproterozoic mobile belts (Figures 1 and 2). The following discussion reviews the geologic setting.

\subsection{The Transbrasiliano Lineament}

On the South America platform, the TBL marks the contact between the Amazonian Craton to the northwest against a region of cratonic fragments, magmatic arcs, allochthonous blocks, and Neoproterozoic mobile belts to the southeast [de Almeida et al., 1981; Cordani et al., 1984; Brito Neves and Cordani, 1991; Brito Neves et al., 1999; Feng et al., 2004; Fuck et al., 2008; de Alvarenga et al., 2009; Tohver et al., 2010]. Northeastward, the TBL ends within the continental platform in South Atlantic offshore in Brazil. The main north striking section of the TBL is on strike with the Hoggar 450'-Kandi shear zone [Caby, 1989; Cordani et al., 2003, 2013a, 2013b; Arthaud et al., 2008], which extends from central Algeria to the Togo coast. The TBL in South America and the Hoggar-Kandi zone in Africa were linked and continuous during the time of the Gondwana Supercontinent [dos Santos et al., 2008].

The TBL continues from the northeastern Brazilian coast and across the northern margin of the Paraná Basin, where it is entirely concealed by sediments [Milani and Ramos, 1998; Feng et al., 2004; Rapela et al., 2007; Ramos et al., 2010]. Using $S$ wave velocity modeling, Feng et al. [2004] recognized the southwest extension of the TBL and noted an additional westward structural trend near the Paraguay mobile belt. Ramos et al. [2010] correlated the south part of the TBL fault system with the crustal discontinuity on the eastern edge of the Sierras Pampeanas, Argentina (Figure 1).

The TBL corresponds to the last tectonic episode associated with the Brasiliano-Pan African Orogeny in Neoproterozoic time [Marini et al., 1984; Cordani et al., 2010, 2013a, 2013b] and shows structural evidence of predominantly dextral transcurrent kinematics [Pimentel and Fuck, 1992; Arthaud, 2007; Dantas et al., 2007]. 
In the southern extension of the Goiás Magmatic Arc, known as the Arenópolis Arc area (Figures 1 and 2), small elongated granite intrusions show pronounced subvertical mylonitic foliation, which cuts across previous ductile deformational structures [Pimentel and Fuck, 1987; Laux et al., 2005]. The brittle nature of this system is represented by the NE striking Serra Negra fault (Figure 2), separating the Cuiabá Group (Paraguay Belt) from a metavolcanic-sedimentary sequence of the Arenópolis Arc [Seer, 1985; Pimentel and Fuck, 1992]. Bordering the east side of this fault, granites are exposed as NE elongated narrow bands, affected by the fault that imprinted mylonitic rocks [Rodrigues et al., 1999; Pimentel et al., 2000] and displaced over $8 \mathrm{~km}$ along the fault [Seer, 1985]. Four deformational stages are recognized in the Cuiabá Group within the Bom Jardim de Goiás region, the earliest three with $\mathrm{N} 20^{\circ}-30^{\circ} \mathrm{E}$ coaxial deformational strike, and the fourth orthogonal to the others [Seer, 1985; Seer and Nilson, 1985; Alvarenga and Trompette, 1993].

The TBL has gone through at least three episodes of reactivation in Phanerozoic time. Small pull-apart basins, such as the Jaibaras trough in Ceará [de Oliveira, 2001] and Água Bonita in Tocantins [Carvalho et al., 2012], resulted from reactivation episodes in Cambrian-Ordovician and Silurian-Devonian time. A third episode accompanied the Cretaceous opening of the Atlantic and was marked by a series of normal faults, sometimes cutting Paleozoic sequences and causing $>500 \mathrm{~m}$ of displacement in the northern flank of the Paraná Basin [Alvarenga et al., 1998].

\subsection{The Paraná Basin}

The Paraná Basin has an elliptical shape; straddles parts of Brazil, Argentina, Paraguay, and Uruguay; and covers an area of more than $1,000,000 \mathrm{~km}^{2}$ in Brazilian territory alone. It is bounded by two important arcs, the NW trending Alto Paranaíba Arch along the northern border and the $\mathrm{N}$ trending Asunción Arch along the western border (Figure 1). The central part of Paraná Basin reaches depths of $7000 \mathrm{~m}$, whereas the northern flank of the basin is much shallower [Milani et al., 2007]. The 2AG1MT stratigraphic well (Petrobrás), located west of the TBL (Figure 2), reached Neoproterozoic basement at $1943 \mathrm{~m}$ depth. Paraná Basin began to form in Ordovician time but was interrupted in the Cretaceous with onset of the Serra Geral tholeitic magmatism, one of the largest continental flood basalts on Earth [Zalán et al., 1991; Frank et al., 2009]. These igneous rocks cover two thirds of the basin area (Figure 1) and reach thicknesses up to $2000 \mathrm{~m}$ aligned with the NE trending depocenter [Milani and Thomaz Filho, 2000].

The continental crust is 40 to $46 \mathrm{~km}$ thick beneath the Paraná Basin, as estimated from teleseismic receiver function analysis [Assumpção et al., 2002] and gravity modeling [Vidotti et al., 1998]. The crust thins to approximately 30 to $35 \mathrm{~km}$ beneath the northern flank of the basin [Assumpção et al., 2004, 2013]. The TBL separates the Paraguay Belt to the northwest from other basement domains to the southeast, all concealed beneath the Paraná Basin [Cordani et al., 1984]. Using gravity and isostatic arguments, Molina et al. [1988] proposed that crustal growth resulted from mantle-derived crustal underplating beneath the basin and east of the TBL. This thickened crust comprises a single tectonic unit named the Paraná Block [Cordani et al., 1984] or Paranapanema Craton [Mantovani et al., 2004]. It is considered to be stable, relatively undeformed, bounded by high gravity gradients that coincide with collisional structures characterizing Neoproterozoic subduction [Mantovani and Brito Neves, 2005; Ramos et al., 2010].

The basement underlying the Paraná Basin was in place by the end of the Brasiliano Orogeny $(\sim 550 \mathrm{Ma})$, forming a mosaic of terranes juxtaposed along numerous mobile belts [de Almeida and Hasui, 1984] consisting predominantly of Pre-Devonian granite-gneiss units and metamorphosed supracrustal units [de Almeida et al., 1981; Cordani et al., 1984]. Neoproterozoic mobile belts, including the Paraguay Belt (to the west), Brasilia Belt (to the north), Ribeira Belt (to the east), and Dom Feliciano (to the south) border the basin and form part of its basement. Along its northern and western margins, the Paraná Basin is bounded by the Arenópolis Magmatic Arc (Brasilia Belt) and the Cuiabá Group (Paraguay Belt), revealing a part of the basement composition in this part of the basin (Figure 2).

The Arenópolis Magmatic Arc consists of orthogneiss units that generally separate volcano-sedimentary belts [Pimentel and Fuck, 1992]. The Paraguay Belt consists mainly of metasedimentary rocks of the Cuiabá Group, strongly folded and metamorphosed during the Brasiliano Orogeny [Alvarenga and Trompette, 1993;

de Alvarenga et al., 2009]. Both the Paraguay Belt and the Arenópolis Magmatic Arc regions host large synorogenic to postorogenic granites (Figure 2) in relation to the final deformational phase of the Brasiliano Orogeny, circa 550 Ma [Pimentel et al., 1996, 2000; Godoy et al., 2007, 2010]. 
During most of the Phanerozoic, the SW region of West Gondwana was a convergent system consisting of several orogenic cycles [Ramos et al., 1986; Heilbron et al., 2000; Cawood, 2005; Vaughan and Pankhurst, 2008]. Orogenic stress enabled transtensional reactivation of NE trending Precambrian crustal discontinuities and the consequent development of initial NE elongated depocenters for Paraná Basin sediments [Milani, 1997, 2004]. Vidotti et al. [1998] suggested that the early depocenter was emplaced as a rift basin following the Brasiliano Orogeny and prior to Ordovician time and probably was positioned near the northern flank of the basin.

Zalán et al. [1991] recognized two major structural styles that strongly influenced Paraná Basin sediments: (i) deformation associated with igneous intrusions, and (ii) deformation associated with reactivation of brittle NW and NE trending tectonism. According to these authors, the most common associated NE trending structures are those related to strike-slip movement, such as en echelon and reverse faults, folds, and flower structures. The preferred kinematic character is transcurrent movement, as observed in the TBL. A third structural subordinate group with $\mathrm{E}$ trending lineaments was also recognized, with tectonism beginning in the Triassic and continuing into the Mesozoic, suggesting a relationship with the opening of the Atlantic Ocean.

The sedimentary rocks of the Paraná Basin were deposited between Ordovician and Late Jurassic (Figure 1), and were subsequently covered by a later magmatic event in the Early Cretaceous (Serra Geral Formation) related to the start of Gondwana paleocontinental breakup [Hawkesworth et al., 1992]. NW trending fault zones are intruded by numerous diabase dikes and are usually wider than the NE trending faults zones. The sedimentary sequence of the study area was affected by dikes and thin sills (about $100 \mathrm{~m}$ thick), which lack exposure within the northwest portion of the area. Younger basins developed in the Upper Cretaceous in response to the isostatic load of overlying magmatic rocks [Fernandes and Coimbra, 1996].

In Late Cretaceous time, two alkaline intrusive events affected the border of the Paraná Basin in 87-80 Ma and 70-60 Ma [de Almeida and Melo, 1981]. Several mafic-ultramafic alkaline plutonic and subvolcanic bodies from the Goiás Alkaline Province (GAP) [Junqueira-Brod et al., 2002] intruded the Arenópolis Arc area and the sedimentary units of northern Paraná Basin. Seven of them occur in the east part of the study area.

\section{Methodology}

Many quantitative techniques are available to interpret concealed geologic sources from observed magnetic anomalies [Blakely, 1996; Nabighian et al., 2005]. In this paper we utilize matched-filter analysis [Syberg, 1972; Phillips, 2001] to provide insights on the map-view geometry of geologic contacts at various depths. Our primary motivation was to enhance magnetic lineaments originating from various depths in order to interpret different tectonic regimes. In addition, our matched-filter analysis supported two-dimensional modeling of magnetic anomalies.

The magnetic data used in this study were compiled from six airborne surveys as described and illustrated in Appendix A.

Geological data were essential to constrain our geophysical interpretations. The geologic map shown in Figure 1 was generalized from CPRM (Serviço Geológico do Brasil) 1:1,000,000 scale mapping [Schobbenhaus et al., 2004]. Stratigraphic profiles of three wells located in the study area and managed by Petrobrás were provided by the ANP (Agência Nacional do Petroleo, Gás Natural e Biombustiveis): 2AG1MT, 2TQ1MT, and 2JAGO1 (Figure 2). In addition, we undertook two field campaigns in the study area (Figure 2) to determine the regional geological setting, acquire structural measurements, and collect rock samples for future work, including dating, petrographic, and petrophysical analysis.

Earthquake locations were obtained from the Brazilian Seismic Bulletin (2012), available at UnB (Universidade de Brasília).

\subsection{Preprocessing Stage of the Magnetic Data}

Our analysis is based primarily on total-field magnetic anomalies; i.e., the total magnetic field of the Earth corrected for diurnal variations, the main geomagnetic field (IGRF), and leveling errors. We used a variety of Fourier-domain transformations on gridded anomaly data to assist our interpretations, including reduction to the pole, upward continuation, directional derivatives, and phase transformations [Blakely, 1996]. 
Transformations were performed with Oasis Montaj 8.1 [Geosoft, 2008] and subsequently integrated and interpreted using ArcMap 10.0 GIS system [Environmental Systems Research Institute, 2010].

We first derived a single, consistent magnetic anomaly grid based on the various disparate surveys described in Appendix A. This was a two-step procedure. (1) Most of our high-resolution aeromagnetic surveys were flown $150 \mathrm{~m}$ above terrain, except for surveys 2009 and 3009, which were flown at $120 \mathrm{~m}$ and $100 \mathrm{~m}$ above terrain, respectively. We analytically upward continued all high-resolution surveys to a common height of $150 \mathrm{~m}$ above terrain and then merged them into a consistent gridded database. The merging process involved removal of regional trends from individual surveys based on misfits in the overlap regions. (2) Although the final gridded database involved meticulous processing and merging, the majority of these data were originally acquired in the 1970s (Appendix A) and thus contain several types of noise, including instrumental errors, different acquisition parameters, variations in flight height/altitude and direction, and imprecise navigation (flown prior to the availability of Global Positioning Systems). The very large Paraná Basin survey, although acquired at an even higher altitude $(1.8 \mathrm{~km})$ and along wider spaced flight lines $(6 \mathrm{~km})$, provides a more consistent regional view. Consequently, we analytically continued the merged high-resolution grid from step 1 upward to $1.8 \mathrm{~km}$ altitude and then merged it with the Paraná Basin survey to produce our final compilation. Even though the upward continuation process decreases anomaly resolution somewhat, a consistent database is a distinct advantage for regional-scale interpretations.

The shape of a magnetic anomaly depends both on the shape of the magnetic source and the vector directions of its magnetization and Earth's ambient field. Nonvertical magnetization and ambient field vectors impart a skewness to magnetic anomalies that tends to complicate interpretation. This problem is acute in Brazil, where the inclination of Earth's main field is shallow $\left(-20^{\circ}\right)$, and anomaly amplitudes are low. The skewness effect can be reduced or eliminated by reduction to the pole [Baranov and Naudy, 1964], a transformation that centers the positive part of a magnetic anomaly over its source. Reduction to the pole, when applied to anomalies with shallow inclinations and low amplitudes, introduces long-wavelength artifacts elongated in the direction of magnetic declination $\left(-17.8^{\circ}\right)$. We suppressed these artifacts with the application of an amplitude correction [Grant and Dodds, 1972; Geosoft, 2008]. This correction introduces a second inclination $\left(\mathrm{I}^{\prime}\right)$ that is used to control the amplitude of the reduction-to-pole operator near the equator, where $I^{\prime}$ is an inclination greater than the true inclination of the magnetic field. The amplitude correction was calculated using the complementary angle of the magnetic inclination, which effectively removes the long-wavelength noise without unduly sacrificing geologic signal with similar trends. Reduction to the pole is less useful in settings where remanent magnetization or magnetization anisotropy is significant [MacLeod et al., 1993], causing negative lobes that still remain around some anomalies, and low-amplitude, high-frequency noise as well that must be considered in our interpretations. Although the reduced-to-pole magnetic anomalies were our primary tool for locating magnetic sources, the original grid was used as the basis for matched-filter analyses.

\subsection{Matched-Filter Analysis}

The power spectrum of magnetic anomalies depends on the depth to magnetic source. Specifically, for a statistical ensemble of magnetic sources at depth $Z$, the algorithm of radially averaged power spectra, calculated from magnetic anomalies and plotted as a function of wave number $k$, forms a straight line with slope $-2 k Z$ [Spector and Grant, 1970]. In principle, multiple source depths will appear in the power spectrum as multiple straight-line slopes. The matched-filter technique capitalizes on this relationship by fitting multiple straight lines to radially averaged power spectra [Phillips, 2001], thereby providing estimates of source depth for each layer. With these depth estimates, filters can be designed to emphasize anomalies originating from the various layers.

Matched-filter analysis [Syberg, 1972; Phillips, 2001] involves three steps: (1) radially averaged power spectra are computed from subsets of the magnetic anomaly grid; (2) the shapes of the spectra are modeled with equivalent source layers at best fit depths, where shallow magnetic layers are depth limited (dipole-source layers), and the deepest magnetic layer is modeled as half space; and (3) amplitude and Wiener filters are

calculated for each layer and applied to the magnetic anomalies in order to enhance anomalies originating from those important depths. Each depth layer corresponds to the maximum average depth of a statistical population of true sources. 

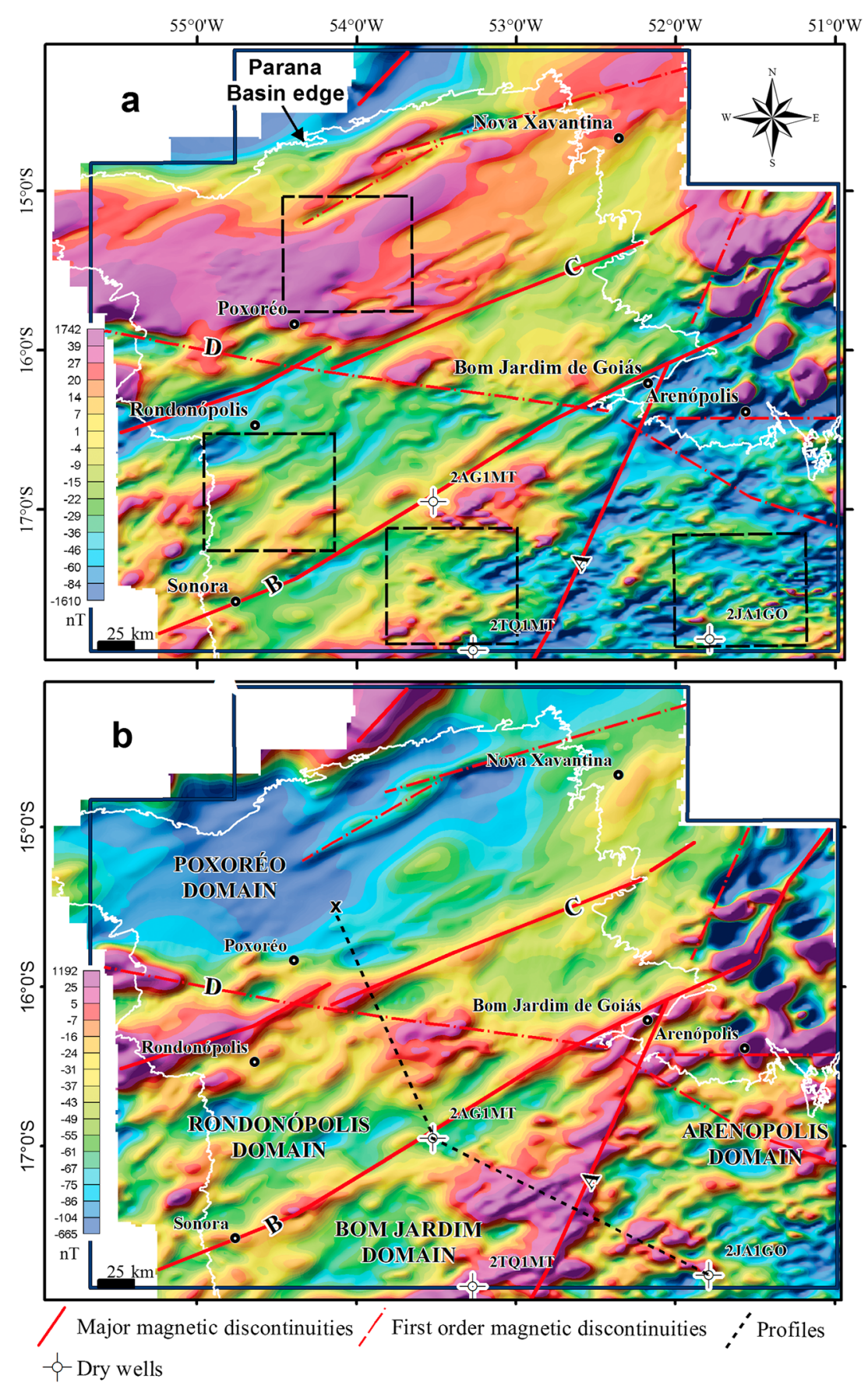

Figure 3. Maps of the (a) total-field magnetic anomaly and (b) the reduced-to-pole magnetic anomaly. Four magnetic domains are separated by three major NE-SW trending discontinuities: Serra Negra (A); Baliza (B); and General Carneiro (C). Also shown is the WNW-ESE trending São Vicente lineament (D). Black squares in Figure 3a represent areas selected for radial power spectrum analysis (Figures 4 and 5). Black lines in Figure $3 \mathrm{~b}$ indicate profiles for two-dimensional magnetic modeling (Figure 7).

In general, shallow and deep magnetic sources dominate the high- and low-wave number parts of the power spectrum, respectively, which facilitates the straight-line fitting process. On the other hand, it is theoretically not possible to distinguish long-wavelength, shallow magnetic sources from long-wavelength, deep magnetic sources [Phillips, 2001]. This limitation was considered during our matched-filter analysis.

The input data for the matched-filter analysis was the original total-field anomaly prior to application of reduction to the pole. On the other hand, subsequent two-dimensional magnetic modeling was conducted on the basis of the total-field anomaly reduced to pole. 


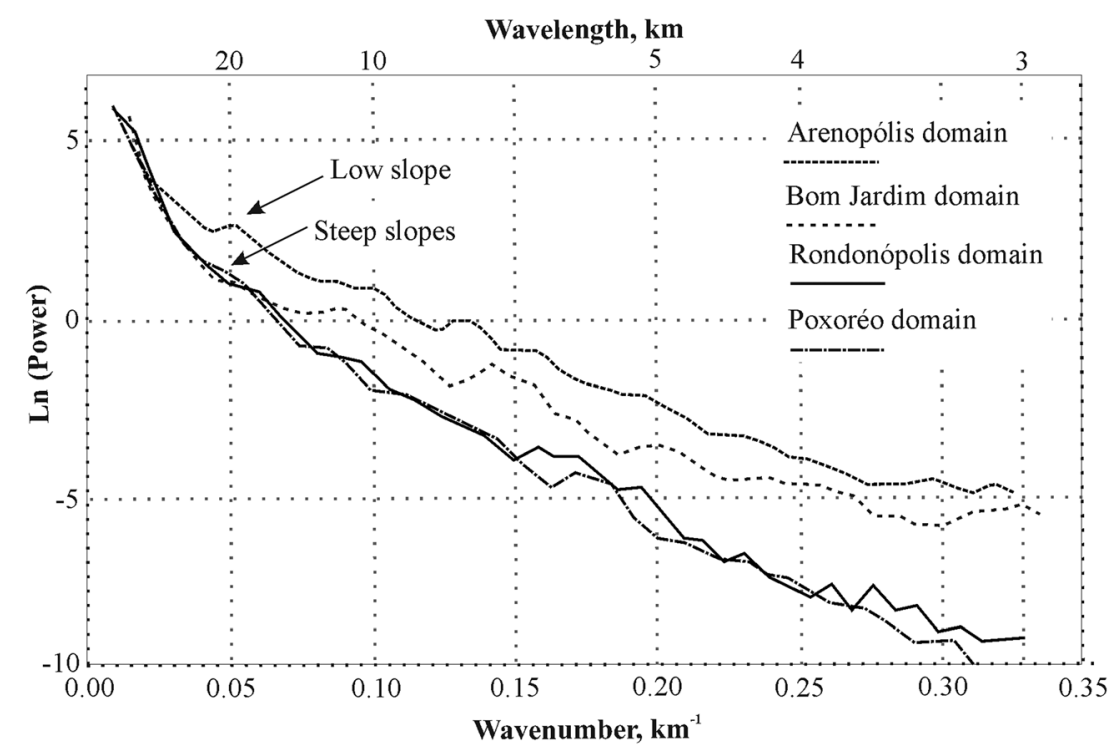

Figure 4. Comparison of the radial power spectra of the Arenópolis, Bom Jardim, Rondonópolis, and Poxoréo domains.

\section{Results}

\subsection{Magnetic Domains}

Broad patterns of total-field and reduced-to-pole magnetic anomalies reflect general properties of the crust. On the basis of magnetic anomaly patterns, we distinguished four regions in our study area separated from one another by three NE trending magnetic discontinuities. The four domains are here named after geographic locations: from east to west, the Arenópolis, Bom Jardim, Rondonópolis, and Poxoréo domains (Figure 3). The strong magnetic discontinuity separating the Arenópolis and Bom Jardim domains is here named the Serra Negra lineament after the fault of the same name in this locality [Seer, 1985]. The Bom Jardim and Rondónopolis domains are separated by the Baliza lineament, and the Rondonópolis and Poxoréo domains are separated by the General Carneiro lineament. An additional WNW-ESE striking lineament was identified on the basis of disruption and shifting of NE lineaments. We refer to it as the São Vicente lineament because it crosses a granite intrusion of the same name near the western border of Paraná Basin (Figure 2).

Qualitatively, the spectral content of magnetic anomalies changes systematically from east to west. The Arenópolis domain in the east is marked by short-wavelength magnetic anomalies having steeper horizontal gradients than surrounding areas, suggesting relatively shallow and strong magnetic sources. These most likely correspond to volcanic rocks of the Serra Geral Formation that crop out in the southern part of the study area and mafic-ultramafic rocks within the Arenópolis Magmatic Arc area exposed to the north (Figure 2). Long-wavelength anomalies in the northern part of the Arenópolis domain are caused by Cretaceous alkaline intrusions. The Bom Jardim domain, on the other hand, is a combination of short- and long-wavelength magnetic anomalies, and the Rondonópolis domain is characterized by medium-wavelength and intermediate intensity anomalies. The Poxoréo domain at the northwest of our study area is represented by smoothly varying, long-wavelength, high-amplitude magnetic fields. This east-to-west transition from short-wavelength to long-wavelength anomalies may indicate east-to-west changes in lithology, a general east-to-west deepening of magnetic sources, or both.

The Poxoréo domain includes a broad magnetic low in reduced-to-pole anomalies (Figure 3b), indicating a region of low crustal magnetization. This could be caused by a concealed sedimentary basin centered just south of the northern boundary of the Paraná Basin and/or a thicker package of metasedimentary rocks of the Cuiabá Group. The magnetic low is bisected by a significant linear magnetic high associated with volcanic rocks from the Nova Xavantina Group (Figures 2 and 3b).

Figure 4 describes our spectral analysis of magnetic anomalies to quantitatively assess magnetic properties of each domain. For each domain we selected a small but representative subarea of magnetic anomalies (Figure 3a), calculated the two-dimensional Fourier transform for each subarea, and averaged the two-dimensional 
Table 1. Ranges and Averages of Depth Obtained From Matched-Filter Analysis for Each Magnetic Domain

\begin{tabular}{lccc} 
& \multicolumn{3}{c}{ Ranges/Average Depth for Each Zone $(\mathrm{km})$} \\
\cline { 2 - 4 } Magnetic Domain & Shallow & Intermediate & Deep \\
\hline Arenópolis & Topography & $2.4-3.7 / 3$ & $18.3-28.5 / 23$ \\
Bom Jardim & Topography & $2.6-3.2 / 3$ & $14.5-15.1 / 15$ \\
Rondonópolis & $1.2-1.7 / 1.5$ & $5.2-6.7 / 6$ & $15.2-24.2 / 20$ \\
Poxoréo & $0.4-0.6 / 0.5$ & $5.4-5.6 / 5.5$ & $17.5-20.6 / 19$ \\
\hline
\end{tabular}

spectra within concentric rings centered on the origin to obtain radial power spectra. Figure 4 shows the logarithm of the radial spectra for each area, where the slope of each spectrum is proportional to magnetic source depth [Spector and Grant, 1970]. As expected, the power spectrum of the Arenópolis domain has lowest slope, indicative of near-surface volcanic rocks of the Serra Geral Formation. The power spectrum of the Poxoréo and Rondonópolis domains has the steepest slope, indicating deep magnetic sources (Figure 4).

\subsection{Depth Analyses of Magnetic Anomalies}

We employed matched-filter analysis [Phillips, 1997, 2007] to estimate the average depth to important magnetic sources within each magnetic domain of the study area. Each domain can be considered to consist of a sedimentary section atop magnetic basement, which in turn may be underlain by deep magnetic crust. Each of these depth zones has characteristic magnetic properties that can be discerned by matched-filter analysis. Moreover, in the Arenópolis domain, we expect that matched-filter analysis will help illuminate magnetic sources beneath the highly magnetic, near-surface volcanic rocks of the Serra Geral Formation.

Matched-filter analysis was applied multiple times to each domain, using subareas displayed in Figure 3a, as well as additional partially overlapping boxes, with range and average values as shown in Table 1. Negative depths were determined in the Arenópolis and Bom Jardim domains, implying very short wavelength signal possibly caused by near-surface volcanic rocks of the Serra Geral Formation. These shallowest depths were interpreted as volcanic rocks exposed at the topographic surface, as indicated in Table 1.

Shallow depths determined from the matched-filter analysis (Figure 5) are consistent with geologic information available for the study area. Shallow magnetic bodies are mostly intrusions and volcanic rocks, an interpretation supported in most areas by surface geologic mapping [Schobbenhaus et al., 2004]. In other areas, the interpreted igneous rocks are concealed by Paraná Basin or more recent sediments. Stratigraphic studies conducted in the Paraná Basin [Assine et al., 1994; Milani and Ramos, 1998] and three wells with maximum depth of $2107 \mathrm{~m}$ (2AG1MT, 2TQ1MT, and 2JAGO1; Figure 2) are consistent with our basin depth estimation (Figure 5). Deep zones are interpreted as lower crust. Three of the four domains (Arenópolis, Rondonópolis, and Poxoréo) have lower crustal depths similar to global averages ( $\geq 20-25 \mathrm{~km}$; Rudnick and Fountain [1995]). These estimates are also in good agreement with local crustal thickness estimates of 30-35 km and $43 \mathrm{~km}$ near the southeastern corner of the study area [Assumpção et al., 2013]. However, the deepest crustal magnetic contrast of the Bom Jardim domain is only $15 \mathrm{~km}$, suggesting either crustal thinning or the presence of a highly magnetized body $15 \mathrm{~km}$ depth, possibly a large mafic intrusion. Blum and Pires [1996] produced a Curie depth map of the central region of Goiás, which offers insights for our study area. They estimated an average Curie depth of $30 \mathrm{~km}$, with shallower peaks related to faults, including part of the TBL. These Curie depth variations possibly contribute to greater depth ranges shown by our deepest layers (Table 1).

The matched-filter technique provides amplitude values for each depth zone. We qualitatively related these amplitude values to the "magnetic significance" of each depth zone, attributed to both the intensity of magnetization and the thickness of the zone. The two shallower zones of the Arenópolis magnetic domain show the highest amplitude values compared to other domains (Figure 5), which we interpret as the presence of larger concentrations of volcanic rocks within the Paraná Basin, and probably within shallow depth levels of the basement as well.

With important magnetic depth zones thus determined, matched filters were designed to extract magnetic anomalies originating from each depth (Figure 6). In order to minimize the interference of near-surface magnetic wavelengths from the Serra Geral Formation, we applied the amplitude filters calculated for each layer of the Rondonópolis spectral analyses to the magnetic anomalies of the entire study area. According to the matched-filter analysis, the Rondonópolis domain has the deepest levels for the shallow and intermediate depth zone compared to the other magnetic domains (Table 1). 


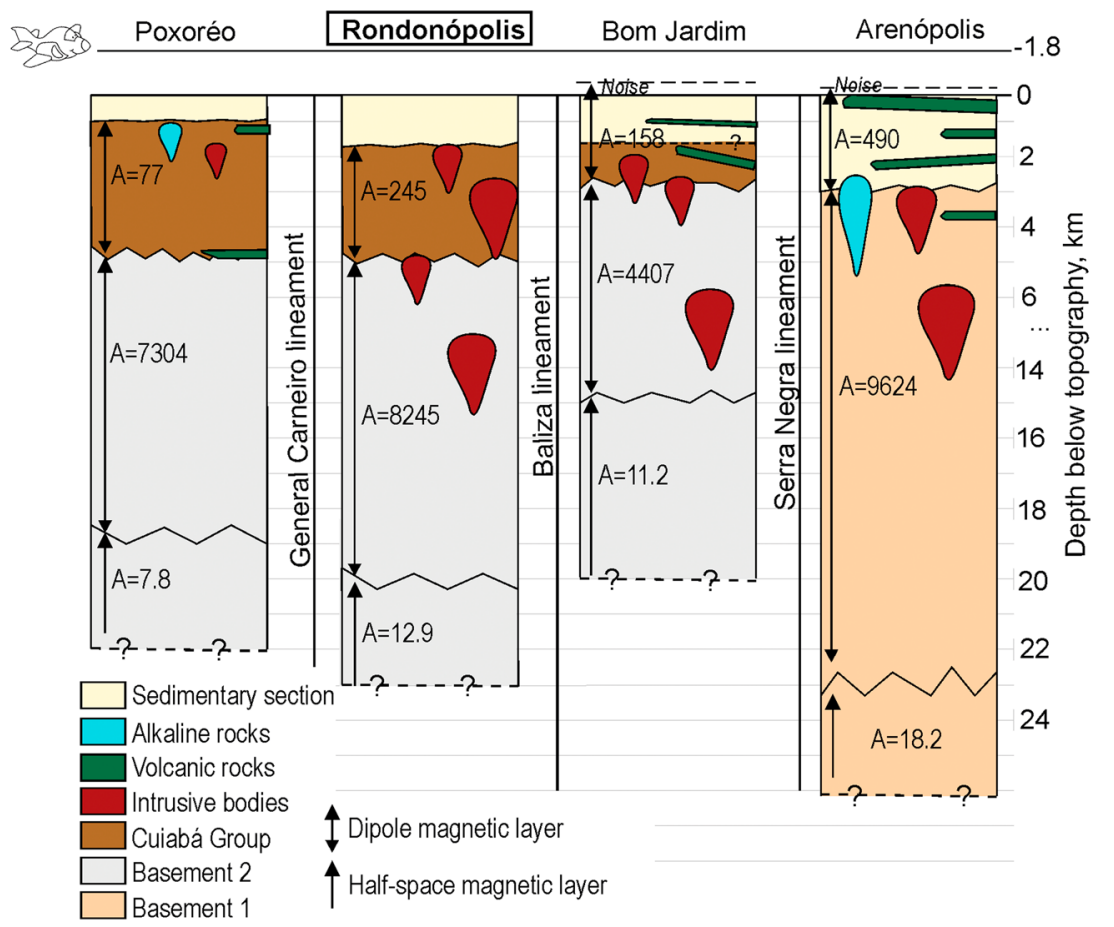

Figure 5. Schematic illustration showing the results and interpretation of matched-filter analyses for each magnetic domain, including the respective amplitude values (A). The amplitude filters calculated for each layer of the Rondonópolis spectral analyses were applied to the magnetic anomalies of the entire study area.

In our study, lineaments are qualitatively distinguished from each other according to their magnetic expression in length, width, and depth. First-order lineaments have large extensions in all directions and normally separate different magnetic domains, whereas second- and third-order lineaments are shallower and commonly do not extend more than $100 \mathrm{~km}$ and $20 \mathrm{~km}$, respectively (Figure 6). Our geologic interpretations are as follows:

1. The deepest zone (Figure $6 \mathrm{a}$ ) is represented by a magnetic half space with top at $20 \mathrm{~km}$ depth. The three major NE striking lineaments previously identified in the reduced-to-pole magnetic anomaly field (Figure 3) are well represented at this depth (Figure 6a'), suggesting that they are significant crustal tectonic discontinuities. Additional first-order NE striking trending lineaments also are well represented. The WNW striking São Vicente lineament (Figure 6a', label D) offsets the General Carneiro lineament (Figure 6a', label C) in a dextral sense. Semicircular shaped magnetic bodies in the NE portion of the study area are enhanced in this view and are caused by Cretaceous alkaline bodies, such as those exposed in the Arenópolis Magmatic Arc area. Although these are near-surface intrusive bodies, they are represented by long-wavelength, high-amplitude magnetic anomalies difficult to discriminate from deeper sources [Phillips, 2001]. The Serra Negra and Baliza lineaments in the Arenópolis Magmatic Arc area are significantly masked by these alkaline bodies at this depth level.

2. The $6 \mathrm{~km}$ depth zone (Figure $6 \mathrm{~b}$ ) is interpreted to be Precambrian basement and is associated with medium-wavelength magnetic lineaments, interpreted as second-order discontinuities. Matched-filter analysis illuminated a set of NE and NW striking lineaments in the southeastern part of the study area, not apparent in the original data. These lineaments may represent a westward extension of structures of the Arenópolis domain beyond the Serra Negra fault, possibly explaining the transitional nature of the Bom Jardim domain between adjacent domains, as noted earlier. The General Carneiro lineament and the northern margin of the Paraná Basin show parallel second-order NE striking lineaments. The NE trending sigmoidal shapes visible at this depth (Figure 6b', red lines in the inset) may indicate kinematic mechanisms, possibly local shifts caused by the influence of NW and E striking faults. The NW striking São Vicente lineament interrupts the NE striking sigmoidal lineaments. In the northern Arenópolis Arc area, some magnetic lineaments are enhanced despite the presence of high-amplitude anomalies due to the alkaline intrusive bodies. 

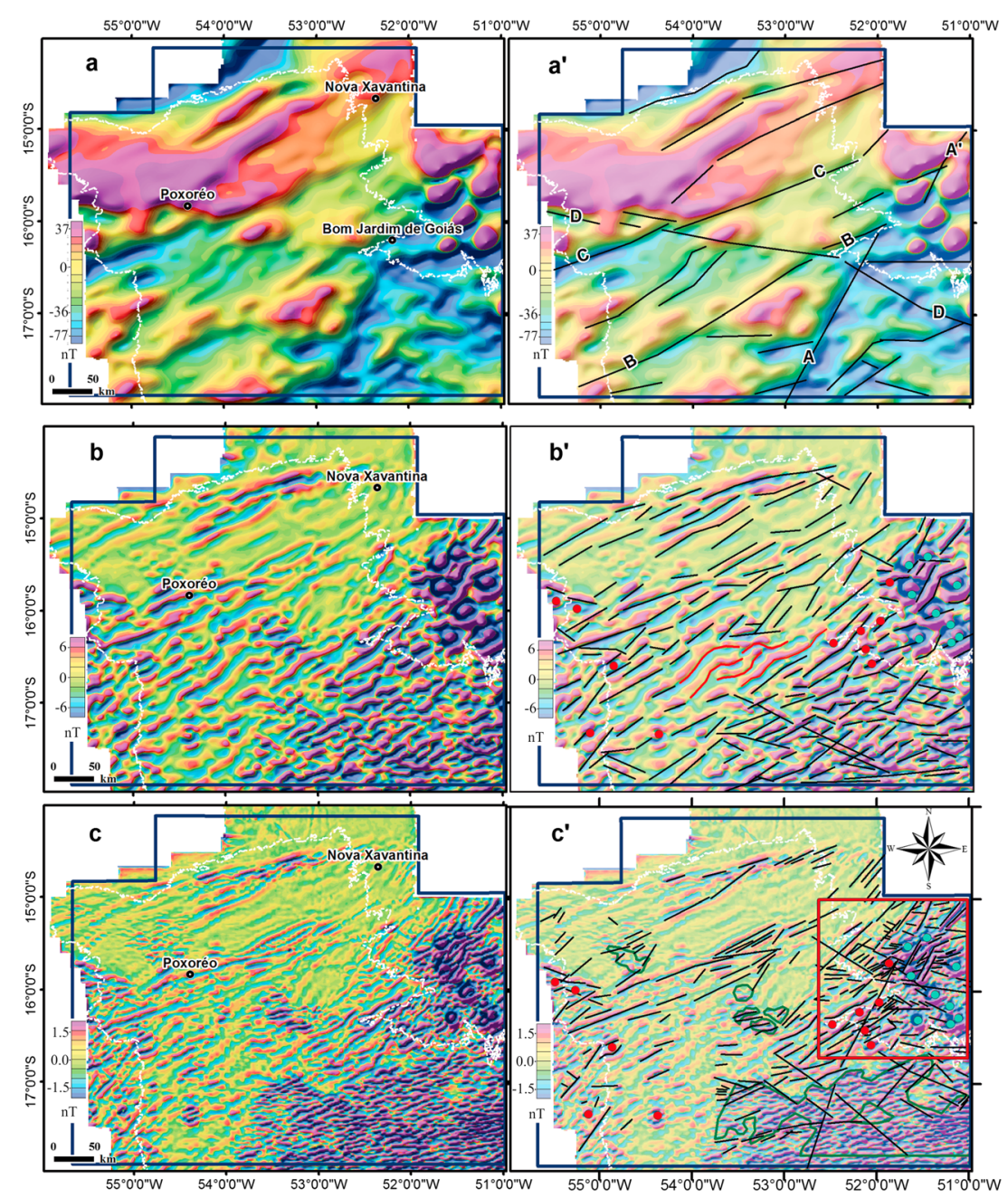

Figure 6. Anomalies emphasized for three depth zones as determined from matched-filter analysis (a) $20 \mathrm{~km}$; (b) 6 km; (c) $1.5 \mathrm{~km}$. ( $\left.a^{\prime}-c^{\prime}\right)$ Identical to Figures $6 a-6 c$ but include interpretations. Black lines (Figure $6 a^{\prime}$ ) are the interpreted lineaments, including the major magnetic discontinuities: Serra Negra (A), Baliza (B), General Carneiro (C), and São Vicente (D). Red and blue dots (Figures $6 b^{\prime}$ and $6 c^{\prime}$ ) mark granites and alkaline bodies, respectively, based on magnetic anomalies interpretations and geologic correlations. The green line (Figure $6 c^{\prime}$ ) marks the boundary of the Cretaceous volcanic rocks, mostly concealed by sedimentary rocks. Sigmoidal shapes are marked with red lines. The white dashed line in all panels outlines the border of the Paraná Basin. The red square shows the area of Figure 8.

3. The shallowest depth zone corresponds to magnetic sources at $1.5 \mathrm{~km}$ depth, including near-surface geological features (Figure $6 c$ ). We identified third-order magnetic lineaments, the Serra Geral Formation boundary, and intrusive bodies within this depth zone, in some cases supported by geologic data [Schobbenhaus et al., 2004]. Most of the lineaments interpreted at this level correlate with lineaments identified at deeper levels. Short-wavelength anomalies of the Serra Geral Formation in the south are easily distinguished from long-wavelength anomalies caused by sedimentary rocks of the Paraná Basin. The Arenópolis Arc area includes a set of NW and E striking lineaments with important kinematic and tectonic relations (Figure $6 c^{\prime}$, red square in the inset, and Figure 8), which will be explored in the discussion section.

\subsection{Two-Dimensional Magnetic Modeling}

The main magnetic depth zones interpreted from matched-filter analysis (Figure 5) supported two-dimensional modeling of magnetic anomalies, previously reduced to pole (Figure 7). Two profiles were chosen, nearperpendicularly crossing magnetic anomalies within Arenópolis, Bom Jardim, Rondonópolis, and Poxoréo domains (Figure 3b). Two exploratory wells (2AG1MT and 2JA1GO) were used to mark out basin depth estimates and to indicate volcanic rocks occurrences and limit the profiles. First, our models were designed to separate 

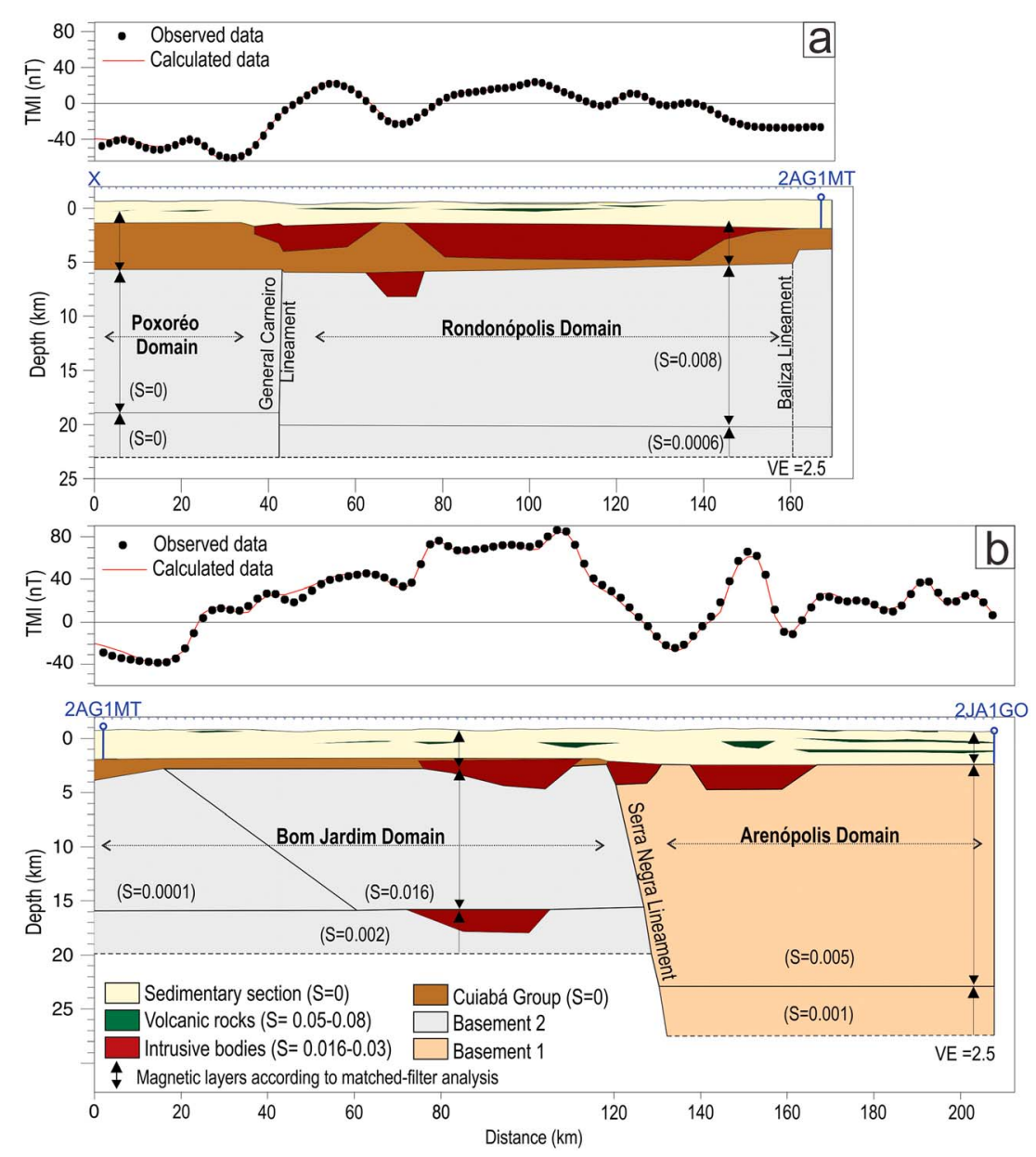

Figure 7. Two-dimensional models developed on the basis of the anomalous magnetic field reduced to pole. (a) X-2AG1MT profile, crossing the Poxoréo and Rondonópolis domains, limited by an important magnetic gradient associated with the General Carneiro Lineament. The Baliza lineament is located close to the east extreme of the profile and does not show apparent magnetic contrasts. (b) 2AG1MT-2JA1GO profile, crossing another important magnetic gradient, the Serra Negra Lineament, separating the Arenópolis and Bom Jardim domains. Blue lines show the 2AG1MT and 2JA1GO wells. See Figure 3 for map location.

the crust in three main magnetic depth zones, according to the matched-filter analysis (Table 1 and Figure 5). These zones were modeled with different susceptibility values, except for the Poxoréo Domain (see discussion below). Different magnetic patterns of the crust are also vertically limited by the main magnetic lineaments of the study area. The Baliza lineament is not as evident as the other lineaments because it is located near the start and end points of the profiles. On the other hand, the Serra Negra and General Carneiro lineaments are enhanced by important magnetic gradients showed in the 2AG1MT-2JA1GO (Figure 7a) and X-2AG1MT (Figure 7b) profiles, respectively. In general, the shallower depth layer is interpreted as nonmagnetized, sedimentary, and metasedimentary rocks of the Paraná Basin and Cuiabá Group, respectively. Magnetic sources modeled within the basin and basement layers are generally correlated with volcanic rocks and intrusive bodies, respectively.

The X-2AG1MT profile crosses the General Carneiro lineament and shows a significant magnetic contrast between Rondonópolis and Poxoréo domains (Figure 7a). While the first domain includes magnetic anomalies that we distinguish as distinct sources within the basin and the crust, the Poxoréo domain does not comprise significant high-amplitude magnetic anomalies and shows low magnetic background values up to $-50 \mathrm{nT}$ in this profile. Apparently this low magnetic signature is related to part of a very long wavelength magnetic source(s) originated from deep crustal levels, with undetectable magnetic contrast that we were not able to model. The Baliza Lineament is inferred by a fault that displaces the Cuiabá Group, but its magnetic response is not evident because the cross-section edge does not include the entire wavelength of its causative source. The 2AG1MT-2JA1GO profile crosses the Serra Negra lineament (Figure 7b). The Bom 
Jardim domain includes an important highly magnetized zone of the crust, which is bounded on the west by a magnetic lineament possibly associated to the Baliza lineament. In addition, this domain has the shallowest depth values related to the deepest zone, compared to the other magnetic domains. In our model, this shallower depth was partially interpreted to be caused by two possible variables: crustal faulting and a deep highly magnetized body. Our models indicate Arenópolis domain as a different and thicker crustal terrane, bounded on the west by the Serra Negra lineament.

\section{Discussion}

Having determined significant magnetic lineaments for each depth zone, we now discuss their relationship with the TBL and implications for the evolution of Paraná Basin.

We interpret the major NE striking lineaments, Serra Negra, Baliza, and General Carneiro, as zones of weakness within basement rocks, separating four tectonic blocks characterized by different structural patterns. An additional deep WNW striking magnetic discontinuity, São Vicente, subdivides these major blocks. Shallow lineaments are believed to be subsidiary structures that follow the trends of major structures. Field measurements acquired in basement and basin units in the region of Bom Jardim de Goiás and along a NW section of $1000 \mathrm{~km}$ length that crosses the study area (Figure 2) indicate five characteristic strike orientations for the faults and fractures: N45-60E, N25-30E, N50W, N80E-N80W, and N10W (Figure 9d). The first four orientations measured in the field correspond to magnetic lineament orientations in the study area (Figure 9c), the first two related mainly to the primary structural framework of the TBL. The third and fourth strike groups are associated with Cretaceous reactivation, represented by extensional structures.

The majority our fieldwork measurements were undertaken in sedimentary units of Paraná Basin (Figure 2), where NW striking structures are predominant (Figure 9d). On the other hand, we interpreted magnetic lineaments of the entire study area, including basement and deep crustal units, which are mostly characterized by NE striking directions (Figure 9c).

\subsection{Serra Negra Discontinuity}

The Serra Negra discontinuity with the same trend as the TBL (strike N30 $\mathrm{E}$ ) is the most expressive magnetic lineament at the $20 \mathrm{~km}$ depth level, separating the Arenópolis from the Bom Jardim domains (Figures 6 and 7). We suggest that the Serra Negra discontinuity is exposed in the Bom Jardim de Goiás region as a normal fault juxtaposing two Precambrian geologic domains, the Arenópolis Magmatic Arc and the Paraguay Belt [Seer, 1985]. This tectonic contact continues southward beneath the Paraná Basin.

The relationships between the Serra Negra lineament and the postorogenic granites ( $500 \mathrm{Ma})$, the Serra Geral Formation $(\sim 132-133 \mathrm{Ma})$, and the alkaline intrusions $(\sim 80 \mathrm{Ma})$ are well represented in the intermediate $(6 \mathrm{~km})$ and shallow $(1.5 \mathrm{~km})$ magnetic depth zones (Figures 6 to 8). We interpret these as episodes of TBL reactivation as follows: (1) The Serra Negra reactivation included strike-slip and dip-slip displacement of postorogenic granites (Figure 8, Labels 2 and 3, respectively). According to Seer [1985], the Macacos granite (Figure 8, Label 2) is laterally displaced $>8 \mathrm{~km}$. (2) The Serra Negra lineament marks the northwestern boundary of the Serra Geral Formation. The Serra Geral Formation contributes very shallow magnetic signatures to the Arenópolis domain, in contrast to the Bom Jardim domain, which has smaller anomalies caused by deeper sources; e.g., the Serra Negra normal fault. (3) In the region of the alkaline intrusions, the Devonian sequence of the Paraná Basin is faulted by structures associated with the Serra Negra lineament (Figure 8). These faults were probably reactivated by intrusions during Upper Cretaceous time, which also imprinted deformation on preexisting structures.

According to our matched-filter analysis, the top of the basement in the Arenópolis domain (Figures 5 and 7) is about $3 \mathrm{~km}$ deep, deeper than seen in well 2JAGO1 ( $2130 \mathrm{~m}$, as estimated by Petrobrás geologists). At this depth level, NE striking lineaments are emphasized instead of shallower high-amplitude magnetic signatures of the Serra Geral Formation (Figure 6). We interpret these lineaments as structures associated with a reactivation of the TBL, involving the formation of grabens and horsts within the Paraná Basin and controlling the deposition of the Serra Geral Formation volcanic flows.

In the Bom Jardim domain, the top of the Cuiabá Group was not clearly identified by the matched-filter analysis. The Cuiabá Group comprises metasedimentary schists with some graphite content, that have generally low susceptibility values. The low magnetic signature of this unit was concealed by the higher magnetic content of 

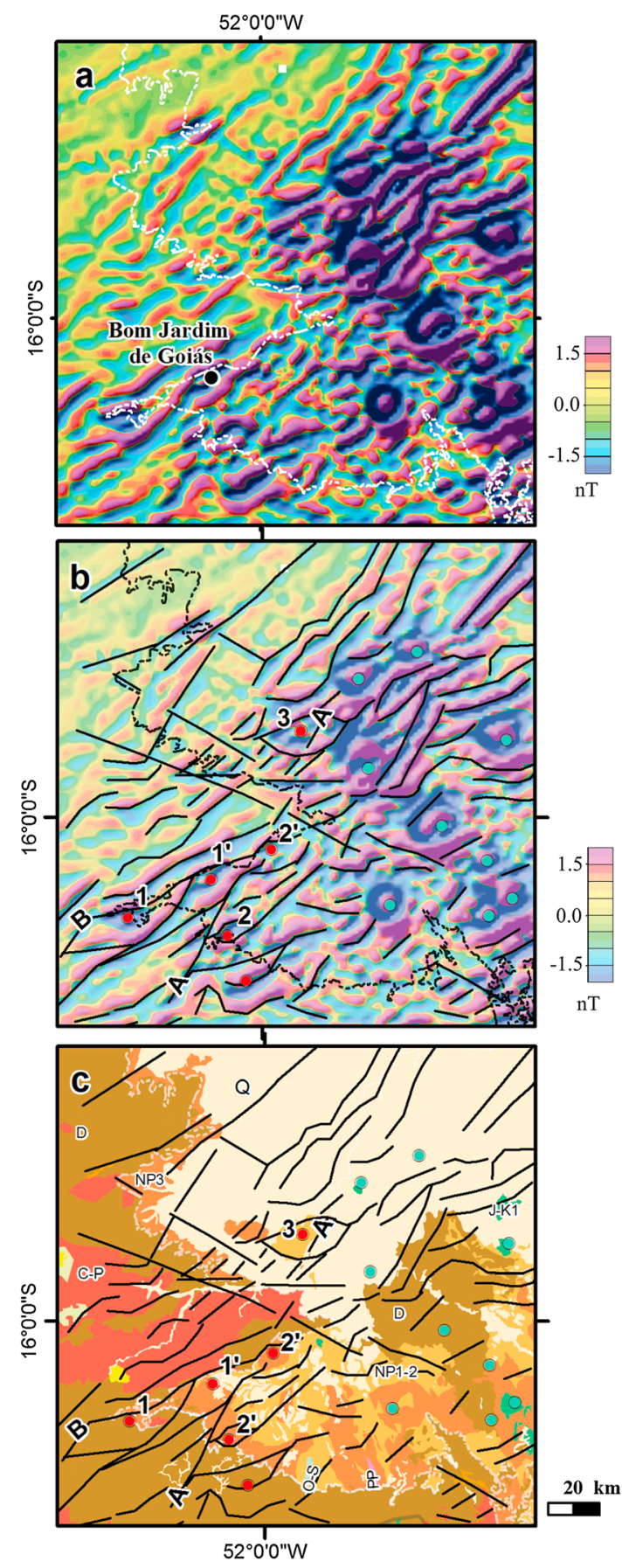

Figure 8. (a) Magnetic anomalies filtered to emphasize source at $1.5 \mathrm{~km}$ depth. (b) Same as Figure 8a but with interpreted lineaments shown as black lines. Red and blue dots indicate deformed granites and alkaline bodies, respectively, interpreted from magnetic anomalies and geologic correlations. Numbers 1, 2, and 3 refer to Serra Verde, Macacos, and Araguaiana postorogenic granites, respectively. Letters A and $B$ are Serra Negra and Baliza magnetic discontinuities, respectively. (c) The interpretation superimposed on geology. See Figure 1 for geologic labels. See Figure 6 for map location. the overlying Serra Geral Formation (Figures 5-7). The basement below the Cuiabá Group, probably within the Amazonian craton, shows notable NE striking subsidiary lineaments, part of the Serra Negra discontinuity (Figure 6b').

\subsection{Baliza Discontinuity}

The Baliza discontinuity is characterized by $\mathrm{N} 60^{\circ} \mathrm{E}$ trending magnetic lineaments. Although this is the most common magnetic trend within the study area, the Baliza lineament is less distinctive than other discontinuities (Figure 6b), possibly because it extends to shallower depths. The Baliza discontinuity is a reactivated structure that marks the western limit of the largest occurrence of the Serra Geral Formation in the study area. Intrusive bodies occur in some places along the Baliza lineament, with northern intrusions appearing more deformed than to the south (Figures $6 b^{\prime}, 6 c^{\prime}$ and 8). In the Bom Jardim de Goiás region, the shallower depth zone comprises three deformed granite intrusions aligned as dextral sigmoidal lineaments, limited by the northern portion of the Baliza lineament (Figure 8). Two of the granite bodies were mapped in the surface and are referred to as Serra Verde and Macacos postorogenic granites (Figure 8, Label 1 and 2, respectively) [Seer, 1985; Rodrigues et al., 1999]. We interpret these deformation zones as possible shear zones active at the end of the Brasiliano Orogeny ( $550 \mathrm{Ma})$. In our fieldwork, we identified folds, fractures, and faults in the Ordovician-Silurian and Carboniferous sedimentary sequences of the Paraná Basin related to a shear component of the TBL deformation (Figures 9a and 9b).

Later reactivations of the Baliza lineament involved faulting of the Paraná Basin Devonian and Carboniferous sequences (Figure 8), introducing $\mathrm{N} 60^{\circ}-70^{\circ} \mathrm{E}$ striking structures within the study area, including the Paraná Basin units and faults that extend to the Arenópolis Magmatic Arc area. Lineaments having the same $\mathrm{N} 60-70^{\circ} \mathrm{E}$ trend as the Baliza lineament occur within the entire Rondonópolis domain, which we interpret as subparallel subsidiary structures. Some of these reactivated structures established important control of Late Cretaceous subbasins developed above the Paraná Basin (Figure 10).

\subsection{General Carneiro Discontinuity}

The General Carneiro lineament comprises strong magnetic signatures originating from both deep and shallow crustal levels and with strike similar to the Baliza lineament. The General Carneiro and Baliza lineaments and their subsidiary structures converge into a major fault (Serra Negra lineament) near the 

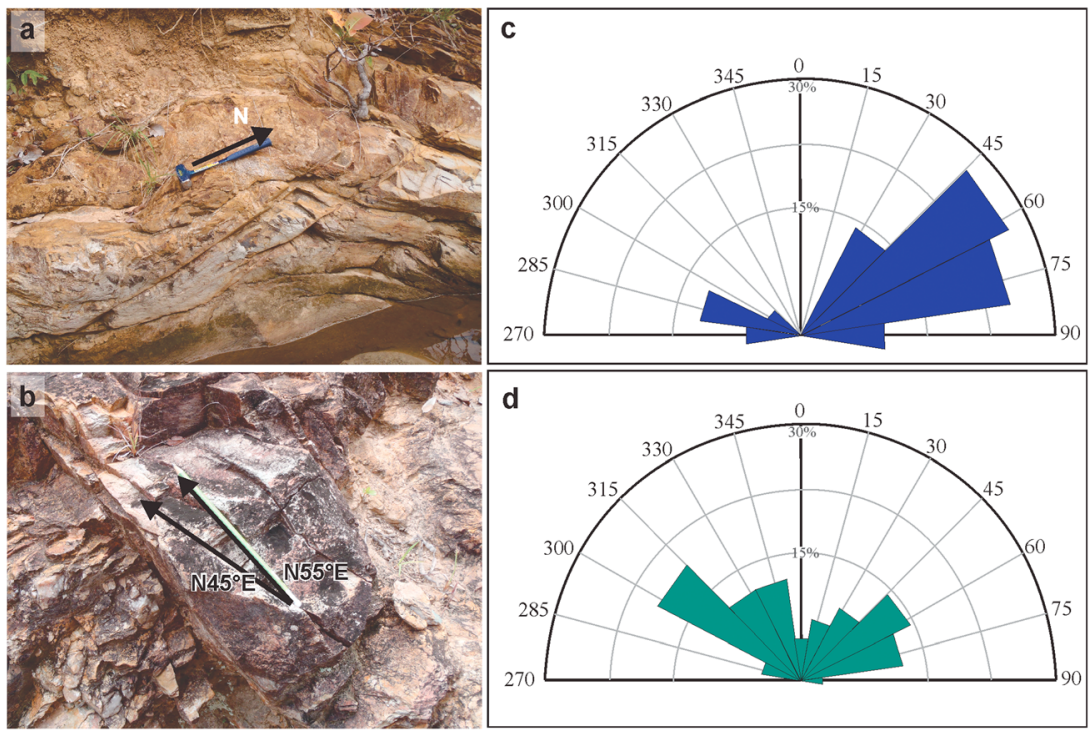

Figure 9. Silurian-Ordovician sandstone from (a) Paraná Basin folded and (b) faulted by Baliza lineament and associated structures, adjacent to the Cuiabá Group. See Figure 2 for map location (AJ08 point). Rose diagrams with (c) 351 strike orientations of magnetic lineaments interpreted from matched-filter analysis (Figure 6), and (d) 128 regional field measurements of strike orientations acquired in the Bom Jardim de Goiás area and along a WNW profile crossing $1000 \mathrm{~km}$ in the study area (Figure 2). Most of our field measurements were undertaken in Paraná Basin units.

northeastern limit of the study area, whereas the lineaments diverge westward in the southern part (Figures 3,6 , and 10). This change in structural strike is not well understood, but we suggest that it is related to a change of the mechanical properties between the two different tectonic domains, the Arenópolis Magmatic Arc (Brasilia Belt) to the east and the Paraguay Belt to the west (Figures 1 and 2). The main trend of the northern Paraguay Belt was determined by the first deformational phase (D1) comprised by isoclinal folds with axial planar foliation (S1) trending $\mathrm{N} 60^{\circ} \mathrm{E} / 70^{\circ} \mathrm{NW}$ [Manzano et al., 2008], which is compatible with the strike direction of the General Carneiro and Baliza lineaments.

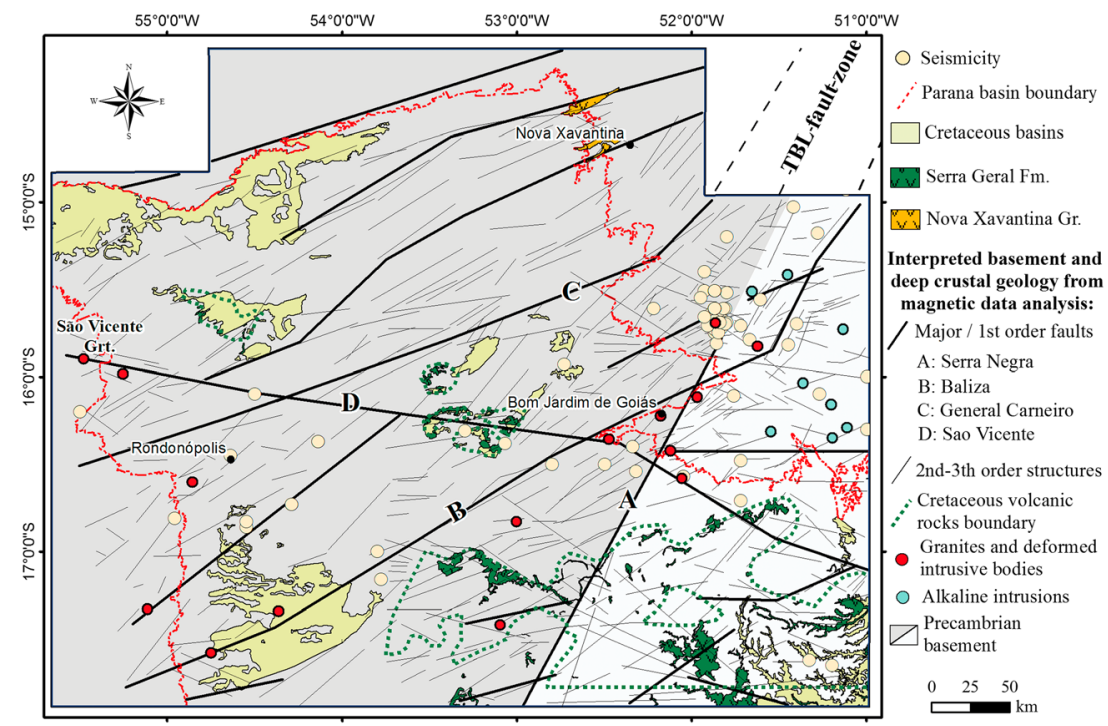

Figure 10. Map of geological and tectonic features of the study area that are mostly concealed by sediments of the Paraná Basin, including major crustal discontinuities, subsidiary structures, intrusive bodies, and the Serra Geral Formation boundary. Two Precambrian basement lithologies are illustrated. Light yellow dots are recorded seismicity, mostly along NW trending reactivated structures. 


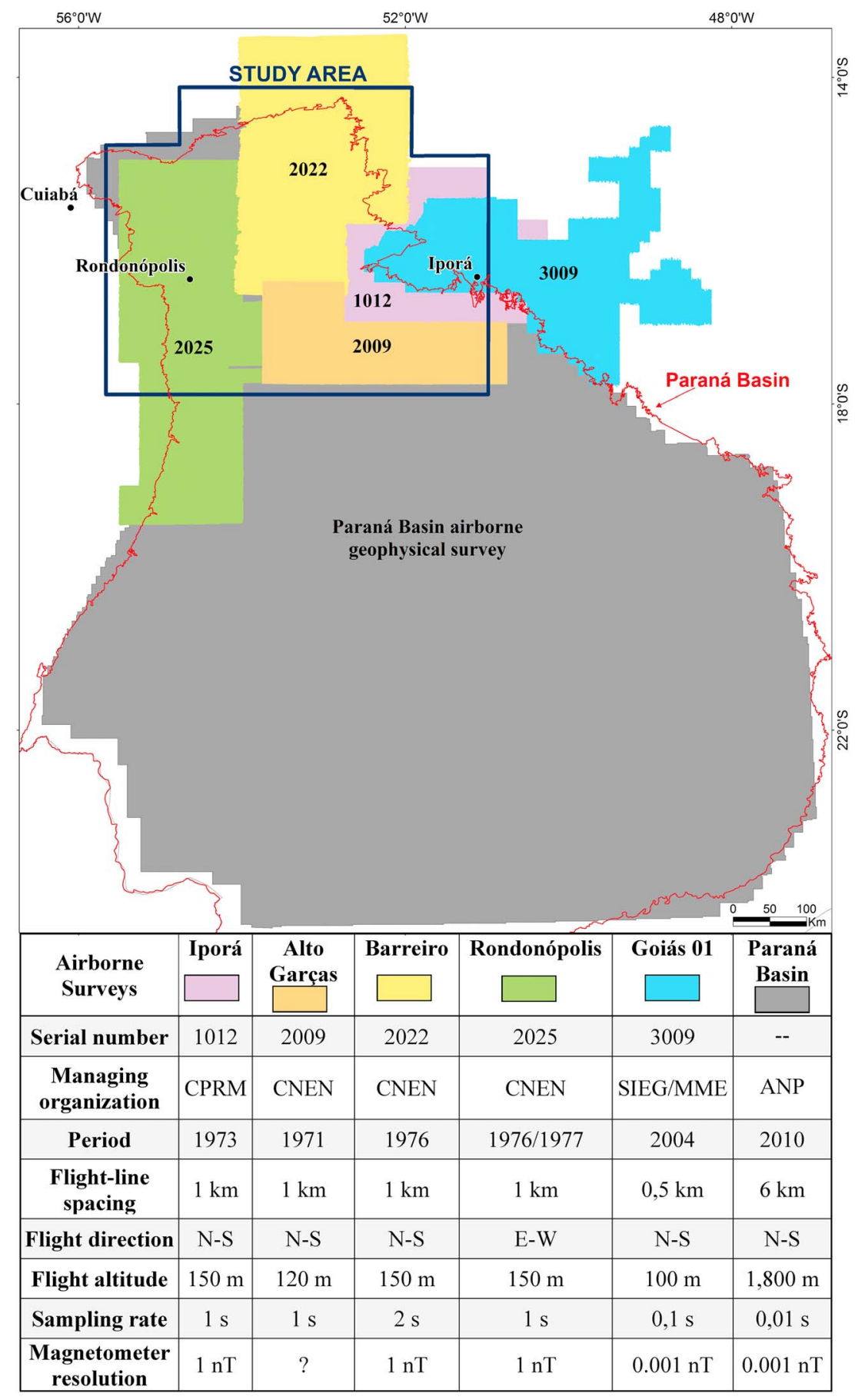

Figure A1. Airborne geophysical surveys. State companies that managed the surveys are shown as CPRM (Serviço Geológico do Brasil); CNEN (Comissão Nacional de Energia Nuclear); SIEG/MME (Secretaria de Indústria e Comércio de Goiás/Ministério de Minas e Energia); ANP (Agência Nacional do Petróleo, Gás Natural e Biocombustíveis). Blue polygon indicates limits of study area.

In the extreme eastern and western parts of the General Carneiro lineament, the Paraná Basin border exhibits greater NE-SW extension, which we interpret as resulting from strike-slip movement along this lineament.

In the Poxoréo domain, magnetic lineaments that occur along Cretaceous basins are related to volcanic rocks and faults parallel to the General Carneiro discontinuity and the Paraguay Belt deformation trend. At the northern Paraná Basin boundary, N70E first- and second-order magnetic lineaments are related to Neoproterozoic volcanic rocks of the Nova Xavantina Group (Figure 10). 


\subsection{São Vicente Lineament}

Some NE striking lineaments originating from deep and shallow depth zones are disrupted by NW striking lineaments. The most representative example is the São Vicente lineament, which displaces the General Carneiro lineament in a dextral sense. Earthquakes are aligned subparallel to the São Vicente lineament (Figure 10), suggesting that it is now reactivated. NW striking lineaments are aligned with the boundary of Cretaceous volcanic rocks and are related to the Cretaceous alkaline intrusive bodies (Figure 10).

\section{Conclusions}

The Serra Negra lineament, the most prominent magnetic component of the Transbrasiliano Lineament in northern Paraná Basin, separates two main tectonic crustal blocks. The western block comprises the Paraguay Belt that overlies the Amazon Craton and the eastern block includes the Arenópolis Magmatic Arc and other basement rocks that extend southwards. The primary TBL orientation in this area is $\mathrm{N} 30^{\circ} \mathrm{E}$, but different mechanical properties and heritage structures of the western domain have induced directional changes in some of the TBL structures, making them subparallel to the Paraguay Belt, as observed along most of the Baliza (N60 ${ }^{\circ}$ ) and General Carneiro (N70 ${ }^{\circ}$ ) discontinuities.

TBL strike-slip faults at shallow levels are associated with deep transcurrent shear zones $(\sim 20 \mathrm{~km})$ related to large zones of weakness; they are the structural origin of shallower TBL structures within the basement, which is about 3 to $1 \mathrm{~km}$ deep under the Paraná Basin and crops out in the Arenopólis Magmatic Arc and Paraguay Belt areas. Sigmoidal structures interpreted from magnetic anomalies are associated with intrusive bodies and are consistent with high-grade deformation generally related to dextral ductile-plastic deformation observed in outcrops in the Bom Jardim de Goiás area. Subsidiary structures are seen in shallow zones overlying basement. These structures are related to brittle deformation, marked by linear magnetic features that we interpret as reactivated structures. Prior to Cretaceous reactivation, the TBL displaced postorogenic granites along strike-slip and dip-slip faults. Shear components of the TBL imprint folds and faults in the initial sedimentary sequences of the Paraná Basin.

Two of the most recent large-scale reactivations of the TBL are manifested as faults that affected both the Paraná Basin Carboniferous sequences in the Bom Jardim de Goiás area and Devonian sequences in the central Arenópolis Magmatic Arc area. These faults and associated structures accommodated tectonic subsidence in certain areas, and some of these depocenters were filled by sediments during the Cretaceous period. During this time, NE striking structures were shifted by NW striking structures that still remain active as suggested by earthquakes in this area. In addition, the NW striking structures are related to the

Acknowledgments

We are grateful for the sponsorship of FUB/Petrobrás under cooperation term 0050.0053151.09.9; and to CNPq (Conselho Nacional de Desenvolvimento Cientifico e Tecnológico) for the grants to J.B.C., R.A.F., C.J.S.A., and E.L.D. We also thank ANP (Agência Nacional do Petróleo, Gás Natural e Biocombustíveis), CPRM (Serviço Geológico do Brasil), CNEN (Comissão Nacional de Energia Nuclear), and SGM / SIC-GO (Secretaria de Indústria e Comércio do Estado de Goiás) for providing access to geophysical data for academic purposes; GEOSOFT for providing the software Oasis Montaj 8.1; ESRI for providing the tool package ArcGis 10 under the contract 2011 MLK 8733; IMAGEM for making possible the agreement between IG-UnB and ESRI; the Laboratory of Remote Sensing and the Laboratory of Applied Geophysics of the IG-UnB (Instituto de Geociências da Universidade de Brasília) for the use of their facilities. Our paper was greatly improved by constructive comments from Dan Scheirer, Walter Medeiros, and an anonymous reviewer. emplacement of the Goiás Alkaline Province intrusive bodies.

\section{Appendix A: Airborne Geophysical Surveys}

Six airborne geophysical surveys were used in this study. Five of them are high-resolution surveys. The most recent one, the Paraná Basin survey, is low-resolution data (Figure A1).

\section{References}

Alvarenga, C. J. S., and R. Trompette (1993), Evolução tectônica brasiliana da Faixa Paraguai: A estruturação da região de Cuiabá, Rev. Bras. de Geociências, 23, 18-30.

Arthaud, M. H. (2007), Evolução neoproterozóica do Grupo Ceará (Domínio Ceará Central, NE Brasil): da sedimentação à colisão continental brasiliana, Ph.D thesis, Instituto de Geociências, Universidade de Brasília, Brasília, DF, Brazil.

Arthaud, M. H., R. Caby, R. A. Fuck, E. L. Dantas, and C. V. Parente (2008), Geology of the northern Borborema Province, NE Brazil and its correlation with Nigeria, NW Africa, in West Gondwana: Pre-Cenozoic Correlations Across the South Atlantic Region, vol. 294, edited by R. J. Pankhurst et al., pp. 49-67, Geological Society of London, London.

Assine, M. L., P.C. Soares, and E. J. Milani (1994), Sequências tectono-sedimentares mesopaleozóicas da Bacia do Paraná, Rev. Bras. de Geociências, 24(2), 77-89.

Assumpção, M., D. E. James, and J. A. Snoke (2002), Crustal thickness in SE Brazilian shield by receiver function analysis: Implications for isostatic compensation, J. Geophys. Res., 107(B12006), doi:10.1029/2001JB000422.

Assumpção, M., M. An, M. Bianchi, G. S. L. França, M. Rocha, J. R. Barbosa, and J. Berrocal (2004), Seismic studies of the Brasília Fold Belt at the western border of the São Francisco craton, central Brazil, using receiver function, surface wave dispersion, and teleseismic tomography, Tectonophysics, 388, 173-185, doi:10.1016/j.tecto.2004.04.029.

Assumpção, M., M. Bianchi, J. Julià, F. L. Dias, G. Sand França, R. Nascimento, S. Drouet, C. G. Pavão, D. F. Albuquerque, and A. E. V. Lopes (2013), Crustal thickness map of Brazil: Data compilation and main features, J. South Am. Earth Sci., 43, 74-85, doi:10.1016/j.jsames.2012.12.009.

Baranov, V., and H. Naudy (1964), Numerical calculation of the formula of reduction to the magnetic pole, Geophysics, 29, 67-79, doi:10.1190/1.1439334. 
Blakely, R. J. (1996), Potential Theory in Gravity and Magnetic Applications, Cambridge Univ. Press, Cambridge, England.

Blum, M. d. L. B., and A. C. B. Pires (1996), Superfície Curie da região central de Goiás, Rev. Bras. de Geociências, 26(3), 197-208.

Brito Neves, B. B., and U. G. Cordani (1991), Tectonic evolution of South America during the Late Proterozoic, Precambrian Res., HolandaElsevier, 53, 23-40, doi:10.1016/0301-9268(91)90004-T.

Brito Neves, B. B., R. A. Fuck, U. G. Cordani, and A. Thomaz Filho (1984), Influence of basement structures on the evolution of the major sedimentary basins of Brazil, J. Geodyn., 1(3-5), 495-510, doi:10.1016/0264-3707(84)90021-8.

Brito Neves, B. B., M. C. Campos Neto, and R. A. Fuck (1999), From Rodinia to Western Gondwana: An approach to the Brasiliano-Pan African Cycle and orogenic collage, Episodes, 22(03), 155-166.

Caby, R. (1989), Precambrian terranes of Benin-Nigeria and northeast Brazil and the late Proterozoic south Atlantic Rift, Geol. Soc. Am. Special Paper, 230, 145-158, doi:10.1130/SPE230-p145.

Carvalho, D. L. O., R. M. Vidotti, J. O. Araújo Filho, and P. R. Meneses (2012), Geologia, aerogeofísica e gravimetria terrestre da porção central do Graben de Água Bonita, sudoeste de Tocantins e noroeste de Goiás, Brasil, Rev. Bras. de Geociências, 30(4), 483-494.

Cawood, P. A. (2005), Terra Australis Orogen: Rodinia breakup and development of the Pacific and lapetus margins of Gondwana during the Neoproterozoic and Paleozoic, Earth Sci. Rev., 69, 249-279, doi:10.1016/j.earscirev.2004.09.001.

Chiarini, M. F. N. (2007), Contribuição da aerogeofísica na caracterização de suturas e de sistemas transcorrentes: O exemplo de Porangatu, Brasil Central, M.S. thesis, Instituto de Geociências, Universidade de Brasília, Brasília, DF, Brazil.

Cordani, U. G., and K. Sato (1999), Crustal evolution of the South American Platform based on Nd isotopic systematics on granitoid rocks, Episodes, 22(3), 167-173.

Cordani, U. G., B. B. Brito Neves, R. A. Fuck, R. Porto, A. Thomaz Filho, and F. M. B. da Cunha (1984), Estudo preliminar de integração do Pré-cambriano com os eventos tectônicos das bacias sedimentares brasileiras, Ciência, Técnica, Petróleo, Seção de Exploração de Petróleo, $15,20-27$.

Cordani, U. G., B. B. Brito Neves, and M. S. D' Agrella-Filho (2003), From Rodinia to Gondwana: A review of the available evidence from South America, Gondwana Res., 6(2), 275-284, doi:10.1016/S1342-937X(05)70976-X.

Cordani, U. G., B. B. Brito Neves, and R. A. Thomaz Filho (2010), Estudo Preliminar de integração do Pré-Cambriano com os eventos tectônicos das bacias sedimentares brasileiras (Atualização), Boletim de Geociências da Petrobrás, 17, 205-219.

Cordani, U. G., M. M. Pimentel, C. E. G. de Araújo, M. A. S. Basei, R. A. Fuck, and V. A. V. Girardi (2013a), Was there an Ediacaran Clymene Ocean in central South America, Am. J. Sci., 313(6), 517-539, doi:10.2475/06.2013.01.

Cordani, U. G., M. M. Pimentel, C. E. G. de Araújo, and R. A. Fuck (2013b), The significance of the Transbrasiliano-Kandi tectonic corridor for the amalgamation of West Gondwana, Braz. J. Geol., 43(3), 583-597, doi:10.5327/Z2317-48892013000300012.

Dantas, E. L., R. A. Fuck, C. G. de Oliveira, M. M. Pimentel, D. A. Sordi, and T. Almeida (2007), Geometria Côncava do Sistema de Empurrões no Arco Magmático de Mara Rosa, Goiás, XI Simpósio Nacional de Estudos Tectônicos, Natal-RN, Extended Abstracts, vol. 1, pp. 202-204, SBG, São Paulo, SP, Brazil.

de Almeida, F. F. M., and Y. Hasui (1984), O Pré-Cambriano do Brasil, Edgard Blücher, São Paulo, SP, Brazil.

de Almeida, F. F. M., and M. S. Melo (1981), A Bacia do Paraná e o vulcanismo mesozóico, in the Mapa Geológico do Estado de São Paulo, Scale 1:50,000, pp. 46-81, IPT, São Paulo, SP, Brazil.

de Almeida, F. F. M., Y. Hasui, B. B. Brito Neves, and R. A. Fuck (1981), Brazilian structural provinces: An introduction, Earth Sci. Rev., 17, 1-29, doi:10.1016/0012-8252(81)90003-9.

de Almeida, F. F. M., B. B. Brito Neves, and C. D. R. Carneiro (2000), The origin and evolution of the South American Platform, Earth Sci. Rev., 50 , 77-111, doi:10.1016/S0012-8252(99)00072-0.

de Alvarenga, C. J. S., E. M. Guimarães, M. L. Assine, and J. A. de Perinotto (1998), Sequência Orodovício-Siluriano e Devoniano no Flanco Norte da Bacia do Paraná, Anais da Academia Brasileira de Ciências, 70(3), 587-606.

de Alvarenga, C. J. S., P. C. Boggiani, M. Babinski, M. A. Dardenne, M. F. Figueiredo, R. V. Santos, and E. L. Dantas (2009), The Amazonian Paleocontinent, in Neoproterozoic-Cambrian Tectonics, Global Change and Evolution: A Focus on Southwestern Gondwana, Developments in Precambrian Geology, vol 16, edited by C. Gaucher et al., pp.15-28, Elsevier, Amsterdam, Netherlands, doi:10.1016/S0166-2635(09)01602-8.

de Oliveira, D. C. (2001), Reavaliação da e volução tectono-magmática do Graben de Jaibaras (nordeste do Brasil), Acta Geol. Hispanica, $36,53-95$.

dos Santos, T. J. S., A. H. Fetter, P. Hackspacher, W. R. Van Schumus, and J. A. Nogueira Neto (2008), Neoproterozoic tectonic and magmatic episodes in the NW sector of Borborema Province, NE, during assembly of Western Gondwana, J. South Am. Earth Sci., 25(3), 271-284, doi:10.1016/j.jsames.2007.05.006.

Environmental Systems Research Institute (2010), ArcGIS Desktop: Release 10.0. Redlands, Environmental Systems Research Institute, Calif.

Fairhead, J., and S. Maus (2003), CHAMP satellite and terrestrial magnetic data help define the tectonic model for South America and resolve the lingering problem of the pre-break-up fit of the South Atlantic Ocean, Leading Edge, 22, 779-783, doi:10.1190/1.1605081.

Feng, M., M. S. Assumpção, and S. Van Der Lee (2004), Group-velocity tomography and lithospheric S-velocity structure of the South American continent, Phys. Earth Planet. Inter., 147, 315-331, doi:10.1016/j.pepi.2004.07.008.

Fernandes, L. A., and A. M. Coimbra (1996), A Bacia Bauru (Cretáceo Superior, Brasil), Anais da Academia Brasileira de Ciências, 68(2), 195-205.

Ferreira, C. O. (2009), A extensão do arco magmático de Goiás ao longo do Lineamento Transbrasiliano: Estudo baseado na aplicação dos métodos U-Pb e Lu-Hf por LA-MC-ICP-MS, M.S. thesis, Instituto de Geocências, Universidade de Brasília, Brasília, DF, Brazil.

França, A. B., et al. (1995), Phanerozoic correlation in Southern South America, in Petroleum Basins of South America, Memoir 62, edited by A. J. Tankard et al., pp. 129-161, AAPG, Danvers, Mass.

Frank, H. T., M. E. B. Gomes, and M. L. L. Formoso (2009), Review of the areal extent and the volume of the Serra Geral Formation, Paraná Basin, South America, Pesquisas em Geociências, 36(1), 49-57.

Fuck, R. A., B. B. Brito Neves, and C. Schobbenhaus (2008), Rodinia descendants in South America, Precambrian Res., 160, 108-126, doi:10.1016/j.precamres.2007.04.018.

Geosoft (2008), Oasis Montaj: Release 8.1, Geosoft Inc, Toronto, Canada.

Godoy, A. M., J. C. Manzano, A. S. Ruiz, and L. M. B. de Araujo (2007), Os granitóides Brasilianos pós-tectônicos da faixa de dobramentos Paraguai MS e MT, Geologia USP, Série Científica, 7, 29-44.

Godoy, A. M., F. E. C. Pinho, J. C. Manzano, L. M. B. de Araújo, J. A. da Silva, and M. Figueiredo (2010), Estudos isotópicos das rochas granitoides Neoproterozóicas da Faixa de Dobramento Paraguai, Rev. Bras. de Geociências, 40(3), 380-391.

Grant, F. S., and J. Dodds (1972), MAGMAP FFT Processing System Development Notes, Paterson Grant and Watson Ltd, Canada, Toronto.

Hawkesworth, C. J., K. Gallagher, S. Kelley, M. Mantovani, D. W. Peate, M. Regelous, and N. W. Rogers (1992), Paraná magmatism and the opening of the South Atlantic, in Magmatism and the Causes of Continental Break-up, Geological Society Special Publication, vol. 68, edited by B. C. Storey et al., pp. 221-240, American Association of Petroleum Geologists, Tulsa, Oklahoma.

Heilbron, M., W. Mohriak, C. M. Valeriano, E. J. Milani, J. C. H. Almeida, and M. Tupinambá (2000), From collision to extension: The roots of the south-eastern continental margin of Brazil, in Atlantic Rifts and Continental Margins, Geophysical Monograph Series, vol. 115, edited by M. Talwani and W. Mohriak, pp. 1-34, AGU, Washington, D. C. 
Junqueira-Brod, T. C., H. L. Roig, J. C. Gaspar, J. A. Brod, and P. R. Meneses (2002), A província alcalina de Goiás e a extensão de seu vulcanismo kamafugítico, Rev. Bras. de Geociências, 32, 559-566.

Laux, J. H., M. M. Pimentel, E. L. Dantas, S. L. Junges, and R. Armstrong (2005), Two Neoproterozoic crustal accretion events in the Brasília Belt, central Brazil, J. South Am. Earth Sci., 18, 183-198.

MacLeod, I. N., S. Vierra, and A. C. Chaves (1993), Analytic signal and reduction-to-the-pole in the interpretation of total magnetic field at low magnetic latitudes, 3rd International Congress of the Brazilian Geophysical Society, SBGf, extended abstract, 830-835.

Mantovani, M. S. M., and B. B. Brito Neves (2005), The Paranapanema lithospheric block: Its importance for Proterozoic (Rodinia, Gondwana) supercontinent theories, Gondwana Res., 8, 303-315, doi:10.1016/S1342-937X(05)71137-0.

Mantovani, M. S. M., M. C. L. Quintas, and B. B. Brito Neves (2004), Delimitation of the Paranapanema Proterozoic Block: A geophysical contribution, Episodes, 28, 18-22.

Manzano, J. C., A. M. Godoy, and L. M. B. de Araújo (2008), Contexto tectônico dos granitóides Neoproterozóicos da faixa de dobramento Paraguai, MS e MT, Geociências, 27(4), 493-507.

Marini, O. J., R. A. Fuck, M. A. Dardenne, and J. C. M. Danni (1984), Província Tocantins-Setores central e sudeste, in O Pré-Cambriano do Brasil, edited by F. F. M. Almeida and Y. Hasui, pp. 205-264, Edgard Blücher, São Paulo, SP, Brazil.

Milani, E. J. (1997), Evolução tectono-estratigráfica da Bacia do Paraná e seu relacionamento com a geodinâmica fanerozóica do Gondwana sul-ocidental, PhD thesis, Universidade Federal do Rio Grande do Sul, Porto Alegre, RS, Brazil.

Milani, E. J. (2004), Comentários sobre a origem e evolução tectônica da Bacia do Paraná, in Geologia do Continente Sul-Americano: Evolução da Obra de Fernando Flávio Marques de Almeida, edited by V. Mantesso-Neto et al., pp. 265-279, Beca, São Paulo, SP, Brazil.

Milani, E. J., and V. A. Ramos (1998), Orogenias paleozóicas no domínio sul-ocidental do Gondwana e os ciclos de subsidência da Bacia do Paraná, Rev. Bras. de Geociências, 28(4), 527-544.

Milani, E. J., and A. Thomaz Filho (2000), Sedimentary basins of South America, in Tectonic Evolution of South America, edited by U. G. Cordani et al., pp. 389-449, 31st International Geological Congress, Rio de Janeiro, RJ, Brazil.

Milani, E. J., J. H. G. Melo, P. A. Souza, L. A. Fernandes, and A. B. França (2007), Bacia do Paraná, Bol. de Geociências da Petrobrás, 15(2), 265-287. Molina, E. C., and N. Ussami (1989), Interpretação dos dados gravimétricos da parte norte da Bacia do Paraná, Rev. Bras. de Geociências, $19,187-196$.

Molina, E. C., N. Ussami, N. C. de Sá, D. Blitzkow, and O. F. Miranda Filho (1988), Deep crustal structure under Paraná Basin (Brazil) from gravity study, in The Mesozoic Volcanism of the Paraná Basin: Petrogenetic and Geophysical Aspects, edited by E. M. Piccirillo and A. J. Melfi, pp. 271-283, IAG/USP, São Paulo, SP, Brazil.

Nabighian, M. N., V. J. S. Grauch, R. O. Hansen, T. R. Lafehr, Y. Li, J. W. Peirce, J. D. Phillips, and M. E. Ruder (2005), 75th Anniversary The historical development of the magnetic method in exploration, Geophysics, 70, 33ND-61ND, doi:10.1190/1.2133784.

Phillips, J. D. (1997), Potential field geophysical software for the PC, version 2.2. U.S. Geological Survey Open File Report No. 97-725.

Phillips, J. D. (2001), Designing matched band-pass and azimuthal filters for the separation of potential-field anomalies by source region and source type, 15th Geophysical Conference and Exhibition, Australian Society of Exploration Geophysicists, extended abstract,1-4, doi:10.1071/ASEG2001ab110.

Phillips, J. D. (2007), Geosoft eXecutables (GX's) developed by U.S. Geological Survey, version 2.0, with notes on GX development from Fortran code: U.S. Geological Survey Open-File Report 2007, 1355p.

Pimentel, M. M., and R. A. Fuck (1987), Late Proterozoic granitic magmatism in southwestern Goiás, Brazil, Rev. Bras. de Geociências, $17,415-425$.

Pimentel, M. M., and R. A. Fuck (1992), Neoproterozoic crustal accretion in central Brazil, Geology, 20(4), 375-379, doi:10.1130/0091-7613 (1992)020<0375:NCAICB > 2.3.CO;2.

Pimentel, M. M., R. A. Fuck, and C. J. S. Alvarenga (1996), Post-Brasiliano (Pan-African) high-K granitic magmatism in central Brazil: Late Precambrian/early Paleozoic extension, Precambrian Res., 80, 217-238, doi:10.1016/S0301-9268(96)00016-2.

Pimentel, M. M., R. A. Fuck, H. Jost, C. F. F. Filho, and S. M. de Araújo (2000), The basement of the Brasilia Fold Belt and the Goiás Magmatic Arc, in Tectonic Evolution of South America, edited by U. G. Cordani et al., pp. 190-229, 31st International Geological Congress, Rio de Janeiro, RJ, Brazil.

Ramos, V. A., T. E. Jordan, R. W. Allmendinger, C. Mpodozis, S. M. Kay, J. M. Cortés, and M. A. Palma (1986), Paleozoic terranes of the central Argentine-Chilean Andes, Tectonics, 5, 855-880, doi:10.1029/TC005i006p00855.

Ramos, V. A., G. Vujovicha, R. Martino, and J. Otamendic (2010), Pampia: A large cratonic block missing in the Rodinia supercontinent, J. Geodyn., 50, 243-255, doi:10.1016/j.jog.2010.01-019.

Rapela, C. W., R. J. Pankhurst, C. Casquet, C. M. Fanning, E. G. Baldo, J. M. González-Casado, C. Galindo, and J. Dahlquist (2007), The Rio de la Plata craton and the assembly of SW Gondwana, Earth Sci. Rev., 83(1-2), 49-82, doi:10.1016/j.earscirev.2007.03.004.

Rodrigues, J. B., S. M. L. C. Gioia, and M. M. Pimentel (1999), Geocronologia e geoquímica de ortognaisses da região entre lporá e Firminópolis: Implicações para a evolução do Arco Magmático de Goiás, Rev. Bras. de Geociências, 29(2), 207-216.

Rudnick, R. L., and D. M. Fountain (1995), Nature and composition of the continental crust: A lower crustal perspective, Rev. Geophys., 33(3), 267-309, doi:10.1029/95RG01302.

Schobbenhaus, C., C. L. Ribeiro, L. A. Oliva, J. T. Takanohashi, A. G. Lindenmayer, J. C. Vasconcelos, and V. Orlandi (1975), Folha Goiás SD.22, with explanatory text, in Carta Geológica do Brasil Milionésimo, edited by C. Schobbenhaus, DNPM, Brasília, DF, Brazil.

Schobbenhaus, C., J. H. Gonçalves, J. O. S. Santos, M. B. Abram, R. L. Neto, G. M. M. Matos, R. M. Vidotti, M. A. B. Ramos, and J. D. A. Jesus (Eds) (2004), Carta Geológica do Brasil ao Milionésimo, Sistema de Informações Geográficas—SIG, 41 CD-ROMs, Scale 1:1,000,000, CPRM, Brasília, DF, Brazil.

Seer, H. J. (1985), Geologia, deformação e mineralização de cobre no complexo vulcanossedimentar de Bom Jardim de Goiás, M.S. Dissertation, Universidade de Brasília, Brasília, DF, Brazil.

Seer, H. J., and A. A. Nilson (1985), Contribuição à geologia das unidades Pré-Cambrianas da região de Bom Jardim de Goiás, Simpósio de Geologia do Centro-Oeste, 2. Goiânia, Atas, Goiânia, SBG, 267-281.

Spector, A., and F. S. Grant (1970), Statistical models for interpreting magnetic data, Geophysics, 35(2), 293-302.

Syberg, F. J. R. (1972), A Fourier method for the regional-residual problem of potential fields, Geophys. Prospect., 20, 47-75.

Tohver, E., R. I. F. Trindade, J. G. Solum, C. M. Hall, C. Riccomini, and A. C. Nogueira (2010), Closing the Clymene ocean and bending a Brasiliano belt: Evidence for the Cambrian formation of Gondwana, southeast Amazon craton, Geology, 38(3), 267-270, doi:10.1130/G30510.1.

Vaughan, A. P. M., and R. J. Pankhurst (2008), Tectonic overview of the West Gondwana margin, Gondwana Res., 13(2), 150-162, doi:10.1016/j. gr.2007.07.004

Vidotti, R. M., C. E. Ebinger, and J. D. Fairhead (1998), Gravity signature of the western Paraná basin, Brazil, Earth Planet. Sci. Lett., 159, 117-132, doi:10.1016/S0012-821X(98)00070-3

Zalán, P. V., S. Wolff, M. A. M. Astolfi, I. S. Vieira, J. C. J. Conceição, V. T. Appi, E. V. Santos Neto, J. R. Cerqueira, and A. Marques (1991), The Paraná Basin, Brazil, in Interior Cratonic Basins, Memoir, vol. 51, edited by M. W. Leighton et al., pp. 681-708, AAPG, Tulsa, Okla. 
Artigo submetido à Tectonophysics em 08/2014

6.

Revisão submetida em 03/2015

Crustal framework of the northwest Paraná Basin, Brazil: insights from joint modeling of magnetic and gravity data

Authors:

Julia B. Curto ${ }^{1}$, Roberta M. Vidotti ${ }^{1}$, Richard J. Blakely ${ }^{2}$, Reinhardt A. Fuck ${ }^{1}$

'Instituto de Geociências, Universidade de Brasília, Brasília, Brasil

${ }^{2}$ U.S. Geological Survey, Menlo Park, CA, United States

Corresponding author: Julia B. Curto (julia.curto@gmail.com)

Address: Instituto de Geociências, Universidade de Brasília, Campus Darcy Ribeiro ICC - Ala Central CEP 70.910-900 - Brasília / DF - Brasil

Phone numbers: $556181360199 ; 556131076985$ 


\begin{abstract}
The Transbrasiliano Lineament (TBL) is a major Proterozoic strike-slip shear zone crossing the Paraná Basin, Brazil, yet the relationship between the TBL and basin structures is poorly understood. Magnetic and gravity data are available from the whole northwestern region of the Paraná Basin and provide insights into crustal partitioning and basement geometry. Joint 2D modeling of these data was performed in three strategic sections of the study area. Two smaller sections were constrained by available borehole data and receiver function analysis. Modeling of these sections facilitated modeling of the third, larger NW-SE section, which crosses the basin in an area with significant lack of data. These three sections together form the basis for a preliminary tectonic model of the northern Paraná Basin. The TBL includes strong N30 ${ }^{\circ}$ trending gravity and magnetic gradients represented by the Serra Negra fault zone. This structure separates two crustal tectonic domains, the Paranapanema Block to the east, and the Amazon paleocontinent to the west. The tectonic domain northeast of the fault is represented by the Arenópolis Magmatic Arc. The $\mathrm{N} 60^{\circ}-70^{\circ}$ E-trending General Carneiro fault, also reflected in gravity anomalies, forms another important magnetic contact. Our tectonic model shows a region of crustal thinning between the two fault zones, where structures associated with possible reactivation form small Cretaceous basins. The Baliza fault may accommodate significant vertical displacements of Devonian and Carboniferous sections of the Paraná Basin. The main structures revealed in the sections are associated with grabens and horsts, interpreted as reactivated structures that controlled Paraná Basin sedimentation. The northwestern portion of the basin exhibits basement asymmetry caused by dip- and strike-slip faulting along the TBL.
\end{abstract}

Keywords: Paraná Basin; Transbrasiliano Lineament; magnetic anomaly; gravity anomaly, 2D modeling 


\section{Introduction}

The Paraná Basin is among the five largest Phanerozoic basins of the South American Platform, and, like most large sedimentary basins of the world, our geological knowledge comes primarily from hydrocarbon exploration. Until 2012, about 97\% of all wells in the Paraná Basin were drilled in the east-central portion of the basin, which reaches depths of $7 \mathrm{~km}$. In contrast, stratigraphic data from the northwestern flank of the basin are relatively sparse, despite depths of only 2 to $3 \mathrm{~km}$ (Milani et al., 2007). A lack of seismic studies also contributes to our limited knowledge of the tectonic history of the basin and the structural framework of underlying basement.

The Transbrasiliano Lineament (TBL; Schobbenhaus et al., 1975; Brito Neves et al., 1984; Curto et al., 2014; Figure 1) is a zone of $\mathrm{N} 30^{\circ} \mathrm{E}$ trending Neoproterozoic strike-slip faults that crosses the South American Platform, of which at least $3000 \mathrm{~km}$ is within Brazilian territory (Brito Neves et al., 1999; Fairhead and Maus, 2003; Ramos et al., 2010; Tohver et al., 2010; Cordani et al., 2013). This continental-scale structure is poorly understood, especially where it is concealed by Phanerozoic sedimentary cover. In an earlier paper (Curto et al., 2014), we showed that the early phase of Paraná Basin evolution was associated with TBL structures along the northern flank of the basin. In this paper, we focus on the same study area, aiming to better understand the tectonic setting through joint modeling of magnetic and gravity data from different surveys made available by various institutions (Figure 4). We investigate geophysical anomalies from the entire crustal section to reveal structures and geologic units from deep to shallow crustal levels in order to establish the relationship between Precambrian basement and reactivated structures within the Paraná Basin.

\section{Geological setting}

\subsection{Basement units}

The study area is located in the Tocantins Province (Figure 1; Almeida et al., 1981), which is composed of the Brasília, Paraguay and Araguaia mobile belts (Figure 2). This branching system of mobile belts originated from a set of Neoproterozoic orogenic processes related to the Brasiliano orogenic collage (800 - 500 Ma; Brito Neves and Fuck, 2013; Brito Neves et al., 2014). It resulted from convergence of three main geologic domains: the Amazonas craton to the west, the São Francisco craton to the east, and the Paranapanema block to the southeast (Figure 1). Pre-Cryogenian basement within the mobile belts ( $>850 \mathrm{Ma}$, Brito Neves and Fuck, 2013) was intensely reworked during this convergence. 
In the western part of the Brasília Belt, the Goiás Magmatic Arc (Figures 1 and 2, label GMA), generated by subduction of pre-existing oceanic lithosphere, evolved from intra-oceanic arc magmatism (920-860 Ma, Pimentel and Fuck, 1992; Pimentel et al., 1997, 2000, 2011; Laux et al., 2005; Matteini et al., 2010) to younger continental arc magmatism (670-600 Ma; Laux et al., 2005; Fuck et al., 2006; Oliveira et al., 2003). The younger magmatic event corresponds to an important period of plate interaction and subduction (Brito Neves and Fuck, 2013), marked by collision and metamorphism of greenschist to amphibolite facies at ca. 630-600 Ma (Pimentel et al., 1991; Cordani et al.,2013; Brito Neves et al., 2014). The GMA is divided into the northern Mara Rosa sector and southern Arenópolis sector (Figure 3, label AA).

The Paraguay Belt surrounds the southwestern border of the Amazonian plate. It has been interpreted as a sedimentary basin formed on the continental margin of the Amazonian paleocontinent, subsequently inverted to a foreland basin during Brasiliano convergence (Almeida, 1964; Alvarenga et al., 2009; Dantas et al., 2009). The northern sector of the Paraguay Belt is characterized by increased metamorphic polarity toward east, marked by E-W thrusts. The basal unit consists of metasedimentary rocks of the Cuiabá Group ( $635 \mathrm{Ma}$; Alvarenga et al., 2004), which crops out along the northern boundary of the Paraná Basin, and is limited to the east by the Serra Negra fault (Figure 3; Seer, 1985; Pimentel and Fuck, 1992).

Late to post-orogenic bimodal intrusions of gabbro and granite intruded the Arenópolis magmatic arc 600-500 Ma (Pimentel et al., 2011). Granitic rocks also intruded in deformed Cuiabá Group of the Paraguay Belt (550 - 500 Ma, Godoy et al., 2007, 2010). The transcurrent Transbrasiliano lineament (TBL, Figure 1) was formed during the final phase of the Brasiliano orogeny (< 560 Ma; Brito Neves and Fuck, 2013; Cordani et al., 2013) and now extends northeast-southwest across the Borborema Province, Parnaíba Basin, Tocantins Province, Paraná Basin, Paraguay Belt, and terminates at the eastern edge of Sierras Pampeanas, Argentina (Figure 1; Ramos et al., 2010). Phanerozoic basins formed in the Cambrian in response to reactivation of Precambrian basement structures, including the TBL (Brito Neves et al., 1984; Cordani et al., 2009a).

The basement underlying the Paraná basin was in place by the end of the Brasiliano orogeny and is poorly known. The recognized units are associated with a set of Neoproterozoic mobile belts that surround the basin (Figure 2). As of 2008, 124 wells have been drilled to investigate the Paraná Basin, but only three are located in the study area (Figure 3). In the south part of the 
area, the 2JA1GO and 2TQ1MT wells reached depths of 2.1 and $2.0 \mathrm{~km}$, respectively, without encountering basement. The Cuiabá Group was sampled by the 2AG1MT well $(1.9 \mathrm{~km})$. Approximately $30 \mathrm{~km}$ northeast of this well, the Araguainha impact dome exposed a 4-5 km wide core of porphyritic granite into Devonian sedimentary units (Engelhardt et al., 1992; Lana et al., 2008; Figure 3, label 7).

\subsection{Sedimentary Basin}

Initial subsidence of the Paraná Basin in Ordovician time was related to reactivation of NE-SW basement structures (Zalán et al., 1991; França et al., 1995; Milani et al., 2007; Heilbron et al., 2000). The current basin configuration, however, is the product of a long process of evolution, from Ordovician to Cretaceous time, involving the superposition of multiple tectonic stages (Milani and Ramos, 1998) that hinder the identification of the initial depocenter. NE-SW and N$\mathrm{S}$ oriented isopach distributions of the basal sedimentary sequences suggest that the basin probably initiated near the western flank of its present extent (Zalán et al.,1991; Milani and Ramos, 1998). Milani and Ramos (1998) argued that initial sedimentation is represented by the Rio Ivaí Supersequence and was controlled by the TBL. Three main phases of subsidence are recorded in the 2AG1MT well (Figure 3) during Ordovician-Silurian, Devonian, and Carboniferous-Permian periods (Zalán et al., 1991; Milani and Ramos, 1998). In the Early Cretaceous, the Serra Geral tholeiitic magmatism covered two thirds of the basin area (Zalán et al., 1991). The main phase of magmatism ( 133-132 Ma; Renne et al., 1992) reached thicknesses up to 2,000 $\mathrm{m}$ aligned with the NE-trending depocenter (Milani and Thomaz Filho, 2000), whereas magmatic activity was significantly reduced in the northwest part of the basin (Milani and Ramos, 1998). The presence of a dense and thick layer of volcanic rocks caused crustal overload and subsequent final phase of subsidence in the central portion of the Paraná Basin.

The study area consists of parts of the states of Goiás, Mato Grosso, and Mato Grosso do Sul, and is dominantly overlain by sedimentary sequences of the Paraná Basin and more recent deposits, while the remaining area includes basement composed of the Goiás Magmatic Arc in the Arenópolis area (Pimentel and Fuck, 1992, Pimentel et al., 2000) and metasedimentary rocks of the Paraguay Belt to the west (Alvarenga and Trompette, 1993; Alvarenga et al., 2009; Figures 2 and 3).

\section{Geophysical Framework}

Forward modeling of gravity and magnetic data was performed to determine the relationship between Precambrian discontinuities associated with the TBL and structures of the Paraná 
Basin. The majority of previous 2D, potential-field modeling of Brazilian tectonic provinces and Paleozoic sedimentary basins has focused on the analysis of gravity data (Molina and Ussami, 1989; Vidotti et al., 1998; Mantovani et al, 2005; Ventura et al., 2011; Mariani et al., 2013), although some recent work has included magnetic data (e.g., Castro et al., 2013). In addition to potential-field modeling, the analysis of deep seismic-refraction (Soares et al., 2006), receiverfunction (Assumpção et al., 2002; 2013), seismic tomographic (Rocha et al., 2011; Azevedo et al., 2015), and magnetotelluric (Bologna et al., 2013; Bologna et al., 2014) data have contributed to a better understanding of tectonic boundaries, discontinuities, and crustal faulting along the TBL and within the Paraná Basin.

Soares et al. (2006) and Ventura et al. (2011) analyzed the partitioning of Precambrian crust of the Tocantins Province in the region indicated in Figures 1 and 2 (section S1) using deep seismic-refraction and gravity data. These authors proposed that crustal thickness increases westward from 36-38 km in the Goiás Magmatic Arc to $42-43 \mathrm{~km}$ in the Araguaia Belt. They interpreted this westward increase in crustal thickness as being caused by different phases and directions of subduction, based on possible overlapping crust and delamination of the lower crust, and distinct properties of the lithospheric mantle. Blum and Pires (1996) estimated an average Curie depth of $30 \mathrm{~km}$ in this same region, with shallow regions of the Curie isotherm related to faults, including the TBL. Regionally, the NE-SW trending zone between Amazonian and São Francisco paleoplates (Figure 1), in agreement with the main trend of TBL, is characterized by thinner lithosphere compared to adjacent terranes (Rocha et al., 2011; Azevedo et al., 2015), which may explain high intraplate seismicity along this direction (Assumpção and Sacek, 2013).

Pavão et al. (2012) and Assumpção et al. (2013) compiled crustal thickness values obtained with receiver-function analysis and seismic-refraction data and showed that the area of the TBL, within the northern portion of Paraná Basin, is characterized by thinned crust ranging from 31 to $36 \mathrm{~km}$ thick. Crust thickens southeastward toward the center of the basin, where it reaches thicknesses of between 40 and $46 \mathrm{~km}$ (Figure 1). The central region is marked by a gravity high related to the cratonic Paranapanema Block beneath the basin depocenter (Molina et al., 1988; Vidotti et al., 1998; Mantovani et al., 2005). Mariani et al. (2013) analyzed satellite gravity data and suggested that crustal thickening reflects either underplating or mafic-ultramafic intrusions related to Cretaceous tholeiitic magmatism. Vidotti et al. (1998) calculated forward models from a north-south regional gravity low, bounded by gravity highs between the Paranapanema Block and the Paraná Basin western boundary. They interpreted the negative gravity anomaly as 
reflecting a 3- to 8-km deep graben superimposed on crust marked by magmatic underplating. Thus, previous gravity studies indicate underplating at the base of the crust beneath the Paraná Basin. Using magnetotelluric data, Bologna et al. (2013) recorded a strongly conductive mid-tolower crust in the region that includes the gravimetric low (Vidotti et al., 1998) contrasting with lower conductivities to the east. This difference in conductivity was interpreted as the result of two different lithospheric domains.

Previous studies to develop forward 2D models from magnetic data have focused on local anomalies applied to mineral exploration. A few studies have used magnetic data to interpret broad-scale characteristics of the TBL (Chiarini, 2007; Carvalho et al., 2012) and northern Paraná Basin. Curto et al. (2014), for example, applied a matched-filter technique to magnetic anomalies in the same area as presented here and related the TBL to the tectonic evolution of the basin. They further separated the region into four tectonic domains marked by different compositions and crustal depths. The lineaments that limit these blocks were interpreted as first order structures of the TBL fault zone including, from east to west, Serra Negra, Baliza, and General Carneiro (Figures 3 and 5), which are shown in the models presented here.

\section{Joint Modeling of Gravity and Magnetic Data}

Gravity models can be either process-oriented or static (Watts, 2001; Karner et al., 2005). Process-oriented models take into account the geological processes involved in the formation and development of the basin, such as rifting, compaction, erosion, lithospheric flexure, underplating, intrusion, and volcanism. In static models, density values are determined in order to explain observed gravity anomalies. We assume that both processes are appropriate in the modeling of magnetic data.

We used both procedures described above. Known tectonic and geological features in the study area were important constraints in building the models. Data from stratigraphic wells (2AG1MT, 2JA1GO and 2TQ1MT), paleomagnetism, and analysis of receiver function were also taken into account. The wells, however, are located in the SE portion of the study area, and only one (2AG1MT) reached basement. Knowledge of the tectonic evolution of the northwestern Paraná Basin is limited.

The Paraná Basin lies within the craton (Milani and Ramos, 1998), but the dominant processes leading to subsidence remain unclear. In general, in the analysis and interpretation of gravity signatures of extensional and cratonic sedimentary basins, anomalies are related to the following 
geological features: (i) negative anomalies are caused by low-density sediments that fill the depocenters; (ii) positive anomalies around the basin are associated with structural highs and basement rocks; and, (iii) positive anomalies at or near the depocenters are commonly related to intrusions and/or high density volcanic rocks in the crust or upper mantle (Gunn, 1997; Vidotti et al., 1998; Blakely et al., 2014). In some cases, isostatic compensation may cause crustal thinning, resulting in broad gravity highs superimposed on the shorter-wavelength depocenter anomaly (Karner et al., 2005). Nevertheless, we chose to ignore flexural subsidence and other isostatic effects in the crust because the study area is restricted to the northwest edge of the basin and does not extend significantly beyond it. We assumed in our modeling that the northern part of the Paraná Basin is consistent with a multiple faulting kinematic model along NE and NW striking structures (Zalán et al. 1991), with tectonism favored by zones of crustal weakness partly related to the TBL.

$2 \mathrm{D}$ and 2.5D modeling of magnetic anomalies over large areas is less common in the geophysical literature than gravity modeling. In addition to tectonic complexities intrinsic to the regional geological setting, there are two important attributes of the magnetic field that may complicate modeling: (i) the presence of unknown remnant magnetization, and (ii) low geomagnetic inclinations. Additionally, available magnetic data may have insufficient resolution to properly sample anomalies from shallow portions of the crust, possibly producing aliased anomalies that mask deeper sources. Magnetic anomalies observed in regional surveys are the sum of different local magnetic fields originating from throughout the crustal section, limited in depth by the Curie isotherm. With an understanding of these difficulties, simultaneous modeling of gravity and magnetic data remains a powerful method to resolve crustal discontinuities and structures. Gravity data can resolve ambiguities related to the interpretation of magnetic anomalies, and additionally allow the modeling of the crustal-mantle boundary (Mohorovicic discontinuity). Our proposed models were developed from a long and careful process, but ambiguities are a natural part of potential-field interpretation, and other models based on additional data are encouraged.

\section{Methodology}

The first stage of our methodology focused on pre-processing the data and building a single database from six airborne geophysical surveys (Figure 4). The modeling was performed from gridded data sections of magnetic (Figure 5a) and Bouguer gravity anomalies (Figure 5b) and a digital terrain model, all generated from the compiled database. Longer profiles were modeled based on the reduced-to-pole magnetic anomalies (Figure 5a), since remanent magnetization data are available only for the Cretaceous volcanic rocks of the Serra Geral Formation, which occur in 
the southeastern part of the study area (Ernesto and Pacca, 1988). The processing steps were performed using the software Oasis Montaj (Geosoft, 2014), including its extension for 2D modeling, GM-SYS.

Magnetic and gravity lineaments additionally were interpreted based on the tilt derivative (Miller and Singh, 1994; Verduzco, 2004) of the reduced-to-pole anomalous magnetic field and vertical derivative of Bouguer anomalies, respectively (Figure 6). Parameters and estimates essential to modeling were constrained by data obtained from the literature, plus the results of complementary analyses performed in this study:

(1) Ranges and average values of rock density and susceptibility, based on Telford et al. (1990) and from studies conducted in areas with similar geologic context (Ventura et al., 2011; Pereira and Mantovani, 2012; Dutra et al., 2012), were used to guide our physical properties estimates.

(2) We used remanent magnetization directions obtained through paleomagnetic analysis of Paraná Basin volcanic rocks (Ernesto and Pacca, 1988). Shallow volcanic sills in this area cause high-amplitude magnetic anomalies, and we used paleo-inclination values to conduct a first modelling of magnetic data not reduced-to-pole. Magnetic data from profiles in regions with unknown remanent magnetization direction were reduced to the pole using the modern geomagnetic field. The comparison between models built from paleo-inclinations and from modern inclinations was used to validate the reduction-to-pole filtering since it normally causes distortion of magnetic anomalies at low geomagnetic inclinations (Blakely, 1996). The values of remanent inclination and declination are respectively: $-36.6^{\circ}$ and $1.7^{\circ}$ for normal polarity and $36.6^{\circ}$ and $181.7^{\circ}$ for reversed polarity. Dutra (2011) reported similar values for Cretaceous alkaline intrusions in Arenópolis: inclination and declination of $-40.3^{\circ}$ and $1.8^{\circ}$ for normal polarity and $40.3^{\circ}$ and $181.8^{\circ}$ for reversed polarity.

(3) Depth values of the basement were constrained by three stratigraphic wells. The 2AG1MT well reached the Cuiabá Group, considered to be basement at this site, at a depth of $1943 \mathrm{~m}$. The 2JA1GO and 2TQ1MT wells have maximum depths of $2107 \mathrm{~m}$ and $2020 \mathrm{~m}$, respectively; both bottomed in the Devonian sequence of the Paraná Basin and did not reach basement.

(4) Crustal thickness estimates based on receiver-function data (Assumpção et al., 2002; Bianchi, 2008; Lloyd et al., 2010; Albuquerque et al., 2010; Figures 1 to 3) and deep seismic-refraction data (Soares et al., 2006; Ventura et al., 2011; Figures 1 and 2) were compiled by Pavão et al. (2012).

(5) Because the wells and analysis of receiver function provide mainly the depth values of the basin/basement and crust/mantle interfaces, respectively, previous work (Curto et al., 2014), and 
additional results given by the Euler deconvolution (Thompson, 1982; Reid et al., 1990) and Matched-Filter (Syberg, 1972; Phillips, 2001) techniques were analyzed to obtain other depth levels.

The sections for the joint modeling of magnetic and gravity data were positioned subperpendicular to gravity and magnetic lineaments. The first two sections $X-X^{\prime}$ and $Y-Y^{\prime}$ were modeled in order to support the modeling of the larger Z-Z' section, selected as the most representative for the understanding of the northern sector of the Paraná Basin, its basement and crustal partitioning covered by the basin (Figure 5). Sections $\mathrm{X}-\mathrm{X}^{\prime}$ and $\mathrm{Y}-\mathrm{Y}^{\prime}$ were chosen based on additional data from wells and analysis of receiver function, which are concentrated in the southern part of the study area. The most northern portion of the study area has insufficient data for this type of analysis. Section Z-Z' was placed in the central region, to cover a larger portion of the study area and to contribute to our understanding, based on more consistent models generated for the south. These three sections were modeled according to the following general steps:

(1) Modeling of longer anomaly wavelengths was based on preliminary definitions of major crustal interfaces between mantle, lower crust, and upper crust, including the broad limit between basement and basin.

(2) Separation of the layers found in the previous step in accordance with major magnetic lineaments determined by Curto et al. (2014): Serra Negra, Baliza and General Carneiro. The placement and geometry of the lineaments were refined according to the gravity signatures and Euler solutions. In most cases, magnetic lineaments are marked by steep gravity gradients.

(3) Definition of shallow bodies, $<10 \mathrm{~km}$ deep, was based on the interpretation of the shorter wavelengths of the observed data and the Euler solutions.

(4) Intermediate wavelengths were modeled by sub-dividing the blocks located at depths shallower than $20 \mathrm{~km}$. This procedure simulates horizontal variations in the composition of the upper crust.

(5) Final adjustment of the model focused on both the geometry and physical properties of the bodies and blocks identified in steps 3 and 4. Blocks and shallow bodies were classified according to numbers and letters, respectively. Each class is related to a specific range of susceptibility and/or density values (Table 1). 


\section{Results}

The magnetic anomaly map of the study area (Figures 5) and its tilt derivative (Figure 6) show that the $\mathrm{TBL}$ has a well-defined $\mathrm{N} 30^{\circ} \mathrm{E}$ trend, in agreement with its overall extension from the Atlantic continental shelf to the northwest flank of the Paraná Basin, where structural ramifications diverge from the main fault (Vidotti et al., 2011). Within the northwest Paraná Basin, the TBL includes three first-order NE lineaments. The $\mathrm{N} 30^{\circ} \mathrm{E}$ regional trend of the $\mathrm{TBL}$ is mainly represented by the Serra Negra lineament (Curto et al. 2014). Other trends vary predominantly around $\mathrm{N} 60^{\circ}-70^{\circ} \mathrm{E}$ and are concentrated west of the Serra Negra lineament; these include the Baliza and General Carneiro lineaments. Magnetic and gravity anomalies often are not coincident to each other. Nevertheless, it is possible to observe their relationship through regional gravity anomalies associated with or subparallel to the main magnetic lineaments of the area (Figures 5 and 6).

The tilt derivative (Miller and Singh, 1994; Verduzco, 2004) map of the reduced-to-pole magnetic anomaly enhances magnetic lineaments from sources throughout the crustal section (Figure 6a). The map of the vertical derivative (Nabighian, 1984) of Bouguer anomalies emphasizes shallow density contrasts and highlights the relationship between magnetic lineaments and areas with steep gravity gradients (Dz, Figure 6b). The Serra Negra lineament (label A in Figures 5 and 6) clearly shows this relationship. Negative gravity anomalies caused by shallow sources strike NE, E-W, NNW, and N-S and coincide with part of the drainage network of the study area (Figure 6b). The drainage is commonly associated with structures and topographic breaks, indicating a possible relationship with neotectonic reactivation of fractures and/or faults of the basement. Neotectonism is also related to seismicity in the area, as discussed by Curto et al. (2014).

\subsection{Depth estimates}

Euler Deconvolution is one method to estimate source depth from magnetic anomalies. This method relies on a numerical "structural index" related to source geometry (Reid et al., 1990), essentially a measure of the fall-off rate of the magnetic field with distance from the source. We used structural indices of 0 and 1, appropriate for contacts and faults, respectively, to map vertical gravity and magnetic discontinuities at different depth levels. We also used a structural index of 2, appropriate for cylindrical forms, in the Y-Y' section (Figure 8) due to unsatisfactory results given by index 1 . Convolution windows of $7.5 \times 7.5,10 \times 10$, and $15 \times 15 \mathrm{~km}$ were found to be most useful in improving the tradeoff between greater depths of investigation solution scattering. The Euler solutions (Figures 7 to 9) show correspondence with most of the boundaries 
between blocks of the intermediate and shallow portions of the crust $<15 \mathrm{~km}$ deep. Some Euler solutions from gravity and magnetic data do not correspond perfectly, but they do complement each other and support a better constrained model. On the other hand, modeled features that are not related to any Euler solutions of gravity or magnetic data (e.g., below body B, block 7, XX' profile; figure 7) draws attention for other possible hypotheses.

Tilt-derivative, vertical derivative, and Euler deconvolution provided information about the upper $15 \mathrm{~km}$ of the crust, and were important constrains to the basin-basement interface modeling, varying from 1 to $4 \mathrm{~km}$ deep. Matched-filter analysis of Bouguer anomalies helped estimate the depth of deeper crustal zones. This method uses analyses of the radial power spectrum to design filters that essentially emphasize anomalies originating from important source depths (Syberg, 1972; Phillips, 2001). Tests were conducted on several partially overlapping sub-areas. Despite the statistical treatment, an important depth population varies widely, between 13 and $24 \mathrm{~km}$, indicating qualitatively that the crustal zoning also varies greatly, and possibly occurs at the boundary between the upper and lower crust. This limit is generally estimated at a depth of $20 \mathrm{~km}$ (Curto et al., 2014) using the matched-filter analysis for magnetic data.

\subsection{Two-Dimensional Models}

In the northwest Paraná Basin, first order lineaments within the TBL zone separate into four major geophysical domains. The Serra Negra lineament is characterized by a significant change in the wavelength of regional gravity, accompanied by an overall westward increase in intensity (Figures 7-9). The increase in intensity continues at the General Carneiro lineament, but with subtler changes in the regional gravity. This characteristic is most noticeable in longer sections since they include a greater variation in the potential field intensity (Figure 9). Major points of field change are indicated by steep gravity and magnetic gradients. The blocks bounded by lineaments were modeled with different dimensions and/or physical properties. More significant changes in physical properties characterize blocks with different numbers (Table 1). Close to the Serra Negra Lineament, the blocks labeled 6 display high magnetization, characterizing a notable magnetic zone of the study area. The 2JA1GO well and the 44-km crustal thickness obtained by receiver function analysis constrain the modeling near the eastern boundary of the three sections. This well bottomed at $2107 \mathrm{~m}$ without reaching basement. The two shallower layers were modeled as nonmagnetic, but include intrusive bodies along their length that are strongly magnetic. These bodies correspond in part to diabase sills recorded in the 2JA1GO and 2TQ1MT wells, as well as outcrops registered in geological maps (Schobbenhaus et al., 2004). The sill thicknesses in the wells, as well as the models, are up to $100 \mathrm{~m}$ and $300 \mathrm{~m}$, respectively. 
Lithostratigraphic data from the three wells (2AG1MT, 2JA1GO, 2TQ1MT) were included in the Y-Y' and Z-Z' sections (Figures 3, 8 and 9). On the other hand, the first two wells in section $\mathrm{X}-\mathrm{X}^{\prime}$ are positioned precisely at its start and end points (Figures 3 and 7). In this section, the magnetic anomalies were not previously reduced-to-pole and we considered possible remanent magnetization in the modeling of shallower bodies, which are marked by anomalies with large amplitudes and small wavelengths, which are difficult to model in the absence of paleomagnetic data (Table 1). Paleo-inclination values were constrained by paleomagnetic data (Ernesto and Pacca, 1988, Dutra, 2011). The crust at the western limit of the $Y^{-} Y^{\prime}$ section is $33 \mathrm{~km}$ thick, given by the analysis of receiver function data compiled by Pavão et al. (2012). This section clearly shows crustal thickness increasing eastward, where it reaches a depth of $44 \mathrm{~km}$. In the 2TQ1MT well, the depth to the top of basement is estimated to be at least $2750 \mathrm{~m}$ (internal report, Petrobras, 1966). The western portions of $Y^{-} Y^{\prime}$ and $Z-Z^{\prime}$ sections include magnetic sources distant from those with known remanent magnetization. Therefore, the magnetic data were first reduced to the pole to allow modeling of shallow bodies with unknown remanent magnetization (Table 1). Due to the low regional magnetic intensity of the study area, some shallow low-amplitude magnetic anomalies were modeled using negative susceptibilities, understanding that negative ferromagnetic susceptibilities do not occur in nature. We considered this approach more appropriate than increasing all susceptibilities in the modeled section to positive values.

\section{Discussion}

Joint modeling of magnetic and gravity data allowed us to compare the Serra Negra, Baliza, and General Carneiro lineaments to known faults or fault zones. Here we propose a preliminary tectonic model (Figure 10) based on the integrated results of our geophysical modeling (Figures 7, 8 and 9), previous geophysical studies, and the known geological framework. The model location is according to the ZZ' profile (Figure 5).

The first geophysical layer, continuous throughout all sections, displays physical characteristics compatible with sedimentary rocks (Table 1) and is related to sedimentary units of the Paraná Basin (Figure 10). Reasonable modeling of the sedimentary thickness was achieved, even though only one of the three wells $(2 \mathrm{AG} 1 \mathrm{MT})$ reached basement $(1.9 \mathrm{~km})$. Intra-sedimentary bodies with high susceptibility and remanent magnetization values (Table 1) were found in several areas of the basin and are interpreted as volcanic rocks, corroborated by the existence of diabase sills of the Serra Geral formation (Ernesto and Pacca, 1988) and 85 Ma old volcanic rocks (Weska, 
2006) that occur in the southeast and northwest portions of the area, respectively. The geophysical contrast between sills and the sedimentary rocks creates remarkable gravity and magnetic gradients. On the other hand, the magnetic contrast between the first and second layer is insignificant, so both were considered nonmagnetic (Table 1). The nonmagnetic second layer correlates with the metasedimentary basement, Cuiabá Group, which is exposed along most of the basin's western boundary. On the basis of exposures in the Bom Jardim de Goiás area (Seer, 1985; Seer and Nilson, 1985; Schobbenhaus et al., 2004) we infer that the Cuiabá Group is bounded eastward by the Serra Negra lineament. The fault associated with this lineament was reactivated < $560 \mathrm{Ma}$ (Brito Neves and Fuck; 2013), probably in the initial Ordovician subsidence of Paraná basin, which conditioned and affected adjacent blocks. Our tectonic model shows that thinning of the Paraná Basin toward the northwest flank (Milani and Ramos, 1998) is not uniform. The formation of horsts and grabens along the entire extension of modeled sections results in an asymmetric configuration for this area of the basin. Our proposed tectonic model (Figure 10) highlights three grabens of 3-4 km deep that are controlled by the Serra Negra, Baliza and General Carneiro faults. Associated structures acted together to bound reactivated blocks. For example, in section $\mathrm{YY}^{\prime}$ and near the $2 \mathrm{TQ} 1 \mathrm{MT}$ well, $\mathrm{N} 60^{\circ}-70^{\circ} \mathrm{E}$ trending magnetic and gravity lineaments apparently disrupt the N30 ${ }^{\circ}$ E Serra Negra lineament (Figures 5 and 6). Consequently, modeled features are influenced by both structural directions (Section YY', figure 8). Due to the NW-direction of the profiles, sub-perpendicular to most of the geophysical anomalies, our models do not address structures with parallel or similar direction. However, analysis of magnetic anomalies and Bouguer maps (Figures 5 and 6) show that structures with other trends also play an important role in reactivation, and for this reason they were considered in our interpretation. In Poxoréo region, the horst and graben system is possibly related to reactivations of NW, NS and NE trending faults, including General Carneiro lineament and associated structures, as the NE Poxoréo and Jaciara faults, to the north (Coimbra, 1991; Figures 3,6 and 10).

Geophysical anomalies originating from the shallow basement, partially indicated by Euler solutions, suggest the presence of intrusive bodies. Faults associated with the TBL enhance the geophysical contrast between intrusive bodies and surrounding rocks. These bodies are separated into two main groups: one with higher magnetic susceptibility and density values, assumed to be mafic to ultramafic rocks; and a second group, characterized by probable felsic rocks (Table 1; Figure 10). The first group is in agreement with rocks originated from the Neoproterozoic magmatic arc (Pimentel and Fuck, 1992; Pimentel et al., 1997, 2000, 2011; Laux et al., 2005) and the Cretaceous magmatism (Ernesto and Pacca, 1988; Renne et al., 1992). Post-orogenic 
intrusions in the basement, such as Macacos, Serra Verde, Serra Negra, São Vicente, Sonora and Araguainha granites (500-600 Ma; Pimentel et al., 2011, Godoy et al., 2007, 2010; Figure 3) are examples of felsic rocks. The center of the Araguainha impact dome provides a unique basement exposure, close to the ZZ' section (Figure 3). These bodies may influence greatly the gravity and magnetic anomalies, which, in most cases, are caused by a combination of more than one geological feature. As an example, the gravity low bounded to the west by the Serra Negra fault zone is caused both by the graben and by felsic intrusions with densities lower than basement, as in the case of the negative contrast generated between the Cretaceous volcanic and sedimentary rocks. This scenario is also supported by magnetic anomalies, which reduce the level of ambiguity. However, it is important to note that this only one working hypothesis among other possibilities. Alternative scenarios could be developed by changing large parts of the model parameters, from the deepest to the shallowest source, and along the horizontal extent.

The Serra Negra fault zone causes strong magnetic and gravity gradients in the study area. The fault zone is associated with high magnetization values, possibly caused by magnetic minerals resulting from percolation of fluids, facilitated by the ductile and subsequent tectonism of the TBL transcurrent system. The Serra Negra fault is the main structure of the TBL shear zone and limits two main tectonic domains characterized by different types of crust and mantle (Figure 10). To the east, the crust is thicker and less dense. The basement in this area is unknown, but our models indicate that the crust in the area covered by the Paraná Basin is $44 \mathrm{~km}$ thick, while near the west and northwest basin edge, the crust is 33 and $39 \mathrm{~km}$ thick (Figures 8 and 9), respectively. Our previous work with matched-filter analyses of magnetic data (Curto et al., 2014) also indicated abrupt differences of crustal depths and composition between different tectonic domains. To the north, a thinner crust is recorded in the Goiás Magmatic Arc (Figure 1, Soares et al., 2006; Pavão et al., 2012; Assumpção et al., 2013).

The abrupt southeastward increase of crustal thickness in the study area suggests the following evolution scenario: The thick basement southeast of the area is represented by the Paranapanema Block, which probably was affected by magmatic accretion resulting from arc magmatism during the Brasiliano subduction in the Neoproterozoic and the Serra Geral magmatism during the Cretaceous. This tectonic relief first resulted from the closing of a Precambrian ocean, limited by two crustal domains. Various authors have discussed the existence of this ocean (Pimentel and Fuck, 1987, 1992; Brito Neves and Cordani, 1991; Almeida et al., 2000; Pimentel et al., 2000; Brito Neves et al., 2009; Cordani et al., 2009a,b; Cordani et al., 2010; Cordani et al., 2013; Bologna et al., 2014; Cordani et al., 2013; Brito Neves et al., 2014), while its association and/or 
relationship with the TBL is sometimes addressed indirectly or secondarily. We believe that an ancient suture zone was intensely reworked in the study area sector of the TBL. Structures and weakness zones related to the TBL may have facilitated the action of magmatic and hydrothermal processes, reactivated faults, and controlled the formation of sedimentary basins.

The thin crust to the west of the Serra Negra fault zone is related to the Amazonian paleocontinent and remains thin up to the General Carneiro fault zone (Figure 10). We suggest that the thinner crust between the two major faults reflects a zone of crustal weakness, in agreement with studies related to the NE trending intra-plate seismicity along the lithospheric thinning in the Tocantins Province (Rocha et al., 2011; Assumpção and Sacek, 2013; Azevedo et al., 2015). In the Neoproterozoic, the thin crust in the study area would have been part of the continental shelf which received sediment of the former basin of the Paraguay Belt, while the eastward-directed Brasiliano subduction was occurring towards the Paranapanema Block. This hypothesis corroborates the foreland basin configuration, as initially suggested by Almeida (1964) and it is still assumed in recent studies (Alvarenga et al., 2009; Dantas et al., 2009). The Paraguay belt becomes thicker westward in the study area, possibly due to convergence thrust tectonics. We believe that the low magnetic intensity and the gravity low in the region north of Poxoréo are caused in part by greater total thickness of sedimentary and metasedimentary rocks ( 5 - $6 \mathrm{~km}$; Figures 5 and 9). An important river system formed by the Rio das Mortes and its tributaries mark, respectively, the possible center of this graben and the fracturing pattern from structural highs associated with this graben (Figure $6 \mathrm{~b}$ ). The crust is about $40 \mathrm{~km}$ thick to the north of the General Carneiro fault, where the thickening trend starts toward the Amazonian Craton.

Apparently, the crustal weakness zone between the Serra Negra and General Carneiro faults was intensely reactivated, resulting in the formation of Cretaceous depocenters and faults of the units of the Paraná Basin. The Baliza fault is a major reactivation structure observable in the field (Curto et al. 2014). To the west of this fault, small depocenters associated with gravity lows correspond to drainages occupying formerly activated structures. Cretaceous volcanic rocks are less abundant and thinner (Figure 10). NW and E-W structures also acted as tectonic control on these rocks through dip- and strike-slip faulting (Figures 3, 5 and 6).

\section{Conclusions}

The joint 2D modeling of magnetic and gravity data allowed us to define major crustal boundaries in the northwestern region of the Paraná Basin. Different depths and geometries of 
major crustal interfaces were characterized, including the crust-mantle and the basement-basin contacts. Local gravity and magnetic anomalies are attributed to physical variations in the shallower levels (upper crust), including the occurrence of intra-sedimentary diabase sills and intrusive bodies in the basement. The modeled blocks and bodies are separated by geophysical discontinuities that cause gravity gradients and magnetic lineaments observed in the map, interpreted as geological structures and contacts. We propose that the $\mathrm{N} 30^{\circ} \mathrm{E}$ trending Serra Negra fault zone is the main tectonic element of the TBL in this area, which is coincident with its regional trend and it serves as the boundary between two tectonic domains with different crustal thicknesses, the Paranapanema Block and the Amazonian paleocontinent. Tectonic compartments to the west are separated by $\mathrm{N} 60^{\circ}-70^{\circ} \mathrm{E}$ trending $\mathrm{TBL}$ regional structures, consistent with the general direction of the northern portion of the Paraguay Fold Belt. The reactivation of regional structures formed horsts and grabens in the area, allowing the initial sedimentation of the Paraná Basin. Subsequent reactivations caused the faulting of the Devonian, Carboniferous and Cretaceous basin units, with subsequent formation of depocenters and sedimentation.

\section{Acknowledgments}

We are grateful for the sponsorship of FUB/Petrobrás under the cooperation term 0050.0053151.09.9; and to CNPq - Conselho Nacional de Desenvolvimento Científico e Tecnológico for the grants to JBC and RAF. We also thank ANP - Agência Nacional do Petróleo, Gás Natural e Biocombustíveis, CPRM - Serviço Geológico do Brasil, CNEN Comissão Nacional de Energia Nuclear, and SGM / SIC-GO (Secretaria de Indústria e Comércio do Estado de Goiás) for providing access to geophysical data for academic purposes; GEOSOFT for providing the software Oasis Montaj 8.1; ESRI for providing the tool package ArcGis 10 under the contract $\mathrm{n}^{\circ} 2011$ MLK 8733; IMAGEM for making possible the agreement between IG-UnB (Instituto de Geociências da Universidade de Brasília) and ESRI; the Laboratory of Remote Sensing and the Laboratory of Applied Geophysics of the IG-UnB for the use of their facilities. We are grateful to U.S Geological Survey for providing access to computer and office facilities. Our paper was greatly improved by constructive remarks from two anonymous reviewers. We are particularly grateful to Jonathan Glen, Daniel Scheirer, and professors Elton Dantas and Carlos Alvarenga for their helpful comments and suggestions during the course of this research. We also thank to professors Naomi Ussami, João M. M. Neto, Mônica Von Huelsen and Lucieth Vieira for their suggestions and reviews, as part of the first author's thesis defense. 


\section{References}

Albuquerque, D. F., Pavão, C.G., França, G. S. L. A., Silva, P. G. N., 2010. O Estudo da Espessura Crustal e Razão Vp/Vs Para as Estações da Rede Sismográfica Nacional (RSNSIS-UnB). IV Simpósio Brasileiro de Geofísica, Brasília, Abstract.

Almeida, F. F. M., 1964. Geologia do Centro-Oeste Matogrossense. Departamento Nacional de Produção Mineral, Rio de Janeiro, Boletim Divisão Geologia Mineralogia 215, 137p.

Almeida, F. F. M. de, Hasui, Y., Brito Neves, B. B., Fuck, R. A., 1981. Brazilian Structural Provinces: An Introduction. Earth-Sci. Rev. 17, 1-29, doi: 10.1016/0012-8252(81)90003-9.

Almeida, F. F. M. de, Brito Neves, B. B., Carneiro, C. D. R., 2000. The origin and evolution of the South American Platform. Earth-Sci. Rev. 50, 77-111.

Alvarenga, C. J. S., and Trompette, R., 1993. Evolução tectônica brasiliana da Faixa Paraguai: a estruturação da região de Cuiabá. Revista Brasileira de Geociências 23, 18-30.

Alvarenga, C. J. S. de, Guimarães, E. M., Assine, M. L., Perinotto, J. A. de, 1998. Sequência Orodovício-Siluriano e Devoniano no Flanco Norte da Bacia do Paraná. Anais da Academia Brasileira de Ciências 70 (3), 587-606.

Alvarenga, C.J.S. de, Santos, R.V., Dantas, E.L., 2004. C-O-Sr isotopic stratigraphy of cap carbonates overlying Marinoan-age glacial diamictites in the Paraguay Belt, Brazil. Precambrian Research 131, 1-21, doi: 10.1016/j.precamres.2003.12.006.

Alvarenga, C. J. S. de, Boggiani, P. C., Babinski, M., Dardenne M. A., Figueiredo, M. F., Santos, R. V., Dantas, E. L., 2009. The Amazonian Paleocontinent. In: Gaucher, C., Alcides, N.S., Halverson, G.P., and Frimmel, E. H. (Eds.), Neoproterozoic-Cambrian Tectonics, Global Change and Evolution: A focus on southwestern Gondwana, Developments in Precambrian Geology, Elsevier, Amsterdam, 16, pp. 15-28, doi: 10.1016/S01662635(09)01602-8.

Assumpção, M., D. E. James, Snoke, J. A. 2002. Crustal thickness in SE Brazilian shield by receiver function analysis: Implications for isostatic compensation. J. Geophys. Res. 107 (B12006), doi:10.1029/2001JB000422.

Assumpção, M., Sacek, V., 2013. Intra-plate seismicity and flexural stresses in central Brazil. Geophysical Research Letters 40 (3), 487-491, doi: 10.1002/grl.50142

Assumpção, M., Bianchi, M., Julià, J., Dias, F. L., Sand França, G., Nascimento, R., Drouet, S., Pavão, C. G., Albuquerque, D. F., Lopes, A. E. V., 2013. Crustal thickness map of Brazil: Data compilation and main features. J. S. Am. Earth Sci. 43, 74-85, doi: 10.1016/j.jsames.2012.12.009. 
Azevedo, P., Rocha, M., Soares, J. E., Fuck, R., 2015. Thin lithosphere between Amazonian and São Francisco cratons, in central Brazil, revealed by seismic P-wave tomography. Geophysical Journal International 201, 61 - 69, doi: 10.1093/gji/ggv003

Baranov, V., Naudy, H., 1964. Numerical calculation of the formula of reduction to the magnetic pole. Geophysics 29, 67-79, doi: 10.1190/1.1439334.

Bianchi, M. B., 2008. Variações da estrutura da crosta, litosfera e manto para plataforma Sul Americana através da função do receptor para ondas $\mathrm{P}$ e $\mathrm{S}$. [PhD. Thesis]: Universidade de São Paulo, IAG, 132p.

Blakely, R. J., 1996. Potential Theory in Gravity and Magnetic Applications, 2nd ed. Cambridge University Press, Cambridge (UK) (441pp.).

Blakely J.R, Sherrod B.L., Weaver C.S., Wells R.A., Rohay A.C., 2014. The Wallula Fault and tectonic framework of south-central Washington State, as interpreted from magnetic and gravity anomalies. Tectonophysics, 624-625, 32-45, doi: 10.1016/j.tecto.2013.11.006.

Blum, M. de L. B., Pires, A. C. B., 1996. Superfície Curie da Região Central de Goiás. Revista Brasileira de Geociências 26 (3), 197-208.

Bologna, M.S., Nunes, H.O., Padilha, A.L., Vitorello, Í., Pádua, M.B., 2013. Anomalous electrical structure in the northwestern Paraná Basin, Brazil, observed with broadband magnetotellurics. J. S. Am. Earth Sci. 42, 74-82.

Bologna, M. S., Padilha, A. L., Pádua, M. B., Vitorello, Í., Chamalaun, F. H., 2014. ParaguayAraguaia Belt Conductivity Anomaly: A fundamental tectonic boundary in South American Platform imaged by electromagnetic induction surveys. Geochem. Geophy. Geosy. 15 (3), 509-515, doi:10.1002/2013GC004970

Brito Neves, B. B., Cordani, U. G., 1991. Tectonic Evolution of South America during the Late Proterozoic. Precambrian Res. 53 (1-2), 23-40, doi: 10.1016/0301-9268(91)90004-T.

Brito Neves, B.B., Fuck, R. A., Cordani, U. G., Thomaz Filho, A., 1984. Influence of basement structures on the evolution of the major sedimentary basins of Brazil. J. Geodyn. 1 (3-5), 495 510, doi: 10.1016/0264-3707(84)90021-8.

Brito Neves, B. B., Campos Neto, M. C., Fuck, R. A., 1999. From Rodinia to Western Gondwana: an approach to the Brasiliano-Pan African Cycle and orogenic collage. Episodes $22(03), 155-166$.

Brito Neves, B.B., Fuck, R.A., 2013. Neoproterozoic evolution of the basement of the SouthAmerican Platform. Journal of South American Earth Sciences 47, 72 - 89, doi: 10.1016/j.jsames.2013.04.005 
Brito Neves, B. B., Fuck, R. A., Pimentel, M . M., 2014. The Brasiliano collage in South America: a review. Brazilian Journal of Geology 44 (3), 493-518, doi: 10.5327/Z23174889201400030010

Carvalho, D.L.O., Vidotti, R. M., Araújo Filho, J. O., Meneses, P. R., 2012. Geologia, aerogeofísica e gravimetria terrestre da porção central do Graben de Água Bonita, sudoeste de Tocantins e noroeste de Goiás, Brasil. Revista Brasileira de Geofísica 30(4), 483-494.

Chiarini, M.F.N., 2007. Contribuição da aerogeofísica na caracterização de suturas e de sistemas transcorrentes: o exemplo de Porangatu, Brasil Central. [M.S. Thesis]: Universidade de Brasília, Instituto de Geociências, Brasília, 108 p. Available at: http://hdl.handle.net/10482/1941

Coimbra, A.M., 1991. Sistematização crítica da obra. [PhD Thesis]: Universidade de São Paulo, Instituto de Geociências, $54 \mathrm{p}$.

Cordani,U.G., Brito Neves, B.B., Fuck, R.A., Porto, R., Thomaz Filho, A., Da Cunha, F.M.B., 2009a. Estudo preliminar de integração do Pré-Cambriano com os eventos tectônicos das bacias sedimentares brasileiras (Republicação). Bol. Geoci. Petrobras, Rio de Janeiro 17 (1), 133-204.

Cordani,U.G., Brito Neves, B.B., Thomaz Filho, A., 2009b. Estudo preliminar de integração do Pré-Cambriano com os eventos tectônicos das bacias sedimentares brasileiras (Atualização). Bol. Geoci. Petrobras, Rio de Janeiro 17 (1), 205-219.

Cordani, U. G., Fraga, L. M., Reis, N., Tassinari, C. C. G., Brito Neves, B. B., 2010. On the origin and tectonic significance of the intra-plate events of Grenvillian-type age in South America: A discussion. Journal of South American Earth Sciences 29, 143-159, doi:10.1016/j.jsames.2009.07.002

Cordani, U. G., Pimentel, M. M., Araújo, C. E. G. de, Basei, M. A. S., Fuck, R. A., Girardi, V. A. V., 2013. Was there an Ediacaran Clymene Ocean in central South America. Am. J. Sci. 313, 517-539, doi: 10.2475/06.2013.01.

Curto, J. B., Vidotti, R. M., Fuck, R. A., Blakely, R. J., Alvarenga, C. J. S., Dantas, E. L., 2014. The tectonic evolution of the Transbrasiliano Lineament in northern Paraná Basin, Brazil, as inferred from aeromagnetic data. J. Geophys. Res. Solid Earth, 119, doi:10.1002/2013JB010593.

Dantas, E. L., Alvarenga, C. J. S., Santos, R. V., Pimentel, M. M., 2009. Using Nd isotopes to understand the provenance of sedimentary rocks from a continental margin to a foreland basin in the Neoproterozoic Paraguay Belt, Central Brazil. Precambrian Research 170, 1-12, doi: 10.1016/j.precares.2008.11.005 
De Castro, D.L., Fuck, R.A., Phillips, J.D., Vidotti, R.M., Bezerra, F.H.R., Dantas, E.L., 2013. Crustal structure beneath the Paleozoic Parnaíba Basin revealed by airborne gravity and magnetic data, Brazil. Tectonophysics 614, 128-145.

Dutra, A. C., 2011. Inversão tridimensional de dados gravimétricos e magnéticos da Província Alcalina de Goiás: Investigando o controle tectônico. [Ph.D Thesis]: Universidade de São Paulo, IAG, $151 \mathrm{p}$.

Dutra, A.C., Marangoni, Y.R., Junqueira-Brod, T.C., 2012. Investigation of the Goiás Alkaline Province, Central Brazil: Application of gravity and magnetic methods. J. S. Am. Earth Sci. $33,43-55$.

Engelhardt, W. V., Matthäi, S., K., Walzebuck, J., 1992. Araguainha impact crater, Brazil. I. The interior part of the uplift. Meteoritics \& Planetary Science 27 (4), 442-457, doi: 10.1111/j.1945-5100.1992.tb00226.x

Ernesto, M., Pacca, I. G., 1988. Paleomagnetism of the Paraná Basin flood volcanics, Southern Brasil. In: Piccirillo, E.M., Melfi, A. J. (Eds.), The Meozoic Flood Volcanism of the Paraná Basin: Petrogenic and Geophys. Aspects. IAG-USP Press., São Paulo, Brazil, pp. 229-255.

Fairhead, J., Maus, S., 2003. CHAMP satellite and terrestrial magnetic data help define the tectonic model for South America and resolve the lingering problem of the pre-break-up fit of the South Atlantic Ocean. The Leading Edge 22, 779-783, doi: 10.1190/1.1605081

França, G. S. 2003. Estrutura da crosta no sudeste e centro-oeste do Brasil, usando função do receptor. [Ph.D Thesis]: Universidade de São Paulo, IAG, 143p.

França, A. B., Milani, E. J., Schneider, R. L., López-Paulsen, O., López-Pugliessi, J. M., Suárez, S. R., Santa Ana, H., Wiens, F., Ferreiro, O., Rossello, E. A., Bianucci, H. A., Flores R. F. A., Vistalli, M. C., Fernández-Seveso, F. , Fuenzalida, R. P., Muñoz N., 1995. Phanerozoic correlation in Southern South America. In: Tankard et al. (Eds.), Petroleum basins of South America, Memoir 62, AAPG, Danvers, Massachusetts, pp. 129-161.

Fuck, R. A., Brito Neves, B. B., Schobbenhaus, C., 2008. Rodinia descendants in South America. Precambrian Res.160, 108-126, doi:10.1016/j.precamres.2007.04.018.

Geosoft, 2014. Oasis montaj 8.1.Toronto, Canada: Geosoft Inc.

Gibson, S. A., Thompson, R. N., Weska, R. K., Dickin, A. P., Leonardos, O. H., 1997. Late Cretaceous rift-related upwelling and melting of the Trindade starting mantle plume head beneath western Brazil. Contrib. Mineral. Petr. 126 (3), 303-314.

Godoy, A. M., Manzano, J. C., Ruiz, A. S., Araujo, L. M. B. de, 2007. Os Granitóides Brasilianos Pós-Tectônicos da Faixa de Dobramentos Paraguai MS e MT. Geologia USP, Série Científica 7, 29-44. 
Godoy, A. M., Pinho, F. E. C., Manzano, J. C., Araújo, L. M. B. de, Silva, J. A. da, Figueiredo, M., 2010. Estudos isotópicos das rochas granitoides Neoproterozóicas da Faixa de Dobramento Paraguai. Revista Brasileira de Geociências 40 (3), 380-391.

Grant, F.S., Dodds, J., 1972. MAGMAP FFT Processing System Development Notes, Paterson Grant and Watson Ltd, Toronto, Canada.

Gunn, P.J., 1997. Application of aeromagnetic surveys to sedimentary basin studies. AGSO Journal of Australian Geology \& Geophysics 17 (2), 133-144.

Heilbron, M., Mohriak, W., Valeriano, C. M., Milani, E. J., Almeida, J. C. H., Tupinambá, M., 2000. From collision to extension: the roots of the south-eastern continental margin of Brazil. In: M. Talwani and Mohriak W. (Eds.), Atlantic Rifts and Continental Margins, Geophysical Monograph Series 115, AGU, Washington, DC, pp.1-34.

Karner, G.D., Studinger, M., Bell, R.E., 2005. Gravity anomalies of sedimentary basins and their mechanical implications: Application to the Ross Sea basins, West Antarctica. Earth Planet. Sci. Lett. 235, 577 - 596, doi:10.1016/j.eps1.2005.04.016.

Lana, C., Souza Filho, C. R., Marangoni, Y. R., Yokoyama, E., Trindade, R. I. F., Tohver, E., Reimold, W. U., 2008. Structural evolution of the $40 \mathrm{~km}$ wide Araguainha impact structure, central Brazil. Meteoritics \& Planetary Science 43 (4), 701-716, doi: 10.1111/j.19455100.2008.tb00679.x

Lloyd, S., Van der Lee. S., França, G. S., Assumpção, M., Feng, M., 2010. Moho map of South America from receiver functions and surface waves. J. Geophys. Res. 115, B11315, doi:10.1029/2009JB006829.

Mantovani, M.S.M., Quintas, M.C.L., Shukowsky, W., Brito Neves, B.B., 2005. Delimitation of the Paranapanema Proterozoic block: A geophysical contribution. Episodes 28, 18-22.

Mariani, P., Braitenberg, C., Ussami, N., 2013. Explaining the thick crust in Paraná basin, Brazil, with satellite GOCE gravity observations. J. S. Am. Earth Sci. 45, 209-223.

Matteini, M., Dantas, E. L., Pimentel, M. M., Bühn, B., 2010. Combined U-Pb and Lu-Hf isotope analyses by laser ablation MC-ICP-MS: methodology and applications. Anais da Academia Brasileira de Ciências 82 (2), 479-491, doi: 10.1590/S0001-37652010000200023

Milani, E.J., Ramos, V. A.,1998. Orogenias paleozóicas no domínio sul-ocidental do Gondwana e os ciclos de subsidência da Bacia do Paraná. Revista Brasileira de Geociências 28 (4), 473 484.

Milani, E.J., Thomaz Filho, A., 2000. Sedimentary Basins of South America. In: Cordani et al. (Eds.), Tectonic Evolution of South America, 31st International Geological Congress, Rio de Janeiro, RJ, Brazil, pp. 389-449. 
Milani, E.J., Henrique, J., Melo, G. De, Souza, P.A. De, Fernandes, L.A., França, A.B., 2007. Bacia do Paraná. Bol. Geoc. Petrobras, Rio de Janeiro 15 (2), 265-287.

Miller, H. G., Singh, V., 1994. Potential field tilt- a new concept for location of potential field sources. J. Appl. Geophys. 32, 213-217, doi: 10.1016/09269851(94)90022-1

Molina, E. C., Ussami, N., 1989. Interpretação dos dados gravimétricos da parte norte da Bacia do Paraná. Revista Brasileira de Geociências 19, 187-196.

Molina, E.C., Ussami, N., de Sá, N.C.., Blitzkow, D., Miranda F., O.F., 1988. Deep crustal structure under Paraná Basin (Brazil) from gravity study. In: Piccirillo, E.M., Melfi, A.J. (Eds.), The Mesozoic Volcanism of the Paraná basin: Petrogenic and Geophysical Aspects. IAG/USP, São Paulo, pp. 271-283.

Nabighian, M. N., 1984. Toward a three-dimensional automatic interpretation of potential field data via generalized Hilbert transforms; fundamental relations. Geophysics 49 (6), 780-786, doi: 10.1190/1.1441706.

Pavão, C.G., França, G.S., Marotta, G. S., Menezes, P.H.B.J., Neto, G.B.S., Roig, H.L., 2012. Spatial Interpolation Applied a Crustal Thickness in Brazil. Journal of Geographic Information System 04, 142-152.

Pereira, W. R., Mantovani, M. S. M, 2012. Inversão de dados geofísicos do Complexo AlcalinoCarbonatítico do Barreiro, Araxá (MG). Geologia USP. Série Científica 12, 15-30, doi: 10.5327/Z1519-874X2012000200002.

Phillips, J. D., 2001. Designing matched band-pass and azimuthal filters for the separation of potential-field anomalies by source region and source type. 15th Geophysical Conference and Exhibition, Australian Society of Exploration Geophysicists, Extended Abstracts.

Pimentel, M. M., Fuck, R. A., 1987. Late Proterozoic granitic magmatism in southwestern Goiás, Brazil. Revista Brasileira de Geociências 17, 415-425.

Pimentel, M. M., Fuck, R. A., 1992. Neoproterozoic crustal accretion in central Brazil. Geology 20 (4), 375-379, doi: 10.1130/0091-7613(1992)020<0375:NCAICB>2.3.CO;2.

Pimentel M. M., Fuck, R. A., 1994. Geocronologia Rb-Sr da porção sudoeste do Maciço Mediano de Goiás. Revista Brasileira de Geociências 24 (2), 104-111.

Pimentel, M. M., Fuck, R.A., Jost, H., Filho, C. F. F., de Araújo, S. M., 2000. The basement of the Brasilia Fold Belt and the Goiás Magmatic Arc. In: Cordani et al.(Eds.), Tectonic Evolution of South America, 31st International Geological Congress, Rio de Janeiro, RJ, Brazil, pp. 190-229.

Pimentel M.M., Fuck R.A., Gioia S.M.C.L., 2000. The Neoproterozoic Goiás Magmatic Arc, Central Brazil: A review and new Sm-Nd Isotopic Data. Revista Brasileira de Geociências 30 (1), 35-39. 
Ramos, V. a., Vujovich, G., Martino, R., Otamendi, J., 2010. Pampia: A large cratonic block missing in the Rodinia supercontinent. J. Geodyn. 50, 243-255, doi: 10.1016/j.jog.2010.01019.

Reid, A.B., Allsop, J.M., Granser, H., Millett, A.J., Somerton, I.W., 1990. Magnetic interpretation in three dimensions using Euler deconvolution: Geophysics 55, 80-91.

Renne, P. R., Ernesto, M., Pacca, I. G., Coe, R. S., Glen, J., Prévot, M., Perrin, M., 1992. The age of Paraná flood volcanism, rifting of Gondwanaland, and the Jurassic-Cretaceous Boundary. Science 253, 975-979.

Rocha, M.P., Schimmel, M., Assumpção, M., 2011. Upper-mantle seismic structure beneath SE and Central Brazil from P- and S-wave regional traveltime tomography. Geophysical Journal International 184, 268-286.

Schobbenhaus, C., Ribeiro, C. L., Oliva, L. A., Takanohashi, J. T., Lindenmayer, A.G., Vasconcelos, J.C., Orlandi, V., 1975. Folha Goiás SD.22, with explanatory text. In: Schobbenhaus (Eds.), Carta Geológica do Brasil Milionésimo, DNPM, Brasília, DF, Brazil.

Schobbenhaus, C., Gonçalves, J. H., Santos, J. O. S., Abram, M. B., Neto, Neto, R. L., Matos, G. M. M., Vidotti, R. M., Ramos, M. A. B., Jesus, J. D. A., 2004. Carta Geológica do Brasil ao Milionésimo, Sistema de Informações Geográficas - SIG, 41 CD-ROMs, scale 1:1,000,000, CPRM, Brasília, DF, Brazil.

Seer, H. J.,1985. Geologia, deformação e mineralização de cobre no complexo vulcanossedimentar de Bom Jardim de Goiás. [M.S. Thesis]: Universidade de Brasília, Departamento de Geociências, Brasília, 181p.

Seer, H.J., Nilson, A.A., 1985. Contribuição à geologia das unidades pré-cambrianas da região de Bom Jardim de Goiás. II Simpósio Geologia do Centro-Oeste, Goiânia, SBG-Núcleos Centro-Oeste e Brasília, Extended Abstracts, pp. 25-29.

Soares, J.E., Berrocal, J., Fuck, R. A., Mooney, W.D., Ventura, D.B.R., 2006. Seismic characteristics of central Brazil crust and upper mantle: A deep seismic refraction study. J. Geophys. Res. 111, B12302, doi:10.1029/2005JB003769.

Syberg, F. J. R., 1972. A Fourier method for the regional-residual problem of potential fields. Geophys. Prospecting 20, 47-75.

Telford, W.M., Geldart, L. P., Sheriff, R.E., 1990. Applied Geophysics. Cambridge University Press, Cambridge, doi: 10.1017/CBO9781139167932.

Thompson, D.T., 1982. EULDPH - a new technique for making computer-assisted depth estimates from magnetic data. Geophys. Prosp. 45, 207-246.

Tohver, E., Trindade, R. I. F., Solum, J. G., Hall, C. M., Riccomini, C., Nogueira, A. C., 2010. Closing the Clymene ocean and bending a Brasiliano belt: Evidence for the Cambrian 
formation of Gondwana, southeast Amazon craton. Geology 38 (3), 267-270, doi: 10.1130/G30510.1.

Ventura, D.B.R., Soares, J.E.P., Fuck, R.A., Caridade, L. da C.C., 2011. Caracterização sísmica e gravimétrica da litosfera sob a linha de refração sísmica profunda de Porangatu, Província Tocantins, Brasil Central. Revista Brasileira de Geociências 41, 130-140.

Verduzco, B., Fairhead, J. D., Green, C. M., MacKenzie, C., 2004. New insights into magnetic derivatives for structural mapping. The Leading Edge 23, 116-119.

Vidotti, R. M., 1997. Lithospheric Structure beneath Paraná and Parnaíba Basins, Brazil from regional gravity analysis.[PhD Thesis]: The Univ. of Leeds, School of Earth Sciences, Leeds.

Vidotti, R.M., Ebinger, C.J., Fairhead, J.D., 1998. Gravity signature of the western Paraná basin , Brazil. Earth Planet. Sc. Lett. 159, 117-132, doi: 10.1016/S0012-821X(98)00070-3.

Vidotti, R. M., Curto, Julia B., Fuck, R. A., Dantas, E. L., Almeida, T., 2011. Magnetic Expression of the Transbrasiliano Lineament, Brazil. AGU Fall Meeting 2011, San Francisco, Abstracts.

Zalán, P. V., S. Wolff, M. A. M. Astolfi, I. S. Vieira, J. C. J. Conceição, V. T. Appi, E. V. Santos Neto, J. R. Cerqueira, A. Marques, 1991. The Paraná Basin, Brazil. In: Leighton (Eds.). Interior cratonic basins, Memoir 51, pp. 681-708, AAPG, Tulsa, Oklahoma.

Watts, A. B., 2001. Isostasy and Flexure of the Litho-sphere, 1st ed. Cambridge University Press, Cambridge (UK) (458 pp.).

Weska, R. K., 2006. Uma síntese do Cretáceo Superior Mato-Grossense. Geociências 25 (1), 71 81. 
Table 1 - Physical properties used in the modeling of $X-X^{\prime}, Y-Y^{\prime}$ and Z-Z' sections.

Rock Properties of Density, Magnetic Susceptibility, and Magnetic Remanescence used in 2D Models.

\begin{tabular}{|c|c|c|c|c|c|c|c|c|c|c|}
\hline \multirow[b]{2}{*}{ Models } & \multirow[b]{2}{*}{ Blocks/Layers } & \multicolumn{3}{|c|}{ Density $\left(\mathrm{kg} / \mathrm{m}^{3}\right)$} & \multicolumn{3}{|c|}{ Magnetic Susceptibility } & \multicolumn{3}{|c|}{ Magnetic Remanence } \\
\hline & & Min & Max & Density & Min & Max & Susc & $\begin{array}{c}\text { Mag } \\
(\mathrm{A} / \mathrm{m})\end{array}$ & $\begin{array}{c}\text { Inc } \\
\text { (deg) }\end{array}$ & $\begin{array}{c}\text { Dec } \\
\text { (deg) }\end{array}$ \\
\hline \multirow{11}{*}{$+1^{20}$} & Bodies A & 2670 & 2700 & variable & 0.008 & 0.03 & variable & & & \\
\hline & Bodies B & 2700 & 2850 & variable & 0.01 & 0.04 & variable & & & \\
\hline & Layer 1 & & & 2460 & & & 0 & & & \\
\hline & Layer 2 & & & 2640 & & & 0 & & & \\
\hline & Block 1 & & & 3290 & & & 0 & & & \\
\hline & Block 2 & & & 3210 & & & 0 & & & \\
\hline & Block 3 & & & 2910 & & & 0 & & & \\
\hline & Block 4 & & & 2940 & & & 0 & & & \\
\hline & Blocks 5 & 2680 & 2710 & variable & 0.002 & 0.008 & variable & & & \\
\hline & Blocks 6 & 2675 & 2710 & variable & 0.01 & 0.03 & variable & & & \\
\hline & Blocks 7 & 2700 & 2710 & variable & 0 & 0.005 & variable & & & \\
\hline \multirow{3}{*}{ z } & Block 8 & & & 2710 & & & 0.008 & & & \\
\hline & Blocks 9 & & & 2700 & 0 & 0.001 & variable & & & \\
\hline & Block 10 & & & 2690 & & & 0.006 & & & \\
\hline \multirow{2}{*}{$x$} & Shallow & \multirow{2}{*}{2750} & \multirow{2}{*}{2800} & \multirow{2}{*}{ variable } & \multirow{2}{*}{0.05} & \multirow{2}{*}{0.08} & \multirow{2}{*}{ variable } & $0.5-4$ & $-36.6^{\circ}$ & $1.8^{\circ}$ \\
\hline & volcanic rocks & & & & & & & $\begin{array}{ll}\mathrm{R} & 0.5-4 \\
\end{array}$ & $36.6^{\circ}$ & $181.8^{\circ}$ \\
\hline \multirow{2}{*}{$\mathrm{Y}$ and $\mathrm{Z}$} & Shallow & \multirow{2}{*}{2750} & \multirow{2}{*}{2800} & \multirow{2}{*}{ variable } & $\mathrm{N} \quad 0.05$ & 0.08 & \multirow{2}{*}{ variable } & & & \\
\hline & volcanic rocks & & & & R -0.03 & -0.02 & & & & \\
\hline
\end{tabular}




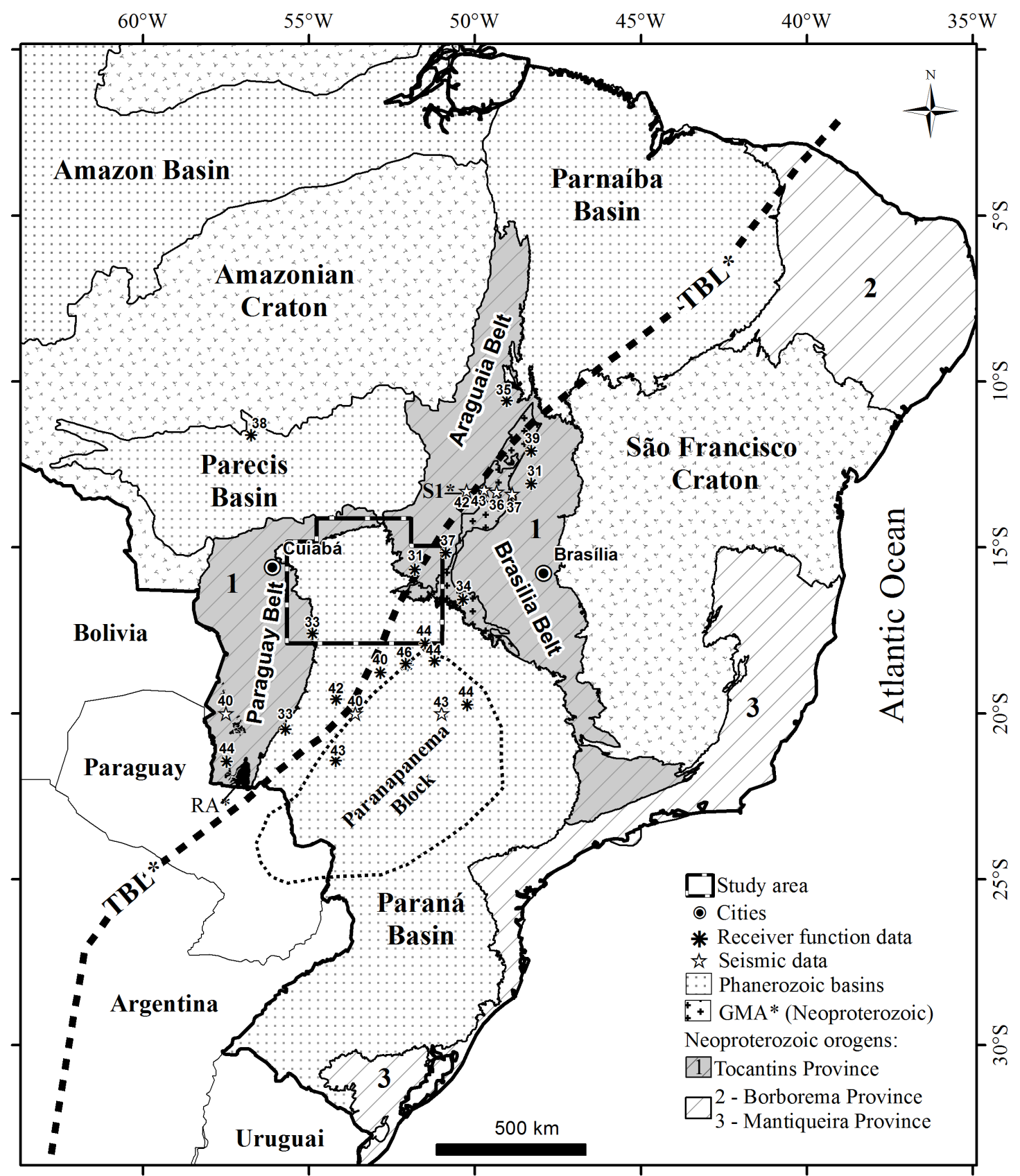

*TBL - Transbrasiliano Lineament; GMA - Goiás Magmatic Arc; RA - Rio Apa Block; S1 - Seismic line (Soares et al., 2006)

Figure 1 - Major tectonic units of the study area. The Transbrasiliano Lineament (TBL) is according to interpretation of magnetic data (Vidotti et al., 2011; Curto et al., 2014) and previous studies (e.g., Ramos et al., 2010). Crustal thickness data are derived from analysis of receiver function and seismic refraction compiled by Pavão et al. (2012). 


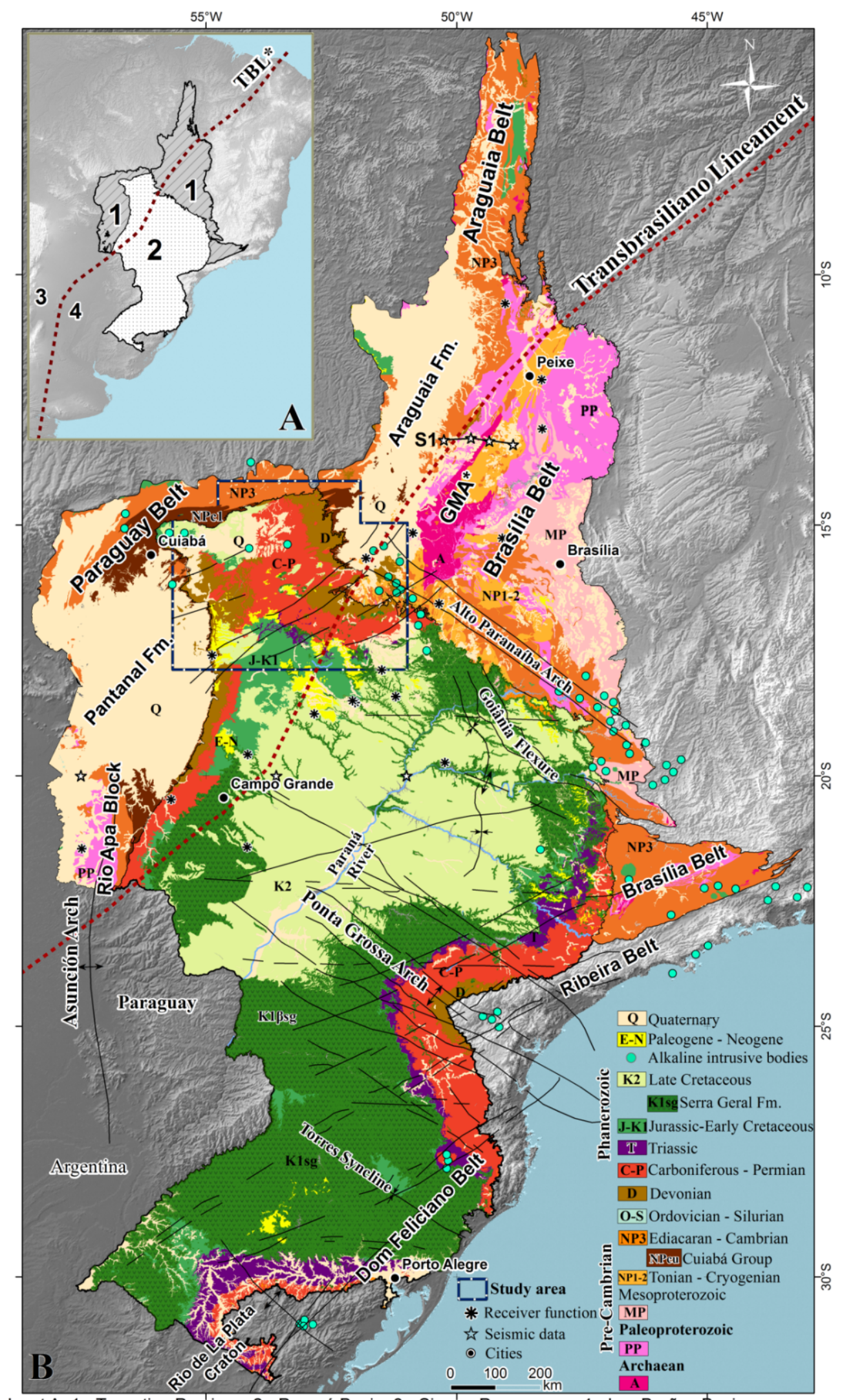

Inset A: 1 - Tocantins Province; 2 - Paraná Basin; 3 - Sierras Pampeanas; 4 - Las Breñas Basin;

LTB: Tranbrasiliano lineament. Inset B: GMA - Goiás Magmatic Arc; S1 - Seismic line (Soares et al., 2006)

Figure 2 - A: Location of the Tocantins Province and Paraná Basin in the South American

Platform. B: Geological units of inset A, classified according to their age. Structures and Cretaceous alkaline intrusive bodies are exposed. Seismic refraction and receiver function data compiled by Pavão et al. (2012) were also included. 


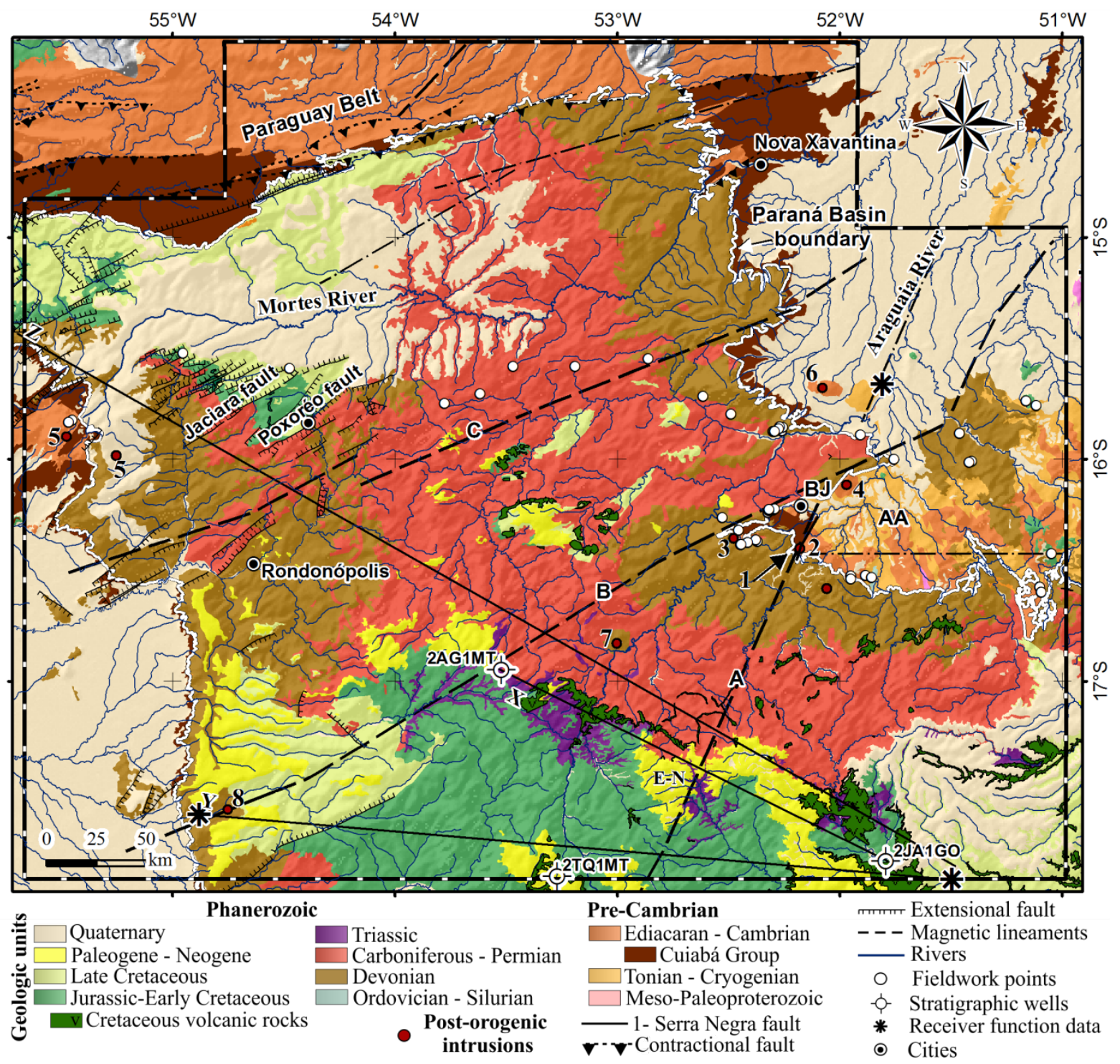

Figure 3 - Generalized geology of the study area (Schobbenhaus et al., 2004). Lineaments A (Serra Negra), B (Baliza) and C (General Carneiro) are based on the interpretation of magnetic data. Also shown are the fieldwork locations. 


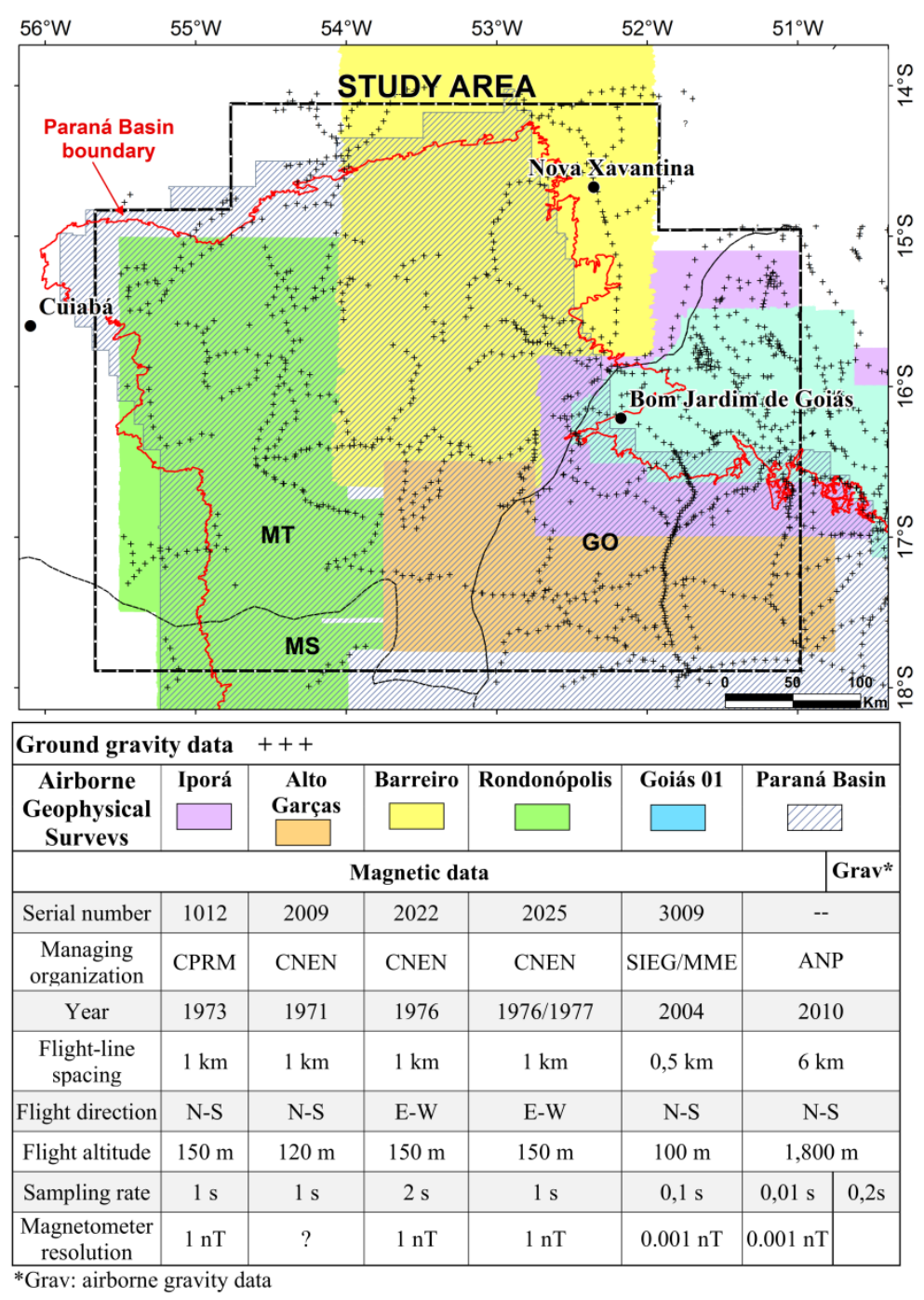

Figure 4 - Airborne gravity and magnetic surveys used in this study. Also, ground gravity data were acquired in previous research projects by Vidotti (1998) and various institutions, including the Instituto Brasileiro de Geografia e Estatística (IBGE), Instituto de Astronomia, Geofísica e Ciências Atmosféricas, Universidade de São Paulo (IAG/USP) and the Instituto de Geociências, Universidade de Brasília (IG/UnB). The database was provided by the Laboratory of Applied Geophysics (LGA) of IG/UnB. 

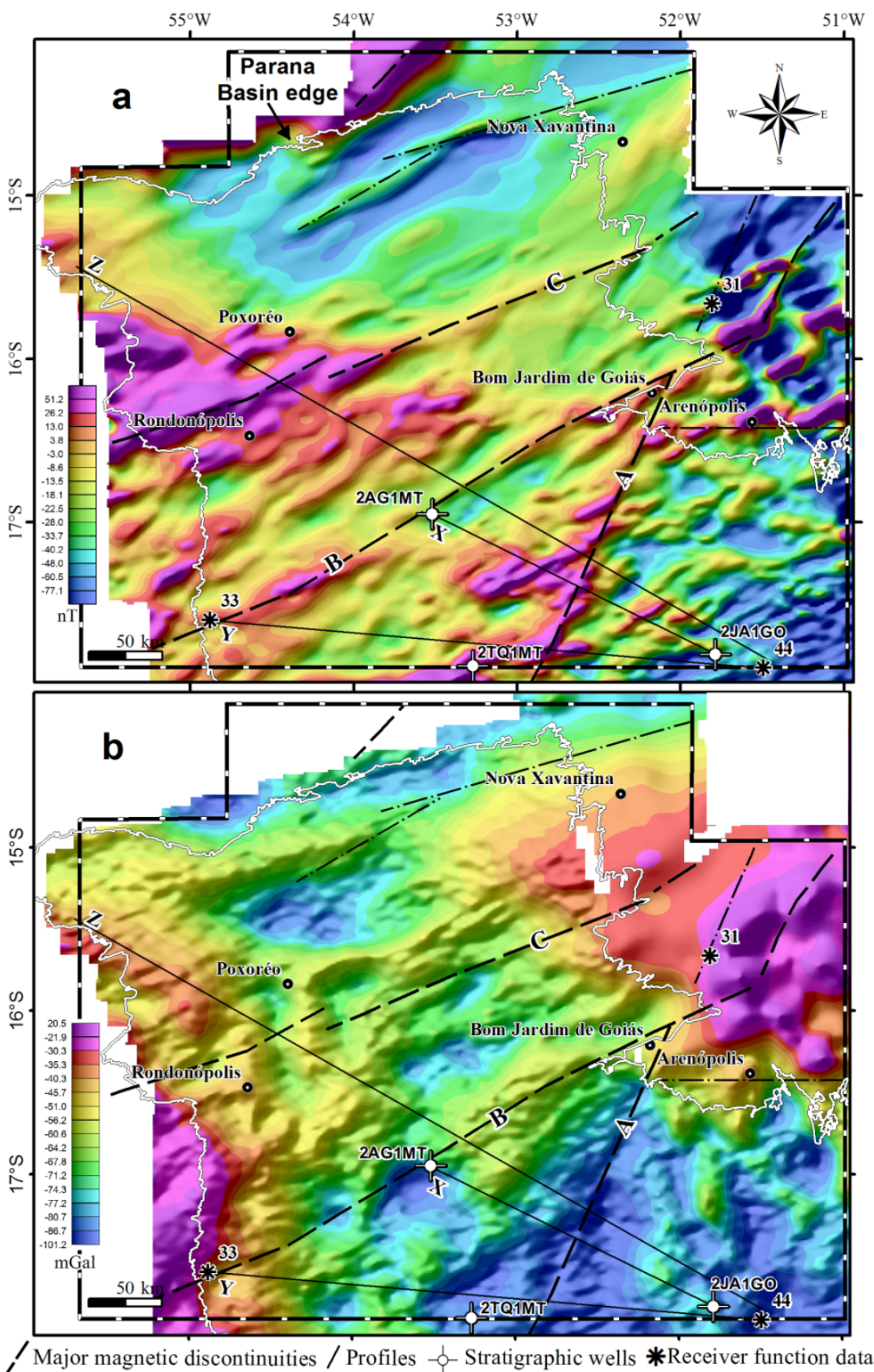

Figure 5 - (a) Map of reduced-to-pole magnetic anomalies. (b) Map of Bouguer anomalies. Both maps show the locations of cross-sections used in 2D modeling of the data. Lineaments A (Serra Negra), B (Baliza) and C (General Carneiro) are based on the interpretation of magnetic data. The crustal depth values are from analysis of receiver function data, as compiled by Pavão et al. (2012). 


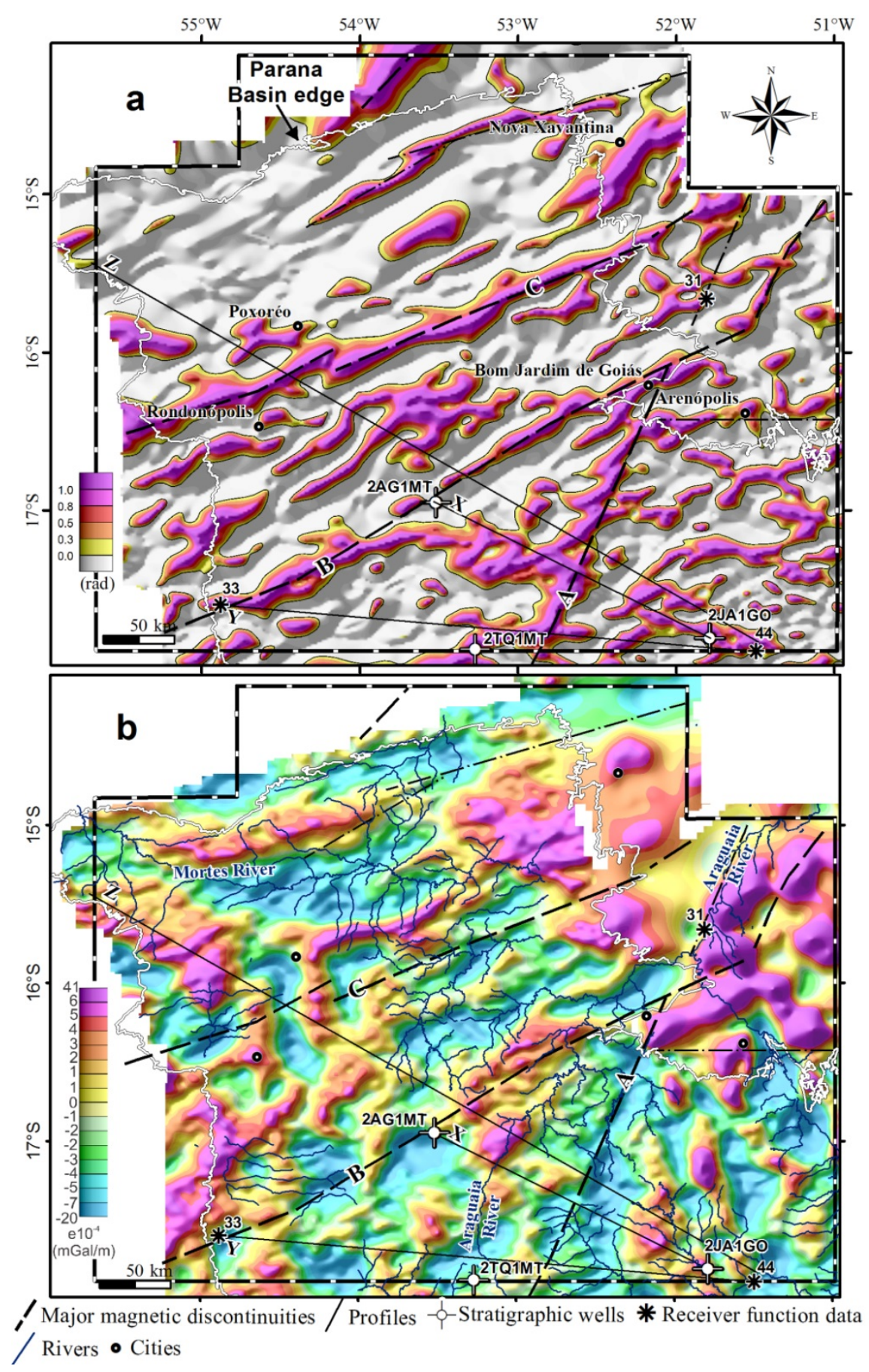

Figure 6 - (a) Map of the tilt derivative of the reduced-to-pole magnetic anomalies. Black contour line indicates where the tilt derivative $=0$, which in principle overlies magnetic contacts. (b) Map of the vertical derivative of the Bouguer anomalies. See Figure 5 for explanation of other lines and labels. The drainage network shown in (b) corresponds with gravity lows, except the Araguaia River, which is intended only as a reference to facilitate comparison between spatial models. 

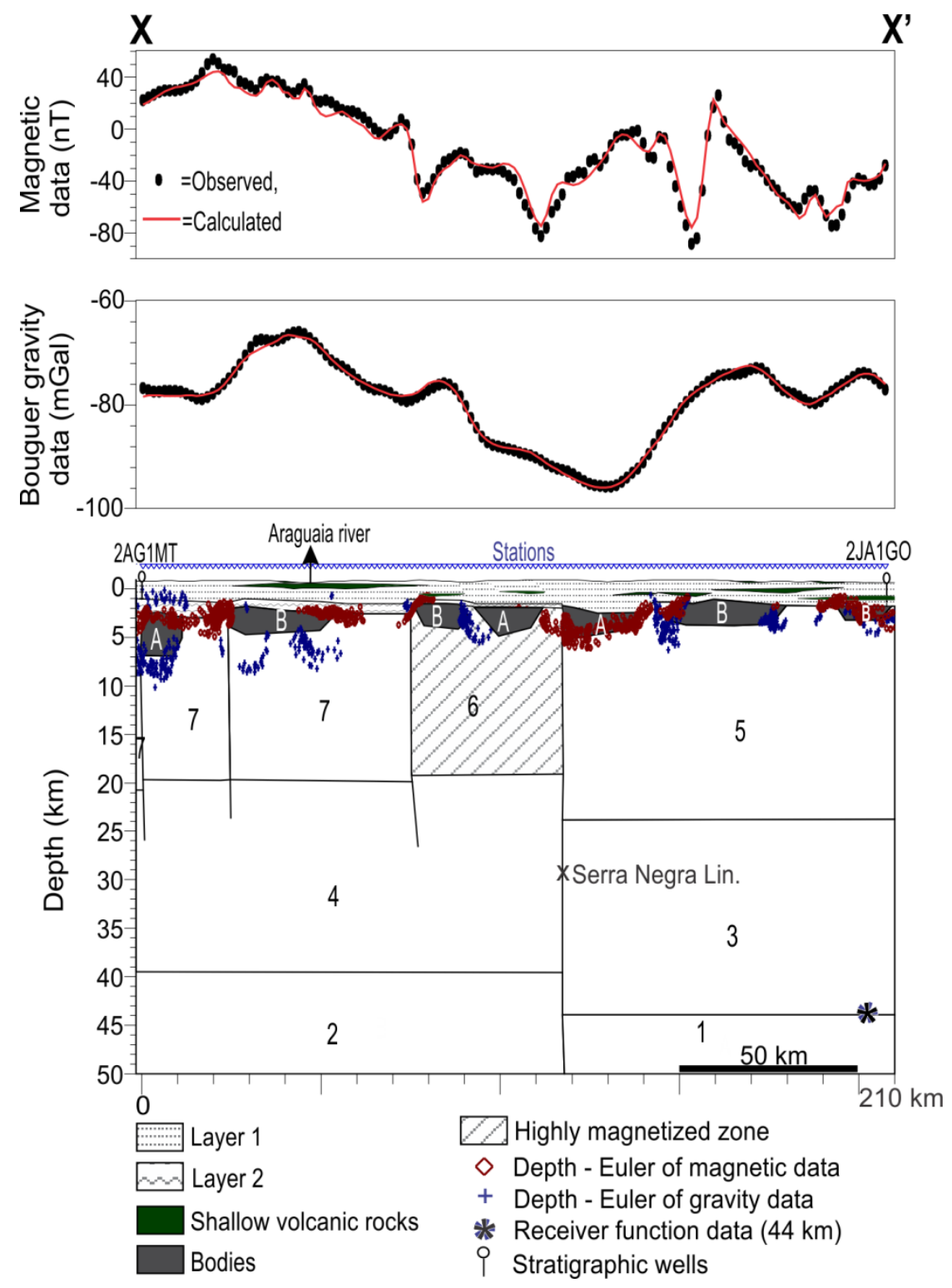

Figure 7 - 2D model of magnetic and gravity data from section $\mathrm{X}-\mathrm{X}^{\prime}$. The magnetic data were not previously reduced to pole. See Figures 3, 5 and 6 for location. Crustal thickness was obtained from receiver function analysis data, compiled by Pavão et al. (2012). Numbers and letters identify blocks and bodies. Their corresponding physical properties are described in Table 1. 

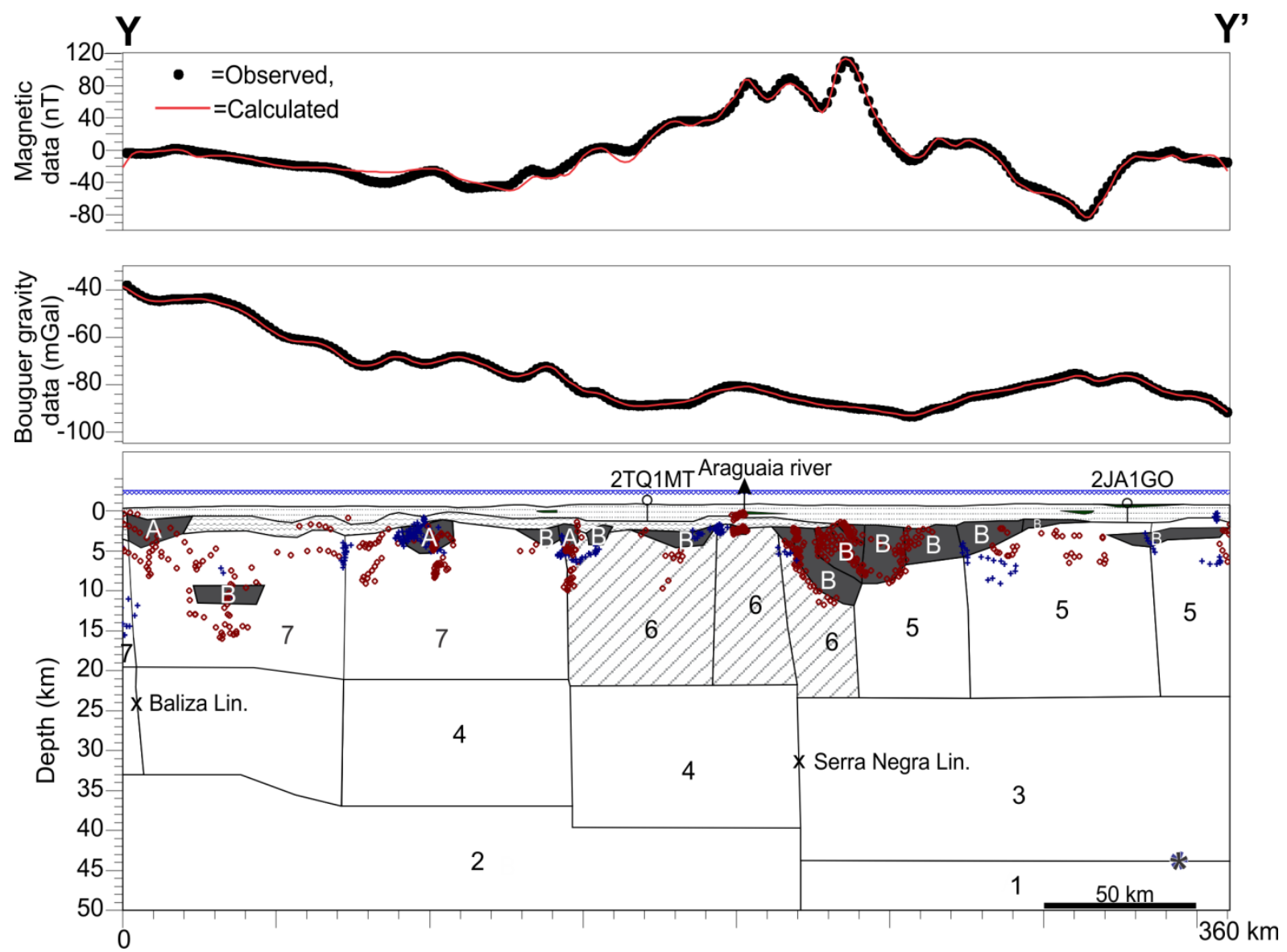

Figure 8 - Two-dimensional model of magnetic and gravity data from section $\mathrm{Y}-\mathrm{Y}^{\prime}$. The magnetic data reduced to pole. See Figures 3, 5 and 6 for map location. Numbers and letters identify blocks and bodies. Their corresponding physical properties are described in Table 1 . Symbols and acronyms are described in figure 7. 

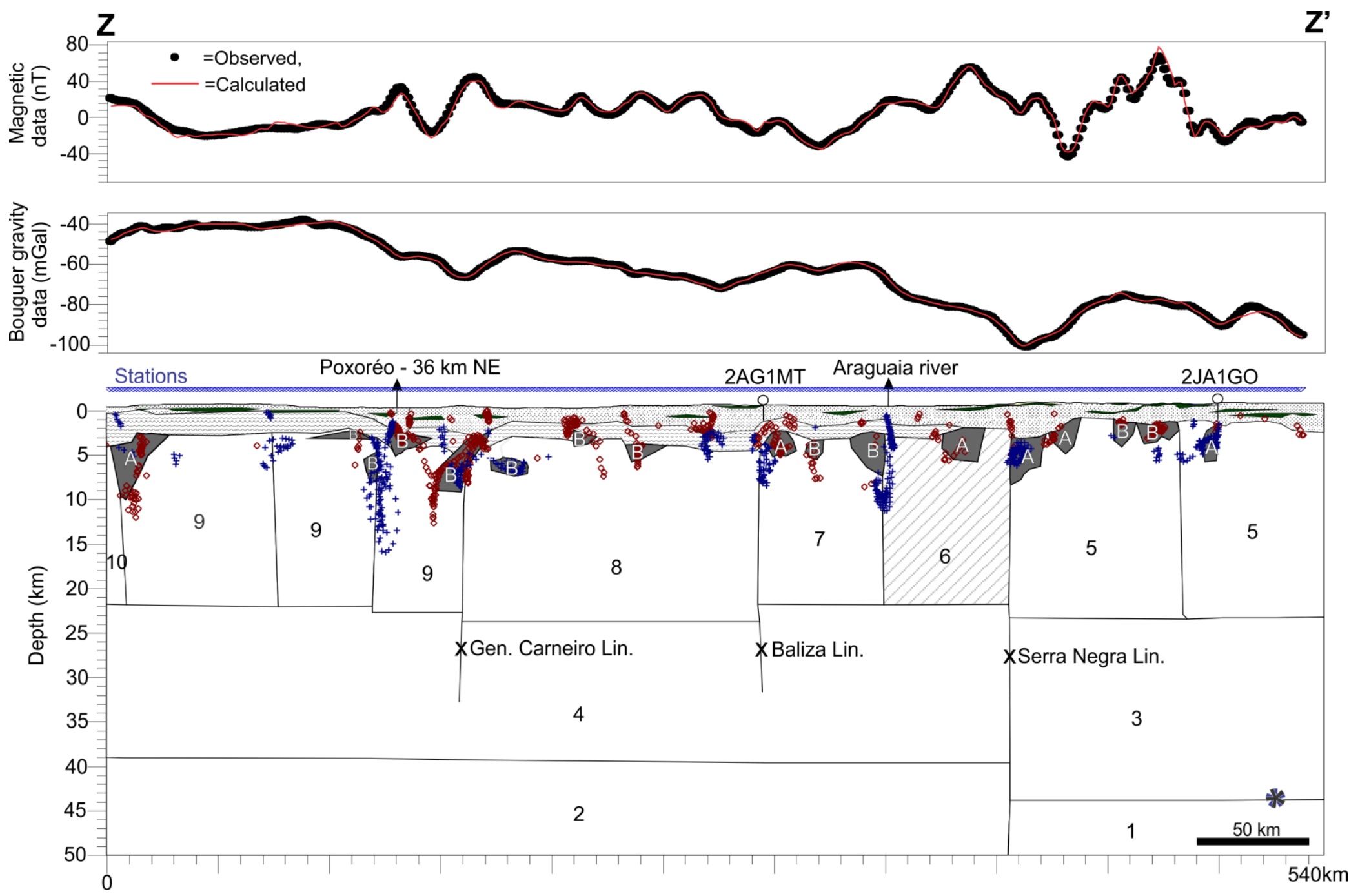

Figure 9 - Two-dimensional model of magnetic and gravity data from section Z-Z'. The magnetic data was reduced to pole. See Figures 3, 5 and 6 for map location. Numbers and letters identify blocks and bodies. Their corresponding physical properties are described in Table 1. Symbols and acronyms are described in figure 7. 


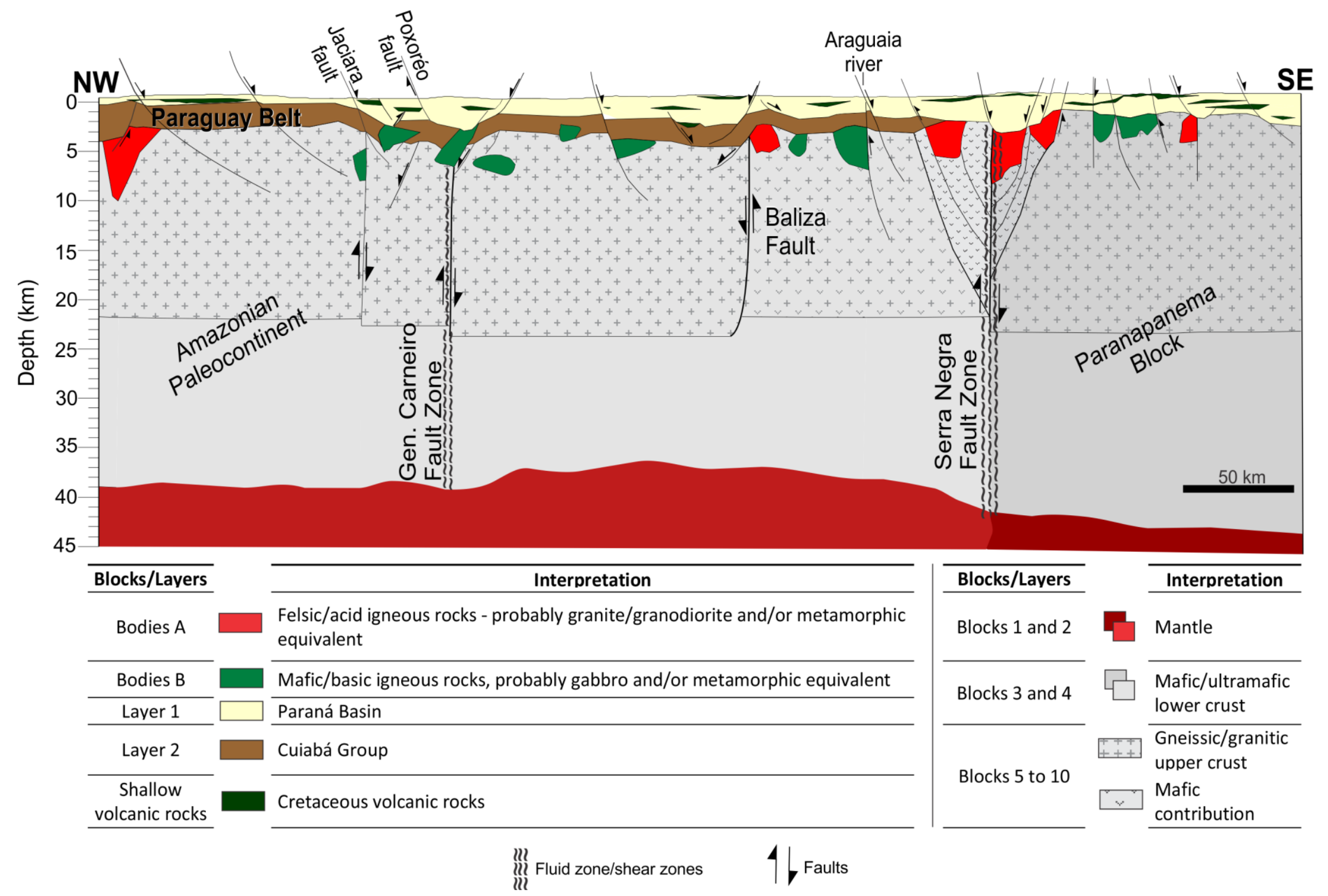

Figure 10 - Tectonic model inferred from magnetic and gravimetric models (Figures 7, 8 and 9) and geological data. 


\section{Análise tectônica}

"Não podemos resolver os problemas com a mesma mentalidade que usamos para criá-los" Albert Einstein (1879 - 1955), fisico

Anomalias magnéticas associadas ao Lineamento Transbrasiliano (LTB) foram caracterizadas conforme tendências direcionais, disposição em profundidade e mecanismos cinemáticos. Busca por estimativas de profundidades ao longo dos lineamentos magnéticos relacionados ao LTB levou ao desenvolvimento do artigo que integra o capítulo 4, que inclui avanços alcançados com a utilização da técnica do tilt-depth (Salem et al., 2010). A complementação em ambiente de sistemas de informação geográfica (SIG) mostra variações na profundidade do topo dos lineamentos magnéticos na área de estudo com maior segurança e clareza.

Diferenciação de padrões geofísicos permitiu a definição de domínios magnéticos regionais, interpretados como compartimentos tectônicos limitados por descontinuidades crustais. Assinaturas geofísicas mais rasas $(<5 \mathrm{~km})$, passíveis de serem identificadas sem interferência relevante de ruído proveniente de altas frequências, foram correlacionadas a estruturas e corpos ígneos do embasamento da Bacia do Paraná, além de rochas vulcânicas e subvulcânicas intrasedimentares. O tópico constitui o escopo do artigo apresentado no capítulo $5 *$. Resultados obtidos com dados gravimétricos corroboram em parte lineamentos e profundidades obtidos com base no campo magnético anômalo. Diferenças entre as análises evidenciam duas características importantes e intrínsecas ao campo potencial e suas respectivas fontes: (i) certas fontes com significado geológico podem mostrar contrastes de densidade, mas não de propriedades magnéticas e vice-versa; (ii) alta anisotropia do campo magnético em baixas latitudes magnéticas dá origem a distorções das anomalias em relação ao posicionamento e dimensionamento de suas fontes geradoras, mesmo quando reduzidas ao polo. Ambos os fatores foram considerados na interpretação conjunta dos dados, como exposto no artigo do capítulo 6, no qual é proposto modelo 2D para o arcabouço estrutural da crosta do noroeste da Bacia do Paraná e que mostra as principais falhas que influenciaram o desenvolvimento da bacia.

\footnotetext{
*Resumos com resultados preliminares apresentados em congressos estão nos anexos
} 


\subsection{Intepretação geofísica e integração com dados geológicos}

Interpretação qualitativa dos dados geofísicos foi realizada a partir da classificação de lineamentos em diferentes ordens. A ordem dos lineamentos depende de sua extensão em superfície e em profundidade; quanto maior, menor a escala de observação. Lineamentos magnéticos de primeira ordem alcançam profundidades maiores que $10 \mathrm{~km}$ e foram correlacionados a estruturas e contatos geológicos regionais. Lineamentos magnéticos de segunda e terceira ordem são interpretados como estruturas e feições geológicas locais e mais rasas (topo em profundidade $<5 \mathrm{~km}$ ), como corpos intrusivos e soleiras de rochas ígneas. Enquanto lineamentos magnéticos muitas vezes são marcados por estruturas enriquecidas por minerais magnéticos, anomalias gravimétricas refletem o contraste lateral de densidade na crosta, que pode ser acentuado, ou não, nas zonas de falha. Assim, estruturas são em geral melhor marcadas por lineamentos magnéticos. Estruturas podem ser indicadas por gradientes gravimétricos importantes, mas, por exemplo, se a falha não representar contato entre unidades litológicas com densidades distintas, não haverá anomalia gravimétrica relacionada a essa estrutura. Por outro lado, os dados gravimétricos assumiram importância ímpar na definição das falhas do topo do embasamento da Bacia do Paraná, onde o contraste de densidade é notável. Mesmo nos casos em que o embasamento é metassedimentar, por exemplo, o contraste de densidade pode ser mais importante do que o contraste magnético entre as rochas metassedimentares e sedimentares da bacia. Outra contribuição relevante dos dados gravimétricos se deu na interpretação da interface crosta-manto (Descontinuidade de Mohorovicic) e do limite entre diferentes tipos de crosta em profundidades maiores que a superfície Curie, estimada em torno de $30 \mathrm{~km}$ (Blum e Pires, 1996). As estimativas de espessura crustal obtidas na modelagem dos dados gravimétricos (Figuras 6.7 a $6.10^{*}$ ) corroboraram os dados de função do receptor (Assumpção et al., 2002; 2013; Pavão et al., 2012).

A integração dos levantamentos geofísicos aos dados regionais do projeto aerogeofísico Bacia do Paraná realçou lineamentos de primeira ordem e domínios magnéticos/gravimétricos relacionados a estruturas crustais e compartimentos tectônicos, respectivamente. Foram realizadas correlações com unidades geológicas conhecidas e discutidas na literatura, como apresentado no capítulo 2 (ex.: Almeida, 1967, 1985; Almeida et al., 1981; Seer, 1985; Zalan et al., 1991; Fuck et al., 1993, 1994; Milani, 1997; Pimentel et al., 2000; Alvarenga et al., 2000). A continuidade entre estruturas mapeadas em superfície e lineamentos mais rasos com aqueles em maiores profundidades evidenciou a real extensão dessas estruturas.

\footnotetext{
*As figuras referidas no texto estão em acordo com os respectivos capítulos; por exemplo Figura 6.10 corresponde à figura 10 do Capítulo 6 e a Figura 7.1 se refere à figura 1 do presente capítulo
} 
A maior parte das estruturas rasas parece ser continuação ou resultado da reativação de estruturas mais profundas. Análise das anomalias magnéticas de cada aerolevantamento de maior resolução permitiu identificar maior densidade de lineamentos de segunda e terceira ordem, bem como outras feições locais. O mapa de lineamentos foi utilizado como base para os trabalhos de campo. As principais tendências direcionais, relacionadas a estruturas nas porções mais rasas do embasamento da Bacia do Paraná, foram consolidadas a partir da integração dos dados magnéticos e de campo. Cerca de 128 medidas estruturais, adquiridas na região de Bom Jardim de Goiás e ao longo de seção NW, com aproximadamente $1.000 \mathrm{~km}$ na área de estudo, indica cinco direções predominantes de falhas e juntas: $\mathrm{N} 45-60^{\circ} \mathrm{E}, \mathrm{N} 25-30^{\circ} \mathrm{E}, \mathrm{N} 50^{\circ} \mathrm{W}, \mathrm{N} 80^{\circ} \mathrm{E}-$ $\mathrm{N} 80^{\circ} \mathrm{W}$ e $\mathrm{N} 10^{\circ} \mathrm{W}$. As primeiras quatro orientações correspondem a direções de lineamentos magnéticos da área (Figura 5.9c). Há maior densidade do terceiro e quarto grupo de direções nas medidas feitas em afloramentos; fato relacionado a dois fatores: (i) direções NE são características da trama estrutural do embasamento neoproterozóico, enquanto direções NW são associadas a reativações ocorridas no Cretáceo e, portanto, mais pronunciadas nas unidades da Bacia do Paraná; e (ii) o número de medidas estruturais realizadas na bacia é maior do que nas rochas do embasamento.

A discussão desenvolvida na próxima seção é sequenciada a partir dos lineamentos NE Serra Negra, Baliza, General Carneiro e São Vicente, os quais limitam compartimentos tectônicos que são analisados segundo elementos geológicos locais, mais rasos, e regionais, mais profundos. Em seção posterior, serão discutidas as reativações fanerozóicas e estruturas EW e NW. O objetivo é contribuir para melhor entendimento sobre a influência e controle que o embasamento e as estruturas do LTB exerceram na evolução da Bacia do Paraná.

\subsection{Descontinuidades crustais e compartimentos tectônicos}

Três grandes lineamentos magnéticos com direção NE (Serra Negra, Baliza, General Carneiro) são relacionados a zonas de fraqueza crustal e separam blocos tectônicos caracterizados por diferentes padrões reológicos e estruturais (Figuras 5.3, 5.5 e 6.10). Descontinuidade adicional de direção NW-W (São Vicente) subdivide os blocos maiores.

A descontinuidade de Serra Negra, com mesma tendência direcional que o LTB $\left(\mathrm{N} 30^{\circ} \mathrm{E}\right)$, é o lineamento magnético mais expressivo no nível crustal em torno de $20 \mathrm{~km}$ de profundidade. Altos valores de magnetização do lineamento podem ser causados por minerais magnéticos resultantes da percolação de fluidos, provenientes do intenso tectonismo dúctil Brasiliano. Modelos geofísicos apresentados no capítulo 6 (Figuras 6.7 a 6.9) mostram gradientes 
gravimétricos regionais, que refletem variação lateral de densidade crustal causada pela transição entre diferentes domínios e falhas associadas ao lineamento Serra Negra (Figura 6.10).

A descontinuidade de Serra Negra está exposta em sua fase rúptil e dúctil na região de Bom Jardim de Goiás, onde coloca em contato conjunto de sequências metavulcano-sedimentares e ortognaisses do Arco Magmático de Goiás (Pimentel e Fuck, 1992), a leste, e rochas metassedimentares neoproterozóicas da Faixa Paraguai (Seer, 1985; Seer e Nilson, 1985; Alvarenga et al., 2000), a oeste da falha (Figura 7.1a). Desloca o granito Macacos em movimentação transcorrente em aproximadamente $8 \mathrm{~km}$ (Seer, 1985); o granito mostra formato alongado ao longo da falha e foliação milonítica vertical a subvertical nas bordas (Rodrigues et al., 1999). A análise da geologia e a imagem do tilt do campo magnético anômalo sugerem que o lineamento Serra Negra continua a sul em níveis mais profundos, em domínio dúctil, sotoposto às rochas sedimentares da Bacia do Paraná e limitando os domínios Arenópolis e Bom Jardim, estes caracterizados por diferentes tipos de crosta (Figura 7.1b). A fase rúptil é indicada localmente por falhas normais que ocorreram durante a reativação mesozóica, colocando em contato unidades devonianas da Bacia do Paraná e granito pós-orogênico (número 3, Figura 7.1). O lineamento Serra Negra controla parte do canal do Rio Araguaia no norte da área de estudo, que é desviado no sentido EW à leste de Barra do Garças, por falha, indicando tectônica recente (Figura 7.1b). Em feição similar, a estrutura é marcada a sul de Bom Jardim de Goiás por canal de drenagem, marcado na imagem de radar (SRTM, Figura 7.1a), que cruza as formações Furnas e Ponta Grossa, sem causar deslocamento aparente, e desaparece em superfície no contato NWW dessas unidades com a Formação Aquidauana.

A leste do lineamento Serra Negra, o domínio Arenópolis inclui dois contextos principais com diferentes assinaturas magnéticas e gravimétricas, limitados por descontinuidade com direção geral noroeste (Lineamento São Vicente), identificado nos dados magnéticos regionais (Figura 5.3a). A sul, estão as unidades da Bacia do Paraná e a norte, o Arco Magmático de Arenópolis. Na região do arco, intrusões da Província Alcalina de Goiás conferem às assinaturas magnéticas e gravimétricas anomalias de grande amplitude e comprimentos de onda. Dados magnéticos de alta resolução possibilitaram a localização precisa de corpos alcalinos, diques e estruturas de $2^{\mathrm{a}}$ e $3^{\mathrm{a}}$ ordem (Anexo A3). No entanto, tanto em dados de maior, quanto de menor resolução, feições mais profundas são mascaradas pelos corpos alcalinos, o que limitou o uso da análise do matched-filter e a modelagem conjunta 2D nessa região. $\mathrm{O}$ forte contraste entre as respostas gravimétricas regionais a norte e a sul do lineamento São Vicente (Figura 6.5b) está relacionado não só à diferença de densidade entre as rochas da Bacia do Paraná e as rochas 

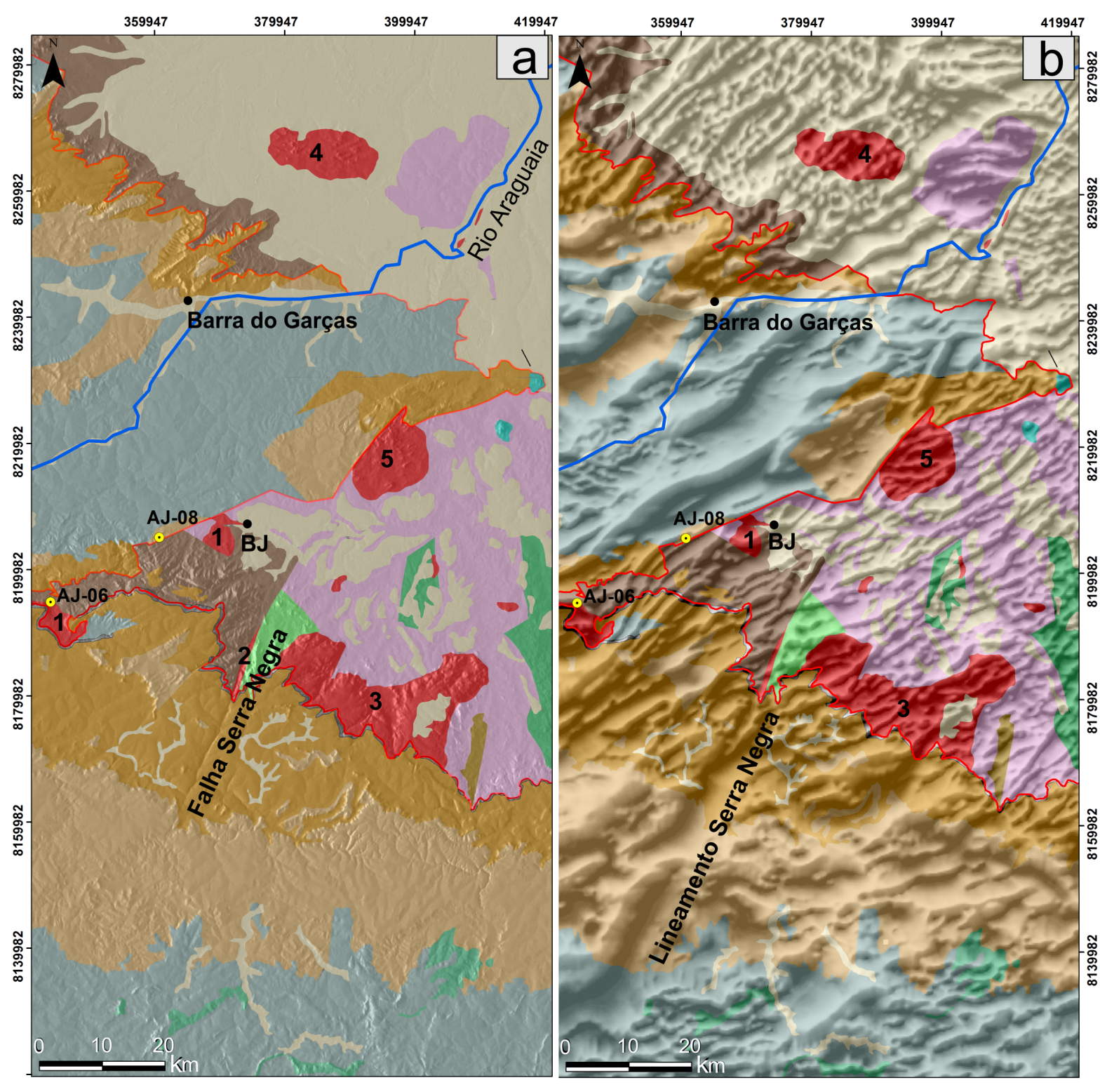

Geologia

$\square$ Coberturas cenozóicas Intrusões alcalinas

Bacia do Paraná

Formação Serra Geral

Formação Aquidauana

Formação Ponta Grossa

Formação Furnas

Granitos

pós-orogênicos

1- Serra Verde; 2 - Macacos;

3 - Serra Negra; 4 - Araguaiana; 5 - ?

Faixa Paraguai

$\square$ Grupo Cuiabá

Arco Magmático de Arenópolis

Seq. Vulcano-sedimentar de

Bom Jardim de Goiás

Seq. Vulcano-sedimentar de

Arenópolis-Piranhas

Ortognaisses

O Ponto amostrado

- Cidades

BJ - Bom Jardim de Goiás

Figura 7.1 - a) Geologia sobreposta à topografia (SRTM). b) Geologia sobreposta ao tilt do campo magnético anômalo da junção dos dados

magnéticos de maior resolução. A linha vermelha marca a borda da Bacia do Paraná. AJ-06 e AJ-08 são amostras de rocha coletadas em campo. 
ígneas a norte, mas principalmente à diferença significativa de espessuras crustais. A análise de função do receptor indica espessura crustal de $31 \mathrm{~km}$ na parte do lineamento a norte de Bom Jardim de Goiás (Figura 6.5; Assumpção et al., 2002; 2013; Pavão et al., 2012). Na modelagem dos dados gravimétricos, a crosta sotoposta às rochas sedimentares da Bacia do Paraná foi caracterizada por menor densidade e maior espessura $(\sim 43 \mathrm{~km})$, o que corrobora dados de função do receptor e valores estimados em análise espectral e modelagem gravimétrica a sul da área de estudo (Vidotti et al. 1998). A crosta mais espessa é interpretada como extremo noroeste do Bloco Paranapanema (Cordani et al., 1984; Mantovani e Quintas, 1996; Mantovani e Brito Neves, 2005; Mantovani et al., 2005). Esta hipótese corrobora com a sugestão de Santos (2014), que aponta o bloco como possível área-fonte de zircão detrítico de idade paleoproterozóica da Formação Furnas na região norte da bacia.

A análise matched-filter e a modelagem conjunta de dados magnéticos e gravimétricos na região do Bloco Paranapanema indica limite da crosta inferior e superior em torno de 20-25 km de profundidade (Figuras 5.5 e 6.10). Devido à natureza dos dados geofísicos, corpos magnéticos foram identificados somente em níveis de profundidade da crosta superior, próximo ao topo do embasamento. A distinção de corpos félsicos/ácidos e máficos/básicos teve como base a estimativa de valores de susceptibilidade magnética e densidade que se ajustaram a anomalias locais com menores comprimentos de onda, inseridas em comprimentos de onda regionais. A correlação dos corpos com embasamento aflorante mais próximo, o Arco Magmático de Arenópolis e a Faixa Paraguai, sugere que as rochas félsicas são granitos a granodioritos sin a pós-orogênicos, similares aos granitos Araguaiana, Serra Negra, Macacos e Serra Verde (Figura 7.1), enquanto rochas máficas são provavelmente gabros, relacionados ao magmatismo cretáceo. A hipótese foi assumida para os demais compartimentos tectônicos da área de estudo.

No domínio a oeste do lineamento Serra Negra, lineamentos expressivos com direção $\mathrm{N} 60^{\circ}-70^{\circ} \mathrm{E}$ modificam o padrão direcional $\mathrm{N} 30^{\circ} \mathrm{E}$ observado nas estruturas do LTB ao longo de sua extensão nordeste, até o litoral do Ceará. Os dados sugerem que essa mudança é causada por soma de fatores, tais como: (i) caracterização da trama estrutural do embasamento précambriano imposta pelo novo campo de tensões gerado na amalgamação brasiliana do Bloco Paranapanema a sudeste; (ii) configuração da borda do Cráton Amazônico em padrão geral lesteoeste no norte da área de estudo, observado similarmente em superfície nos empurrões da Faixa Paraguai; (iii) reativação fanerozóica de estruturas $\mathrm{N} 60^{\circ}-70^{\circ} \mathrm{E}$, formadas sob as condições descritas nos itens i e ii. As imagens geradas a partir dos dados magnéticos revelam em maior densidade as estruturas brasilianas mais profundas, enquanto que lineamentos magnéticos relacionados as estruturas rasas $(<2 \mathrm{~km})$ são menos evidentes. 
Os lineamentos $\mathrm{N} 60^{\circ}-70^{\circ} \mathrm{E}$ principais, Baliza e General Carneiro, dividem a crosta em três domínios tectônicos. Nessa região, a Faixa Paraguai abrange o pacote supracrustal neoproterozóico do paleocontinente Amazônico e inclui o Grupo Cuiabá como sua unidade basal. O Grupo Cuiabá é limitado pela falha de Serra Negra e está em contato com a maior parte do flanco norte da Bacia do Paraná. Dessa maneira é interpretado como embasamento da bacia na área e restrito aos domínios a oeste do lineamento Serra Negra. Além da expressiva assinatura magnética, a zona entre os lineamentos Baliza e Serra Negra, a sudoeste de Bom de Jardim de Goiás, é marcada por resposta gravimétrica positiva, interpretada na modelagem como alto estrutural do embasamento e menor espessura crustal (Figura 6.10). A espessura crustal modelada corrobora dados de função do receptor (Assumpção et al., 2002; 2013; Pavão et al., 2012), que indicam $33 \mathrm{~km}$ na extremidade sudoeste do Lineamento Baliza e $31 \mathrm{~km}$ a norte de Bom Jardim de Goiás. Apesar de ser caracterizada na modelagem geofísica como paleocontinente Amazônico, a crosta nessa região provavelmente inclui zona de transição entre o mesmo e o Bloco Paranapanema, a leste. Anomalias magnéticas alongadas ao redor dos granitos da região de Bom Jardim de Goiás são paralelas e quase adjacentes ao lineamento Baliza e indicam deformações relacionadas a componentes cisalhantes da transcorrência do LTB (Figuras 5.8, 7.1b), sugerindo fase dúctil no final da Orogenia Brasiliana. Em trabalho de campo, observou-se falha normal associada ao lineamento Baliza (Figura 7.1b, ponto AJ-08), colocando em contato o Grupo Cuiabá e a Formação Aquidauana da Bacia do Paraná, fato que indica reativação rúptil pós-Carbonífero.

A noroeste do lineamento Baliza, os domínios Rondonópolis e Poxoréu são separados pelo lineamento General Carneiro. O domínio Rondonópolis revela inúmeros lineamentos magnéticos de $2^{\mathrm{a}}$ ordem, que se dispõem como sigmóides (Figura 5.6 e figura 2 - Anexo B4). Uma fase tectônica tardia é relacionada ao lineamento São Vicente, com direção NW, que oblitera e aparentemente desloca os sigmóides e o lineamento General Carneiro. Nível mais raso do embasamento é formado por rochas metassedimentares do Grupo Cuiabá, representado por resposta geofísica menos expressiva.

Ao norte, a região de Poxoréu possui maioria de assinaturas magnéticas e gravimétricas com maiores comprimentos de onda e refletem principalmente diferenças na composição de níveis crustais mais profundos, revelando poucas feições magnéticas próximas à superfície, exceto em duas áreas. Próximo a Poxoréu, assinaturas magnéticas rasas são associadas a rochas vulcânicas mapeadas como parte de magmatismo basáltico neocretáceo (Weska, 2006). Em Nova Xavantina, lineamentos $\mathrm{N} 60^{\circ} \mathrm{E}$ são marcados por profundidade geral de $2 \mathrm{~km}$ (Figura 4.6), associados a zona de cisalhamento (Silva, 2007). O lineamento General Carneiro alcança 
profundidade em torno de $20 \mathrm{~km}$ e é paralelo a contraste gravimétrico importante entre os domínios Poxoréu e Rondonópolis.

Médias ponderadas dos valores de profundidades na área de estudo, obtidas na análise de matched-filter (Capítulos 3 e 5), sugerem profundidades de 1,2, 2,5 e 4,4 km para o topo do embasamento neoproterozóico com uso de dados magnéticos, e 2,4 e 2,7 km com dados gravimétricos. Por meio da técnica do tilt-depth, a predominância das assinaturas magnéticas é de 2 a $3 \mathrm{~km}$ de profundidade (Figura 4.7). Os resultados indicam que 2,5 km é a aproximação mais segura para a espessura geral da bacia na área, corroborando com a média de profundidade dos poços estratigráficos 2AG-1-MT, 2JA-1-GO e 2TQ-1-MT. As variações de profundidade foram em parte interpretadas como estruturas indicativas do relevo assimétrico do embasamento da Bacia do Paraná, que representam reativações fanerozóicas, discutidas na próxima seção. As assinaturas mais rasas podem ser explicadas devido à presença de soleiras de rochas básicas.

\subsection{Evolução Tectônica - do Neoproterozóico às Reativações Fanerozóicas}

Este estudo partiu da concepção inicial de que o surgimento da zona de falhas transcorrentes NE do LTB é atribuído a alívio pós-orogênico da Orogenia Brasiliana (Schobbenhaus et al., 1975; Cordani et al., 1984). Como visto no capítulo 2, a Orogenia Brasiliana (Almeida e Hasui, 1984) é reconhecida como a amalgamação de dois domínios tectônicos de escala continental, o paleocontinente Amazônico, a oeste, e todo o conjunto précambriano a leste do LTB (ex.: Pimentel e Fuck., 1992; Fuck et al., 2008). Entre esses domínios, um oceano ("Goiás"; Pimentel et al., 2000; Cordani et al., 2009) foi subductado e consumido durante diferentes fases da colagem orogênica (Brito Neves e Cordani, 1991; Cordani et al., 2010b; Cordani et al., 2013; Brito Neves et al., 2014). Após a consolidação da Província Tocantins, as reativações no início do Fanerozóico resultaram nos primeiros depocentros da Bacia do Paraná, que continuaram a se desenvolver de acordo com o surgimento de novos esforços. Estruturas NW e E-W passaram a fazer parte do arcabouço tectônico da bacia principalmente no período de reativação meso-Cenozóica.

Nos últimos quatro anos, produções científicas alanvancaram discussões importantes relacionadas à formação do Gondwana (Pimentel et al., 2011; Tohver et al., 2012; Brito Neves e Fuck, 2013, 2014; Cordani et al., 2013a, b; Brito Neves et al., 2014, Fuck et al., 2014), promovendo contínuo aprofundamento do entendimento geotectônico da área de estudo. Com base na integração dos resultados alcançados e de informações adquiridas por meio da revisão bibliográfica realizada, o cenário evolutivo para área de estudo, do Neoproterozóico ao 
Mesozóico, é representado de forma sucinta no quadro esquemático de evolução tectônica (Figura 7.3). A representação de diferentes fases tectônicas tem como intuito propor os possíveis mecanismos de formação das principais falhas do Lineamento Transbrasiliano e subsequentes reativações que influenciaram a configuração da Bacia do Paraná. Vale ressaltar que a proposta de evolução é simplificada e requer revisão e construção de modelos alternativos na medida da aquisição de novos dados geológicos, paleomagnéticos e isotópicos.

No início da década de 90, dados geológicos e geofísicos existentes não foram suficientes para sustentar a hipótese de subducção na zona do LTB, sugerida por Brito Neves e Cordani (1991). A diferença entre a espessura crustal do Bloco Paranapanema e dos domínios do Arco Magmático de Arenópolis e paleocontinente Amazônico, na adjacência oeste do lineamento Serra Negra (Domínio Bom Jardim), é de até $11 \mathrm{~km}$. A modelagem dos dados gravimétricos da crosta inferior mostra valores de densidade menores do que a da crosta a oeste (Figuras 6.6 a 6.9), dando suporte à hipótese de espessamento crustal por acresção magmática vertical em resposta a subducção sob a Bacia do Paraná, não necessariamente com contribuição de underplating. A análise corrobora resultado do estudo de estruturas crustais com ondas de superfície (An e Assumpção, 2006), no qual os autores favorecem a hipótese de subsidência em detrimento de underplating, como proposto por Molina et al.(1988), Vidotti et al.(1998) e Mariani et al. (2013). Em análise de dados gravimétricos, Mariani et al. (2013) sugerem aumento de densidade na base da crosta da bacia. Pelo fato da área de estudo incluir apenas parte do Bloco Paranapanema, não há dados suficientes para invalidar a hipótese de underplating em outras regiões do bloco.

Com base nos argumentos acima, o primeiro estágio de evolução tectônica da área de estudo (Figura 7.3) é representado pela convergência e consumo de crosta ocêanica do paleocontinente Amazônico. É inferida subducção dirigida para leste, sob o Bloco Paranapanema, onde houve formação de arco magmático, correlacionado ao Arco Magmático de Arenópolis (900-630 Ma; Pimentel et al., 2000). Diferentemente da porção nordeste da área, onde o arco inclui rochas com assinatura de magmatismo juvenil (Laux et al., 2005), na região do Bloco Paranapanema provavelmente as assinaturas teriam forte influência crustal e menor densidade. Na região SE do paleocontinente Amazônico, Alvarenga e Trompette (1992) e Dantas et al., (2009) propõem que a Faixa Paraguai tenha sido paleo-prisma sedimentar de margem passiva, posteriomente invertido para bacia foreland. A menor espessura crustal encontrada na modelagem gravimétrica do domínio Bom Jardim provavelmente está relacionada a crosta da paleo-margem continental. O afinamento crustal do domínio e do arco também pode ter tido influência de processos de delaminação. 
A colisão final é registrada em $630-550 \mathrm{Ma}$ ao longo de todo o conjunto das faixas móveis Pampeana - Paraguai - Araguaia - Pharusiana (Pimentel e Fuck, 1987; Pimentel et al., 2000; Jahn et al., 2001; Cordani et al., 2013) e na deformação e formação de falhas de empurrão da Faixa Paraguai. A baixa intensidade gravimétrica na porção norte da área sugere maior espessura do Grupo Cuiabá, possivelmente controlada pela disposição geométrica dos empurrões (Figura 7.3). Em análise de condutividade crustal, Bologna et al. (2014) também propõem maior espessura do pacote metassedimentar grafitoso na seção basal da Faixa Paraguai (Grupo Cuiabá).

No final da Orogenia Brasiliana, ca. 600 Ma (Cordani et al., 2013a,b; Brito Neves et al., 2014), o alívio crustal pós-orogênico desencadeou reativações de estruturas brasilianas como zonas de cisalhamento e falhas de transcorrência. O conjunto das estruturas reativadas na área, predominantemente NE, constitui o Lineamento Transbrasiliano. A zona que abrange o contato entre o paleocontinente Amazônico e o conjunto a leste, formado pelas rochas do arco magmático e do Bloco Paranapanema, confere a assinatura magnética regional principal do lineamento. A zona de falhas principal se estende na área de estudo com direção $\mathrm{N} 30^{\circ} \mathrm{E}$, formando o lineamento Serra Negra, que continua para sul, até o limite sul do Bloco Rio Apa (Vidotti et al., 2011; Anexo B1). Outras estruturas importantes, como o lineamento General Carneiro, foram formadas no paleocontinente Amazônico com direção predominantemente $\mathrm{N} 60^{\circ}-70^{\circ} \mathrm{E}$, paralelamente às falhas de empurrão da Faixa Paraguai.

A principal fase de movimentação do LTB é reconhecida como dextral na Província Borborema (Vauchez et al., 1995), Gráben da Água Bonita (Zalán et al., 1986); Arco Magmático de Goiás (Pimentel et al., 1996; Cordani et al., 2013b; Fuck et al., 2014), Porangatu (Chiarini, 2007; Dantas et al., 2007) e a leste das Sierras Pampeanas (Rapela et al., 2007). Cinemática transcorrente sinistral é apontada por Seer (1985) na falha Serra Negra e Silva (2007) em zona de cisalhamento $\mathrm{N} 60^{\circ}-70^{\circ} \mathrm{E}$, paralela ao lineamento General Carneiro, na região de Nova Xavantina. Fairhead e Maus (2003) sugerem fase tectônica regional com cinemática sinistral. Em interpretação realizada por Chamani (2011), unidades devonianas e carboníferas da Bacia do Paranaíba mostram reativações com deslocamento sinistral. Os componentes cinemáticos de estruturas formadas na Orogenia Brasiliana apresentam maior destaque nas assinaturas magnéticas do que componentes relacionados às reativações fanerozóicas do LTB, especialmente se estas forem de caráter rúptil. Não é seguro sugerir a separação temporal das fases cinemáticas do LTB, diante da dificuldade de distingui-las quanto ao reflexo da sobreposição de diferentes estágios tectônicos nas anomalias magnéticas. As relações cinemáticas sugeridas a seguir foram construídas a partir de único elipsóide de tensões, em consideração à tectônica regional predominante. O Lineamento Serra Negra é expressão regional do conjunto das principais 
estruturas $\mathrm{N} 30^{\circ} \mathrm{E}$ do $\mathrm{LTB}$ na área e, apesar de representar a fase final da Orogenia Brasiliana, foi utilizado como marcador no elipsóide geral de tensões exposto na Figura 7.2a. Antes da transcorrência principal, dobras e falhas de empurrão foram elementos comuns em resposta às forças compressivas da orogenia. Falhas de empurrão da Faixa Paraguai são compatíveis com a direção mostrada no elipsóide (Figura 7.2a). A direção sugere colisão final da Orogenia Brasiliana na área, marcada pela colagem do Cráton Paranapanema a sul-sudeste. A indicação de transcorrência sinistral, é corroborada pela análise de Seer (1985), que sugere regime de transcorrência convergente sinistral na zona de falha Serra Negra.

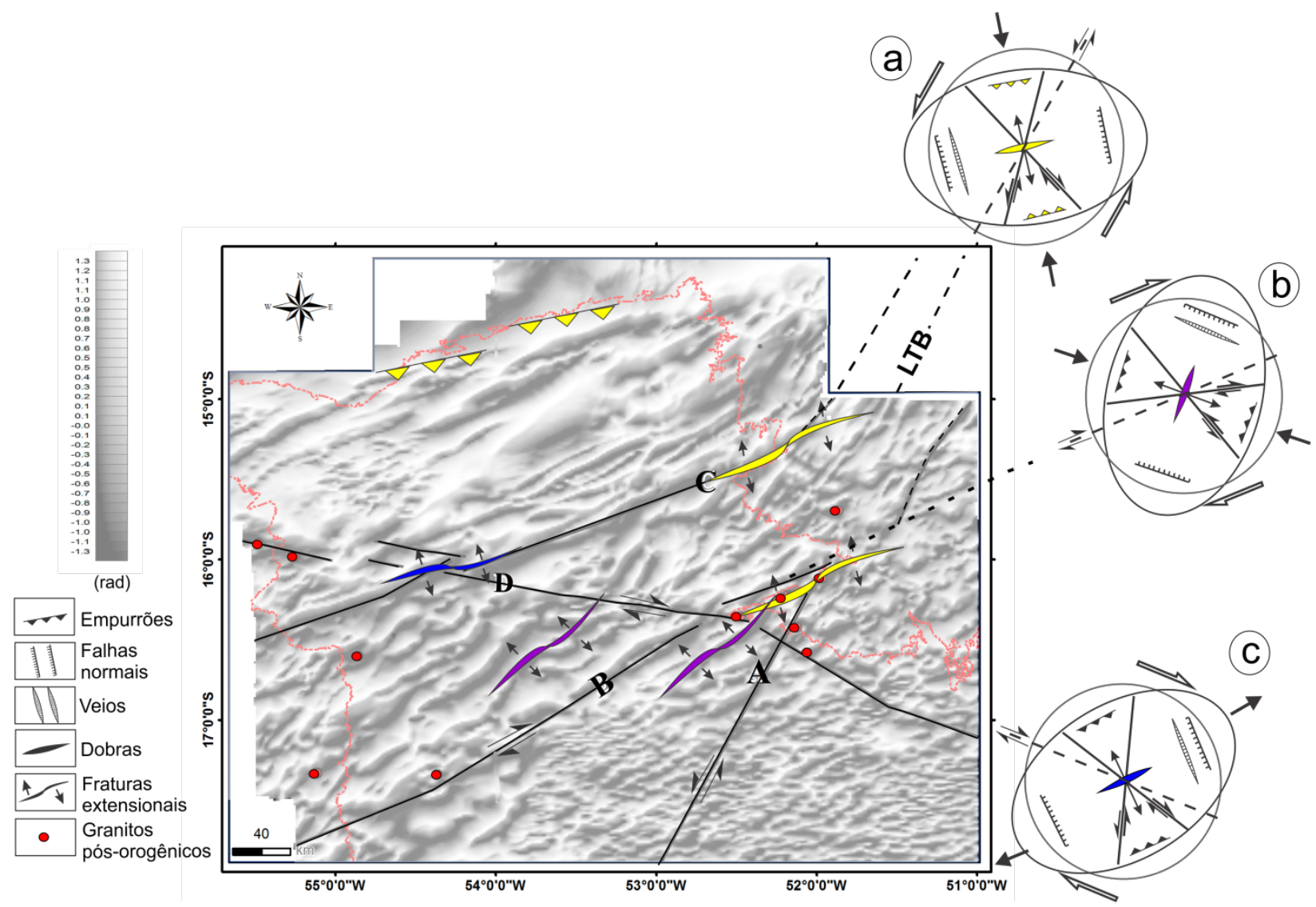

Figura 7.2 - Análise de mecanismos cinemáticos no tilt do campo magnético anômalo. a) Fase sinistral $\mathrm{N} 30^{\circ} \mathrm{E}$ do LTB; b) Fase dextral N60 ${ }^{\circ}-70^{\circ} \mathrm{E}$; $\left.\mathbf{c}\right)$ Movimentação dextral NW. Estão expostos no mapa em amarelo, magenta e azul os componentes dos elipsóides a, b e c, respectivamente. Os lineamentos são A: lineamento Serra Negra; B: Baliza; C: General Carneiro; e D: São Vicente.

Na região de Bom Jardim de Goiás o conjunto de sigmóides adjacente ao lineamento Baliza mostra aparente zona de cisalhamento (Figura 7.1b) que se dispõe segundo o componente do elipsóide que corresponde a dobras ou fraturas extensionais, sob condições de deformação não-coaxial com sentido sinistral da zona correspondente ao lineamento Serra Negra (Figura 7.2a). Apesar de estudos indicarem fases deformacionais sub-coaxiais no Grupo Cuiabá (Seer, 
1985), estas foram observadas em seções epidérmicas da Faixa Paraguai (C. Alvarenga, comunicação pessoal), enquanto os sigmóides nos dados magnéticos são associados a maiores profundidades $(>2 \mathrm{~km})$. Movimentações transcorrentes na direção dos lineamentos $\mathrm{N} 60^{\circ}-70^{\circ} \mathrm{E}$ também devem ser levadas em consideração (Figura 7.2b). Se o cisalhamento se desenvolveu na transcorrência do próprio lineamento Baliza, a cinemática dos sigmóides passa a ser no sentido dextral (Figuras 5.8 e $7.2 b$ ).

Regime transtensivo ocorreu em evento tardio, relacionado à intrusão dos granitos pósorogênicos em zonas de fraqueza ao longo dos lineamentos (Figura 7.1, ponto AJ-06; Figura 7.2), e posteriormente, a reativações que darão início aos primeiros depocentros da Bacia do Paraná.

A subsidência inicial da Bacia do Paraná ocorreu em depressões alongadas na direção NESW, induzidas pela reativação de zonas de fraqueza brasilianas. O LTB acomodou depocentros transtensivos no embasamento noroeste da bacia. Três eventos transtensivos principais são relacionados à fases de subsidência (Milani, 1997) e ocorreram há cerca de 440 Ma, 296 Ma e $144 \mathrm{Ma}$ (Quintas et al., 1999). Segundo Heilbron et al. (2000), o primeiro evento é associado ao novo campo de tensões atribuído à Orogenia Oclóyica (500 a 425 Ma; Ramos et al., 1986), marcada pela subducção do Oceano Panthalassa na margem meridional de Pangea.

A tectônica transtensiva inicial da Bacia do Paraná não foi um evento isolado, como ocorreu nos grábens de Jaibaras no Ceará (Oliveira, 2001; Pedrosa Jr. et al., 2014) e Água Bonita em Tocantins (Carvalho et al., 2012), os quais são pequenas bacias tipo pull-apart que resultaram de episódios de reativação no Cambriano-Ordoviciano e Siluriano-Devoniano, respectivamente. As principais ramificações estruturais NE do LTB no noroeste da Bacia do Paraná, representadas pelas falhas Serra Negra, Baliza e General Carneiro (Anexo A3), condicionaram a formação de pelo menos três meio-grábens, separados por altos estruturais, que compõem o relevo assimétrico do embasamento (Figura 7.3). A modelagem dos dados geofísicos mostra as falhas reativadas deslocando rochas intrusivas no topo do embasamento e dispostas em mergulho obliquo às falhas verticais transcorrentes (Figura 6.10).

Resultado da reativação Ordoviciana-Siluriana é observada a sudeste da área, incluindo depocentro balizado a oeste pelo lineamento Serra Negra e com espessuras sedimentares, estimadas na modelagem geofísica, em torno de 3-4 km (Figura 6.10). A leste do graben, o poço 2JA1GO está localizado em alto estrutural, revelado na modelagem, e mostra sequência devoniana entre $1645 \mathrm{~m}$ e $2107 \mathrm{~m}$ de profundidade, onde a perfuração foi finalizada sem alcançar o embasamento. Em mapa, o baixo gravimétrico que marca o depocentro se inicia na borda da bacia e continua para sul com trend $\mathrm{N}-\mathrm{S}$, acompanhando a extensão do lineamento 
Serra Negra (Figuras 6.5b e 6.6b). Parte da anomalia NS foi analisada por Vidotti et al. (1998) e Assumpção et al. (2009), que sugerem presença de paleográben situado entre 3 e $8 \mathrm{~km}$ de profundidade. A presença de unidades da Formação Furnas na região do Arco Magmático de Arenópolis permite inferir que o importante depocentro também teria continuidade para norte, antes do falhamento cretáceo que modificou a geomorfologia da bacia. A hipótese é corroborada pelas falhas normais descontínuas na sequência siluriana, registradas como resultado da reativação da falha Serra Negra (Seer, 1985). Em estudo de proveniência e paleocorrentes na área, Santos (2014) indica fluxo de deposição de sedimentos da Formação Furnas para noroeste, com contribuição de grãos detríticos neoproterozóicos e mesoproterozóicos de zircão, possivelmente provenientes do Arco Magmático de Goiás e Bloco Paranapanema, respectivamente.

Falhas $\mathrm{N} 60^{\circ}-70^{\circ}$ no embasamento também promoveram a formação de gráben na zona do lineamento General Carneiro, limitada a norte pela falha de Poxoréu (Figura 6.10). Entre Rondonópolis e Poxoréu, lineamento gravimétrico norte-sul (Figura 6.6b) é evidenciado em falhas normais, que movimentam as sequências devoniana e carbonífera-permiana (Anexos A1 e A3) e é associado ao aumento local da espessura sedimentar, observado na modelagem gravimétrica (Figura 6.10). Na região de Bom Jardim de Goiás, o lineamento Baliza define parte do limite da bacia e evidencia falha normal, com abatimento das unidades da bacia a norte, em relação as rochas do Grupo Cuiabá (Figura 5.8 e 7.1). Esta interpretação é corroborada pelos trabalhos de Seer (1985), Alvarenga et al. (1998) e Andrade et al. (2012). O primeiro autor registra a sul falha normal $\mathrm{N} 60^{\circ}-70^{\circ} \mathrm{E}$, paralela ao lineamento, que desloca aproximadamente 100 a $130 \mathrm{~m}$ das unidades a norte, enquanto os dois últimos trabalhos mapearam deslocamentos maiores que $500 \mathrm{~m}$ causados por reativações de estruturas com orientações entre $\mathrm{N} 60^{\circ} \mathrm{E}-\mathrm{EW}$, provavelmente relacionadas ao lineamento Baliza (Figura 7.1b, ponto AJ-08).

A reativação meso-cenozóica (Zalán, 2004) mostra forte relação com estruturação da Bacia do Paraná e facilitou a implantação do magmatismo Serra Geral. A presença de embasamentos distintos na área de estudo condicionou, reologicamente, respostas particulares a essa tectônica. $\mathrm{Na}$ região de Poxoréu, a reativação de lineamentos do LTB gerou conjunto de falhas $\mathrm{N} 60^{\circ}-70^{\circ} \mathrm{E}$ que claramente controlam sequencias cretáceas e promovem altos estruturais (Anexo A3). A noroeste, baixo gravimétrico e magnético alinhado ao Rio das Mortes sugere depocentro com aproximadamente $50 \mathrm{~km}$ de extensão lateral NS, desenvolvido ao longo de estruturas $\mathrm{N} 60^{\circ}-70^{\circ} \mathrm{E}$ que controlaram a sedimentação cretácea e atual (Figuras 6.5b, 6.6b; 6.10; Anexo A3). A falha de Poxoréu limita a bacia cretácea e é marcada por alto gravimétrico, paralelo ao lineamento General Carneiro (Figura 6.6b). A anomalia gravimétrica positiva é interpretada como alto 
estrutural do embasamento neoproterozóico, que se reflete em mapa no alongamento $\mathrm{N} 60^{\circ}-70^{\circ} \mathrm{E}$ dos limites da Bacia do Paraná (Anexo A3). A falha foi registrada por Northfleet et al., (1969) com $160 \mathrm{~km}$ de extensão e aproximadamente $300 \mathrm{~m}$ de rejeito vertical. Tectônica sindeposicional, com falhas gravitacionais e de transferência são observadas nas estruturas do hemigraben que configura bacia adjacente à falha de Poxoréu (Silva, 2014). Santos (2014) sugere que as falhas de Poxoréu e Jaciara, a norte (Anexos A1 e A3), são resultado de reativação no Permiano, que estruturou as rochas devonianas da bacia. Essa região foi pouco afetada pelo magmatismo Serra Geral, mas rochas vulcânicas próximas a Poxoréu são relacionadas a magmatismo mais recente, com cerca de $85 \mathrm{Ma}$ (Weska, 2006). Possivelmente a configuração estrutural e a ausência da Formação Serra Geral nessa região promoveram o desenvolvimento de pacote sedimentar meso-cenozóico de natureza distinta da classificação de Fernandes e Coimbra (1996) e Schobbenhaus et al. (2004), que colocam essas unidades como parte do Grupo Bauru. Weska (2006) relaciona o magmatismo dessa região ao chamado Rifte Rio das Mortes, o qual teria como borda SW a falha Poxoréu. Não foram encontradas evidências geofísicas que sustentem a hipótese de rifte neo-cretácico nessa região. No entanto, forte assinatura magnética no limite norte da área, que se estende na direção da Bacia dos Parecis, merece atenção e estudos de maior detalhe.

Estruturas com direção NW e EW são indicativas da reativação Meso-Cenozóica. A sudeste da área, as direções marcam contatos entre as unidades da Bacia do Paraná e soleiras de rochas ígneas cretáceas estão encaixadas em estruturas $\mathrm{NW}$, correspondente muitas vezes à rede de drenagem da bacia (Figuras 5.10 e Anexo A3). O truncamento entre estruturas NW e NE na parte norte do lineamento Serra Negra corresponde à zona sismogênica (Figura 5.10), onde é registrada a menor espessura crustal da área de estudo $(31 \mathrm{~km}$; Assumpção et al., 2002; 2013; Pavão et al., 2012). Sismos também foram registrados próximo à extensão do lineamento São Vicente, $\mathrm{N} 80^{\circ} \mathrm{W}$ e $\mathrm{N} 60^{\circ} \mathrm{W}$, o qual não é marcado por feição magnética expressiva, mas é ressaltado por obliterar grande parte dos lineamentos magnéticos NE e por marcar o limite entre a parte da Bacia do Paraná que encobre o Bloco Paranapanema, a sul, do Arco Magmático de Arenópolis, a norte (Figura 7.2). Este limite provavelmente está relacionado ao soerguimento da região norte, no Arco de Bom Jardim (Almeida, 1986; Fulfaro et al., 1994; Almeida et al., 2000), possivelmente concomitante aos soerguimentos do Cretáceo registrados na bacia (Tello Saenz et al., 2003; Hackspacher et al., 2004). Na margem leste da Bacia do Paraná, o caráter ascendente do embasamento é relacionado a épocas de resfriamento no Neocretáceo Inferior, Paleoceno e, em menor importância, Mioceno (Godoy et al., 2006; Franco-Magalhães et al., 2010). Em analogia ao Arco do Alto Paranaíba (Ladeira et al., 1971), ao qual são vinculados o enxame de 
diques do $\mathrm{Az}^{\circ} 125$ e as intrusões alcalinas com idade 80-100 Ma (Hasui e Haralyi, 1991, MoraesRocha et al., 2014), o Arco de Bom Jardim abrigou os corpos intrusivos da Província Alcalina de Goiás e parte deles mostra alinhamento NW (Figuras 5.8 e 5.10). O arqueamento causou a erosão de grande parte de sua cobertura fanerozóica, composta por unidades da Bacia do Paraná e, na região interna aos limites atuais da bacia, principalmente entre Rondonópolis e Bom Jardim de Goiás, proporcionou a exposição das unidades permo-carboníferas em superfície (Figura 2.2 e Anexo A1). Coimbra (1991) relacionou o soerguimento NE do substrato noroeste da Bacia do Paraná durante o Cretáceo Superior à Antéclise de Rondonópolis. Parte das reativações de estruturas NE do LTB nas unidades fanerozóicas sobrepostas ao paleocontinente Amazônico resultaram em falhas normais que configuram pequenas bacias cretáceas (Figura 5.10). A região do domínio Bom Jardim, entre os lineamentos General Carneiro e Serra Negra, apresenta a menor espessura crustal da área de estudo e concentra maior parte dos sismos, que reflete a neotectônica gerada pela reativação de estruturas NE e NW.

Lineamentos magnéticos com direção aproximadamente $\mathrm{N} 80^{\circ} \mathrm{W}-\mathrm{EW}-\mathrm{N} 80^{\circ} \mathrm{E}$ correspondem a evento tectônico mais recente e são escassos comparados aos que pertencem à trama estrutural mais antiga. O melhor representante magnético nesta direção é falha EW na região de Barra do Garças (Figura 5.8). A tectônica provavelmente causou movimentações no lineamento Serra Negra. Na região próxima à cidade, o rio Araguaia muda abruptamente de direção, de NE, segundo o lineamento Serra Negra, para EW (Figura 7.1). Os modelos geofísicos (Capítulos 5 e 6) não mostram compartimentações geradas por essas estruturas, possivelmente devido à sua menor contribuição magnética, bem como à direção dos perfis, NW-SE. 

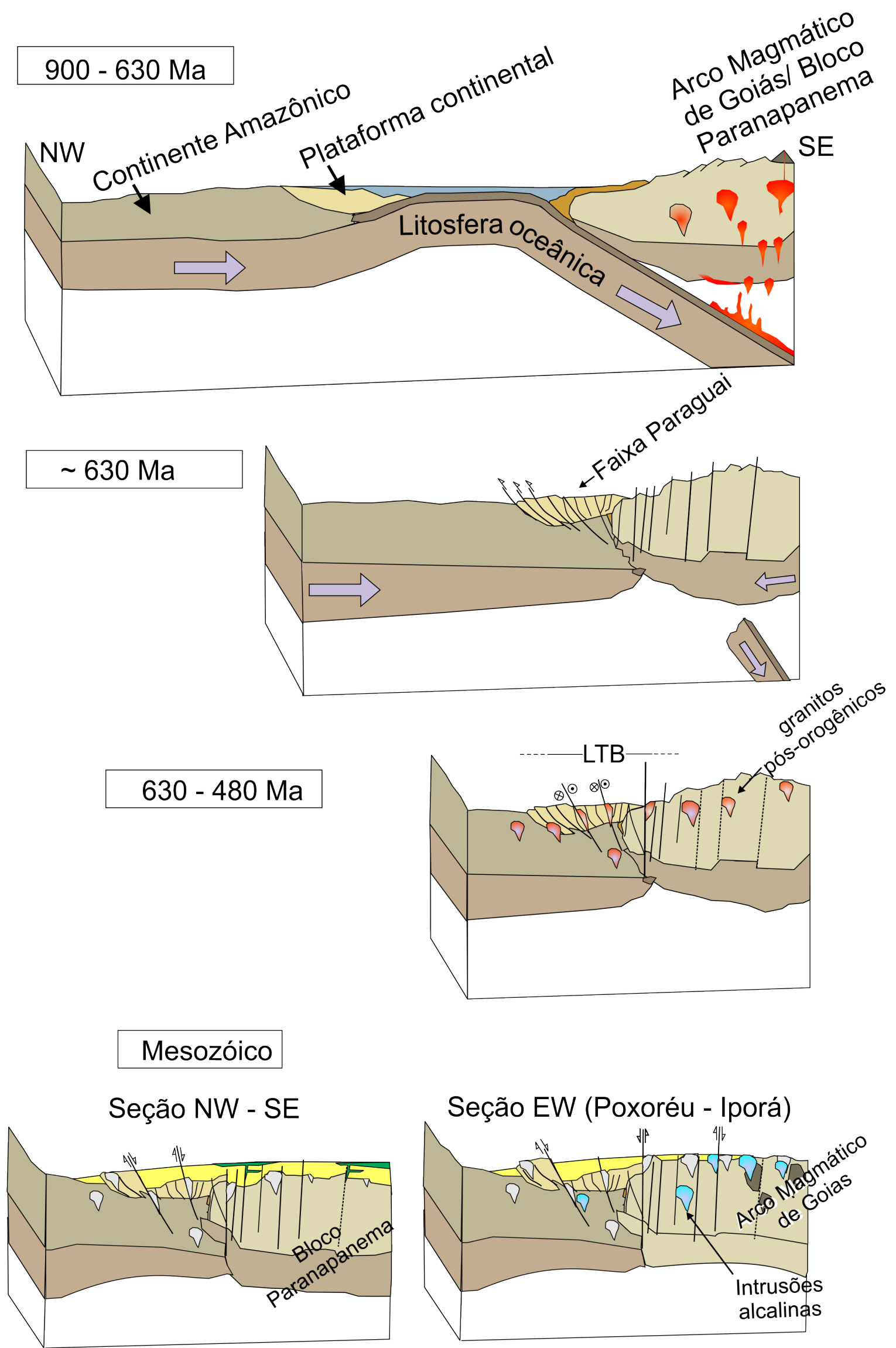

Figura 7.3 - Esquema de evolução tectônica para a área de estudo, desde a Orogenia Brasiliana ( 630 Ma) até a formação do Lineamento Transbrasiliano (LTB; 630-480 Ma) e da Bacia do Paraná (Paleozóico-Mesozóico). As seções NW-SE e Poxoréu- Iporá são idealizadas. Sem escala. 


\section{Conclusões}

"Acredite naquele que diz procurar a verdade. Desconfie daquele que diz que a encontrou... ", André Gide (1869-1951), escritor

\section{Em relação a técnicas de processamento geofísico}

Além do uso de técnicas de decorrugação, filtros direcionais e suavizadores, o processamento de dados geofísicos adquiridos na década de 70 necessitou da análise individual das linhas de voo, com subsequente uso de operações estatísticas no banco de dados para suavização de picos isolados sem significado geológico até grandes faixas de sinal ruidoso.

* A junção de projetos aerogeofísicos com diferentes resoluções e direção de linhas de aquisição foi realizada juntamente com o balanceamento estatístico dos dados nas zonas de intersecção, evitando que o contraste gerasse ruído ao longo da linha de sutura e anomalias distorcidas, induzindo falsas interpretações. Em razão da grande área de sobreposição entre os projetos, a resolução final permaneceu mais próxima aos dados com menor resolução. A junção nesse caso é indicada para análise regional, enquanto o uso individual de cada projeto é indicado para análise em escalas de maior detalhe.

* O método da derivada tilt do campo magnético anômalo realçou conjunto de lineamentos relacionados a contatos e falhas geológicas. As direções predominantes são $\mathrm{N} 60^{\circ}-70^{\circ} \mathrm{E}$, $\mathrm{N} 25^{\circ}-30^{\circ} \mathrm{E}, \mathrm{N} 50^{\circ} \mathrm{W}$ e $\mathrm{N} 80^{\circ} \mathrm{E}-\mathrm{N} 80^{\circ} \mathrm{W}$.

A técnica matched-filter permitiu o realce de anomalias magnéticas e gravimétricas em diferentes profundidades do campo magnético anômalo e anomalias Bouguer, respectivamente. A margem de erro, inerente ao uso da técnica, foi controlada (i) pela aplicação da técnica em sub-áreas retangulares de mesmo tamanho, parcialmente sobrepostas, e (ii) pela análise estatística de histogramas de densidade, com cálculo de médias ponderadas das principais populações. Os níveis de profundidade crustais mais importantes são 2,5 km para o topo do embasamento da Bacia do Paraná, $20 \mathrm{~km}$ para a interface crosta superior/inferior e 33 e $43 \mathrm{~km}$ para a interface crosta/manto, a oeste e leste do Lineamento Serra Negra, respectivamente. 
* A baixa inclinação magnética e a presença de magnetização remanente proveniente de diferentes fontes causam forte anisotropia nas anomalias, dificultando a aplicação de técnicas, como tilt-depth e modelagem 2D. Apesar da instabilidade do algoritmo, a redução ao polo com correção de amplitude (uso de pseudo-inclinação) mostrou-se ferramenta útil para delineação mais acurada de estruturas geológicas do embasamento da Bacia do Paraná. A amplitude do gradiente total foi utilizada como validação parcial para a redução ao polo de anomalias mais rasas.

As anomalias Bouguer e magnéticas reduzidas ao polo foram modeladas de forma simultânea em 2D, minimizando possíveis ambiguidades. O contraste lateral causado por falhas geológicas que colocaram em contato zonas crustais com diferentes valores de densidade e magnetização gera importantes lineamentos. Essas anomalias foram identificadas e modeladas de acordo com sua profundidade e geometria, permitindo definir os principais limites crustais e o relevo do embasamento da região noroeste da Bacia do Paraná. Anomalias gravimétricas e magnéticas locais foram atribuídas a variações físicas de níveis rasos, incluindo ocorrência de soleiras e corpos intrusivos no embasamento da bacia. Variações gravimétricas regionais contribuiram para o mapeamento da profundidade da interface crosta/manto (Descontinuidade de Mohorovicic), corroborando dados de função do receptor.

Mapa de profundidade de lineamentos magnéticos foi gerado a partir do desenvolvimento de metodologia prática em ambiente de sistema de informação geográfica (SIG), baseada na análise espacial e estatística da derivada tilt. Dados sintéticos mostraram a confiabilidade do método, indicando situações onde há maior possibilidade de dados com baixa acurácia, como em fontes sobrepostas e possíveis distorções na geometria das anomalias magnéticas devido a redução ao polo em baixas inclinações magnéticas. $O$ conhecimento sobre erros sistemáticos é necessário para a interpretação cuidadosa dos resultados. A interpolação de valores de profundidade calculados com ângulos diferentes do tilt aumenta a chance de encontrar resultados mais confiáveis. Em contraste com soluções calculadas com a Deconvolução de Euler, a análise do tilt permitiu estimativas de profundidade distribuídas continuamente ao longo do contato de fontes magnéticas, além de apresentar intervalo maior de valores de profundidade. 


\section{Em relação aos aspectos geotectônicos}

A configuração do Lineamento Transbrasiliano não é unidirecional. Ramificações estruturais ocorrem no noroeste da Bacia do Paraná. A orientação primária do lineamento na área é $\mathrm{N} 30^{\circ} \mathrm{E}$, atribuída ao lineamento Serra Negra, o qual é o componente magnético regional mais evidente do Lineamento Transbrasiliano no noroeste da Bacia do Paraná, separando dois blocos crustais principais, com características magnéticas ou gravimétricas distintas. O bloco a oeste é composto pela Faixa Paraguai estabelecida na margem do paleocontinente Amazônico e o bloco a leste inclui o Arco Magmático de Goiás e rochas do embasamento que se estendem a sudeste, o Bloco Paranapanema.

* As falhas de transcorrência do Lineamento Transbrasiliano em níveis rasos são associadas a zonas de cisalhamento em profundidade que atingem níveis da crosta superior e inferior $(\sim 20 \mathrm{~km})$, configurando extensas zonas de fraqueza crustal. O aspecto magnético regional dessas zonas marca as descontinuidades NE, englobando conjunto de estruturas que se intersectam e dividem o embasamento em vários blocos adjacentes.

A espessura crustal estimada para o domínio do Bloco Paranapanema é de aproximadamente $43 \mathrm{~km}$, com tendência de espessamento para sudeste, enquanto que o domínio oeste mostra afinamento crustal de aproximadamente $10 \mathrm{~km}$ na zona de fraqueza crustal disposta entre os lineamentos Serra Negra e General Carneiro. Essa configuração crustal e demais propriedades geofísicas da crosta e manto sugerem subducção brasiliana dirigida para leste, sob o Bloco Paranapanema, onde houve provável acresção magmática com formação do equivalente meridional do Arco Magmático de Goiás. A crosta mais fina a oeste é inferida como margem antiga do paleocontinente Amazônico, onde houve formação da Faixa Paraguai. A norte do lineamento General Carneiro, a crosta volta a apresentar tendência de espessamento na direção do cráton Amazônico.

O desenvolvimento do Lineamento Transbrasiliano marca a fase final da Orogenia Brasiliana e mostra componentes de transcorrência sinistral e destral. Direções $\mathrm{N}-60^{\circ} \mathrm{E}$ e $\mathrm{N} 70^{\circ} \mathrm{E}$, associados à transcorrência $\mathrm{N} 30^{\circ} \mathrm{E}$, também marcam componentes distensionais superimpostos, reativados no Fanerozóico, como falhas normais ou direcionais. Diferenças mecânicas e estruturas brasilianas preexistentes no paleocontinente Amazônico e provenientes do esforço regional causado pela convergência do Bloco Paranapanema a sudeste induziram a predominância de estruturas do Lineamento Transbrasiliano consistentes 
com as direção geral da porção norte da Faixa Paraguai, como observado nas descontinuidades Baliza $\left(\mathrm{N} 60^{\circ} \mathrm{E}\right)$, General Carneiro $\left(\mathrm{N} 70^{\circ} \mathrm{E}\right)$ e estruturas subsidiárias.

* O embasamento não aflorante ( $>3 \mathrm{~km}$ de profundidade) na região de Bom Jardim de Goiás mostra anomalias magnéticas dispostas como sigmóides ao longo do lineamento Baliza $\left(\mathrm{N} 60^{\circ} \mathrm{E}\right)$, interpretadas como estruturas formadas sob deformação plástica associada a transcorrência do Lineamento Transbrasiliano. Sugere-se que essa transcorrência ou reativação transcorrente transtensiva do lineamento Baliza permitiu a ascensão e alojamento de granitos pós-orogênicos. Aspectos cinemáticos dextrais e sinistrais são observados em estruturas brasilianas e nas reativações fanerozóicas marcadas principalmente nas estruturas observadas em unidades da Bacia do Paraná.

* Os lineamentos Serra Negra, Baliza e General Carneiro mostram efeito de deslocamentos verticais a oblíquos observados no embasamento e nas sequências fanerozóicas. Os níveis de profundidade do embasamento neoproterozóico da região noroeste da Bacia do Paraná estão em torno de 1,2 - 4,4 km. A modelagem do relevo do embasamento sugere disposição de horsts e meio-grábens, alinhados a $\mathrm{NS}, \mathrm{N} 30^{\circ} \mathrm{E}$ e $\mathrm{N} 60^{\circ}-70^{\circ} \mathrm{E}$, e resultantes da reativação de estruturas do Lineamento Transbrasiliano.

A reativação se deu em dois períodos principais. O mais antigo, no Ordoviciano-Siluriano, foi responsável por configurar os depocentros que acomodaram as sequências iniciais. Grábens com até $4 \mathrm{~km}$ de espessura sedimentar foram modelados nas adjacências dos lineamentos Serra Negra e General Carneiro. O segundo período foi marcado pela tectônica distensiva durante a abertura do Atlântico, no Jurássico-Cretáceo, causando falhamentos nas sequências pré-jurássicas da Bacia do Paraná.

A reativação do Jurássico-Cretáceo foi de suma importância para a configuração geomorfológica atual da bacia, resultante de três efeitos principais: soerguimento, reativação e instalação de novos depocentros. Estruturas associadas aos lineamentos Baliza e General Carneiro definem limites da bacia com direções $\mathrm{N} 60^{\circ}-70^{\circ} \mathrm{E}$. Essas estruturas, em conjunto com lineamentos $\mathrm{N} 50^{\circ} \mathrm{W}$ e $\mathrm{N} 80^{\circ} \mathrm{E}-\mathrm{N} 80^{\circ} \mathrm{W}$, balizam a região caracterizada pelo soerguimento pelo qual o Arco Magmático de Arenópolis foi condicionado a partir do Jurássico, na estrutura denominada Arco Bom Jardim de Goiás. Assim como a intrusão de rochas alcalinas do Cretáceo Superior nos arcos de Ponta Grossa e Alto Paranaíba, a Província Alcalina de Goiás foi alojada no Arco Bom Jardim de Goiás. O contínuo 
soerguimento nessa região promoveu a erosão de sequências sedimentares da Bacia do Paraná e a exposição das rochas alcalinas e do embasamento pré-cambriano em superfície. Os lineamentos NW controlam soleiras de diabásio da Formação Serra Geral (Cretáceo Inferior), na região de Jataí, e obliteram ou, por vezes, deslocam lineamentos NE.

* A tectônica juro-cretácea causou intensa reativação na crosta a oeste do lineamento Serra Negra. Ao longo do lineamento Baliza, a crosta mais fina e a ocorrência de pequenas bacias cretáceas alongadas e encaixadas em falhas NE sugerem zona de maior reativação jurocretácea e neotectônica, que atestada pelos sismos registrados na região. A borda norte da bacia e a extensão noroeste do lineamento da falha de Poxoréo, associada ao lineamento General Carneiro, configuram altos topográficos alinhados a $\mathrm{N} 60^{\circ}-70^{\circ} \mathrm{E}$ que limitam o gráben do Rio das Mortes, preenchido por rochas sedimentares cretáceas e sedimentos recentes.

* O cruzamento entre o lineamento Serra Negra e lineamentos EW e NW na região do granito Araguaiana, a norte de Barra do Garças, sugerem estruturas que ainda permanecem ativas, como registrado pela sismicidade anômala na área. 


\section{Referências Bibliográficas}

Almeida F.F. M., 1967. Origem e evolução da Plataforma Brasileira, Boletim do Departamento Nacional de Produção Mineral, 241, DNPM-DGM, Rio de Janeiro, 36p.

Almeida F.F.M., 1969. Diferenciação tectônica da Plataforma Brasileira, in: Anais do Congresso Brasileiro de Geologia, 23, SBG, Salvador, 29-46.

Almeida F.F.M., 1980. Tectônica da Bacia do Paraná no Brasil, Relatório da Paulipetro, 14.091, IPT, São Paulo, 187p.

Almeida F.F.M., 1981. Província Tocantins: Setor Sudoeste, in: Almeida, F. F. M., Hasui, Y. (Eds.). O Pré-Cambriano do Brasil. Ed. Blücher, São Paulo, pp. 265-281.

Almeida F.F.M., 1984. Província Tocantins - setor sudoeste, in: Almeida, F.F.M., Hasui, Y. (Eds.). O Pré Cambriano do Brasil, Ed. Blücher, São Paulo, pp. 265-281.

Almeida F.F.M., 1985. Alguns problemas das relações geológicas entre o Cráton Amazônico e as faixas de dobramentos marginais a leste, in: Atas do Simpósio de Geologia do Centro-Oeste, 2, SBG, Goiânia, 3-14.

Almeida F.F.M., 1986. Distribuição regional e relações tectônicas do magmatismo pós - Paleozóico no Brasil. Revista Brasileira de Geociências, 16, 02, 325-349.

Almeida F.F.M., Mantovani M.S.M., 1975. Geologia e geocronologia do granito de São Vicente, Mato Grosso. Anais da Academia Brasileira de Ciências, 47, 451-458.

Almeida F.F.M., Hasui Y., Brito Neves B.B., Fuck R.A., 1977. Províncias estruturais brasileiras, in: Atas do Simpósio de Geologia do Nordeste, 8, SBG, Campina Grande, 363-391.

Almeida F.F.M., Melo M.S., 1981. A Bacia do Paraná e o vulcanismo mesozoico, in: Mapa Geológico do Estado de São Paulo, escala 1:50.000. São Paulo, IPT, 1, pp. 46-81.

Almeida F.F.M., Hasui Y., Ponçano W.L., Dantas A.S.L., Carneiro C.D.R., Melo M.S., Bistrichi C.A., 1981. Mapa geológico do Estado de São Paulo: escala 1:500.000 - volumes I e II. São Paulo, IPT, Divisão de Minas e Geologia Aplicada.

Almeida F.F.M., Hasui Y., 1984. O Pré-Cambriano do Brasil, Ed. Blucher, São Paulo, 378p.

Almeida F.F.M., Brito Neves B.B., Carneiro, C.D.R., 2000. The origin and evolution of the South American Platform. Earth Science Reviews, 50, 77-111.

Alvarenga C.J.S., Trompette R., 1988. Upper Proterozoic glacial environment of the border of Amazonian Craton and its evolution towards the adjacent Paraguay Belt. (Mato Grosso, Brazil), in: Abstracts of communications and introduction to field trip of Earth's Glacial Record Meeting, International Geological Correlation Project, 260, IGCP-UNESCO/UFMT, Cuiabá, 31-44

Alvarenga C.J.S., Trompette R., 1993. Evolução tectônica brasiliana da Faixa Paraguai: a estruturação da região de Cuiabá. Revista Brasileira de Geociências, 23, 18-30. 
Alvarenga C.J.S., Guimarães E.M, Assine M.L., Perinotto J.A., 1998. Sequência Orodovício-Siluriano e Devoniano no flanco norte da Bacia do Paraná. Anais da Academia Brasileira de Ciências, 70, 03, 587-606.

Alvarenga C.J.S., Moura C.A.V., Gorayeb P.S.S., Abreu F.A.M., 2000. Paraguay and Araguaia belts, in: Cordani U.G., Milani E.J., Thomaz Filho A. Campos D.A. (Eds). Tectonic evolution of South America. 31st. International Geological Congress, Rio de Janeiro, pp. 183-193.

Amaro V., 1989. Geologia e petrologia da Sequência Metavulcânica de Jaupaci - GO e lineamentos associados. Dissertação de Mestrado, Instituto de Geociências, Universidade de Brasília, 237p.

Amaral G., Cordani U.G., Kawashita K., Reynolds J.H., 1966. Potassium-argon dates of basaltic rocks from Southern Brazil. Geochimica et Cosmochimica Acta, 30, 02, 159-189.

An, M., Assumpção, M., S., 2006. Crustal and upper mantle structure in the intracratonic Paraná Basin, SE Brazil, from surface wave dispersion using genetic algorithm. Journal of South America Earth Sciences, 21, 173-184.

Andrade A.P.U., Alvarenga C.J.S., Fuck R.A., 2012. Influência do Lineamento Transbrasiliano na borda norte da Bacia do Paraná, divisa Mato Grosso - Goiás, in: Anais do Congresso de Geologia, 46, SBG.

Araújo Filho J.O., 2000. The Pirineus syntaxis: an example of intersection of two Brasiliano fold thrust belts in Central Brazil, and its implications for the tectonic evolution of Western Gondwana. Revista Brasileira de Geociências, 30, 144-148.

Arkani Hamed J., 1988. Differential reduction-to-the-pole of regional magnetic anomalies. Geophysics, $53,12,1592-1600$.

Arkani Hamed J., 2007. Differential reduction to the pole: Revisited. Geophysics, 72, 01, L13-L20.

Arthaud M.H., 2007. Evolução neoproterozóica do Grupo Ceará (Domínio Ceará Central, NE Brasil): da sedimentação à colisão continental brasiliana. Tese de Doutorado, Instituto de Geociências, Universidade de Brasília, 132p.

Arthaud M.H., Caby R., Fuck R.A., Dantas E.L., Parente C.V., 2008. Geology of the Northern Borborema Province, NE Brazil and its correlation with Nigeria, NW Africa, in: Pankhurst R.J., Trouw R.A.J., Brito Neves B.B., De Wit M.J. (Eds.). West Gondwana: Pre-Cenozoic correlations across the South Atlantic region. Geological Society of London, 294, London, pp. 49-67.

Assine M.L., 1996. Aspectos da estratigrafia das seqüências pré- carboníferas da Bacia do Paraná no Brasil. Tese de Doutorado, Instituto de Geociências, Universidade de São Paulo, 207p.

Assine M.L., Soares P.C., 1989. Correlações nas seqüências mesopaleozóicas da Bacia do Paraná. Acta Geológica Leopoldensia, 12, 29, 39-48.

Assine M.L., Soares P.C., Milani E.J., 1994. Seqüências tectono-sedimentares mesopaleozóicas da Bacia do Paraná. Revista Brasileira de Geociências, 24, 02, 77-89.

Assumpção M.S., Sacek V., 2013. Intra-plate seismicity and flexural stresses in central Brazil. Geophysical Research Letters, 40.

Assumpção M.S., James D.E., Snoke J.A., 2002. Crustal thickness in SE Brazilian shield by receiver function analysis: implications for isostatic compensation. Journal of Geophysical Research, 107, B1, ESE 2-1-ESE-2-14. 
Assumpção M. S., An M., Bianchi M.B, França G.S.L.A., Rocha M.P., Barbosa J.R., Berrocal J., 2004. Seismic studies of the Brasília Fold Belt at the western border of the São Francisco craton, central Brazil, using receiver function, surface wave dispersion, and teleseismic tomography. Tectonophysics, 388, 173-185.

Assumpção M.S., Barbosa J.R., Prado R.L., Bordotti F., Dias F., 2009. Sedimentary thickness in the Paraná Basin using high-frequency receiver function: Estimated depth of a buried graben in the MS/GO border, in: 11th Anais do International Congress of the Brazilian Geophysical Society, 11, SBGf, Salvador.

Assumpção M.S., Bianchi M., Julià J.C., Dias F.L., França G.S.L.A., Pavão C.G., Albuquerque, D.F., Lopes, A.E.V., 2013. Crustal thickness map of Brazil and adjacent areas: Data compilation and main features. Journal of South American Earth Sciences, 43, 74-85.

Azevedo P.A., Rocha M.P., Soares J.E.P., Fuck R.A., 2015. Thin lithosphere between the Amazonian and São Francisco cratons, in Central Brazil, revealed by seismic P-wave tomography. Geophysical Journal International, 201, 61-69.

\section{$\boldsymbol{B}$}

Barbour A.P., Girardi V.A.V., Kawashila K., Souza A.M.S., 1979. Geologia do complexo máficoultramáfico alcalino de Santa Fé, Goiás. Boletim IG-USP, 10, 11-18.

Bhattacharyya B.K., 1969. Bicubic spline interpolation as a method for treatment of potential field data. Geophysics, 34, 03, 402-423.

Baranov V., Naudy H., 1964. Numerical calculation of the formula of reduction to the magnetic pole. Geophysics, 29, 67-79.

Blakely R.J., 1996. Potential Theory in Gravity \& Magnetic Applications, Cambridge University Press, $464 \mathrm{p}$.

Blum M.L.B., Pires A.C.B., 1996. Superfície Curie da região central de Goiás. Revista Brasileira de Geociências, 26, 03, 197-208.

Boggiani P.C., Alvarenga C.J.S., 2004. Faixa Paraguai, in: Mantesso-Neto, V., Bartorelli, A.,Dal Ré Carneiro, C., Brito-Neves, B.B. (Eds.). Geologia do Continente Sul-Americano. Ed. Beca, São Paulo, pp.113-118.

Bologna M.S., Nunes H.O., Padilha A.L., Vitorello I., Pádua M.B., 2013. Anomalous electrical structure in the northwestern Paraná Basin, Brazil, observed with broadband magnetotellurics. Journal of South American Earth Sciences, 42, 74-82.

Bologna M.S., Padilha A.L., Pádua M.B., Vitorello I., Chamalaun F.H., 2014. Paraguay-Araguaia Belt conductivity anomaly: A fundamental tectonic boundary in South American Platform imaged by electromagnetic induction surveys. Geochemical Geophysics Geosystems, 15, 03, 509-515.

Bongiolo A. de B. e S., Souza J. De., Ferreira F. J. F., Castro L. G. de., 2013. Grav_Mag_Prism: A Matlab/Octave program to generate gravity and magnetic anomalies due to rectangular prismatic bodies. Revista Brasileira de Geofísica, 31, 3, 347-363.

Briggs I.C., 1974. Machine contouring using minimum curvature. Geophysics, 39, 1, 39-48. 
Brito Neves B.B., 1999. América do Sul: Quatro fusões, quatro fissões e o processo acrescionário andino. Revista Brasileira de Geociências, 28, 03, 01-20.

Brito Neves B.B., 2011. The Paleproterozoic in the South American Continent: Diversity in the geological time. Journal of South American Earth Sciences, 32, 1-20.

Brito Neves B.B., Cordani U.G., 1991. Tectonic evolution of south america during the Late Proterozoic. Precambrian Research, 53, 01, 23-40.

Brito Neves B.B., Cordani A., Thomaz Filho A., 1984. Influence of basement structures on the evolution of the major sedimentary basins of Brasil. Journal of Geodynamics, 1, 495-510.

Brito Neves B.B., Campos Neto M.C., Fuck R.A., 1999. From Rodinia to Western Gondwana: an approach to the Brasiliano-Pan African Cycle and orogenic collage. Episodes, 22, 03, 155-166.

Brito Neves, B. B., Fuck, R. A., 2013. Neoproterozoic evolution of the basement of the South America Platform. Journal of South America Earth Sciences, 47, 72-89.

Brito Neves B.B., Fuck R.A., 2014. The basement of the South American Platform: half Laurentian (NNW) + half Gondwanan (E-SE) domains. Precambrian Research, 244, 75-86.

Brito Neves, B. B., Fuck, R. A., Pimentel, M. M., 2014. The Brasiliano Collage in South America: A review. Brazilian Journal of Geology, 44, 3, 493-518.

\section{C}

Caby R., 1989. Precambrian terranes of Benin-Nigeria and northeast Brazil and the late Proterozoic south Atlantic Rift. Geological Society of America Special Papers, 230, 145-158.

Caby R., Bertrand J.M., Black R., 1981. Pan-African ocean closure and continental collision in the Hoggar-Iforas segment, Central Sahara, in: Kroner, A. (Ed.). Precambrian Plate Tectonics. Elsevier. pp. 407-434.

Cady J.W., 1980. Calculation of gravity and magnetic anomalies of finite-length right polygonal prisms. Geophysics, 45, 10, 1507-1512.

Campos Neto M.C., 2000. Orogenic Systems from Southwestern Gondwana: an approach to BrasilianoPanAfrican Cycle and Orogenic Collage in Southeastern, in: Cordani U.G., Milani E.J., Thomaz Filho A., Campos D.A. (Eds.). Tectonic evolution of South America. 31st. International Geological Congress, Rio de Janeiro, pp. 335-365.

Campos Neto M.C., Caby R., 1999. Neoproterozoic high-pressure metamorfism and tectonic constraint from the nappe system south of the São Francisco Craton, southeast Brazil. Precambrian Research, 97, 3-26.

Caputo M.V., Melo J.H.G., Streel M., Isbell J.L., 2008. Late Devonian and Early Carboniferous glacial records of South America., in: Fielding C.R., Frank T.D., Isbell J.L. (Eds.). Resolving the Late Paleozoic ice age in time and space. Special Paper, 441, GSA, Boulder, pp. 161-173.

Carvalho D.L.O., Vidotti R.M., Araújo Filho J.O., Meneses P.R., 2012. Geologia, aerogeofísica e gravimetria terrestre da porção central do Graben de Água Bonita, sudoeste de Tocantins e noroeste de Goiás, Brasil. Revista Brasileira de Geofísica 30, 4, 483-494. 
Chiarini, M. F. N., 2007. Contribuição da aerogeofísica na caracterização de suturas e de sistemas transcorrentes: o exemplo de Porangatu, Brasil Central. Dissertação de Mestrado, Instituto de Geociências, Universidade de Brasília, 108p.

Chamani M.A.C., 2011. Tectônica intraplaca e deformação sinsedimentar induzida por abalos sísmicos: o Lineamento Transbrasiliano e estruturas relacionadas na Província Parnaíba, Brasil. Dissertação de Mestrado, Instituto de Geociências, Universidade de São Paulo, 206p.

Coimbra A.M., 1991. Sistematização crítica da obra. Tese de Livre-Docência, Instituto de Geociências, Universidade de São Paulo, 54 p.

Cooper G.R.J., Cowan D.R., 2005. Differential reduction to the pole. Computers and Geosciences, 31, 8, 989-999.

Cordani U.G., Brito Neves B.B., Fuck R.A., Porto R., Thomaz Filho A., Cunha F.M.B., 1984. Estudo preliminar de integração do Pré-cambriano com os eventos tectônicos das bacias sedimentares brasileiras. Ciência Técnica Petróleo, 1-70.

Cordani U.G., Sato K., 1999. Crustal evolution of the South American Platform, based on Nd isotopic systematics on granitoids rocks. Episodes, 22, 3, 167-173.

Cordani U.G., Sato K., Teixeira W., Tassinari C.C.G., Basei, M.A.S., 2000. Crustal evolution of the South American Platform, in: Cordani U.G., Milani E.J., Thomaz Filho A., Campos D.A. (Eds). Tectonic evolution of South America. 31st. International Geological Congress, Rio de Janeiro, pp. 1940.

Cordani U.G., Brito Neves B.B., D’Agrella Filho, M.S., 2003. From Rodinia to Gondwana: a review of the available evidence from South America. Gondwana Research, 6, 2, 275-284.

Cordani U.G., Teixeira W., D'Agrella Filho M.S., Trindade R.I., 2009. The position of the Amazonian Craton in supercontinents. Gondwana Research, 15, 396-407.

Cordani U.G., Brito Neves B.B., Fuck R. A., Porto R., Thomaz Filho A., Cunha F.M.B., 2010a . Estudo preliminar de integração do Pré-Cambriano com os eventos tectônicos das Bacias Sedimentares Brasileiras (Republicação). Boletim de Geociências da PETROBRAS, 17, 137-204.

Cordani U.G., Brito Neves B.B., Thomaz Filho A., 2010b. Estudo preliminar de integração do PréCambriano com os eventos tectônicos das bacias sedimentares brasileiras (Atualização). Boletim de Geociências da PETROBRAS, 17, 205-219.

Cordani U.G., Pimentel M.M., Araújo C.E.G., Basei M.A.S., Fuck R.A., Girardi V.A.V., 2013a. Was there an Ediacaran Clymene ocean in central South America? American Journal of Science, 313, 6, $517-539$.

Cordani U.G., Pimentel M.M., Araújo C.E.G., Fuck R.A., 2013b. The significance of TransbrasilianoKandi tectonic corridor for amalgamation of West Gondwana. Brazilian Journal of Geology, 43, 3, 583-597.

CPRM, 2011. http://www.cprm.gov.br/ Base de metadados de Projetos Aerogeofísicos. Acesso em abril de 2011.

\section{D}

Dantas E. L., Fuck R.A., Oliveira C.G., Pimentel M.M., Sordi D.A., Almeida T., 2007. Geometria côncava do sistema de empurrões no arco magmático de Mara Rosa, Goiás, in: Anais do Simpósio Nacional de Estudos Tectônicos, 11, SBG, Natal, 202-204 
Dantas E. L., Pimentel, M. M., Santos, R. V., Alvarenga, C. J. S., 2009. Using Nd isotopes to understand the provenance of sedimentary rocks from a continental margin to a foreland basin in the Neoproterozoic Paraguay Belt, Central Brazil. Precambrian Research, 170, 1-12.

Dardenne M.A., 2000. The Brasília fold belt, in: Cordani U.G., Milani E.J., Thomaz Filho A., Campos D.A. (Eds). Tectonic evolution of South America. 31st. International Geological Congress, Rio de Janeiro, pp.: 231-263.

Del'Arco J.O., Silva R.H., Tarapanoff L., Freire F.A., Pereira, L.G.M., Souza, S.L., Luz, L.G., Palmeira, R.C.B., Tassinari, C.C.G., 1982. Folha SE. 21 Corumbá e Parte da Folha SE. 20, Geologia, in: RADAMBRASIL, Levantamento de Recursos Naturais, 27, Rio de Janeiro, MME, pp. 25- 160.

Dutra A.C., 2011. Inversão tridimensional de dados gravimétricos e magnéticos da Província Alcalina de Goiás: Investigando o controle tectônico. Tese de doutorado, Universidade de São Paulo, Instituto de Astronomia, Geofísica e Ciências Atmosféricas, 151p.

\section{$\boldsymbol{E}$}

Ernesto M., Pacca I.G., 1988. Paleomagnetism of the Paraná Basin flood volcanics, Southern Brasil., in: Piccirillo, E.M., Melfi, A. J. (Eds.). The Meozoic flood volcanism of the Paraná Basin: Petrogenic and geophysical aspects. IAG-USP Press, São Paulo, pp. 229-255.

\section{$\boldsymbol{F}$}

Faria A., 1982. Formação Vila Maria - nova unidade litoestratigráfica siluriana da Bacia do Paraná. Ciências da Terra, 3, 12-15.

Fairhead J.D., Maus S., 2003. Champ satellite and terrestrial magnetic data help define the tectonic model for South America and resolve the lingering problem of the pre-break-up fit of the South Atlantic Ocean. The Leading Edge, 22, 8, 779-783.

Feng M., Assumpção M.S., Van Der Lee S., 2004. Group-velocity tomography and lithospheric Svelocity structure of the South American continent. Physics of the Earth and Planetary Interiors, 147, $315-331$.

Fernandes L.A., Coimbra A.M., 1996. A Bacia Bauru (Cretáceo Superior, Brasil). Anais da Academia Brasileira de Ciências, 68, 2, 195-205.

Ferré E.C., Gleizes G., Caby R., 2002. Tectonics and post-collisional granite emplacement in an obliquely convergent orogen: the Trans-Saharan belt, Eastern Nigeria. Precambrian Research, 114, 199-219.

Fetter A.H., Santos T.J.S., Van Schumus W.R., Hackspacher P.C., Brito Neves B.B., Arthaud M.H., Nogueira Neto J.A., Wernick E., 2003. Evidence for Neoproterozoic continental arc magmatism in the Santa Quitéria Batholith of Ceará State, NW Borborema province, NE Brazil: implications for the assembly of West Gondwana. Gondwana Research, 6, 2, 265-273.

Ferreira-Filho C.F., Pimentel M.M., Araújo S.M., Laux J., 2010. Layered intrusions and volcanic sequences in Central Brazil: Geological and geochronological constraints for Mesoproterozoic (1.25 $\mathrm{Ga})$ and Neoproterozoic $(0.79 \mathrm{Ga})$ igneous associations. Precambrian Research, 183, 617-634.

Fiori A.P., Wandersen R., 2014. Tensões e deformações em Geologia, Ed. Oficina de Textos, São Paulo, $255 \mathrm{p}$. 
FitzGerald D., Reid A., McInerney P., 2004. New discrimination techniques for Euler deconvolution. Computer \& Geosciences, 30, 5, 461-469.

Foster M.R., Jines W.R., Van Der Weg K., 1970. Statistical elimination of systematic errors at intersections of lines of aeromagnetic survey data. Journal of Geophysical Research, 75, 1507-1511.

Fuck R.A., Sá E.F.J., Pimentel M.M., Dardenne M.M., Soares, A.C.P., 1993. As faixas de dobramentos marginais do Cráton do São Francisco: Síntese dos conhecimentos, in: Dominguez J.M.L., Misi A. (Eds.). O Craton do São Francisco. SGM/CNPQ/Sociedade Brasileira de Geologia, Salvador, pp. 161185.

Fuck R.A., Pimentel M.M., Silva L.J.H.D.R., 1994. Compartimentação tectônica na porção oriental da Província Tocantins, in: Boletim de Resumos Expandidos do Congresso Brasileiro de Geologia, 38, SBG, Balneário Camboriú, 215-216.

Fuck R.A., Dantas E.L., Pimentel M.M., Junges S.L., Moraes R., 2001. Nd isotopes, U-Pb single grain and SHRIMP zircon ages from basement rocks of the Tocantins Province, in: Extended Abstract of South American Symposium on Isotope Geology, 3, Servicio Nacional de Geologia y Mineria, Santiago, 141-144.

Fuck R. A., Brito Neves B.B., Schobbenhaus C., 2008. Rodinia descendants in South America. Precambrian Research, 160, 108-126.

Fuck R. A., Dantas E. L., Pimentel M. M., Botelho N. F. Armstrong R., Laux J. H., Junges S. L., Soares J. E. P., Praxedes I. F., 2014. Paleoproterozoic crust-formation and reworking events in the Tocantins Province, Central Brazi: a contribution for Atlantica supercontinent reconstruction. Precambrian Research, 244, 53-74.

Fulfaro V.J., Perinotto J.A.J., Barcelos J.H.A., 1994. Margem goiana de Grupo Bauru: Implicações na litoestratigrafia e paleogeografia, in: Boletim do Simpósio sobre o Cretáceo do Brasil, 3, UNESP, Rio Claro, 81-84.

Franco Magalhães A.O.B., Hackspacher P.C., Saad, A.R., 2010. Exumação tectônica e reativação de paleolineamentos no Arco de Ponta Grossa: termocronologia por traços de fissão em apatitas. Revista Brasileira de Geociências, 40, 2, 184-195.

França A.B., Potter P.E., 1988. Estratigrafia, ambiente deposicional e análise de reservatório do Grupo Itararé (Permocarbonífero), Bacia do Paraná (Parte 1). Boletim de Geociências da PETROBRAS, 2, 147-191.

\section{$\boldsymbol{G}$}

Geosoft Incorporated, 2014. Oasis montaj, version 7.8.1 (OL): Toronto, Canada.

Grant F.S., Dodds J., 1972. MAGMAP FFT Processing System Development Notes, Paterson Grant and Watson Limited, Toronto.

Godoy D. F., Hackspacher P. C., Guedes S., Hadler Neto J. C., 2006. Reconhecimento da Tectônica Mesozóica-Cenozóica na borda leste da Bacia do Paraná através da aplicação de traços de fissão em apatitas no Domo de Pitanga (sudoeste de Rio Claro, SP). Revista Geociências, 25, 1/3, 151-164.

Godoy A.M., Manzano J.C., Ruiz A.S., Araujo L.M.B., 2007. Os granitóides brasilianos pós - tectônicos da Faixa de Dobramentos Paraguai MS e MT. Geologia USP. Série Científica, 7, 29-44, 2007. 
Godoy A.M, Pinho F., E., C., Manzano J.C, Araújo L.M.B, Silva J.A., Figueiredo M., 2010. Estudos isotópicos das rochas granitóides neoproterozóicos da Faixa de Dobramento Paraguai. Revista Brasileira de Geociências, 40, 3, 380-391.

Gohrbandt K.H.A., 1993. Paleozoic paleogeographic and depositional developments on the central protoPacific margin of Gondwana: Their importance to hydrocarbon accumulation. Journal of South American Earth Sciences, 6, 4, 267-287.

Green A.A., 1983. A comparison of adjustment procedures for levelling aeromagnetic survey data. Geophysics, 48, 6, 745-753.

\section{$\boldsymbol{H}$}

Hackspacher P.C., Ribeiro L.F.B., Ribeiro, M.C.S., Fetter, A.H., Hadler Neto, J.C., Tello, C.A.S., Dantas, E.L., 2004. Consolidation and break-up of the South American Platform in Southeastern Brazil: Tectonothermal and denudation histories. Gondwana Research, 7, 1, 91-101.

Haney M., Johnston C. Li Y., Nabighian M.N., 2003. Envelopes of 2D and 3D magnetic data and their relationship to the analytic signal: Preliminary results, in: Technical Program Expanded Abstracts of SEG International \& $73^{\text {rd }}$ Annual Meeting, 22, SEG, Dallas, 596-599.

Hasui Y., 2009. A grande colisão pré-cambriana do Sudeste brasileiro e sua relação com a geologia estrutural, in: Anais do Simpósio de Geologia do Sudeste, 11, SBG, Rio Claro, 12-12.

Hasui Y., Sadowsk, G.R., Suguio K., Fuck G.F., 1975. - The Phanerozoic tectonic evolution of the western Minas Gerais State. Anais da Academia Brasileira de Ciências, 47, 431-438.

Hasui Y., Haralyi N.L.E., 1991. Aspectos lito-estruturais e geofísicos do soerguimento do Alto Paranaíba. Geociências, 10, 57-77.

Heilbron M., Mohriak W., Valeriano C.M., Milani E., Almeida J.C.H., Tupinambá M., 2000. From collision to extension: The roots of the south-eastern continental margin of Brazil, in: Mohriak W., Talwani M. (Eds). Atlantic rifts and continental margins. American Geophysical Union, Geophysical Monograph Series, 115, 1-34

Howell D.G., 1985 (original publication). Terranes, in: Moores E.M., 1990 (Ed.). Shaping the Earth: Tectonics of continents and oceans. Readings from Scientific American, pp. 98-111.

Hrouda F., Chlupáèová M., Chadima M., 2009. The use of magnetic suscpetibility of rocks in geological exploration (Case histories study). Terraplus, Geophysical equipment supplier.

\section{$\boldsymbol{J}$}

Jahn B., Caby R., Monie P., 2001. The oldest UHP eclogites of the World: age of UHP metamorphism, nature of protoliths and tectonic implications. Chemical Geology, 178, 143-158.

Junges S.L., Pimentel M.M., Moraes R., 2002. Nd isotopic of the Neoproteroic Mara Rosa arc, central Brazil: Implications for the evolution of Brasilia belt. Precambrian Research, 117, 101-118.

Junqueira Brod T.C., Roig H.L., Gaspar J.C., Brod J.A., Meneses P.R., 2002. A Província Alcalina de Goiás e a extensão de seu vulcanismo kamafugítico. Revista Brasileira de Geociências, 32, 559-566. 
Kearey P., Brooks M., Hill I., 2009. Geofísica de exploração. Ed. Oficina de Textos, São Paulo, 438p.

Kuyumjian R.M., Dias R.R., 1991. Anfibolitos Proterozóicos de Goiás, Brasil: Representantes de vulcanismo basáltico de arcos magmáticos. Geochimica Brasiliensis 5, 1-2, 35-44.

\section{$\boldsymbol{L}$}

Laux J.H., Pimentel M.M., Dantas E.L., Junges S.L., Armstrong R., 2005. Two Neoproterozoic crustal accretion events in the Brasília Belt, central Brazil. Journal of South American Earth Sciences, 18, $183-198$.

Ladeira E.A., Braun O.P.G., Cardoso R.N., Hasui Y., 1971. O Cretáceo em Minas Gerais, in: Anais do Congresso Brasileiro de Geologia, 25, SBG, 15-31.

Li X., 2006. Understanding 3D analytic signal amplitude. Geophysics, 71, 2, L13-L16.

López Gamundí O., Rossello E.A., 1993. Devonian-Carboniferous unconformity in Argentina and its relation to Eo-Hercynian orogeny in southern South America. Geologische Rundschau, 82, 136-147.

Luyendyk A.P.J., 1997. Processing of airborne magnetic data. Journal of Australian Geology and Geophysics, 17, 2, 31-38.

\section{$M$}

Machado S.A.M., 1990. Estudo do comportamento das feições lineares observado em dados aeromagnéticos da Bacia do Paraná. Dissertação de Mestrado, Universidade Federal do Pará, Centro de Geociências, 144p.

MacLeod I.N., Jones K., Dai T.F., 1993. 3-D Analytic signal in the interpretation of total magnetic field data at low magnetic latitudes. Exploration Geophysics, 24, 4, 679-688.

Mantovani M.S.M., Quintas M.C.L., 1996. A contribution to the study of the Parana basin evolution, in: Abstract of the International Geological Congress, 30, IUGS, Beijing, 102-102.

Mantovani M.S.M., Brito Neves B.B., 2005. The Parapanema lithospheric block: Its importance for Proterozoic (Rodinia, Gondwana) supercontinent theories. Gondwana Research, 8, 3, 303-315.

Mantovani M.S.M., Quintas M.C.L., Shukowsky W., Brito Neves B.B., 2005. Delimitation of the Paranapanema Proterozoic block: A geophysical contribution. Episodes, 28, 1, 18-22.

Manzano J.C., Godoy A.M., Araújo L.M.B. de., 2008. Contexto Tectônico dos Granitóides Neoproterozóicos da Faixa de Dobramento Paraguai, MS e MT. Geociências, 27, 4, 493-507.

Mariani P., Braitenberg C., Ussami N., 2013. Explaining the thick crust in Paraná basin, Brazil, with satellite GOCE-gravity observations. Journal of South American Earth Sciences, 45, 209-223.

Marini O.J., Fuck R.A., Dardenne M.A., Danni J.C.M., 1984a. Província Tocantins - setores central e sudeste, in: Almeida, F.F.M., Hasui, Y. (Eds.). O Precambriano do Brasil. Ed. Edgard Blücher, pp. 205-264.

Marini J.O., Fuck R.A.; Danni J.M.C; Dardenne M.A.; Loguercio S.O.C.; Ramalho R., 1984b. As Faixas de Dobramentos Brasília, Uruaçu e Paraguai-Araguaia e o Maciço Mediano de Goiás, in: Schobbenhaus, C. (Ed.). Geologia do Brasil: Texto explicativo do mapa geológico do Brasil e da área oceânica adjacente incluindo depósitos minerais, Escala 1: 2.500.000, MME-DNPM, pp. 251-303. 
Marques A., Zanotto O.A., França A.B., Astolfi M.A.M., Paula O.B., 1993. Compartimentação tectônica da Bacia do Paraná. PETROBRAS /NEXPAR International Report, 87 p.

Marques L.S., Ernesto M., 2004. O magmatismo toleítico da Bacia do Paraná, in: Mantesso Neto V., Bartorelli A. Carneiro C.D.R., Brito Neves B.B. (Eds.). Geologia do Continente Sul-Americano: Evolução da obra de Fernando Flávio Marques de Almeida. Editora Beca, $1^{a}$ ed., São Paulo, pp. 245263.

Marson I., Klingele E.E., 1993. Advantages of using the vertical gradient of gravity for 3-D interpretation. Geophysics, 58, 1588-1595.

Mizusaki A.M.P., 1989. Análise petrográfica e dotação radiométrica do poço 2-TL-1-MS (testemunhos 39 e 40). Relatório Interno, PETROBRAS/CENPES, Rio de Janeiro, 8p.

Milani E. J., 1997. Evolução tectono-estratigráfica da Bacia do Paraná e seu relacionamento com a geodinâmica fanerozóica do Gondwana sul-ocidental. Tese de Doutorado, Universidade Federal do Rio Grande do Sul, Instituto de Geociências, 255p.

Milani E. J., 2004. Comentários sobre a origem e evolução tectônica da Bacia do Paraná, in: Mantesso Neto V., Bartorelli A., Carneiro C.D.R., Brito Neves B.B. (Eds.). Geologia do Continente SulAmericano: Evolução da obra de Fernando Flávio Marques de Almeida. Editora Beca, $1^{\text {a }}$ ed., São Paulo, pp.265-279.

Milani E.J., Ramos V.A. 1998. Orogenias paleozóicas no domínio sul-ocidental do Gondwana e os ciclos de subsidência da Bacia do Paraná. Revista Brasileira de Geociências, 28, 4, 527-544.

Milani E.J., Thomaz Filho A., 2000. Sedimentary Basins of South America, in: Cordani, U.G., Milani, E.J., Thomaz Filho, A., Campos D.A. Tectonic evolution of South America. 31st. International Geological Congress, Rio de Janeiro, pp. 389-449.

Milani E.J., Melo J.H.G., Souza P.A., Fernandes L.A., França A.B., 2007. Bacia do Paraná. Boletim de Geociências da PETROBRAS, 15, 2, 265-287.

Milligan P.R., Gunn P.J., 1997. Enhancement and presentation of airborne geophysical data. Journal of Australian Geology \& Geophysics, 17, 2, 63-75.

Minty B.R.S., 1991. Simple micro-levelling for aeromagnetic data. Exploration Geophysics, 22, 591- 592.

Mioto J.A., Hasui Y., 1988. A zona sismogênica de Porangatu (GO), in: Anais do Congresso Brasileiro de Geologia, 35, SBG, Belém.

Molina E.C., Ussami N., Sá N.C., Blitzkow D., Miranda F.O.F., 1988. Deep crustal structure under Parana Basin (Brazil) from gravity study, in: Piccirillo E.M., Melfi A.J. (Eds.). The Mesozoic volcanism of the Paraná basin: Petrogenetic and Geophysical Aspects, IAG/USP, São Paulo, pp. 271283.

Moraes Rocha L.G., Pires A.C.B., Carmelo A.C., Araújo Filho J.O., 2014. Geophysical characterization of the Azimuth $125^{\circ}$ lineament with aeromagnetic data: Contributions to the geology of central Brazil. Precambrian Research, 249, 273-287.

Miller H. G., Singh V., 1994. Potential field tilt - a new concept for location of potential field sources. Journal of Applied Geophysics, 32, 213-217

Mushayandebvu M. F., Driel P.van, Reid A. B., Fairhead J. D., 2001. Magnetic source parameters of twodimensional structures using extended Euler deconvolution. Geophysics, 66, 3, 814-823. 
Nabighian M.N., 1972. The analytic signal of two-dimensional magnetic bodies with polygonal crosssection: Its properties and use for automated anomaly interpretation. Geophysics 37, 3, 507-517.

Nabighian M. N., 1984. Toward a three-dimensional automatic interpretation of potential field data via generalized Hilbert transforms: Fundamental relations. Geophysics, 49, 780-786.

Nabighian M.N., Grauch V.J.S., Hansen R.O., LaFehr T.R., Li Y., Peirce J.W., Phillips J.D., Ruder M.E., 2005. The historical development of the magnetic method in exploration. Geophysics, 70, 6, 33-61.

Naidu P.S., Mathew M.P., 1998. Analysis of geophysical potential fields. Ed. Elsevier, 298 p.

Northfleet A.A., Medeiros R.A., Mülhmann H., 1969. Reavaliação dos dados geológicos da Bacia do Paraná. Boletim Técnico da Petrobrás, 12, 3, 291-346.

\section{$\boldsymbol{O}$}

Oliveira D.C., 2001. Reavaliação da evolução tectono-magmática do Graben de Jaibaras (nordeste do Brasil). Acta Geologica Hispanica, 36, 1-2, 53-95.

Oppenheim A. V., Schafer, A. W., Buck, J. R., 1998. Discrete-time signal processing. Ed. Prentice Hall, New Jersey, $1120 \mathrm{p}$.

\section{$\boldsymbol{P}$}

Pavão C.G., França G.S.L.A, Marotta G.S., Menezes P.H.B.J., Neto G.B.S., Roig H.L., 2012. Spatial interpolation applied a crustal thickness in Brazil. Journal of Geographic Information System, 04, $142-152$.

Pena G.S., 1975. Projeto Goiânia II, Relatório Final Integrado, Volume I, DNPM/CPRM, 236p.

Pedrosa Júnior, N.C., Vidotti R.M., Fuck R.A., Oliveira K.M.L., Castelo Branco R.M.G., 2014. Structural framework of the Jaibaras Rift, Brazil, based on geophysical data. Journal of South American Earth Sciences, In Press.

Phillips J.D., 2001. Designing matched bandpass and azimuthal filters for the separation of potential-field anomalies by source region and source type, in: Expanded Abstracts of the Geophysical Conference and Exhibition, 15, ASEG, Brisbane, 1-4.

Pimentel M.M., 1985. A Seqüência Vulcano-Sedimentar de Arenópolis-GO: Petrologia ígnea e metamórfica, contexto geotectônico e considerações metalogenéticas preliminares. Dissertação de Mestrado, Universidade de Brasília, Instituto de Geociências, 187p.

Pimentel M.M., Fuck R.A., 1986. Geologia da seqüência vulcano-sedimentar de Arenópolis (GO). Revista Brasileira de Geociências, 16, 217-223.

Pimentel M.M., Fuck R.A., 1987. Late Proterozoic granitic magmatism in southwestern Goiás, Brazil. Revista Brasileira de Geociências, 17, 415-425.

Pimentel M.M., Fuck R.A., 1992. Origin of orthogneiss and metavolcanic rock units in western Goiás: Neoproterozoic crustal accretion in central Brazil. Geochimica Brasiliensis, 5, 1-2, 133-152. 
Pimentel M.M., Heaman L., Fuck R.A., Marini O.J., 1991. U-Pb zircon geochronology of Precambrian tin-bearing continental-type acid magmatism in central Brazil. Precambrian Research, 52, 321-335.

Pimentel M.M., Fuck R.A., Alvarenga C.J.S., 1996. Post-Brasiliano (Pan-African) high-K granitic magmatism in Central Brazil: the role of late Precambrian-early Paleozoic extension. Precambrian Research, 80, 3-4, 217-238.

Pimentel M.M., Whitehouse M.J., Viana M.G., Fuck R.A., Machado N., 1997. The Mara Rosa arc in the Tocantins Province: Further evidence for Neoproterozoic crustal accretion in central Brazil. Precambrian Research, 81, 299-310.

Pimentel M.M., Fuck R.A., Gioia S.M.C.L., 2000. The Neoproterozoic Goiás Magmatic Arc, Central Brazil: A review and new Sm-Nd Isotopic Data. Revista Brasileira de Geociências, 30, 1, 35-39.

Pimentel M.M., Hollanda M.H.B.M., Armstrong R., 2003. SHRIMP U-Pb age and Sr-Nd isotopes of the Morro do Baú mafic intrusion: Implications for the evolution of the Arenópolis volcano-sedimentary sequence, Goiás Magmatic Arc. Anais da Academia Brasileira de Ciências, 75, 3, 331-339.

Pimentel M.M., Jost H., Fuck R.A., 2004. O Embasamento da Faixa Brasília e o Arco Magmático de Goiás, in: Mantesso Neto V., Bartorelli A., Carneiro C.D.R., Brito Neves B.B. (Eds.). Geologia do Continente Sul-Americano: Evolução da obra de Fernando Flávio Marques de Almeida. Editora Beca, $1^{a}$ ed., São Paulo, pp. 355-368.

Pimentel M. M., Ferreira-Filho C F, Armele, A., 2006. Neoproterozoic age of the Niquelândia Complex, Central Brazil: Further ID-TIMS U-Pb and Sm-Nd isotopic evidence. Journal of South American Earth Sciences. 21, 3, 228-238.

Pimentel M.M., Rodrigues J.B, DellaGiustina, M.E.S., Junges, S.L., Matteini, M., 2011. The tectonic evolution of the Neoproterozoic Brasília Belt, Central Brazil, based on shrimp and La-Icpms U-Pb sedimentary provenance data: a review. Journal of South American Earth Sciences, 31, 345-357.

\section{$Q$}

Quintas M.C.L., Mantovani M.S.M., Zalán P.V., 1999. Contribuição ao estudo da evolução mecânica da Bacia do Paraná. Revista Brasileira de Geociências, 29, 2, 217-226.

\section{$\boldsymbol{R}$}

Ramos V.A., Jordan T.E., Allmendinger R.W., Mpodozis C., Kay S.M., Cortés J.M., Palma M.A., 1986. Paleozoic terranes of the central Argentine-Chilean Andes. Tectonics, 5, 6, 855-880.

Ramos, V.A., 1988. Late Proterozoic-Early Paleozoic of South America: a collisional history. Episodes, $11,168-174$.

Ramos V.A., Vujovoch G.I., 1993. Alternativas de la evolución del borde occidental de America del Sur durante el Proterozóico. Revista Brasileira de Geociências, 23, 3, 194-200

Ramos V.A, Vujovicha G., Martino R., Otamendic J., 2010. Pampia: A large cratonic block missing in the Rodinia supercontinent. Journal of Geodynamics, 50, 3-4, 243-255. 
Rapela C.W., Pankhurst R.J., Casquet C., Fanning C.M., Baldo E.G., Gonzdlez Casado J.M., Galindo C., Dahlquist J., 2007. The Rio de la Plata craton and the assembly of SW Gondwana. Earth Science Reviews, 83, 1-2, 49-82.

Rasmussen R, Pedersen L.B., 1979. End corrections in potential field modeling. Geophysical Prospecting, $27,4,749-760$.

Reeves C., 2005. Aeromagnetic Surveys. Principles, Practice \& Interpretation, Geosoft, 155p.

Reid A.B., 1980. Aeromagnetic Survey Design. Geophysics, 45, 5, 973-976.

Reid A.B., Allsop J.M., Granser H., Millett A.J., Somerton I.W., 1990. Magnetic interpretation in three dimensions using Euler deconvolution. Geophysics 55, 1, 80-91.

Reynolds J.M., 2011. An introduction to applied and environmental geophysics, Ed. Wiley-Blackwell, Oxford, 696p.

Roest W.R., Verhoef J., Pilkington M., 1992. Magnetic interpretation using 3-D analytic signal. Geophysics, 57, 116-125.

Rocha M.P., Schimmel, M., Assumpção M.S., 2011. Upper-mantle seismic structure beneath SE and central Brazil from $\mathrm{P}$ and $\mathrm{S}$ wave regional traveltime tomography. Geophysical Journal International, $184,268-286$.

Rodrigues J.B., Gioia S.M.L.C., Pimentel M.M., 1999. Geocronologia e geoquímica de ortognaisses da região de Iporá e Firminópolis: Implicações para evolução do Arco Magmático de Goiás. Revista Brasileira de Geociências, 29, 2, 207-216.

\section{$S$}

Salem A., Williams S., Samson E., Fairhead D., Ravat D., Blakely R.J., 2010. Sedimentary basins reconnaissance using the magnetic Tilt-Depth method. Exploration Geophysics 41, 3, 198-209.

Santos T.B., 2014. Proveniência de zircões detríticos e implicações para a paleogeografia da formação Furnas no noroeste da Bacia do Paraná. Tese de Doutorado, Universidade Federal do Paraná, 119p.

Schobbenhaus, C. et al., 1975. Texto Explicativo, Folha Goiás SD.22, in: Schobbenhaus, C (Ed.) Carta Geológica do Brasil ao Milionésimo, Brasília, DNPM, 99p.

Schobbenhaus C., Gonçalves J.H., Santos J.O.S., Abram M.B., Neto R.L., Matos G.M.M., Vidotti R.M., Ramos M.A.B., Jesus J.D.A., 2004. Carta Geológica do Brasil ao Milionésimo, Sistema de Informações Geográficas - SIG. 46 folhas na escala 1:1.000.000. Brasília, CPRM, 41 CD-ROMS.

Seer H.J., 1985. Geologia, deformação e mineralização de cobre no complexo vulcanossedimentar de Bom Jardim de Goiás. Dissertação de Mestrado. Universidade de Brasília, Instituto de Geociências, $190 \mathrm{pp}$.

Seer H.J., Nilson A.A., 1985. Contribuição à geologia das unidades Pré-Cambrianas da região de Bom Jardim de Goiás, in: Atas do Simpósio de Geologia do Centro-Oeste, 2, SBG, Goiânia, 267-281.

Silva M.F., 2007. Aerogeofísica, litogeoquímica e geologia na caracterização do rifte intracontinental da Faixa Paraguai. Dissertação de Mestrado. Universidade de Brasília, Instituto de Geociências, 117 pp. 
Syberg F.J.R., 1972. A Fourier method for the regional-residual problem of potential fields. Geophysical Prospecting, 20, 1, 47-75.

Soares P.C., 1991. Tectônica Sinsedimentar Cíclica na Bacia do Paraná: Controles. Tese para Professor Titular, Universidade Federal do Paraná, 148p.

Soares P.C., Barcellos P.E., Csordas S.M., 1982. Análise, interpretação e integração de lineamentos a partir de imagens (radar-landsat) e suas relações com a tectônica da Bacia do Paraná. Relatório RT342/82, PAULIPETRO, Consórcio CESP/IPT, 63p.

Soares J.E.P., Berrocal J., Fuck R.A., Mooney W., Ventura D.B.R., 2006. Seismic characteristics of Central Brazil crust and upper mantle: A deep seismic refraction study. Journal of Geophysical Research, 111, B12302.

Spector A., Grant F.S., 1970. Statistical models for interpreting magnetic data. Geophysics, 35, 2, $293-$ 302.

Strieder A.J., Suita M.T.F., 1999. Neoproterozoic tectonic evolution of the Tocantins Structural Province, Central Brazil. Journal of Geodynamics, 28, 2-3, 267-289.

Swain C.J., 2000. Reduction to the pole of regional magnetic data with variable field direction, and its stabilisation at low inclinations. Exploration Geophysics, 31, 2, 78-83.

\section{$\boldsymbol{T}$}

Talwani M., Worzel J.L., Landisman M., 1959. Rapid gravity computations of two-dimensional bodies with application to the Mendocino submarine fracture zone. Journal of Geophysical Research, 64, 1, 49-59.

Tello Saenz C.A., Hackspacher P.C., Hadler N.J.C., Iunes P.J., Guedes O.S., Paulo S.R., Ribeiro L.F.B., 2003. Recognition of Cretaceous, Paleocene and Neogeno activities, through AFTA, in Precambrian areas of the Southeast Brazil: Association with the South Atlantic Ocean opening. Journal of South American Earth Sciences, 15, 765-774

Telford W.M., Geldart L.P., Sheriff R.E., 1990. Applied geophysics, Cambridge University Press, Cambridge, $770 \mathrm{p}$.

Thompson D. T., 1982. EULDPH: A new technique for making computer-assisted depth estimates from magnetic data. Geophysics, 47, 31-37.

Tohver E., Cawood P.A., Rossello E.A., Jourdan F., 2012. Closure of the Clymene Ocean and formation of West Gondwana in the Cambrian: Evidence from the Sierras Australes of the southernmost Rio de la Platacraton, Argentina. Gondwana Research, 21, $394-405$.

\section{$\boldsymbol{U}$}

Urquhart T., 1988. Decorrugation of enhanced magnetic field maps. Expanded abstracts and biographies, 58, SEG, Anaheim, 371-372. 
Vail P.R., Mitchum R.M., Thompson S., 1977. Seismic stratigraphy and global changes of sea level, part 3: relative changes of sea level from coastal onlap, in: Payton C. E. (Ed.). Seismic stratigraphy: applications to hydrocarbon exploration. American Association of Petroleum Geologists, Memoir, 26, pp. $63-81$.

Vasconcelos B.R., Ruiz A.S., 2014. Deformação polifásica do Grupo Cuiabá na região de Poconé (MT), cinturão de dobras e cavalgamentos Paraguai: Implicações cinemáticas e tectônicas, in: Anais do Congresso Brasileiro de Geologia, 47, SBG, Salvador, 1509-1509.

Vauchez A., Neves S.P., Caby R., Corsini M., Egydio-Silva M., Arthaud M., Amaro V., 1995. The Borborema shear zone. Journal of South American Earth Sciences, 8, 247-266.

Ventura D.B.R., Soares J.E.P., Fuck R.A., Caridade L.C.C., 2011. Caracterização sísmica e gravimétrica da litosfera sob a linha de refração sísmica profunda de Porangatu, Província Tocantins, Brasil Central. Revista Brasileira de Geociências, 41, 1, 130-140.

Verduzco B., Fairhead J.D., Green C.M., MacKenzie C., 2004. New insights into magnetic derivatives for structural mapping. The Leading Edge, 23, 116-119.

Vidotti R.M., 1997. Lithospheric structure Beneath Paraná and Parnaíba Basins, Brazil from regional gravity analyses. Tese de Doutorado, The University of Leeds, School of Earth Sciences.

Vidotti R.M., Ebinger C.J., Fairhead J.D., 1998. Gravity signature of the western Paraná basin, Brazil. Earth and Planetary Science Letters, 159, 3-4, 117-132.

Vidotti R.M., Curto J.B., Fuck R.A., Dantas E.L., Almeida T., 2011. Magnetic expression of the Transbrasiliano Lineament, Brazil. Abstracts of the American Geophysical Union Fall Meeting, 17, AGU, San Francisco.

\section{$W / Y$}

Weska R.K., 2006. Uma síntese do Cretáceo Superior Mato-Grossense. Geociências, 25, 1, 71-81.

York D., 2003. Results on Ar/Ar dating of Brazilian rock samples. Argon Geochronology Laboratory, Department of Physics, University of Toronto.

Zalán P.V., Conceição J.C., Wolff S., Astolfi M.A.; Vieira I.S.; Appi V.T.; Neto E.V.S.; Cerqueira J.R.; Zanotto O.A., Paumer M.L., Marques A., 1986. Análise da Bacia do Paraná. Relatório Interno PETROBRÁS, Gt-Os-009/85, Depex-Cenpes, Rio de Janeiro, 195p.

Zalán P.V., Wolff S., Astolfi M.A.M., Vieira I.S., Conceição J.C.J., Appi V.T., Santos Neto E.V., Cerqueira J.R., Marques A., 1991. The Paraná Basin, Brazil, in: Leighton M. W., Kolata D. R., Oltz D. F., Eidel J. J. (Eds.). Interior cratonic basins. American Association of Petroleum Geologists, Memoir, 51, pp. 681-708. 
Zalán P.V., 2004. A evolução fanerozóica das bacias sedimentares brasileiras, in: Mantesso Neto V., Bartorelli A., Carneiro C.D.R., Brito Neves B.B. (Eds.). Geologia do Continente Sul-Americano: Evolução da obra de Fernando Flávio Marques de Almeida. Editora Beca, $1^{a}$ ed., São Paulo, pp. 595612 . 
ANEXO A

Mapas 


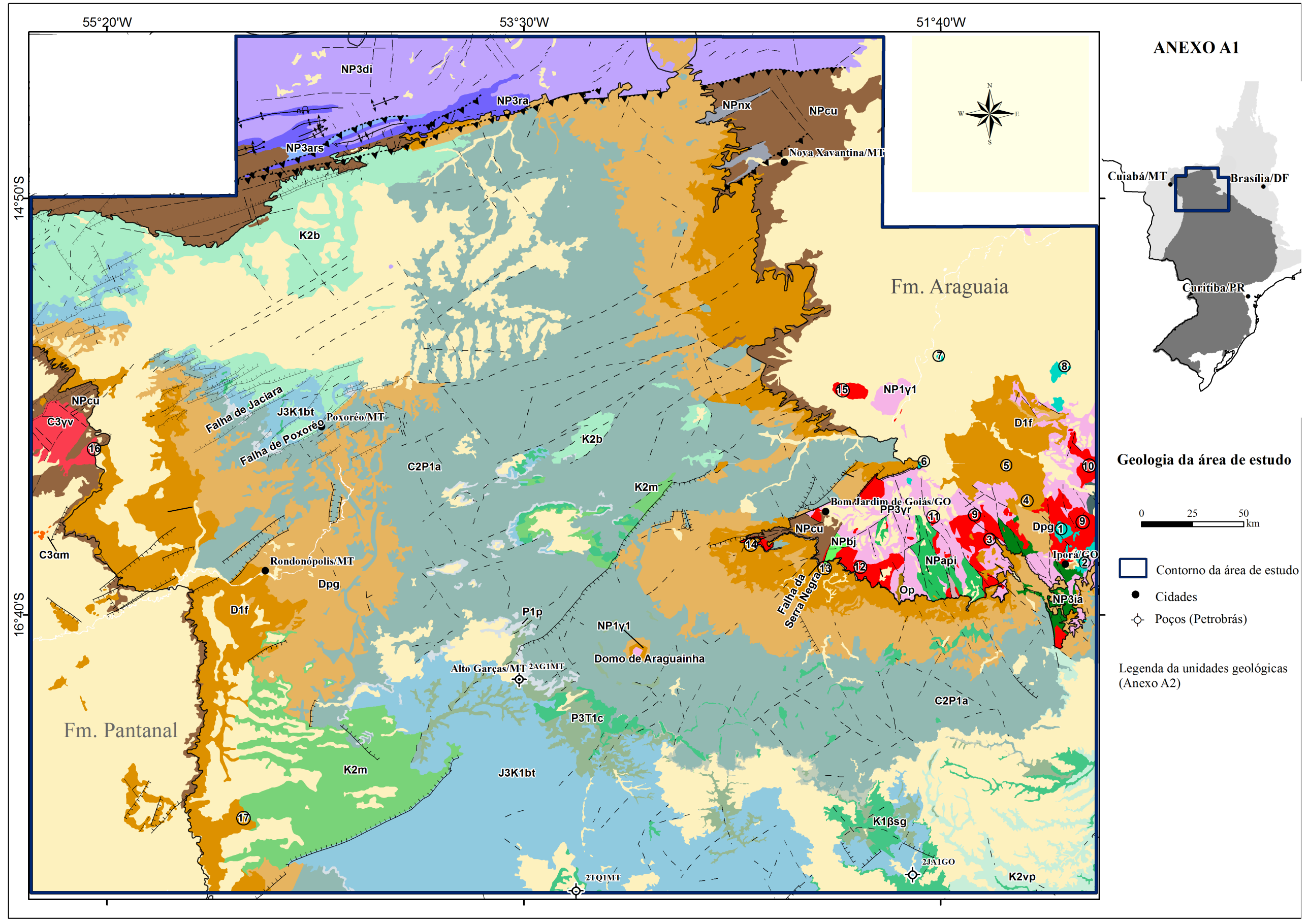


Coberturas Cenozóicas

Complexos alcalinos (Neocretáceo)

Supersequência Bauru (Neocretáceo)

$$
\mathrm{K} 2 \mathrm{~b}
$$

K2m Formação Marília

K2vp Formação Vale do Rio do Peixe

Supersequência Gondwana III (Neojurássico-Eocretáceo)

K1ßsg Formação Serra Geral

J3K1bt Formação Botucatu

Supersequência Gondwana I (Carbonífero a Eotriássico)

P3T1c Formação Corumbataí

$\mathrm{P} 2 \mathrm{i}$ Formação Irati

P1p Formação Palermo

C2P1a Formação Aquidauana

Supersequência Paraná (Devoniano)

Dpg Formação Ponta Grossa

D1f Formação Furnas

Supersequência Rio Ivaí (Ordoviciano-Siluriano)

S12vm Formação Vila Maria

Op Formação Piranhas

Embasamento cambriano

C3am Seq. Vulcânicas Mimoso $\quad$ C 3 $\gamma \mathrm{v}$ Granito São Vicente

Embasamento neoproterozóico

Granitos

Unidades do Arco

Magmático de Goiás (FX. Brasilia):

Seq. Vulcanossedimentar de
Iporá-Amorinópolis

Seq. Vulcanossedimentar de Jaupaci

NPapi $\begin{aligned} & \text { Seq. Vulcanossedimentar de } \\ & \text { Arenópolis-Piranhas }\end{aligned}$

\begin{tabular}{l|l} 
NPbj & Seq. metavulcanossedimentar de \\
Bom Jardim de Goiás
\end{tabular}

NP1 $\gamma 1$ Ortognaisses

\begin{tabular}{|c|c|}
\hline \multicolumn{2}{|c|}{ Fx. Paraguai: } \\
\hline NP3di & Fm Diamantino \\
\hline NP3ra & Fm Raizama \\
\hline NP3ars & Fm. Araras \\
\hline NPcu & Gr. Cuiabá \\
\hline & $\begin{array}{l}\text { Seq. Vulcanossedimentar } \\
\text { de Nova Xavantina }\end{array}$ \\
\hline
\end{tabular}

PP3 $\gamma$ r Gnaisse Ribeirão (Paleoproterozóico)
Localidade de corpos intrusivos: (Alguns somente mapeados em trabalhos de maior escala)

Província Acalina de Goiás (Junqueira-Brod et al., 200)

1 - Córrego dos Bois

2 - Morro do Macaco

3 - Arenópolis

4 - Diorama

5 - Montes Claros de Goiás

$6-$ ?

7 - Morro do Engenho

8 - Santa Fé de Goiás

Granitos do Arco Magmático de Goiás

(Seers, 1985; Pimentel e Fuck, 1992; Pimentel et al., 1996)

9 - Iporá

10 - Serra do Impertinente

11 - Serra do Iran

12 - Serra Negra

13 - Macacos

14 - Serra Verde

Granitos da Faixa Paraguai

(Manzano et al., 2008; Godoy et al., 2007, 2010)

15 - Araguaiana

16 - São Vicente

17 - Sonora

\begin{tabular}{|c|}
\hline Estruturas \\
\hline Uu Anticlinal ou antiforme invertido \\
\hline$\uparrow$ Anticlinal ou antiforme normal \\
\hline - Sinclinal ou sinforme invertido \\
\hline - Sinclinal ou sinforme normal \\
\hline$\checkmark \cdot$ Falha contracional (inversa ou empurrão) \\
\hline ताता Falha extensional (normal) \\
\hline$\rightleftharpoons$ Falha ou zona de cisalhamento transcorrente dextral \\
\hline$\leftrightharpoons$ Falha ou zona de cisalhamento transcorrente sinistral \\
\hline- - - Lineamento indiscriminado \\
\hline
\end{tabular}




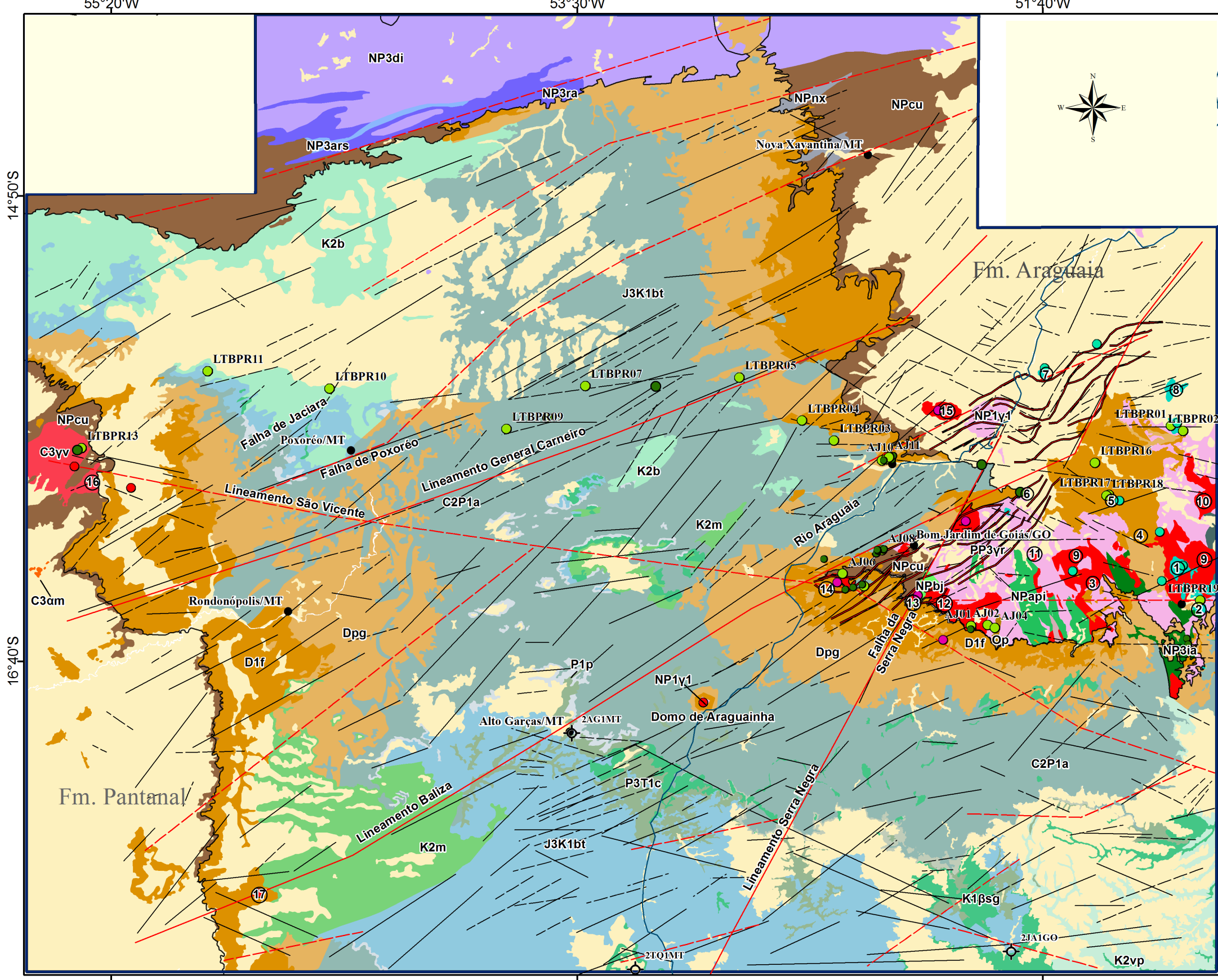

ANEXO A3

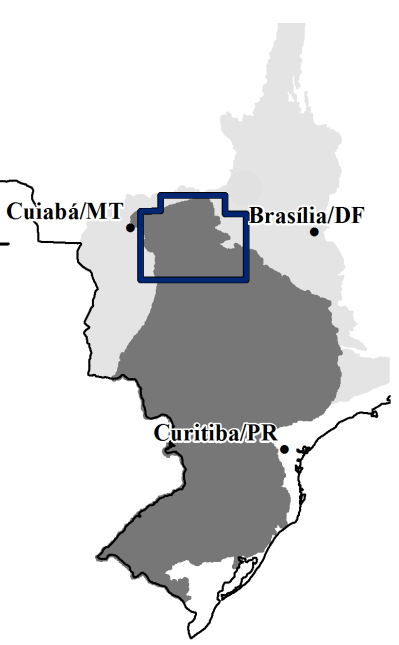

Lineamentos magnéticos geologia conhecid

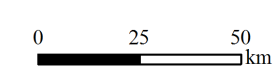

$\square$ Contorno da área de estudo - Cidades

Pontos de trabalho de campo:

- Amostrados

- Não amostrados

-'- Poços (Petrobrás)

- Intrusões alcalinas

- Intrusões deformadas/cisalhadas

- Intrusões

Zonas trancorrentes principais

i Zonas transcorrentes

Lineamentos estruturais

de $1^{\mathrm{a}}$ ordem

/ Lineamentos estruturais

Zonas de cisalhamento

Legenda da unidades geológicas (Anexo A2) 


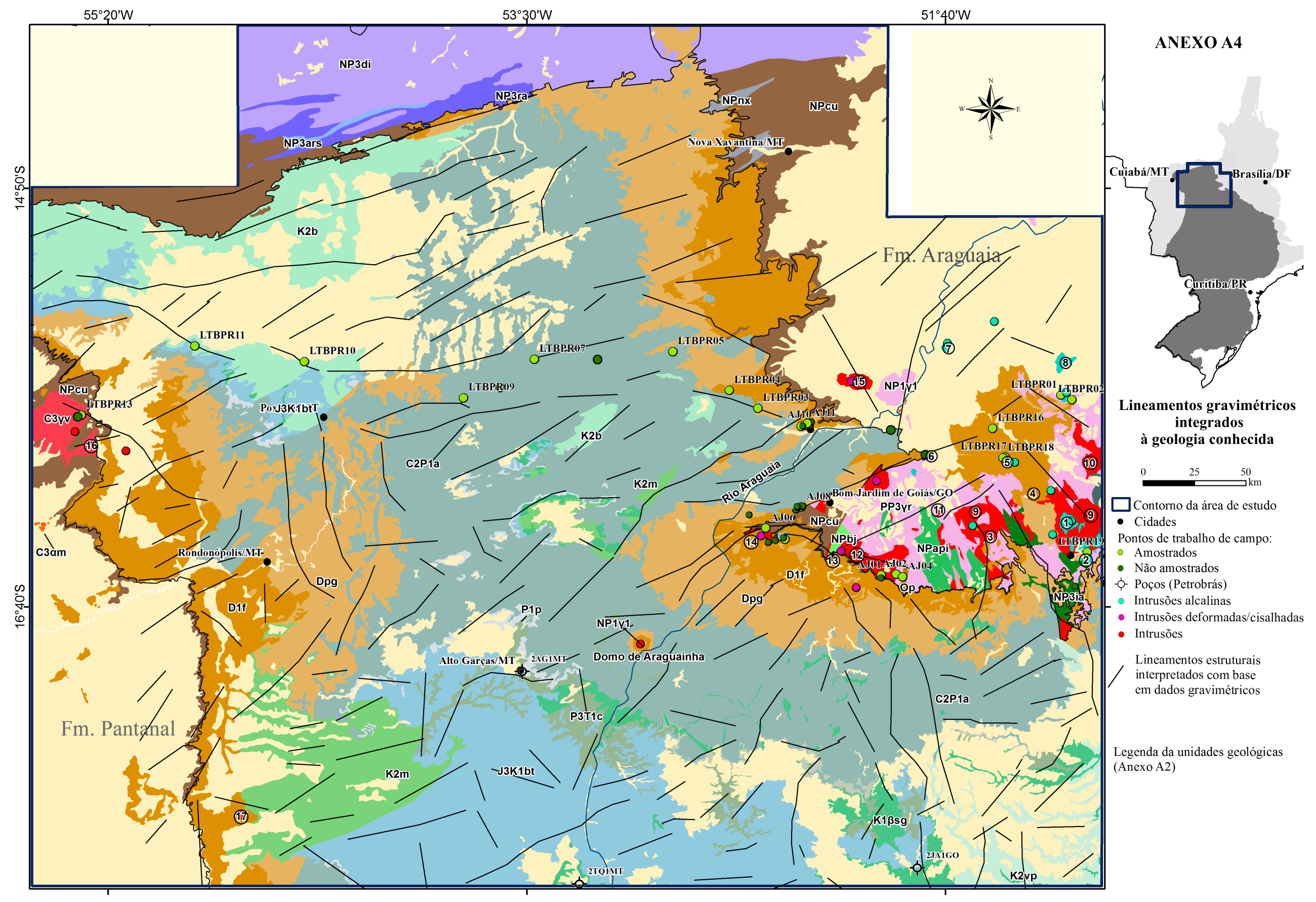




\section{ANEXO B \\ Resumos em Anais}




\title{
ANEXO B1
}

Title:

Authors:

Affiliation:

Publication:

Publication Date:

Origin:

Keywords:

Bibliographic

Code:
Magnetic expression of the Transbrasiliano Lineament, Brazil

Vidotti, R. M.; Curto, J. B.; Fuck, R. A.; Dantas, E. L.; Roig, H. L.; Almei da, T.

AA(Instituto de Geociencias, Universidade de Brasilia, Brasilia, DF, Brazil; rmvidotti@uol.com.br), AB(Instituto de Geociencias, Universidade de Brasilia, Brasilia, DF, Brazil;julia.curto@gmail.com), AC(Instituto de Geociencias, Universidade de Brasilia, Brasilia, DF,

Brazil; reinhardt@unb.br), AD(Instituto de Geociencias, Universidade de Brasilia, Brasilia, DF, Brazil; elton@unb.br), AE(Instituto de Geociencias, Universidade de Brasilia, Brasilia, DF, Brazil; roig@unb.br), AF(Instituto de Geociencias, Universidade de Brasilia, Brasilia, DF, Brazil; tati_almeida@unb.br)

American Geophysical Union, Fall Meeting 2011, abstract \#GP41 A-0986

$12 / 2011$

AGU

[0905] EXPLORATION GEOPHYSICS / Continental structures, [1517] GEOMAGNETISM AND PALEOMAGNETISM / Magnetic anomalies: modeling and interpretation, [8110] TECTONOPHYSICS / Continental tectonics: general

2011AGUFMGP41A0986V

\begin{abstract}
The Transbrasiliano lineament is a continental-sized discontinuity exposed between the Amazonian craton and the eastern portion of the South American Platform. It is over 3,000 km long, extending from northern Paraguay, across the Tocantins Province and the Phanerozoic Paraná and Parnaíba basins, down to the Ceará Atlantic coast. In the context of West Gondwana, this large continental structure extends to the African continent along the 4o30 lineament. Its NE-SW preferential trend is marked by strong magnetic anomalies at the crustal level and by low velocity zones of $\mathrm{S}$ waves within the mantle, suggesting lithosphere thinning. On the surface the Transbrasiliano lineament translates as aligned drainage and ridges in the continental relief, and is comprised of a set of N20-50E Late Neoproterozoic ductile right-lateral shear zones, brittlely reactivated during the Mesozoic. Different interpretations were forwarded along the years, suggesting that the lineament represents a mega-suture active during Gondwana Supercontinent amalgamation, in the Late Neoproterozoic and Early Paleozoic, or seeing the strike-slip ductile faults as the result of shearing related with post-collision stages of the Brasiliano orogeny. Fault reactivation is believed to have controlled graben formation, sediment accumulation and magmatism of the Jaibaras basin in NW Ceará, as well as the establishing of depocentres within the Paraná and Parnaíba basins, influencing also sedimentation at the Atlantic coast. Although a direct link with the lineament has not been established, nearby areas are the site of seismic activity, mainly in NW Ceará and close to the Goiás-Tocantins border in central Brazil. The lineament is covered by aeromagnetic surveys collected over decades. Qualitative interpretation of magnetic and remote sensing data shows that the Transbrasiliano lineament is comprised of a system of ductile shear zones, forming parallel sets of faults
\end{abstract}


penetrating below the large Paraná and Parnaiba intracontinental syneclises with almost continuous traces. Main direction is N45E, connected with splays of E-W and N-S secondary lineaments. Magnetic lineaments developed dominantly along the borders of crustal/lithospheric blocks, determining their limits. Magnetic Euler deconvolution preliminary results indicates depths up to $5 \mathrm{~km}$. The magnetic lineaments continue below the intracratonic Phanerozoic basins, where brittle fault zones characterize several tectonic reactivation events from the Cambrian up to the Cenozoic. These results stress the outstanding role of the Transbrasiliano lineament in the tectonic framework of the Brazilian continental crust/lithosphere and the relevance of its set of faults in the infilling and evolution of large intracontinental Phanerozoic syneclises. 


\section{COMPORTAMENTO ESTRUTURAL DO LINEAMENTO TRANSBRASILIANO NA PORÇÃO NW DA BACIA DO PARANÁ}

Julia B. Curto ${ }^{1}$; Reinhardt A. Fuck ${ }^{1}$; Roberta M. Vidotti ${ }^{1}$

1 UnB

RESUMO: A tectônica estabelecida pelas estruturas do embasamento teve grande influência na evolução das bacias sedimentares brasileiras. Existe uma relação entre as posições geográficas das grandes sinéclises do Paleozóico no Gondwana Ocidental e as estruturas resultantes do desenvolvimento das faixas móveis brasilianas/pan-africanas, do Neoproterozóico ao Eopaleozóico. Dentre as grandes zonas de falhamentos pré-cambrianas do Escudo Brasileiro, o Lineamento Transbrasiliano, uma mega-sutura ativa desde o Neoproterozóico, separa uma grande massa continental a NW, o Cráton Amazônico, de uma outra grande massa continental a SE, formada pela aglutinação de fragmentos cratônicos de diferentes tamanhos e faixas móveis neoproterozóicas. Com direção predominantemente N20-30E, o lineamento corta o extremo noroeste da Província Borborema passando pelo centro da Província Tocantins e continua à sul, por baixo da porção noroeste da Bacia do Paraná. Nesta área da bacia, imediatamente à SW do Complexo Alcalino de Iporá, o Lineamento Transbrasiliano mostra comportamento direcional distinto do que se observa ao longo de sua extensão, desde o litoral do Ceará. Com o intuito de compreender melhor o padrão estrutural do lineamento nesta porção da bacia, foram processados e interpretados dados aerogeofísicos, subsequentemente integrados com dados de sensoriamento remoto e geológicos. A interpretação das imagens derivadas do campo magnético anômalo (amplitude do sinal analítico, primeira derivada vertical e inclinação do sinal analítico) permitiram estabelecer a direção dos diversos segmentos estruturais relacionados ao lineamento. Valores de profundidade aparente foram calculados ao longo de algumas das feições magnéticas lineares observadas, os quais foram separados em dois intervalos principais: um mais profundo, relacionado ao embasamento da bacia, representativo da zona de sutura principal, e aquele relacionado à seção sedimentar, indicando possíveis estruturas de reativação paleozóicas. O conjunto dos resultados obtidos permitiu uma interpretação preliminar do comportamento do Lineamento Tranbrasiliano, em superfície e subsuperfície, e sua relação com o contexto geológico local. Os resultados apresentados neste trabalho são a base de uma próxima etapa, na qual será realizada campanha de reconhecimento geológico em escala de detalhe e concomitante aquisição de dados geofísicos terrestres.
PALAVRAS
CHAVE: LINEAMENTO
TRANSBRASILIANO,
BACIA
DO
PARANÁ, GEOFÍSICA 


\title{
LINEAMENTO TRANSBRASILIANO: INTERPRETAÇÃO DE DADOS AEROGEOFÍSICOS
}

\author{
Roberta M. Vidotti ${ }^{1}$, Reinhardt A. Fuck ${ }^{1}$, Elton L. Dantas ${ }^{1}$, Tati de Almeida ${ }^{1}$, Henrique L. Roig ${ }^{1}$, Julia B. \\ Curto $^{1}$, Nilo C. Pedrosa Jr. ${ }^{1}$, Rafael D. Santos ${ }^{2}$, David L. de Castro ${ }^{2}$; Francisco Hilário R. Bezerra ${ }^{2}$ \\ 1 UnB, 2UFRN
}

ABSTRACT: O Lineamento Transbrasiliano é uma descontinuidade de magnitude continental e representa uma mega-sutura que atuou na formação do supercontinente Gondwana, entre o final do Proterozóico e início do Paleozóico. Este lineamento apresenta traçado que se estende do norte do Paraguai, através da Bacia do Paraná, da Província Tocantins e da Bacia do Parnaíba, até o litoral oeste do Ceará, prolongando-se, inclusive, para o continente africano, no contexto da aglutinação de Gondwana Ocidental. A direção preferencial NE-SW do Lineamento Transbrasiliano é marcada tanto no nível crustal, por anomalias magnéticas, quanto no nível mantélico, por zonas de baixa velocidade de ondas $\mathrm{S}$, especialmente a $100 \mathrm{~km}$ de profundidade, sugerindo afinamento litosférico.

Dados de aeromagnetrometria ao longo de toda a extensão do lineamento foram compilados, processados e interpretados. Os resultados evidenciam uma estrutura com cerca de $100 \mathrm{~km}$ de largura na região do Brasil Central entre as bacias do Paraná e Parnaíba. Na Bacia do Parnaíba há uma continuidade marcante entre zonas de cisalhamento do embasamento cristalino e anomalias magnéticas associadas a falhas na Bacia, o que também é observado em dados de aerogravimetria. Na borda nordeste da Bacia do Parnaíba a continuidade das anomalias magnéticas é marcante ao longo do rifte Jaibaras, onde se encontra em andamento trabalho de interpretação de dados magnéticos, gravimétricos e gamaespectrometricos. Na borda da Bacia do Paraná as anomalias magnéticas apresentam dispersão e interpretações de detalhe encontram-se em andamento para compreender a correlação das diversas anomalias com 0 lineamento.

Interpretação quantitativa de dados de magnetometria, por meio da deconvolução de Euler, foi realizada em toda a extensão do lineamento. Os resultados demonstram que as estruturas relacionadas ao lineamento são subverticais ao longo de toda sua extensão. $\mathrm{Na}$ região central do lineamento, Província Tocantins, as estruturas são contínuas até profundidades de cerca de $1 \mathrm{~km}$ e descontinuas a partir dessa profundidade. Na Bacia do Parnaíba anomalias magnéticas apresentam descontinuidades a partir de $3 \mathrm{~km}$ e as anomalias gravimétricas a partir de $4 \mathrm{~km}$. Na Bacia do Paraná não há ainda resultados conclusivos com relação a continuidade das anomalias em profundidade. Na margem continental nordeste do Brasil, o Lineamento afeta unidades Mesozoicas da Bacia do Ceará e coberturas quaternárias.

Os resultados demonstram a relevância do Lineamento Transbrasiliano na estruturação da crosta continental brasileira. As várias reativações desta megaestrutura influencia o preenchimento e evolução das grandes bacias sedimentares fanerozóicas afetando também bacias sedimentares menores adjacentes.

KEYWORDS: Lineamento Transbrasiliano, Interpretação de dados aerogeofísicos, Magnetometria. 


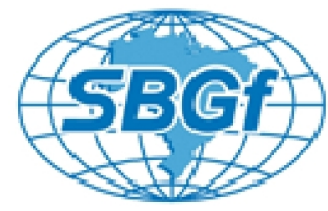

\section{Unveiling the Transbrasiliano fault system in northern Paraná Basin using airborne magnetic data}

Julia B. Curto ${ }^{1}$, Roberta M. Vidotti1, Reinhardt A. Fuck', Richard J. Blakely², Carlos J. S. Alvarenga1', Elton L. Dantas ${ }^{1}$ 'Instituto de Geociências, Universidade de Brasília, Brasília, Brasil; ${ }^{2}$ U.S. Geological Survey, Menlo Park, CA, United States

Copyright 2013, SBGf - Sociedade Brasileira de Geofísica

This paper was prepared for presentation during the $13^{\text {th }}$ International Congress of the Brazilian Geophysical Society held in Rio de Janeiro, Brazil, August 26-29, 2013.

Contents of this paper were reviewed by the Technical Committee of the $13^{\text {th }}$ International Congress of the Brazilian Geophysical Society and do not necessarily represent any position of the SBGf, its officers or members. Electronic reproduction or store of any part of this paper for commercial purposes without the written consent of the Brazilian Geophysical Society is prohibited.

\section{Abstract}

Six airborne magnetic surveys were analyzed with the matched filtering and tilt derivative methods to estimate source depths within the Transbrasiliano fault system in northern Paraná Basin, Brazil. Our interpretation defined the structural framework within three main depth zones, illuminating deep crustal, basement, and basin magnetic sources. The deepest zone exhibits three major northeast-trending crustal discontinuities related to the Transbrasiliano lineament, dividing the region into four geotectonic compartments. In the intermediate depth zone, basement anomalies show dextral displacement westward, with important splay faults from the major transcurrent faults. Shallower sources include granitic and alkaline intrusions, the Serra Geral basalts boundaries, and reactivated brittle structures.

\section{Introduction}

The Transbrasiliano lineament (Figure 1, TBL in the inset) is a Neoproterozoic northeast-trending transcurrent fault system (Schobbenhaus et al., 1975) that separates two major tectonic domains in the South America Platform (Cordani et al., 1984). The western domain is comprised mainly of the Amazonian craton, whereas the eastern domain is a set of orogenic belts, allochthonous blocks, and cratonic rocks. During the time of the Gondwana supercontinent (600 Ma), the African Hoggar-Kandi lineament and the TBL were linked (Caby, 1989) in northern Ceará by the Sobral-Pedro II shear zone. This major fault system produces a distinctive, continent-scale magnetic discontinuity from the Congo region, Africa, to Sierras Pampeanas, Argentina (Fairhead and Maus, 2003; Ramos et al., 2010). Along the northern flank of Paraná basin, the magnetic expression of the TBL shows disparate trending directions.

At least three important reactivation episodes affected the TBL. Two of them occurred during Cambrian-Ordovician and Silurian-Devonian time, forming small cratonic basins, including Jaibaras in Ceara state, and Água Bonita in Tocantins, respectively. The third episode is related to the opening of the Atlantic Ocean in Cretaceous time.

Northeast- and northwest-striking basement structures were widely reactivated in the Paraná basin, causing block-bounded uplifts and subsidence. The initial troughs of the Paraná basin were developed within northeast-trending structures (Zalán et al., 1991; Heilbron et al., 2000), some associated with the TBL. Late Ordovician isopachs of the Paraná basin show NE-SW trending alignments, suggesting sedimentation controlled by the TBL (França et al., 1995; Milani, 1997).

Our study consisted of two main approaches. The first one provides a better understanding of the tectonic framework of the Transbrasiliano lineament in northern Paraná basin. The second one identifies geological evidence for how that tectonic controlled the evolution of the Paraná Basin, from initiation of subsidence to later reactivation.

The study area is located at the northern Paraná basin and includes parts of Goiás (GO), Mato Grosso (MT), and Mato Grosso do Sul (MS) states (Figure 1).

\section{Geology of the study area}

Although the study area is partially covered by Cenozoic sediments of the Araguaia and Pantanal formations, most of the area exhibits exposures of Paraná basin sedimentary units and underlying basement.

An important NE-SW-trending fault crosses the northern flank of the Paraná basin near Bom Jardim de Goiás and marks the tectonic contact between two types of Neoproterozoic basement. The eastern basement is recognized as the Arenópolis Magmatic Arc, which consists of orthogneiss units that generally separate volcano-sedimentary belts (Pimentel and Fuck, 1992). The western basement is represented by the Paraguay fold belt, mainly comprised of the Cuiabá Group, consistent of metasedimentary rocks, strongly folded and metamorphosed during the Brasiliano orogeny (Alvarenga and Trompette, 1993).

According to Zalán et al. (1991), the most common northeast-trending structures in the Paraná basin are related to strike-slip tectonics, including en echelon faults, reverse faults and folds, and flower structures. The preferable kinematic character is transcurrent movement, as observed in the TBL. The opening of the Atlantic Ocean in Cretaceous time formed extensional northwesttrending structures that accommodate tholeitic basalt dikes in Jurassic-Eocretaceous time, and alkaline 
intrusions in the Late Cretaceous in the Paraná basin (Almeida and Melo, 1981). The major depocenter comprises the thickest basalt of this basin, reaching up to $2000 \mathrm{~m}$ deep.

\section{Methodology}

Our analysis was based on the anomalous magnetic field; i.e., the total measured field corrected for diurnal variations, the main geomagnetic field (IGRF), and leveling errors. These data were compiled from six airborne geophysical surveys (Figure 1) with variable characteristics, as described in Table 1.

Our primary motivation was to enhance magnetic lineaments possibly related to tectonic structures. The tilt derivative (Miller and Singh, 1994) of the magnetic anomalous field was used to delineate and qualitatively estimate the depth of linear magnetic sources (Salem et al., 2010).

In addition, we used the matched filtering analyses (Phillips, 2001) to separate magnetic anomalies into additive components representing different source depths. This technique is based on potential field spectra (Spector and Grant, 1970), where radially symmetric parts of the spectra are modeled to determine amplitude and Wiener filters that enhance anomalies originating from important depth ranges (Phillips, 2001).

Our analysis was developed based on two main anomalous magnetic field grids. The first grid was developed by merging all of the individual grids (Table 1), with the exception of the Paraná basin survey, which used more regional acquisition parameters. The Mergedgrid provides a high-resolution view of magnetic anomalous field variations for the entire study area. The second grid in our analysis was derived from the Paraná basin survey alone.

Table 1 - Main features of the airborne geophysical surveys.

\begin{tabular}{|c|c|c|c|c|c|c|}
\hline Projects* $^{\star}$ & 1012 & $\mathbf{2 0 0 9}$ & $\mathbf{2 0 2 2}$ & $\mathbf{2 0 2 5}$ & $\mathbf{3 0 0 9}$ & $\begin{array}{c}\text { Paraná } \\
\text { Basin }\end{array}$ \\
\hline $\begin{array}{c}\text { Flight-line } \\
\text { spacing }\end{array}$ & $1 \mathrm{~km}$ & $1 \mathrm{~km}$ & $1 \mathrm{~km}$ & $1 \mathrm{~km}$ & $0,5 \mathrm{~km}$ & $6 \mathrm{~km}$ \\
\hline $\begin{array}{c}\text { Flight } \\
\text { direction }\end{array}$ & $\mathrm{N}-\mathrm{S}$ & $\mathrm{N}-\mathrm{S}$ & $\mathrm{N}-\mathrm{S}$ & $\mathrm{E}-\mathrm{W}$ & $\mathrm{N}-\mathrm{S}$ & $\mathrm{N}-\mathrm{S}$ \\
\hline $\begin{array}{c}\text { Flight } \\
\text { height }\end{array}$ & $150 \mathrm{~m}$ & $120 \mathrm{~m}$ & $150 \mathrm{~m}$ & $150 \mathrm{~m}$ & $100 \mathrm{~m}$ & $1800 \mathrm{~m}$ \\
\hline
\end{tabular}

*1012- Iporá; 2009 - Alto Garças; 2022 - Barreiro; 2025 Rondonópolis; 3009-Goiás 01

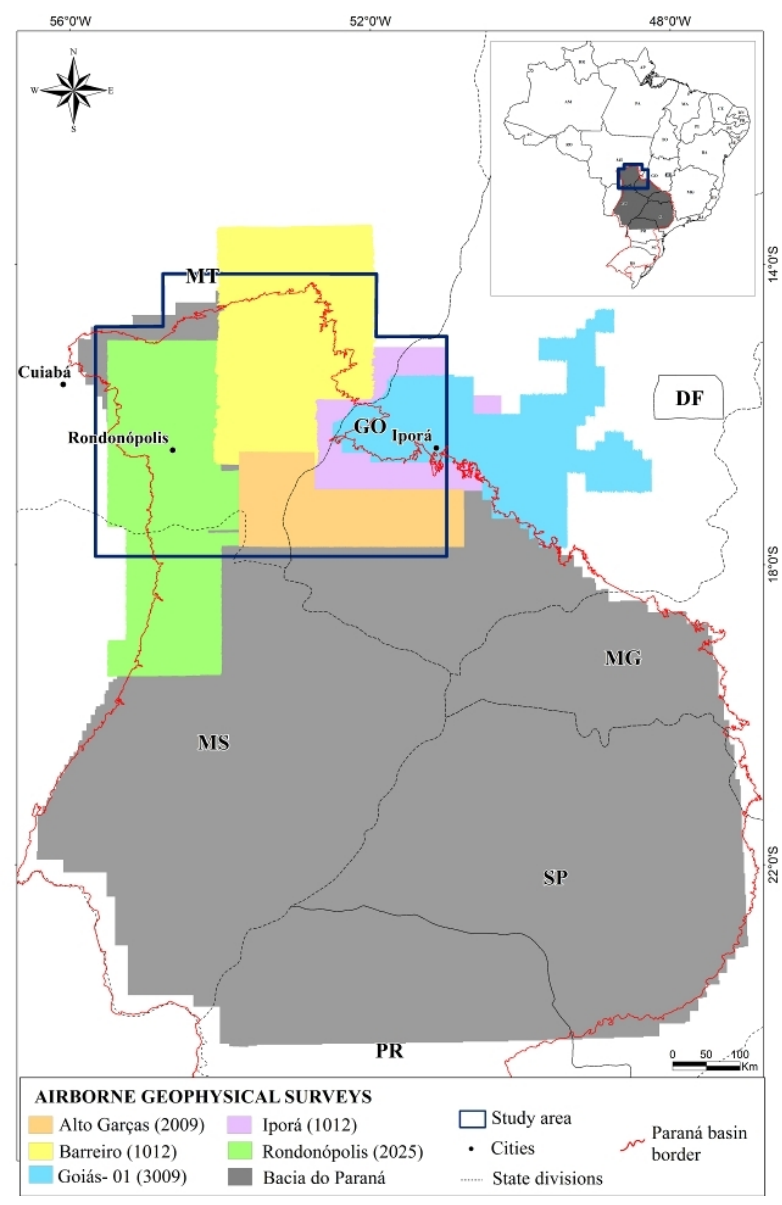

Figure 1 - Location of the study area and the airborne geophysical surveys.

\section{Results}

Our procedure is described in the flowchart of figure 2. Using matched filtering analyses of the Paraná basin survey, we determine three main source zones at 26,6 and $0.8 \mathrm{~km}$ depth; using matched filtering analyses of the Merged-grid four source zones were found at 16, 5.4, 1.1 and $0.3 \mathrm{~km}$ depth. The shallower zones for each grid were not used due to high-frequency noise.

The TILT derivative was used to delineate linear structures from the depth section.

We identified four main regions separated by three major NE-SW trending magnetic discontinuities (Figure 2). These domains were named after geographic locations as follows, from east to west: Arenópolis, Bom Jardim de Goiás, Rondonópolis and Poxoréo. The strong magnetic discontinuity separating the Arenópolis and Bom Jardim de Goiás domains $(A)$ is named after the Serra Negra fault (Seer, 1985). Northwestward, we define the Baliza (B) and General Carneiro (C) lineaments. The NW-SE lineament (D) is also an important structure, here named the São Vicente lineament, which crosses the São Vicente granite in the Mato Grosso. 


\section{Discussion}

Linear magnetic signatures with large wavelengths separate distinct magnetic domains that originate from the deepest parts of the magnetic section. We determined depths of 16 and $26 \mathrm{~km}$ by applying matched filtering to the Merged-grid and Paraná basin survey, respectively (Figure 2). The lineaments correspond to NE-SW crustal discontinuities of the Precambrian basement, separating different geotectonic compartments. The Serra Negra lineament separates the Arenópolis magmatic arc from a different Precambrian terrain, probably belonging to the Paraguay Belt.

The intermediate zone lies at 5.4 or $6 \mathrm{~km}$ depth, as determined from the Merged-grid and Paraná basin survey, respectively. We interpret this zone as plastic to brittle domains that possibly provided the development of regional structures, represented by first-order lineaments in figure 2. Dextral sigmoidal lineaments are strongly enhanced at this depth level. Dextral offsets in trend of higher frequencies lineaments, when compared to deeper zones, reflect possible narrowing of the fault system root and the appearance of shallower and brittle splay faults from this major structure.

The $1 \mathrm{~km}$ depth level is related predominantly to brittle tectonism, with linear magnetic features. The magnetically well-expressed Serra Negra fault is the tectonic contact between the Devonian sequence of the Paraná Basin and the Cambrian Macacos granite, suggesting that the Serra Negra lineament was reactivated as a fault after the Devonian period. NW-SE trending lineaments obliterate most of NE-SW structures. The São Vicente discontinuity is the most pronounced magnetic feature with this trend. Seismicity and Cretaceous alkaline plutons are aligned along these structures (Figure 2). The basalts of the Serra Geral Formation are strongly enhanced at this level.

The tilt derivative analysis illuminated several highly deformed 500 Ma granite plutons, which we interpreted to have been deformed by dextral sigmoidal shear zones.

\section{Conclusions}

The first tectonic elements of the Transbrasiliano lineament shear zone were related to the NE-SW trending Serra Negra and General Carneiro lineaments. Subsequent reactivation invoked dextral strike-slip deformation, manifested by the Baliza lineament and displacement of the Macacos granite along the Serra Negra fault.

The NE-SW dextral Transbrasiliano transcurrent system and subsequent reactivations cause subsidence that accommodated the initial sediments of Paraná basin. It also caused vertical and horizontal displacements along faults that formed smaller depocenters.

The Mesozoic Atlantic Ocean opening resulted in northwest-trending structures, which affected and contributed to reactivation processes of the northeasttrending structures associated with the Transbrasiliano lineament. Northwest-striking structures remain seismically active today.

\section{Acknowledgments}

We thank the sponsorship of FUB/Petrobras under cooperation term 0050.0053151.09.9; and, CNPq Conselho Nacional de Desenvolvimento Científico e Tecnológico, for the grant given to four of the authors. Thanks are also due to ANP - Agência Nacional do Petróleo, Gás Natural e Biocombustíveis, CPRM Serviço Geológico do Brasil, CNEN - Comissão Nacional de Energia Nuclear, and SGM / SIC-GO (Secretaria de Indústria e Comércio do Estado de Goiás) for the permission to use geophysical data for academic purposes; the Laboratory of Remote Sensing and the Laboratory of Applied Geophysics of the IG-UnB (Instituto de Geociências da Universidade de Brasília) for allowing the use of their facilities; the ESRI for providing the tool package ArcGis 10 under the contract no 2011 MLK 8733; and IMAGEM for making feasible the term of use between IG-UnB and the ESRI.

\section{References}

Almeida, F. F. M., Melo, M. S., 1981. A Bacia do Paraná e o vulcanismo mesozoico, in: Mapa Geológico do Estado de São Paulo, escala 1:50.000. São Paulo, IPT, 1, pp. 4681.

Alvarenga, C.J.S., Trompette, R., 1993. Evolução tectônica brasiliana da Faixa Paraguai: a estruturação da região de Cuiabá. Rev. Bras. Geoc., 23, 18-30.

Caby, R., 1989. Precambrian terranes of Benin-Nigeria and northeast Brazil and the late Proterozoic south Atlantic Rift. Geological Society of America, Special Paper 230, 145-158.

Cordani, U. G., Brito Neves, B. B., Fuck, R. A., Porto R., Thomaz Filho, A., Cunha, F.M.B. da, 1984. Estudo preliminar de integração do Pré-cambriano com os eventos tectônicos das bacias sedimentares brasileiras. Ciência Técnica Petróleo, 1-70.

Fairhead J. D. \& Maus S. 2003. Champ satellite and terrestrial magnetic data help define the tectonic model for South America and resolve the lingering problem of the pre-break-up fit of the South Atlantic Ocean. The Leading Edge, 22(8), 779-783.

França, A.B., Milani, E.J., Schneider, R.L., LópczPaulsen, O., López-Pugliessi, J.M., Suárez S., R., Santa Ana, H., Wiens, F., Ferreiro, O., Rossello, E.A., Bianucci, H.A., Flores, R.F.A., Vistalli, M.C., Fernández-Seveso, F., Fuenzalida, R.P., Mufioz, N. 1995. Phanerozoic correlation in Southern South America. In: A. J. Tankard; R. Suárez Soruco; H. J. Welsink (Eds.) Petroleum basins of South America.

Heilbron, M., Mohriak, W. Valeriano, C.M., Milani, E., Almeida, J.C.H., Tupinambá, M.. 2000. From collision to extension: the roots of the south-eastern continental margin of Brazil, in: Talwani, Mohriak, W. (Eds) Atlantic Rifts and Continental Margins. American Geophysical Union, Geophysical Monograph Series, 115, 1-34. 
Milani, E. J., 1997. Evolução tectono-estratigráfica da Bacia do Paraná e seu relacionamento com a geodinâmica fanerozóica do Gondwana sul-ocidental. Tese de Doutorado, Universidade Federal do Rio Grande do Sul, Porto Alegre.

Miller, H. G., Singh, V., 1994. Potential field tilt - a new concept for location of potential field sources: Journal of Applied Geophysics, 32,213-217.

Phillips, J.D., 2001. Designing matched band-pass and azimuthal filters for the separation of potential-field anomalies by source region and source type, in: 15th Geophysical Conference and Exhibition, Australian Society of Exploration Geophysicists, Expanded Abstracts, CD-ROM.

Pimentel, M. M., Fuck, R.A., 1992. Origin of orthogneiss and metavolcanic rock units in western Goiás: Neoproterozoic crustal accretion in central Brazil. Geochimica Brasiliensis, 5, 1/2, 133-152.

Ramos, V.A, Vujovicha, G., Martino, R., Otamendic, J., 2010. Pampia: A large cratonic block missing in the Rodinia supercontinent. Journal of Geodynamics, 50, 243-255

Salem A., Williams S., Samson E., Fairhead D., Ravat D., Blakely R.J. 2010. Sedimentary basins reconnaissance using the magnetic Tilt-Depth method. Exploration Geophysics, 41, 198-209.
Schobbenhaus, C. et al., 1975. Texto Explicativo. Folha Goiás SD.22, in: Schobbenhaus, C (coord.) Carta Geológica do Brasil Milionésimo. Brasília, DNPM.

Seer, H.J., 1985. Geologia, deformação e mineralização de cobre no complexo vulcanossedimentar de Bom Jardim de Goiás. Dissertação de Mestrado. Universidade de Brasília, Brasília, 190 pp.

Spector, A., Grant, F.S., 1970. Statistical models for interpreting magnetic data. Geophysics, 35, 2, 293-302.

Zalán, P. V., Wolff S., Astolfi, M. A. M., Vieira, I. S., Conceição, J. C. J., Appi V. T., Santos Neto, E. V., Cerqueira, J. R., Marques, A., 1991. The Paraná Basin, Brazil, in: Leighton, M. W., Kolata, D. R., Oltz, D. F., Eidel J. J. (Ed.). Interior cratonic basins. Tulsa: American Association of Petroleum Geologists, AAPG. Memoir, 51, pp. 681-708. 


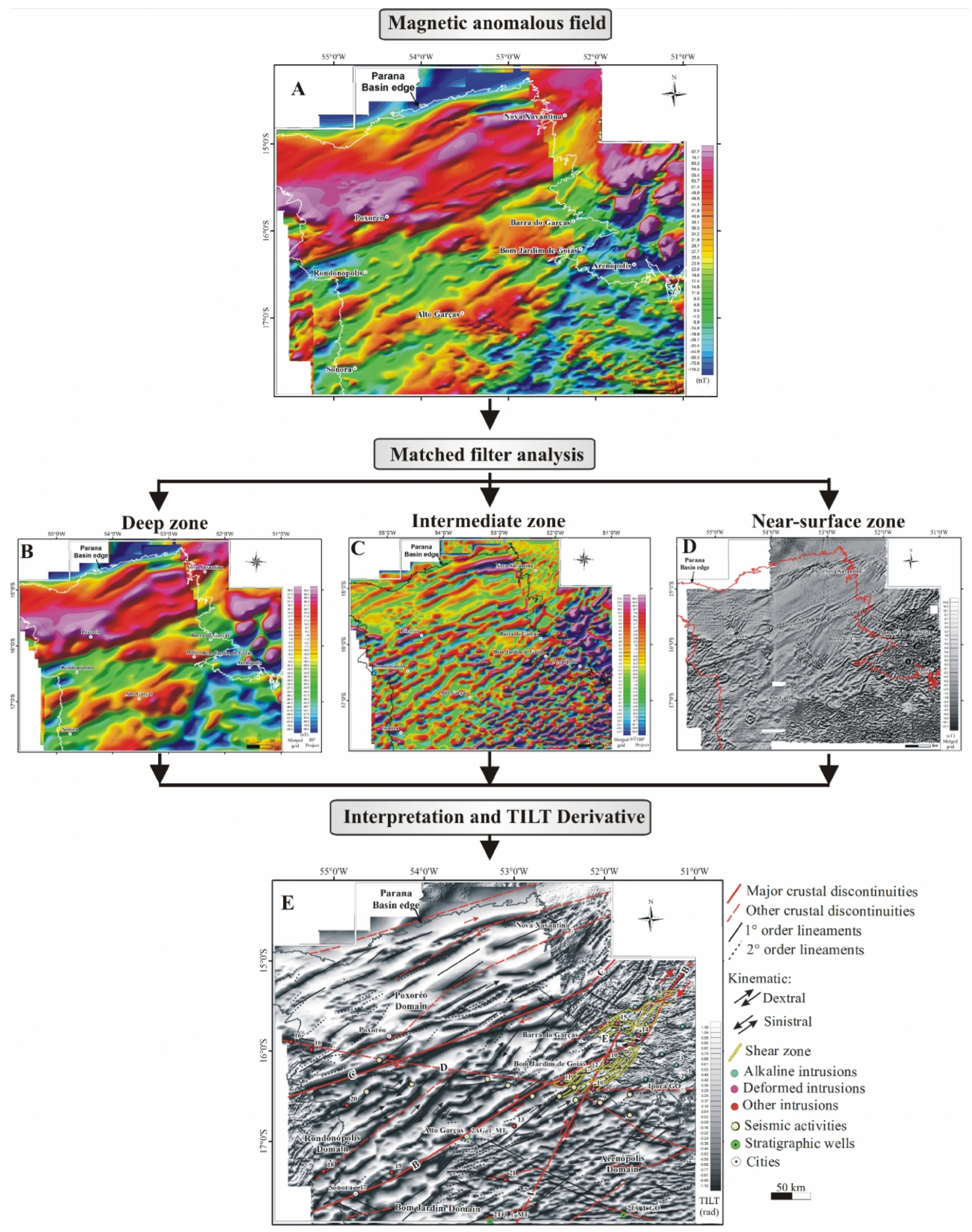

Figure 2 - Grids and interpretation derived by application of matched filtering analysis and tilt-derivative analyses. In A to $C$ and $E$ images, the Paraná basin survey grids overlays the merged-grid. A: Anomalous magnetic field. B to D: Matched filtering results. E: Tilt derivative and the interpreted geological features. Lineaments $A$ to $D$ are, as follows: Serra Negra, Baliza, General Carneiro and São Vicente. 


\title{
ARCABOUÇO TECTÔNICO DA REGIÃO NOROESTE DA BACIA DO PARANÁ, INFERIDO A PARTIR DE MODELAGEM GEOFÍSICA 2D
}

\author{
Curto, J.B. ${ }^{1}$, Vidotti, R.M. ${ }^{1}$, Blakely, R.J. ${ }^{2}$, Fuck, R.A. ${ }^{1}$ \\ ${ }^{1}$ Universidade de Brasília; ${ }^{2}$ U.S. Geological Survey
}

\begin{abstract}
RESUMO: Apesar de ser peça chave no entendimento da história evolutiva da Bacia do Paraná, seu flanco noroeste não possui estudos e dados suficientes para a compreensão de seu arcabouço estrutural e tectônico. A região é afetada pelo Lineamento Transbrasiliano, importante zona de transcorrência proterozóica, mas por estar encoberto pelas rochas sedimentares e vulcânicas da bacia, pouco se sabe de sua configuração, abrangência e tectonismo. A cobertura completa da região noroeste da Bacia do Paraná por dados magnéticos e gravimétricos foi a principal aliada deste trabalho na investigação geofísica de sua compartimentação crustal e da geometria do embasamento. A modelagem conjunta 2D destes dados foi realizada para três seções estratégicas na área de estudo. Duas seções menores foram balizadas por dados pré-existentes de poços e análise de função receptor. A partir da modelagem destas seções, foi possível realizar a modelagem de uma seção maior NW-SE, que cruza toda a região ao longo de uma zona em que há carência significativa de informação e dados. Com base nos resultados alcançados, é proposto um modelo tectônico para área de estudo. A principal estrutura do Lineamento Transbrasiliano é representada por fortes gradientes geofísicos, gravimétrico e magnético, com direção $\mathrm{N} 30^{\circ} \mathrm{E}$, denominada zona de falhas Serra Negra (ZFSN). Esta estrutura separa dois domínios tectônicos crustais, o Bloco Paranapanema, a leste, e o Paleocontinente Amazônico, a oeste. O domínio tectônico a nordeste da ZFSN é representado pelo Arco Magmático de Arenópolis. Outra importante descontinuidade magnética é a zona de falhas de General Carneiro (ZFGC), com direção N60$70^{\circ} \mathrm{E}$, que também mostra relação na modelagem dos dados gravimétricos. Entre a ZFSN e a ZFGC o modelo mostra uma região de afinamento crustal, onde ocorrem muitas estruturas associadas a possíveis reativações e responsáveis pela formação de pequenas bacias Cretáceas. A falha Baliza é mostrada nos modelos e no mapa geológico como causadora de deslocamentos verticais significativos das unidades devonianas e carboníferas da Bacia do Paraná. As principais estruturas expostas nos modelos estão associadas a sistemas de graben e horsts, mostrando que foram alvo de reativações que controlaram a sedimentação da Bacia do Paraná. A porção noroeste da bacia mostra geometria de embasamento assimétrica, que aparentemente indica relação com movimentações causadas por falhamentos direcionais e transcorrentes associados ao Lineamento Transbrasiliano.
\end{abstract}

PALAVRAS-CHAVE: MODELAGEM, GEOFÍSICA, BACIA DO PARANÁ 